\title{
CIÊNCIA DA
}

INFORMACAAO VISÕES E TENDÊNCIAS

MARIA BEATRIZ MARQUES

LILIANA ESTEVES GOMES (COORDS.)

Nishosy.

IMPRENSA DA

UNIVERSIDADE

DE COIMBRA

COIMBRA

UNIVERSITY

PRESS

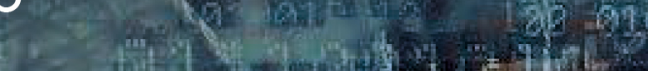

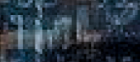


Ciência da Informação: visões e tendências reúne um leque diversificado de olhares e de vozes sobre a Ciência da Informação. Docentes e investigadores de universidades de cinco países, Portugal, Brasil, Espanha, Alemanha e México exploram e problematizam as origens, a evolução, os fundamentos teóricos e epistemológicos da área científica, enquanto ciência pura (visões - diferentes enfoques / perspetivas) e aplicada (tendências - o que vai sendo seguido, ganhando corpo e materialidade).

No seu conjunto, esses contributos alimentam o vital debate sobre o impacto das alterações sociais e tecnológicas no conceito de informação, no ensino e investigação em Ciência da Informação, e no importante papel da informação nas sociedades democráticas. 


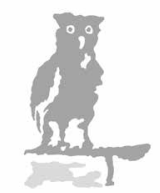

$\begin{array}{lllllllllllll}\text { I } & \text { N } & \text { V } & \text { E } & \text { S } & \text { T } & \text { I } & \text { G } & \text { A } & \text { C } & \tilde{A} & 0\end{array}$

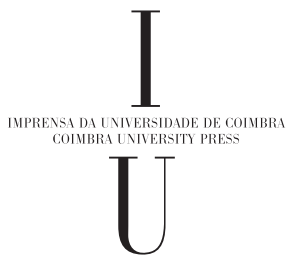




\section{EDIÇÃo}

Imprensa da Universidade de Coimbra Email: imprensa@uc.pt

URL: http//www.uc.pt/imprensa_uc

Vendas online: http://livrariadaimprensa.uc.pt

COORDENAÇÃO EDITORIAL

Imprensa da Universidade de Coimbra

CONCEÇÃO GRÁFICA

Imprensa da Universidade de Coimbra

IMAGEM DA CAPA

Imagem de Pete Linforth por Pixabay

INFOGRAFIA

Raquel Aido

PRINT BY

KDP

ISBN

978-989-26-1895-1

ISBN DIGITAL

978-989-26-1896-8

DOI

https://doi.org/10.14195/978-989-26-1896-8 
CIÊNCIA DA

INFORMAÇÃO

VISÕES E TENDÊNCIAS

MARIA BEATRIZ MARQUES

LILIANA ESTEVES GOMES

(COORDS.) 
(Página deixada propositadamente em branco) 


\section{S U M Á R I O}

INTRODUÇÃO

Maria Beatriz Marques; Liliana Esteves Gomes

EM BUSCA DO FIO DE ARIADNE EM LABIRINTOS DIGITAIS 13

Rafael Capurro

CIÊNCIA DA INFORMAÇÃO TRANS E INTERDISCIPLINAR:

PARA A SUPERAÇÃO DE EQUÍVOCOS

Armando Malheiro da Silva; Fernanda Ribeiro

LA CIENCIA DE LA INFORMACIÓN DOCUMENTAL:

UNA DISCIPLINA TRANSDISCIPLINAR.

Miguel Ángel Rendón Rojas

CIÊNCIA DA INFORMAÇÃO: FUNDAMENTOS E

PERSPETIVAS DA ÁREA CIENTÍFICA

Liliana Esteves Gomes

PARA UMA CIÊNCIA DA INFORMAÇÃO SOCIAL E HUMANA: ANÁLISE CRÍTICA DAS TENDÊNCIAS DA FORMAÇÃO EM INFORMATION SCIENCE E CIÊNCIA DA INFORMAÇÃO NAS "25 MELHORES UNIVERSIDADES DO MUNDO".

Maria Beatriz Marques

CIENCIAS DE LA DOCUMENTACIÓN EN ESPAÑA:

SITUACIÓN Y CAMBIOS A NIVEL DE ESTUDIOS DE GRADO

Sara Martínez Cardama; Mercedes Caridad Sebastián

PERCURSOS DA CIÊNCIA DA INFORMAÇÃO

EM PORTUGAL E NO BRASIL.

Leonor Calvão Borges; Marcelo Nogueira de Siqueira 
OS ARQUIVOS E A ARQUIVOLOGIA NOS PROGRAMAS DE PÓS-GRADUAÇÃO EM CIÊNCIA DA INFORMAÇÃO BRASILEIROS: VÍNCULOS INSTITUCIONAIS

E POSSIBILIDADES DE DIÁLOGOS EPISTEMOLÓGICOS 259

Angelica Alves da Cunha Marques

LA BIBLIOTECA UNIVERSITARIA ¿AL SERVICIO DE LA INVESTIGACIÓN? 285

Llarina González-Solar; Viviana Fernández Marcial

A CIÊNCIA DA INFORMAÇÃO E O MERCADO DE TRABALHO NA ERA DIGITAL: DESAFIOS NA FORMAÇÃO DO PROFISSIONAL DA INFORMAÇÃO 343

Francisco Carlos Paletta; José Antonio Moreiro-Gonzalez;

Waldomiro de Castro Santos Vergueiro

A INFORMAÇÃO COMO BASE PROPOSITIVA, DE DESENVOLVIMENTO E DE MANUTENÇÃO DE MODELOS DE NEGÓCIOS: RELACIONANDO INFORMAÇÃO E INOVAÇÃO EM CONTEXTOS COMPETITIVOS

George Leal Jamil 


\section{N T R O D U Ç Ã O}

\section{N T R O D U C T I O N}

Maria Beatriz Marques Universidade de Coimbra, Faculdade de Letras/ CITCEM / CEGOT

beatrizmarques35@gmail.com ORCID: https://orcid.org/0000-0002-0088-0429

Liliana Esteves Gomes Universidade de Coimbra, Faculdade de Letras/ CITCEM liliana.gomes@fl.uc.pt ORCID: https://orcid.org/0000-0003-3786-2942

No final da segunda década do século XXI, a Informação constitui um recurso com reconhecido valor e consubstancia-se como objeto de conhecimento suscetível de interessar a variadas disciplinas e áreas científicas. A Informação é um ativo fundamental e imprescindível nas organizações, concomitantemente este conceito está também associado ao objeto de uma ciência social, a Ciência da Informação (CI).

Sobre as origens, evolução e objeto da CI, podemos consultar os trabalhos de diversos autores, entre os quais se destacam: Borko, 1968; Wersig \& Nevelling, 1975; Shera \& Cleveland, 1977; Vickery, 1994; Le Coadic, 1996; Saracevic, 1996; Rayward, 1996 e 1997; Williams, Whitmire, \& Bradley, 1997; Fayet-Scribe, 1997; Buckland \& Hahn, 1997; Silva \& Ribeiro, 2002; Capurro, 2003; Vickery \& Vickery, 2004; Robinson \& Karamuftuoglu, 2010; Buckland, 2012; Hjørland, 2014. 
Apesar das múltiplas definições propostas para esta área científica, é interessante verificar que permanece ainda hoje como uma das mais consensuais a que surgiu nas conferências do Georgia Institute of Technology, realizadas em outubro de 1961 e abril de 1962:

Ciência da Informação é a que investiga as propriedades e comportamento da informação, as forças que regem o fluxo da informação e os meios de processamento da informação para um máximo de acessibilidade e uso. O processo inclui a origem, disseminação, coleta, organização, armazenamento, recuperação, interpretação e uso da informação. O campo deriva ou relaciona-se com a matemática, a lógica, a linguística, a psicologia, a tecnologia computacional, as artes gráficas, as comunicações, a biblioteconomia, a gestão e alguns outros campos (Shera \& Cleveland, 1977, p. 265).

Desta definição sobressaem duas tendências diferentes, todavia complementares: a delimitação de um objeto específico de estudo e a presença de uma disciplina científica com identidade própria, gerada e aberta à interdisciplinaridade.

Silva (2006) afirma tratar-se de uma ciência social trans e interdisciplinar (Pombo, 2003 e 2004), dotada de um corpo teórico-metodológico próprio, "que investiga os problemas, temas e casos relacionados com o fenómeno info-comunicacional perceptível e cognoscível através da confirmação ou não das propriedades inerentes à génese do fluxo, organização e comportamento informacionais" (estuda o ciclo informacional na sua plenitude e transversalidade: origem, coleta, organização, armazenamento, recuperação, interpretação, transmissão, transformação e utilização da informação) (Silva, 2006, p. 140-141). No campo científico unitário da CI confluem disciplinas aplicadas: a Arquivística, a Biblioteconomia, a Documentação, a Organização e Métodos e, possivelmente, a Museologia. A CI interage ativa e proximamente com as Ciências da Comunicação (Silva, 2006, p. 107-109) e com um univer- 
so interdisciplinar, rico e variado, de Ciências Sociais e Humanas, e Naturais, sendo uma das várias que integram o campo intercientífico dos Sistemas de Informação, enquanto disciplina de base tecnológica.

No entanto, sabemos que é diversa a fundamentação teórica que sustenta a perspetiva da CI como uma ciência autónoma, com um objeto, um método e uma linguagem próprias.

Recordamos a afirmação de Heilprin (1989, p. 335): "although many laws, hypotheses, and speculations about information have been proposed, adequate scientific and epistemic foundations for a general science of information have not yet appeared". E Zins (2007, p. 335) conclui: "Apparently, there is not a uniform concept of information science. The field seems to follow different approaches and traditions".

Ora, a CI, nos seus mais de 50 anos de evolução, tem propiciado o surgimento de discussões que vão desde o seu estatuto e autonomia científicos, passando pelo objeto de estudo, por problemas terminológicos até às suas conexões interdisciplinares.

Tendo em conta a perspetiva programática da CI, enunciada no decurso das conferências do Georgia Institute of Technology e retomada por Harold Borko (1968), constata-se que esta ciência:

1. Apresenta um campo epistémico que permanece numa fase sincrética e emergente, em que o seu objeto material é designado simultaneamente de Informação e de Conhecimento, como se estes dois termos se referissem ao mesmo fenómeno;

2. No seu estudo, não é clara a metodologia adotada nem a articulação da teoria criada ou importada de outros domínios das Ciências Sociais, com áreas do saber correlatas.

Neste encadeamento, evidencia-se a necessidade de um programa de epistemologia interna que está por cumprir, sobretudo no que concerne a instigar a componente de ciência pura, sem esquecer a componente de ciência aplicada, que desenvolve produtos e serviços.

Há, no imediato, algumas questões essenciais e inquietantes que impõem reflexões críticas e a prossecução de pesquisa investigativa sobre: 
- Como aprofundar ou delimitar os contornos da interdisciplinaridade desenvolvida a par do núcleo transdisciplinar imprescindível da CI?

- Qual(is) o(s) modo(s) para conjugar a análise do fenómeno/ processo informacional com a investigação das suas manifestações, nos diversos setores da atividade humana e social?

- Qual o contributo epistémico da CI para os aspetos estratégicos, operativos e sociais da vida organizacional/empresarial e da Sociedade do Conhecimento?

$\mathrm{Na}$ busca de resposta a perguntas como as enunciadas acima, o livro que agora propomos editar tem o objetivo geral de iniciar um debate científico entre as várias escolas ou autores/investigadores, e, como objetivos específicos, obter/alcançar um amplo conjunto de contributos diferenciados que permitam, na medida tanto quanto possível, uma fundamentação sólida da CI.

O tema abarcará estudos que ilustrem a perspetiva pós-custodial, holística e sistémica da CI. Concomitantemente, releva-se a sua perspetiva inter e transdisciplinar com outras áreas científicas.

Pretende-se, assim, com a organização desta monografia, reunir um conjunto de contributos de especialistas que ajudem a pensar a CI nas suas duas componentes, de ciência pura (visões - diferentes enfoques/ perspetivas) e aplicada (tendências - o que vai sendo seguido, ganhando corpo e materialidade).

\section{Referências Bibliográficas}

BORKO, H. (1968). Information science: What is it? American Documentation, 19(1), 3-5.

BUCKLAND, M. (2012). What kind of science can Information Science be? Journal of Information Science and Technology, 63(1), 1-7.

BUCKLAND, M. K., \& HAHN, T. B. (Eds.) (1997). Special topic issue: History of Documentation and Information Science. Journal of the American for Information Science, April 48(4), 285-379; September 48(9), 773-842.

CAPURRO, R. (2003). Epistemologia y ciencia de la información. Consult. 2 Jan. 2017. Disponível em: http://www.capurro.de/enancib.htm 
FAYET-SCRIBE, S. (1997). The cross-fertilization of the U.S. Public Library Model and the French Documentation Model (IIB, French Correspondent of FID) through the French Professional Association between World War I and World War II. Journal of the American for Information Science, 48(9), 782-793.

HEILPRIN, L. B. (1989). Foundations of information science re-examined. Annual Review of Information Science and Technology, 24, 343-372.

HJØRLAND, B. (2014). Information science and its core concepts: Levels of disagreement. In F. Ibekwe-SanJuan, \& T. M. Dousa (Eds.), Theories of information, communication and knowledge: a multidisciplinary approach (p. 205-235). New York, NY: Springer.

LE COADIC, Y.-F. (1996). A Ciência da Informação. Brasília: Briquet de Lemos.

POMBO, O. (2003). Epistemologia da Interdisciplinaridade. In Colóquio Interdisciplinaridade, Humanismo e Universidade, Porto. Consult. 11 Dez. 2016. Disponível em: http:// webpages.fc.ul.pt/ ommartins/investigacao/portofinal.pdf

POMBO, O. (2004). Interdisciplinaridade: ambições e limites. Lisboa: Relógio D'Água Editores.

RAYWARD, W. B. (1996). The History and Historiography of Information Science: some reflections. Information Processing \& Management, 32(1), 3-18.

RAYWARD, W. B. (1997). The Origins of information science and the International Institute of Bibliography / International Federation for Information and Documentation (FID). JASIS - Journal of the American Society for Information Science, 48(4), 289-300.

ROBINSON, L., \& KARAMUFTUOGLU, M. (2010). The nature of information science: Changing models. Information Research, 15(4). Consult. 16 Nov. 2015. Disponível em: http://www.informationr.net/ir/15-4/colis717.html

SARACEVIC, T. (1996). Ciência da informação: origem, evolução e relações. Perspectivas em Ciência da Informação, 1(1), 41-62.

SHERA, J. H. \& CLEVELAND, D. B. (1977). History and foundations of information science. Annual Review of Information Science and Technology, 12, 249-275.

SILVA, A. M. da (2006). A informação: da compreensão do fenómeno e construção do objecto científico. Porto: Edições Afrontamento e CETAC.COM.

SILVA, A. M. da, \& RIBEIRO, F. (2002). Das "Ciências" Documentais à Ciência da Informação: ensaio epistemológico para um novo modelo curricular. Porto: Edições Afrontamento.

VICKERY, B. C. (Ed.) (1994). Fifty Years of Information Progress: A Journal of Documentation Review. London, England: Aslib.

VICKERY, B. C. \& VICKERY, A. (2004). Information science in theory and practice. München: K.G. Saur.

WERSIG, G., \& NEVELING, U. (1975). The phenomena of interest to information science. The Information Scientist, 9(4), 127-140.

WILLIAMS, R. V., WHITMIRE, L. \& BRADLEY, C. (1997). Bibliography of the History of Information Science in North America, 1900-1995. Journal of the American Society for Information Science, 48, 373-379.

ZINS, C. (2007). Conceptions of information science. Journal of the American Society for Information Science and Technology, 58(3), 335-350. 
(Página deixada propositadamente em branco) 


\title{
EM BUSCA DO FIO DE ARIADNE EM LA B I R I NTOS D I G ITA I S
}

\author{
IN SEARCH OF ARIADNE'S THREAD \\ I N D I G I TAL LABYRINTHS
}

Rafael Capurro

International Center for Information Ethics (ICIE)

rafael@capurro.de

ORCID: https://orcid.org/0000-0002-3839-4637

RESUMO - Os labirintos e fios digitais na sociedade do século XXI cruzam-se com a Ciência da Informação. Neste contexto, analisam-se desafios prementes nas áreas da Ética da Informação, em particular relacionados com questões de Responsabilidade Social, Teoria Crítica, Robótica, Cérebro Global e Filosofia da Informação. Seguidamente, exploram-se diversas perceções acerca das temáticas em análise, com particular destaque para o debate pós evento científico - ISIS Summit Vienna 2015. Conclui-se que os labirintos e fios digitais fazem parte das sociedades atuais, no entanto, muitas vezes eles são confundidos com a própria sociedade e com o nosso ser no mundo.

PALAVRAS-CHAVE - Ética da Informação; Filosofia da Informação; International Society for Information Studies.

ABSTRACT - The labyrinths and digital threads in 21st century society intersect with Information Science. In this context, important 
challenges in the areas of Information Ethics, particularly related to issues of Social Responsability, Critical Theory, Robotics, Global Brain and Information Philosophy are analyzed. Then, several perceptions about the themes under analysis are explored, with emphasis on the debate after the scientific event - ISIS Summit Vienna 2015. It is concluded that labyrinths and digital threads are part of today's societies, however, they are often confused with society itself and with our being in the world.

KEYWORDS - Ethics of Information; Philosophy of Information; International Society for Information Studies.

\section{Introdução ${ }^{1}$}

Em 1994, um grupo de académicos e cientistas começou a iniciativa designada "Foundations of Information Science" (FIS). A primeira conferência foi realizada em Madrid, seguida por Viena (1996), Paris (2005), Pequim (2010), Moscovo (2013) e Viena (2015). Focado no conceito de informação, o grupo estava bem ciente de que diferentes disciplinas interpretam este conceito dentro de seus campos e teorias, dando origem a controvérsias quando se trata de uma abordagem interdisciplinar.

Tendo participado na conferência de Viena, em 1996, e quase vinte anos depois, na conferência de Viena, em 2015, também acompanhei as discussões do grupo FIS na lista de discussão coordenada pelo biólogo espanhol Pedro Marijuán e pude experienciar, em primeira mão, a crescente relevância de uma reflexão interdisciplinar sobre o conceito de informação.

1 Este capítulo resulta, em parte, do contributo do autor em: Capurro, R. (2017). In Search of Ariadne's Thread in Digital Labyrinths. In M. Bottis M. \& T. Alexandropoulou (Eds.), Broadening the horizons of information law and ethics - a time for inclusion (p. 1-19). University of Macedonia Press, 2017. Tradução realizada por Liliana Esteves Gomes. 
A Ciência da Informação tem várias raízes. Uma delas é o seu surgimento, no final dos anos sessenta no contexto da Biblioteconomia, em conexão com a aplicação da tecnologia informática à organização do conhecimento, a designada recuperação de informação.

Com o surgimento da Internet, o conceito de informação abordou questões sociais mais amplas além da área específica da comunicação científica. Embora outras disciplinas tenham usado o conceito de informação, desde o século XIX, este tornou-se relevante nas ciências da Engenharia e das Telecomunicações, particularmente desde que a "Teoria Matemática da Comunicação" de Claude Shannon foi publicada, em 1948 (Shannon, 1948).

Não é meu objetivo dar uma visão geral desta complexa história e sua situação atual (Capurro, 2009). Portanto, gostaria sobretudo, e em primeiro lugar, de discutir algumas das questões tratadas nos painéis e sessões em que estive envolvido durante a Conferência de Viena, relacionadas particularmente com responsabilidade social, Teoria Crítica, Robótica, Cérebro Global e Filosofia da Informação, e resumir o que aprendi sobre os desafios no campo da ética da informação.

Em segundo lugar, vou transmitir os resultados de uma troca de emails que ocorreu após a conferência, entre vários colegas e eu próprio, em que explorámos as nossas perceções dos problemas em questão e os riscos envolvidos, e se éramos ou não capazes de rastrear na sua extensão o mito do fio de Ariadne em labirintos digitais.

\section{A Cimeira ISIS 2015}

A Cimeira ISIS, "The Information Society at the Crossroads. Response and Responsibility of the Sciences of Information" (ISIS Summit, 2015), foi organizada pelo ex-presidente da "International Society for Information Studies" (ISIS), Wolfgang Hofkirchner, na Universidade de Tecnologia de Viena, de 3 a 7 de junho de 2015. 
Wolfgang Hofkirchner foi o anfitrião da " 6 a International Conference on the Foundations of Information Science" (FIS 2015), bem como da " $2^{a}$ International Conference on Philosophy of Information" (ICPI 2015) e " $5^{\mathrm{a}}$ ICTs and Society Conference".

A Cimeira (International Society for Information Studies, 2015) acolheu também várias secções organizadas pela "International Society for Biosemiotic Studies" (ISBS), pela "International Association for Computing and Philosophy" (IACAP) e pela "International Symmetry Association" (ISA).

Neste evento científico participaram cerca de 350 pessoas de 36 países, de todos os continentes, todavia contou apenas com dois participantes de África: o filósofo John Collier, da Universidade de Kwa-Zulu-Natal (Durban, África do Sul) e, cum grano salis, eu próprio como investigador no "African Centre of Excellence for Information Ethics" (ACEIE) na Universidade de Pretória.

Os participantes puderam escolher debater nove temáticas, a saber: história da informação, emancipação ou incapacitação do homem, capacitação de pacientes, informação nas ciências exatas e simetria, guerra informacional, semiose multinível, música, informação e simetria, pesquisa em criação de uma civilização humanizada e pensamento global.

Na sessão de abertura, houve um painel sobre "Responsible Science? Meaningful Technology?”, na qual tive a honra de ser membro, em conjunto com: Armin Grunwald, professor de Filosofia da Tecnologia no "Karlsruhe Institute of Technology", e Diretor do "Institute of Technology Assessment and System Analysis" (ITAS); Gordana Dodig-Crnkovic, professor de Ciência da Computação no "Chalrmers Institute of Technology", Suécia, e agora presidente do ISIS; Shahram Dustdar, professor de Ciência da Computação na Universidade de Tecnologia de Viena; e o moderador, Chris Frauenberger, investigador sénior, do "Institute for Design and Assessment of Technology" da Universidade de Tecnologia de Viena. 
Armin Grunwald fez um discurso introdutório no qual enfatizou os limites do consequencialismo e a necessidade de uma avaliação hermenêutica ao lidar com questões éticas de tecnologia. Este foi um discurso notável, num contexto em que havia muita discussão sobre aspetos sociais e éticos da tecnologia da informação baseada, por exemplo, na Semiótica, Teoria dos Sistemas e Teoria Crítica, mas nenhuma sobre hermenêutica.

De acordo com Grunwald (2015), discussões éticas e legais sobre as consequências das tecnologias são incorporadas, principalmente implicitamente, em narrativas que precisam de ser explicitadas para se entender o contexto histórico em que as decisões, que permitem escolher entre diferentes alternativas ou cenários, são tomadas. E cito:

"While the consequentialist idiom deals with assessing statements about possible futures in terms of their plausibility in order to evaluate their consequences, the hermeneutics of discourse on technological futures focuses on the meaning of these debates for contemporary attitudes towards new technologies. The 'hermeneutic turn' to view the lively and controversial debates about new fields of science or technology not as anticipatory, prophetic or quasi-prognostic talks of the future, but as expressions of our present day. The subject of investigation is not what is being said with more or less justification about coming decades, but what is revealed about us by the fact that these debates are happening today" (Grunwald, 2015).

Tenho trabalhado com hermenêutica e tecnologia da informação e Ciência da Informação desde os anos setenta do século XX (Capurro 1978, 1986, 2010a), todavia tenho a impressão de que, até recentemente, tem sido um diálogo de surdos - com famosas exceções como as de Hubert Dreyfus, Terry Winograd e Fernando Flores. A hermenêutica filosófica permanece, em grande parte, ignorada das 
questões levantadas pela tecnologia da informação, e esta não compreende o que a hermenêutica é.

Grunwald (2015) abriu a porta para um debate interdisciplinar. Este deve incluir, também numa perspetiva hermenêutica, a Teoria dos Sistemas, a Semiótica e a Teoria Crítica.

Um dos maiores defensores da Teoria dos Sistemas e das Ciências da Informação é Wolfgang Hofkirchner, professor do "Institute for Design and Assessment of Technology", na Universidade de Tecnologia de Viena.

A Semiótica foi representada, por exemplo, por Loet Leydesdorff, professor de Dinâmica da Comunicação Científica e Inovação Tecnológica na Universidade de Amsterdão, com o seu trabalho intitulado "Mutual Redundancies and Triple Contingencies among Perspectives", bem como por Søren Brier com a sua contribuição "Cybersemiotics". Christian Fuchs, diretor do "Communication and Media Research Institute", na Universidade de Westminster, Reino Unido, e editor do jornal em acesso aberto "tripleC: Communication, Capitalism \& Critique", apresentou a comunicação "Critical Theory of the Internet: The importance of Raymond Williams, Dallas Smythe and Herbert Marcuse."

No segundo dia participei num fórum formulando a seguinte pergunta: "Os robôs são melhores que os humanos? Ética, limitações e promessas da Inteligência Artificial". Os objetivos deste fórum, coorganizado e patrocinado pela Comunidade Universitária Católica de Viena e pela Fundação Capurro-Fiek, foram analisar questões éticas decorrentes da propagação de robôs na vida quotidiana.

"Do we need to grant highly developed robots rights? Do we need to equip them with ethical norms as science fiction writers have proposed? Is it acceptable to use such machines to harm humans? Are hybrid systems, i.e., humans connected to computer systems acceptable? What is the proprium humanum that distinguishes us from highly skilled robots? Highly developed computer systems and robots are important to humans and can make the world a better place" 
Após curtas apresentações, de Tom Ziemke, Professor de Ciência Cognitiva, Laboratório de Interação, Escola de Informática da Universidade de Skövde, Suécia, intitulada "The body of knowledge: Why robots aren't taking over the world - and why we are giving it to them anyway", de Peter Purgathofer, do "Institute for Design and Assessment of Technology", da Universidade de Tecnologia de Viena sobre "Hard-to-see problems in social robots" e a minha sobre "Agents, patients and robots. About Roboethics" (Capurro, 2012a), houve um debate. Nele participaram Martin Rhonheimer, sacerdote da prelatura católica Opus Dei e atualmente docente na Universidade Pontifícia de Santa Cruz, em Roma, assim como de Søren Brier, do Departamento de Comunicação de Negócios Internacionais, na Escola de Negócios de Copenhaga, Dinamarca. O moderador foi Marco Ragni, do Centro de Ciência Cognitiva do Instituto de Ciência da Computação e Investigação Social, da Universidade de Freiburg, Alemanha.

O que me impressionou neste debate foi a polarização entre, por um lado, um discurso crítico alertando sobre o impacto dos robôs na sociedade e, por outro lado, uma posição neoliberal defendida paradoxalmente, por Martin Rhonheimer, ao argumentar que, numa economia de livre mercado os consumidores deveriam decidir por si próprios o que querem sem qualquer regulamentação legal.

Durante a supramencionada discussão argumentei que, nas sociedades democráticas, a livre decisão dos consumidores em relação ao uso de uma tecnologia tem lugar num contexto ético e político, que conduz à criação de um quadro legal, que não deve ser confundido com uma visão paternalista do Estado, na sua relação com a sociedade civil. Liberdade dentro das regras significa a possibilidade de mudar as mesmas, com base no diálogo, não só no parlamento mas também através dos media e na academia. Sem investigação académica audível há uma tendência de inclinação escorregadia, em direção às polémicas e falta de análise sobre boas e más razões das 
decisões informadas. Isto é verdade, não só no que diz respeito a questões técnicas, mas também às éticas, legais e sociais.

O campo da robótica está a expandir-se rapidamente em todos os tipos de atividades humanas. Uma análise hermenêutica sobre diferentes narrativas subjacentes aos conceitos de robô pode ajudar, a entender melhor, como os robôs estão a ser percebidos em diferentes sociedades. Tornar explícitas as normas e valores, embutidos em tais narrativas, estabelece as bases para um debate ético sobre o desenvolvimento e uso de robôs online, além de meras reflexões consequencialistas (Capurro, 2015a).

A invenção e o uso generalizado da Internet deram origem, desde o início, a diferentes tipos de utopias cibernéticas, como a de John Perry Barlow - "A Declaration of the Independence of Cyberspace" (Barlow, 1996). Vinte anos depois, a Internet é uma realidade global, assim como fonte para novas utopias. Algumas delas foram discutidas na Conferência de Viena sob o rótulo "Cérebro Global".

Gostaria de mencionar apenas duas intervenções, a primeira de Francis Heylighen, professor e investigador na Vrije Universiteit em Bruxelas, bem conhecido pelo "Principia Cybernetica Project", desenvolvido em conjunto com Cliff Joslyn e Valentin Turchin, desde 1989/90. A sua apresentação, intitulada "The Global Brain, a self-organizing, distributed intelligence emerging from the web", foi um resumo deste projeto baseado na combinação de Cibernética e da Teoria dos Sistemas. A segunda, com ideias similares, foi apresentada por Dirk Helbing, professor de Sociologia na ETH Zürich, sob o título "Creating a planetary nervous system as a citizen web".

Sem entrar nestas visões cibernéticas da humanidade, é evidente que elas podem mudar, e de facto já se transformaram em realidades distópicas, como a vigilância e controle global, espionagem cibernética e guerra cibernética, para mencionar apenas algumas.

Embora estes aspetos distópicos tenham sido considerados por Heylighen e discutidos noutras apresentações, fiquei com a 
impressão, pelo menos ouvindo estas duas apresentações, de uma espécie de idealismo cibernético. No caso de Heylighen, a sua visão está relacionada com predecessores teológicos como Pierre Teilhard de Chardin's (1981-1955) "noosphère", bem como com as visões de um sistema de documentação universal, o "Mundaneum Palais Mondial", desenvolvido por Paul Otlet (1868-1944) e Henri La Fontaine (1854-1943), e com as visões mais antigas dos enciclopedistas do Iluminismo.

O cérebro global de hoje assemelha-se ao Google. Perguntei a ambos os oradores: "Por que pensa tanto sobre um cérebro global e não diz nada sobre um estômago global?" Foi uma pergunta provocatória e permaneceu sem resposta.

Também tive a oportunidade de conhecer um jovem antropólogo canadiano, Cadell Last, que procurava um "caminho" para o "Cérebro global" baseado "in an understanding of evolutionary anthropological evidence of our emergence as a species and cybernetic theory" (Last, 2015).

Uma das caraterísticas mais significativas da conferência de Viena foi, na minha perspetiva, o número de participantes chineses e a qualidade das suas apresentações.

Tive o privilégio de participar na " $2^{\mathrm{a}}$ International Conference on Philosophy of Information" (ICPI), organizada por Wu Kun, professor do Departamento de Filosofia da Universidade de Xi'an Jiaotong e Diretor do ICPI, e por Joseph E. Brenner, membro correspondente do "International Center for Transdisciplinary Research", em Paris, Diretor Associado do ICPI e Vice-Presidente da ISIS para a inter e transdisciplinaridade.

A $1^{\text {a }}$ ICPI realizou-se em Xi'an em 2013, uma iniciativa do Centro Internacional de Filosofia da Informação, na Universidade Xi'an Jiaotong, e contou com mais de 100 participantes. As observações que se seguem sobre a conferência ICPI, no âmbito da cimeira ISIS, têm o enfoque em algumas apresentações dos colegas chineses (ICPI, 2015). 
Kun Wu tem realizado investigação em Filosofia da Informação, desde os anos oitenta, defendendo uma "mudança informacional" na ciência e filosofia. No artigo "The Interaction and Convergence of the Philosophy and Science of Information" (Wang, 2015a), Wang cita-o:

"Generally speaking, the Philosophy of Being, as well as the theory of the compartmentalization of the extant domain is the major paradigm of philosophy and makes up the core of philosophical metatheory. Following tradition, we can reasonably summarize "the existential = the material + the mental" as in the traditional Western ontological paradigm, except for few doctrines out of the ordinary. Based on the latest progress in the science of information, the contemporary philosophy of information compartmentalizes the existential domain again. It puts forward a new ontological paradigm: "the existential $=$ the material + the informational". In the light of it, information is constituted by two domains: the objective informational and the subjective informational (mental). Compared with the traditional ontological paradigm, this new one not only reveals a whole fresh existential domain the objective informational world - but also stipu1ates the essence of mind as a form of an advanced state of informational activity" (Wu, 1966, cit. por Wang, 2015a).

Kun Wu obviamente critica a divisão cartesiana entre res cogitans e res extensa ou o mental e o material. Defender um paradigma filosófico baseado no "existencial", equacionado com "o material e o informacional”, pressupõe uma interpretação do conceito ser ou "existência", não apenas em relação ao "material" e "informação", mas também sobre o nosso próprio modo de ser, como ser-no-mundo, para quem os seres se manifestam como o que eles são, ao invés de uma subjetividade sem mundo e isolada, separada dos objetos no chamado mundo exterior (Capurro, 1986). 
Um artigo de Joseph Brenner apoiou o conceito de Kun, de uma convergência da ciência e filosofia sob a influência da Filosofia da Informação. Outra contribuição para este debate ontológico foi apresentada por Qi Tian Wu "A new thinking way about the being and non-being" (Wu, 2015). Jian Wang comparou a filosofia da informação de Kun Wu com a análise de Gilbert Simondon sobre "o modo de existência de objetos técnicos ", bem como com as noções de forma e informação (Wang, 2015b). Ning Li, em "On Sign and Information - A comparison of Philosophy of Technology and Philosophy of Information" analisou Kun Wu e Albert Borgmann (Li, 2015).

Na comunicação "Translating Information” defendi um diálogo filosófico intercultural sobre o conceito informação, que inclui não só as suas raízes latinas e gregas, mas também as traduções e interpretações em árabe, persa e hebraico (Capurro, 2015b e 2014a).

Durante o debate, um colega disse-me que, em chinês, o sinal de informação tem a ver com a respiração. Isso evocou para mim o pensamento taoísta. Observei que o conceito de informação pode ser uma maneira de traduzir Dao no século XXI. Com esta observação também pensei no que aprendi com Carl Friedrich von Weiszäcker sobre o conceito de informação, como sendo uma maneira de traduzir, ou seja, interpretar hoje os conceitos gregos de eidos, idea e morphe. Essa observação deu origem à minha investigação, em Etimologia e História das Ideias, acerca deste conceito nos anos setenta (Capurro, 1978).

\section{Reflexões pós conferência}

Após a conferência, realizou-se uma troca de emails entre vários colegas e eu próprio, em que avaliámos algumas das questões filosóficas e societárias em mãos e as participações envolvidas, e se fomos ou não capazes de rastrear, na sua extensão, o mito do fio de Ariadne em labirintos digitais. 
Para aqueles que podem não estar familiarizados com este mito, posso dizer brevemente que é um mito sobre um guia para a liberdade, que não é um mito no seu todo, mas algo que todos temos necessidade. Quanto ao conceito de labirinto em si, o seu design e função iniciática, notei que faz parte de muitas heranças culturais em todo o mundo (Kern, 1999).

Uso o conceito de labirinto, a fim de abordar questões de conhecimento e poder que nos podem permitir - mas quem nos constitui e quem somos na era digital? - tornar agentes de mudança e não apenas "subjets" digitais, ou seja, objetos de monopólios privados e poderes estatais e incapazes de desenvolver novas formas de liberdade (Capurro, 2014b). Para fazer isso, devemos estar cientes de que o nosso estar no mundo, com os outros, não é idêntico à reificação de nós próprios na Internet. Eu chamo a isso diferença ética.

Seguindo o caminho do pensamento sobre considerar o Dao como informação, enviei um email para Xue-Shan Yan (Yan, 2011), do Departamento de Gestão de Informação da Universidade de Pequim, que não pôde participar na conferência ISIS, mas que é membro da FIS - interpelando-o sobre o sinal chinês para informação e a sua relação com a respiração e a informação. Ele respondeu da seguinte forma:

“The expression of Information in Chinese is 信息 (pronunciation: xin $x i$ ). 信 in ancient Chinese has the meaning of "say something by mouth", "letter"; in modern Chinese it means message (informal or small information); only 息 has the meaning of breathing both in ancient and modern Chinese. If separated 信 or 息 do not have any relationship with Dao. Only when they are combined together the meaning of Dao can emerge" (Xue-Shan Yan, email de 8 de setembro, 2015).

Joseph Brenner achou esta questão intimamente relacionada com a sua investigação sobre "Lógica na Realidade" (Brenner, 2008). 
Iniciámos uma conversa sobre o livro, do filósofo e sinologista francês, François Jullien: "La grande image n'a pas de forme" (Jullien, 2005). O título é uma citação do capítulo $41^{\circ}$ de Tao Te Ching: "The great form has no shape" (Laozi, 2011). Jullien analisa o caminho ou Dao do indeterminado que é expresso em chinês clássico com palavras como ar, vento (feng) ou atmosfera. O vento circula ou "impregna" o que é e o que não é: "The grass must bend, when the wind (feng) blows across it." (Confucius, 2005, xii, 19).

Isto difere das visões platónicas e aristotélicas de que a matéria é 'in-formed' por formas. Vai, na verdade, na direção oposta ao método ocidental - hodos significa 'way' em grego - que começa com o indiferenciado, o mítico caos, o byle (matéria) de Aristóteles ou a chora de Platão (recetáculo ou substrato material) sendo 'in-formed' pelo demiurge, uma espécie de "deus pagão" (Margel, 1995).

De acordo com Jullien, o pintor chinês começa com a forma (xing 形) e passa por o dinamismo ou vitalidade (shi) ou pelo vento ou ar (qi-xiang 氣象), de tal maneira que o que é eventualmente descrito é informis ou sem forma. Isso torna possível que as formas, que estão no fundo e não no topo, se abram para o indeterminado. $\mathrm{O}$ resultado pictórico é a "grande imagem que não tem forma" (Jullien, 2005/2009).

Joseph Brenner enviou-me a seguinte citação, na tradução inglesa de "La grande image" de François Jullien. Ele descobriu que o tradutor usa a forma energia da respiração, imagem da respiração, fenómeno da respiração, respiração-ressonância e espírito da respiração para as palavras em francês, começando com souffle:

"The Chinese also conceived of atmosphere by means of another binomial linked to wind and explicitly associating the visible and invisible. [ ...] The energy of the undifferentiated foundation (of the world) actualizing itself and taking form, this image (phenomenon) spreads out as a 'breath-atmosphere'. Wang Wei indicates this as a principle: "When one contemplates the painting, one must 
look first at the breathimage; then the tonality - clear or confused, limpid or opaque; then the relation structuring (the structural relation of) the principal and secondary mountains" (Jullien, 2009).

Esta compreensão da informação como "no-form" é o oposto dos resultados da minha pesquisa inicial, em Etimologia e História das Ideias, acerca do termo latino informatio como uma tradução dos imponentes termos metafísicos gregos eidos, idea, morphe e typos (Capurro, 1978).

Segui a pista de informatio como documentado no "Thesaurus Linguae Latinae" (ThLL) onde se afirma que informatio é composta da partícula 'in' que significa um reforço e não uma negação do processo de formação (formatio). Embora a partícula 'in' também signifique "não" - como o alpha privativum em grego, por exemplo, em a-letheia (verdade como desocultação) - nenhum uso deste sentido, no que diz respeito à informatio é dado, com exceção de conceitos relacionados tais como informabilis, informia, informitas e informiter.

$\mathrm{Na}$ minha tese mencionei-o, mas não aprofundei. Isso foi feito, posteriormente, por Vinícius Souza de Menezes, doutorando em Ciência da Informação no Centro Brasileiro de Pesquisa em Informação (IBICT) e especialista em filosofia contemporânea, no seu artigo "Information, a critical-philological excursus", em que analisa criticamente a minha interpretação (Menezes, 2015). O que permaneceu esquecido na minha análise leva-o à informatio como aletheia e à metafísica aristotélica e platónica, com a predominância de ser e não de ser como um processo de dar-se (em que sempre fica algo oculto em toda a forma de desocultamento).

Este caminho possibilita uma tradução entre informatio como não-forma e o pensamento chinês de Dao - bem como com a tradição japonesa Musi ou “negação de si” (Nakada \& Tamura, 2005; Capurro, 2005) - através da mediação do pensamento ocidental sobre o abismo da existência, por alguns filósofos citados por Menezes como Wittgenstein, Heidegger e Agamben. 
No trabalho para a primeira conferência chinesa sobre Ética da Informação, que se realizou na Universidade Renmin de Pequim, em 2010 (Capurro 2010b), citei Chuang Tzu:

\begin{abstract}
"Fishing-stakes are employed to catch fish; but when the fish are got, the men forget the stakes. Snares are employed to catch hares, but when the hares are got, men forget the snares. Words are employed to convey ideas; but when the ideas are apprehended, men forget the words. Fain would I talk with such a man who has forgot[en] the words!" (Tzu, 26, 11).
\end{abstract}

Uma questão importante na minha apresentação na conferência do ICPI em Viena foi a relação entre linguagem e informação, como analisada por Carl Friedrich von Weizsäcker (Weizsäcker, 1973) e Martin Heidegger (Heidegger, 1959).

Esta relação hermenêutica é também "an angeletic one" - do grego angelos $=$ mensageiro) - , lidando com a transmissão e mútua troca de mensagens, e não apenas com a sua interpretação; Hermes sendo ambos, o mensageiro dos deuses e o seu intérprete (Capurro \& Holgate, 2011, Capurro, 1978, p. 263-266). Michael Eldred escreve:

\begin{abstract}
"Above all, the mutual exchange (metabole) of messages, the interplay of messaging in which an attentive listening to each other on the part of the interlocutors is essential. All exchange presupposes a mutuality of some kind, no matter how defective (Even subjugation to the other is a kind of exchange.). Mutual exchange is a kind of (at least) double or (complex multiple) movement resulting from the intertwining of the exercise of the powers of the exchangers" (Michael Eldred, email de 9 de setembro, 2015).
\end{abstract}

Após as discussões sobre questões sociais e éticas durante a conferência de Viena, um grupo de colegas - entre eles, Rainer E. 
Zimmermann, professor de Filosofia na Universidade de Ciências Aplicadas de Munique, e José María Díaz Nafría, engenheiro e filósofo, professor da Universidade de León (Espanha) e criador do BITrum, um glossário de conceitos, metáforas e teorias relacionadas com a informação (BITrum, 2015) -, chegam à ideia de criar um grupo de pesquisa chamado SE 104.

O acrónimo correspondia à sala onde teve lugar uma sessão da Cimeira de Viena, sobre questões éticas da Sociedade da Informação, que teve a particularidade de ser difícil para os participantes encontrarem. Esta foi também uma questão geral para a maioria dos participantes, que procuraram as suas salas de sessão no edifício labiríntico da Universidade Técnica de Viena.

A designação deste grupo foi dada com sentido de humor, mas abordou também uma questão séria, em particular quando as teorias propostas e discutidas durante a Cimeira foram os fios de Ariadne nos labirintos digitais e/o(s) labirinto(s) em si mesmos.

De acordo com o mito, o rei de Creta Minos estava em oposição aos reis de Atenas para quem o seu palácio era um labirinto, ou seja, um centro de poder e dominação. O labirinto foi construído por Daedalus, um famoso artesão, para o Rei Minos aprisionar o Minotauro. O Minotauro, meio homem meio touro, é um símbolo do mal, já que o único papel da sua existência era comer donzelas sacrificadas por Minos aos seus deuses. A Filha de Minos, Ariadne, estava disposta a ajudar Teseu, filho do rei Egeu de Atenas, por quem se apaixonou, na sua tarefa de matar o Minotauro, dando-lhe uma espada e um novelo para encontrar o seu caminho para fora do labirinto.

Sugiro usar também a forma plural (fios nos labirintos digitais) uma vez que existem várias possibilidades de moldar a liberdade ao enfrentar labirintos e fios digitais e também porque, como José María Díaz Nafría sugeriu num dos seus emails, os labirintos digitais parecem não ter um centro, com um Minotauro, uma Ariadne e um Teseu. 


\section{Conclusão}

Hoje, estamos dentro de labirintos digitais guiados por fios que se parecem com o de Ariadne, mas muitas vezes deixam-nos incapazes de estarmos atentos ao labirinto como um labirinto, ou seja, como um lugar de poder e dominação negativos.

Na sua "História da Filosofia", Hegel escreve saber que "um ser humano é livre" faz uma "diferença incrível" ("ein ungeheurer Unterschied") na história humana, embora tal conhecimento não signifique a sua realização (Hegel, 1971, p. 40). Não é uma questão de olhar para um exterior ao(s) labirinto(s) digital(ais) no sentido de evitar os desafios históricos da era digital. É, em vez disso, uma questão de saber até que ponto podemos, mais uma vez, ver o labirinto como um labirinto, ou seja, para desvendar conhecimento e poder na era digital como fez, por exemplo, Edward Snowden.

Concordo com Peter Fleissner, professor emérito de Design e Avaliação de Novas Tecnologias na Universidade de Tecnologia de Viena, qualquer restrição por parte de estruturas económicas que dificultam o desenvolvimento emancipatório das pessoas é um indicador para a transformação das atuais sociedades de informação.

A liberdade não é uma propriedade de uma subjetividade sem mundo e isolada, mas uma relação entre os seres humanos num mundo partilhado que se preocupa com o respeito mútuo e a justiça, também na sua relação com o mundo natural a que pertencemos. Ambas as relações, para nós e para o mundo, são hoje mediadas por tecnologias digitais. Elas dão origem à crença de que, ser significa ser digital e, particularmente, que eu sou um ser humano apenas na medida em que eu esteja no mundo digital "coisificado" ou 'in-forming' a mim próprio como dados digitais e acreditando que sou um ser digital.

Chamo a esta crença metafísica digital, que distingo da ontologia digital, em que a compreensão digital do ser é reconhecida, hoje, como um possível caminho, predominante, de nos compreendermos 
a nós mesmos e ao mundo. A diferença entre 'ser' e 'ser como' não é apenas ontológica, mas ética (Capurro, 2012b). A diferença ética entre quem e o que nós somos, ou entre nós mesmos e os nossos dados, é um dos fios de Ariadne (Capurro, Eldred \& Nagel, 2013).

A tarefa de traduzir informação, no sentido que propus na Cimeira de Viena, pode ser entendida como um dos fios de emancipação de Ariadne, do conhecimento e estruturas de poder do labirinto digital.

Procurando uma linguagem de "mutualidade" (Peter Fleissner), ou seja, de estimativa mútua e cuidado pelos outros, na era digital, significa procurar mediações que dependem da nossa capacidade de traduzir os nossos conceitos e valores noutros idiomas e vice-versa, de estar aberto às mensagens vindas do(s) outro(s), particularmente quando parecem estranhas, ou seja, incomuns ou desconhecidas de uma perspetiva normal, uma questão que levou Thomas Kuhn à sua teoria sobre a estrutura das revoluções científicas (Kuhn 1962; Capurro \& Holgate, 2011).

Esta não é apenas uma tarefa teórica, mas também prática, sobre diferentes tipos de exercícios de resistência e de resiliência nos níveis macro e micro, a fim de nos transformar a nós mesmos e às nossas sociedades, em mais livres e justas, na era digital (Capurro, 1995).

\section{Referências Bibliográficas}

Barlow, J. P. (1996). A Declaration of the Independence of Cyberspace. Disponivel em: https://projects.eff.org/ barlow/Declaration-Final.html

Brenner, J. E. (2008). Logic in Reality. New York: Springer.

Capurro, R. (2015a). Living with online robots. Disponível em: http://www.capurro. de/onlinerobots.html

Capurro, R. (2015b). Translating Information. Disponível em: http://sciforum.net/ conference/isis-summit-vienna-2015/paper/2972

Capurro, R. (2014a). Apud Arabes. Notes on Greek, Latin, Arabic, and Persian Roots of the Concept of Information. Disponivel em: http://www.capurro.de/iran.html

Capurro, R. (2014b). Shapes of Freedom in the Digital Age. In Hasan S. Keseroğlu, Güler Demir, Elsa Bitri und Ayşenur Güneş (Eds.), 1st International Symposium 
on Philosophy of Library and Information Science. Ethics: Theory and Practice (p. 1-13). Disponível em: http://www.capurro.de/kastamonu.html

Capurro, R. (2012a). Toward a Comparative Theory of Agents. AI E Society, 27(4), 479-488. Disponível em: http://www.capurro.de/agents.html

Capurro, R. (2012b). Beyond Humanisms. In Toru Nishigaki \& Tadashi Takenouchi

(Eds.), Information Ethics. The Future of the Humanities (p. 26-74). Disponivel em: http://www.capurro.de/humanism.html

Capurro, R. (2010a). Digital hermeneutics: An outline. AI \& Society 35(1), 35-42. Disponível em: http://www.capurro.de/digitalhermeneutics.html

Capurro, R. (2010b). The Dao of the Information Society in China and the Task of Intercultural Information Ethics. Disponível em: http://www.capurro.de/china infoethics2010.html

Capurro, R. (2009). Past, present and future of the concept of information. TripleC, 7 (2), 125-141. Disponível em: http://www.capurro.de/infoconcept.pdf

Capurro, R. (2005). Privacy. An Intercultural Perspective. Ethics and Information Technology, 7, 37-47. Disponível em: http://www.capurro.de/privacy.html

Capurro, R. (1995). Leben im Informationszeitalter. Berlin: Akademie Verlag. Disponível em: http://www.capurro.de/leben.html

Capurro, R. (1986). Hermeneutik der Fachinformation. Munich/Freiburg: Alber. Disponível em: http://www.capurro.de/hermeneu.html

Capurro, R. (1978). Information. Ein Beitrag zur etymologischen und ideengeschichtlichen Begründung des Informationsbegriffs. München: Saur. Disponível em: http://www. capurro.de/info.html

Capurro, R. \& Holgate, J. (2011). Messsages and Messengers. Angeletics as an Approach to the Phenomenology of Communication. Munich: Fink.

Capurro, R., Eldred, M. \& Nagel, D. (2013). Digital Whoness: Identity, Privacy and Freedom in the Cyberworld. Frankfurt: Ontos. Disponível em: https://www.artefact.org/dgtlwhns.pdf

Tzu, C. (2001-2009). The Complete Chuang Tzu Based on James Legge's Translation. Disponível em: http://oaks.nvg.org/zhuangzi25-.html\#26

Confucius (2005). Analects (Transl. James Legge). Disponível em: http://www. gutenberg.org/cache/epub/3330/pg3330-images.html

FIS (Foundations of Information Science). Disponível em: http://fis.sciforum.net/ about-fis/

Grunwald, A. (2015). Responsible Research and Innovation - Limits of consequentialism and the need for hermeneutic assessment. Disponível em: http://summit.is4is. org/programme/schedule/day-one-wednesday-3-june-2015

Hegel, G. W. F. (1971). Vorlesungen über die Geschichte der Philosophie. Frankfurt: Suhrkamp. Vol. 18.

Heidegger, M. (1959). Der Weg zur Sprache. In Unterwegs zur Sprache (p. 83-155). Pfullingen: Neske.

ICPI (2015). International Conference on Philosophy of Information. Disponível em: http://sciforum.net/conference/isis-summit-vienna-2015/stream-icpi 
International Society for Information Studies (2015). ISIS Summit Vienna - The Information Society at the Crossroads: Response and Responsibility of the Sciences of Information. Disponível em: https://isis-summit-vienna-2015.sciforum.net/

ISIS Summit (2015). Programme. Disponível em: http://summit.is4is.org/programme

Jullien, F. (2005/2009): La grande image n'a pas de forme ou du non-objet par la peinture. In La philosophie inquiétée par la pensée chinoise (p. 263-573). Paris: Seuil.

Kern, H. (1999). Labyrinthe. Erscheinungsformen und Deutungen. 5000 Jabre Gegenwart eines Urbilds. München: Prestel.

Kuhn, T. (1962). The Structure of Scientific Revolutions. Chicago: The University of Chicago Press.

Last, C. (2015). Advanced Apes. Evolutionary Science for a Changing World. Disponível em: http://theadvancedapes.com/pathway-to-the-global-brain-a-lecture/

Li, N. G. (2015). On Sign and Information - a Comparison of Philosophy of Technology and Philosophy of Information. Disponível em: http://sciforum.net/conference/ isis-summit-vienna-2015/paper/2961

Laozi (2011). Daode Jing (transl. Charles Muller). Disponível em: http://www. acmuller.net/con-dao/daodejing.html\#div-42

Margel, S. (1995). Le tombeau du dieu artisan, précédé de "Avances" par Jacques Derrida. Paris: Minuit.

Menezes, V. S. de (2015). Informação, um excurso crítico-filológico. Perspectivas em Ciência da Informação, 20 (1), 3-18. Disponível em: http://portaldeperiodicos. eci.ufmg.br/index.php/pci/article/view/2074

Nakada, M. \& Tamura, T. (2005). Japanese conceptions of privacy: an intercultural perspective. Ethics and Information Technology, 7, 1, 27-36.

Shannon, C. E. (1948). A Mathematical Theory of Communication. The Bell System Technical Journal, 27, 379-423, 623-656. Disponível em: http://math.harvard. edu/ ctm/home/text/others/shannon/entropy/entropy.pdf

Wang, J. (2015a). The Interaction and Convergence of the Philosophy and Science of Information. Disponível em: https://sciforum.net/paper/view/conference/2943

Wang, J. (2015b). The Constructive Approach of Informational Ontology and the Transform of Philosophical Notion - the Comparison to the Philosophy of Information of Simondon and Wu Kun. Disponível em: https://sciforum.net/ paper/view/conference/2960

Weizsäcker, C. F. von (1973). Sprache als Information. In Die Einheit der Natur (p. 39-60). Munich: dtv.

Wu, Q. T. (2015). A New Thinking Way About the Being and Non-Being. Disponivel em: http://sciforum.net/conference/isis-summit-vienna-2015/paper/2880

Yan, X.-S. (2011). Information Science: Its Past, Present and Future. Information, 2(3), 510-527. Disponível em: http://www.mdpi.com/2078-2489/2/3/510 


\title{
CIÊNCIA DA INFORMAÇÃO TRANS
}

E INTERDIS C I P L I NAR:

\section{PARA A SUPERAÇÃO DE EQUÍVOCOS...}

\author{
TRANSAND INTERDISCIPLINARY \\ I N F O RMATION SCI ENCE: \\ FOR OVERCOMING MISUNDERSTANDINGS...
}

Armando Malheiro da Silva

Faculdade de Letras da Universidade do Porto / CITCEM

armando.malheiro@gmail.com ORCID: https://orcid.org/0000-0003-0491-3758

Fernanda Ribeiro

Faculdade de Letras da Universidade do Porto / CITCEM

fribeiro@letras.up.pt ORCID: http://orcid.org/0000-0002-5641-9199

\begin{abstract}
RESUMO - Há uma falta de consenso epistemológico sobre o que é a Ciência da Informação (CI) e também não chega a haver consenso sobre o uso dessa expressão. Esta evidência é demasiado conhecida e repetida, mas parece uma inevitabilidade insolúvel. $\mathrm{Na}$ verdade, e até agora, constata-se a impossibilidade prática de surgir uma clara tendência para o diálogo aberto e construtivo que conduza à efetiva superação dos equívocos que nos parecem ser, de alguma maneira, sérios entraves a um posicionamento epistemológico comum.
\end{abstract}


Pretendemos, por isso, aqui destacar os equívocos mais significativos e desmontá-los, apresentando como alternativa a defesa de uma CI trans e interdisciplinar, irredutível a uma atividade profissional específica e, ao mesmo tempo, fundamentadora de uma profissão ajustada ao tempo presente e futuro, e composta por profissões antecedentes (arquivista, bibliotecário, documentalista e museólogo), cujos principais traços funcionais integram mesclados o 'gestor de informação'. PALAVRAS-CHAVE - Ciência da Informação; Trans e Interdis ciplinaridade; Gestor de informação.

ABSTRACT - There is a lack of epistemological consensus on what is Information Science (IS) and there is also no consensus on the use of this expression. This evidence is very much known and repeated, but it seems an insoluble inevitability. In fact, and until now, the practical impossibility of a clear tendency for an open and constructive dialogue that leads to the effective overcoming of the misunderstandings, appears to be a serious obstacle to a common epistemological position. We intend, therefore, to highlight the most significant misunderstandings and deconstruct them, presenting as alternative the defense of a trans and interdisciplinary IS, irreducible to a specific professional activity and, at the same time, founder of a profession adjusted to the present and future times and including previous professions (archivist, librarian, documentalist and museologist), whose main functional features integrate, in a mixed form, the 'information manager'.

KEYWORDS - Information Science; Trans and Interdisciplinarity; Information manager.

\section{Ao princípio os equívocos...}

Usamos o termo equívoco para significar engano ou erro de perspetiva baseado em motivações que importa revelar com rigor. 
A persistência de, pelo menos, quatro desses equívocos ou enganos contribui bastante para a fragilidade que o campo da documentação/ informação exibe no âmbito académico e prático-profissional. Por isso, todo o esforço de clarificação e de superação dos equívocos deve ser considerado urgente, prioritário e vital, mesmo que ainda sejam poucos os que o entendem deste modo.

Os quatro equívocos mencionados podem ser apresentados por esta ordem: $1^{\circ}$ a inalterável existência de várias disciplinas próximas entre si, justificadas por uma perspetiva cumulativa ou fragmentada, propiciadora de relações interdisciplinares no campo, mas vedando qualquer oportunidade de fusão ou integração "refundadora" ou inovadora; $2^{\circ}$ a ambiguidade da célebre definição de CI burilada e exposta, em 1968, por Harold Borko em artigo curto mas marcante; $3^{\circ}$ o viés tecnológico protagonizado pelas Information Schools ou iSchools, passível de ilustração cabal através de manuais recentes sobre Information Science, que se, por um lado, parecem filiar-se na célebre definição formulada por Harold Borko, por outro lado, defraudam-na porque o fascínio do 'fazer' suplanta o desafio árduo do 'conhecer'; e $4^{\circ}$ a confusão persistente entre profissão e atividade científica.

Vejamos, pois, o primeiro equívoco e, para isso, entremos na denominada perspetiva cumulativa ou fragmentada a que se opõe a perspetiva evolutiva, sendo esta associada naturalmente aos defensores da CI trans e interdisciplinar.

$\mathrm{Na}$ perspetiva cumulativa ou fragmentada os muitos autores que reconhecem uma afinidade temática entre diferentes disciplinas aceitam, no entanto, que elas são distintas e independentes umas das outras: Arquivística / Arquivologia; Bibliologia; Bibliografia; Biblioteconomia / Bibliotecologia; Documentação / Ciências Documentais; Museologia; Design de Exposições; Information Science; e Ciência da Informação - todas podem dialogar entre si sem perda de autonomia. Nesta perspetiva, a afinidade admitida tem a ver com o facto de que todas as 
disciplinas lidam com um conteúdo comum ou semelhante não obstante as variações de suporte: manuscritos, dactiloscritos impressos ou gravados/registados em qualquer meio (papel ou digital). Mas a referida afinidade tem a ver, também, com uma forte dimensão profissional: estas disciplinas surgiram a partir de um conjunto de tarefas práticas configuradas num perfil profissional particular - o arquivista, o bibliotecário, o museólogo, o documentalista, etc. Salvar, preservar, organizar, descrever e submeter à consulta ou fruição pública constitui, de facto, um denominador comum de todos estes profissionais. A afinidade é, pois, óbvia, mas a perspetiva cumulativa ou fragmentada carateriza-se pela necessidade de ressaltar e até hiperbolizar a diferença, que afasta e individualiza essas profissões. Trata-se, na prática, de um esforço diferenciador artificial e corporativo, pela prevalência do formal sobre o substancial e a alocação a cada uma dessas disciplinas de um "paradigma" próprio ou que assegure a sua autonomia e "independência" eternas. Podemos dizer que esta não é apresentada hoje como uma perspetiva homogénea, porque o seu apoio epistemológico é cada vez mais frágil. Porém, ela persiste e continua presente na grande maioria dos modelos de formação existentes pelo mundo.

$\mathrm{Na}$ perspetiva evolutiva, há essencialmente um exercício de superação: (a) da interdisciplinaridade limitada e estática; (b) da primazia da profissionalização; e (c) do mal-entendido documental - no final o documento é isso e algo mais... Esta perspetiva evolutiva foi afirmada na Universidade do Porto e traduzida desde 2001 para um projeto formativo: a Licenciatura em Ciência da Informação (com continuação, a partir de 2008, no Mestrado em Ciência da Informação e, de certa forma, no Programa Doutoral em Informação e Comunicação em Plataformas Digitais), que teve como objetivo integrar os diferentes profissionais formados até então num profissional sintético e polivalente - o gestor de informação. Pressupõe-se, portanto, que existe um dinamismo disciplinar que implica a transição das etapas multi e interdisciplinaridade para a 
transdisciplinaridade. É óbvio que esta transição não se opera sem a intervenção decidida no plano epistemológico, mas também no formativo como sucedeu na Universidade do Porto, que serve de exemplo a uma possibilidade concreta: é possível formar profissionais que combinam competências da Arquivística, da Biblioteconomia, da Documentação e da Museologia tradicionais, agregando-lhe fortes competências tecnológicas. Negar esta possibilidade só se justifica por uma negação ou resistência corporativa.

O segundo equívoco relaciona-se com a insistência, sobretudo de autores espanhóis e hispânicos, na informação documental como o objeto da CI. José Antonio Moreiro González usou para título de um seu livro de 2005 essa expressão e procurou fundamentá-la epistemologicamente nesse trabalho, apoiando-se para tal em autores norte-americanos relevantes como Jesse Shera e, sobretudo, Michael Buckland. O seu principal argumento desenvolve-se a partir da premissa de que a informação é conhecimento e, por consequência, é naturalmente abstrata e conceitual, daí que só possa tornar-se evidente através de uma expressão de cariz físico: "Para volverse tangible, la información ha de fijarse en un documento. Cualquer intervención para derivar nuevas formas informativas, manejar mediante la tecnologia, almacenar y recuperar en sistemas concretos, se efetua sobre esta forma física de información" (Moreiro González, 2005, p. 45). E prossegue referindo que até ao aparecimento dos documentos eletrónicos era comum definir documento como possuindo três caraterísticas essenciais: "Objeto que contiene información. Registrada de forma permanente. Que es accesible, comunicable y puede tratarse" (Moreiro González, 2005, p. 47). No entanto, e apesar desta assunção do "paradigma físico" ou otletiano, segundo a identificação de paradigmas proposta por Rafael Capurro (2003), o Autor reconhece que o ciclo informativo não termina com o acesso formal ao documento recuperado: "Exige la posterior aceptación de la informatión por parte del 
conocimiento del receptor. Sin compreensión no habrá cambios en su estado de conocimiento. La acessibilidad semántica al documento es una actuación deductiva concurrente que parte de los esquemas cognitivos que organizan las secuencias de los hechos narrados en un documento, al comparar analógicamente la información captada con las referencias existentes en la memória” (Moreiro González, 2005, p. 47). Por este extrato e outras passagens da obra que estamos a citar percebe-se que o posicionamento de Moreiro González é menos dogmático que o assumido pela "escola francesa", que insiste em cristalizar o documento como um constructo social e sociológico, recusando qualquer aproximação ao cognitivismo e muito menos à Psicologia Cognitiva (Saldanha, 2017, p. 51-53). O Autor espanhol reconhece, implicitamente, a existência do fenómeno informacional como cognitivo ou mental, embora não ouse admitir que a CI possa integrar esta dimensão no seu objeto de estudo.

Espanhóis e franceses ficam, assim, reféns da ambiguidade do Traité de la Documentation (Otlet, 1934): os documentalistas estão amarrados à dimensão física do suporte, apesar de muitas das suas operações terem a ver com a semântica, com o sentido, com o conteúdo, ou seja, com a informação. Este paradoxo é um crónico equívoco que tem de ser definitivamente superado.

O terceiro equívoco é o tecnológico, que retrai e preocupa todos os que privilegiam a dimensão social da CI. E, de facto, desde o aparecimento da Informática e da Information Science, nos finais da década de cinquenta do séc. XX, uma nova e poderosa tecnologia emergiu e tem-se expandido vertiginosamente, absorvendo tarefas e práticas profissionais anteriores. O processamento documental e informacional acabou por ser abrangido e a CI de feição acentuadamente tecnológica tende a subsumir-se nas Ciências da Computação, o que representa, obviamente, uma perda ou um prejuízo em termos epistemológicos. 
Vale a pena, aqui, tornar evidente este risco e para tal é eloquente o exemplo fornecido pela volumosa obra, Handbook of Information Science, dos alemães Wolfgang G. Stock e Mechtild Stock, editada em 2015'. Trata-se de um manual, compêndio ou "trabalho fundamental" sobre CI, destinado a proporcionar uma panorâmica do estado atual desta disciplina nas suas áreas nucleares: recuperação da informação, representação do conhecimento e infometria. Embora seja acessível a leitores de diversas profissões e ciências, visa particularmente académicos, praticantes e estudantes de CI, de Library Science (Biblioteconomia / Documentação), de Ciências da Computação, de Gestão de Informação e de Gestão do Conhecimento.

Através da sua estrutura, exposta adiante, somos apresentados a uma ciência cujo objeto se compõe de três domínios teórico-práticos ou de incidência aplicacional, configurando-se naturalmente adaptada ao "espírito" das iSchools, ou seja, do Consórcio Internacional (envolve o "ramo" norte-americano, o "ramo" europeu e o ramo asiático) de Escolas de Informação ${ }^{2}$, vocacionado para desenvolver este campo científico e suas adjacências, em particular a Tecnologia da Informação, a Library Science, a Informática, a CI e outras. Podese mesmo admitir que o manual se destina, naturalmente, a ser usado nesse espaço amplo e influente de ensino e de investigação.

Mas, antes de entrarmos no cerne desta CI, herdeira direta da Documentação de Paul Otlet (a Biblioteconomia ou Library Science aparece, apenas, relacionada como disciplina vizinha, estatuto que não é atribuído nem à Arquivística, nem à Museologia, o que permite inferir que elas são vistas pelos autores como "distantes", seguindo, aliás, "doutrina" coincidente) e, sobretudo, da Information Science norte-americana, convém determo-nos um pouco sobre o entendimento dos Autores a respeito da disciplina que estudam e praticam.

\footnotetext{
1 A publicação desta obra em alemão ocorreu em 2013.

2 Ver a este respeito o website http://ischools.org/ (acesso em 29-12-2018).
} 
Wolfgang e Mechtild Stock, na parte A do seu manual, introduzem o leitor na CI, começando por definir a disciplina e, seguidamente, tratando tópicos que evidenciam a sua perspetiva epistemológica: conhecimento e informação; informação e compreensão / interpretação (hermenêutica); documentos; e literacia informacional. E, voltando ao princípio, os Autores reconhecem que não existem definições consensualmente aceites de CI e invocam, para isso, a juventude da disciplina por comparação com outras (como a Matemática ou a Física) e o facto de ela estar fortemente interrelacionada com várias disciplinas, como a Tecnologia da Informação e a Economia, cada uma das quais com grande ênfase em suas próprias definições. Mas, entendem e reafirmam, não obstante a falta de uma definição consensual, que a CI é, por um lado, empregue para diferentes propósitos de investigação fundamental (ou pura) e, por outro, tem uma dimensão aplicada. E adiantam uma definição "de trabalho" ou operatória:

Information Science studies the representation, storage and suply as well as the search for and retrieval of relevant (predominantly digital) documents and knowledge (including the environment of information) (Stock \& Stock, 2015, p. 3).

Se rapidamente compararmos esta definição com a de Harold Borko, exposta no seu famoso artigo de 1968, ressalta, de imediato, na dos Autores alemães, um recorte maior do objeto, com o foco posto no estudo do modo de representar, de armazenar e de fornecer / recuperar documentos e conhecimento relevantes (predominantemente digitais, com uma leve referência ao "ambiente informacional"). De fora ficou o propósito de estudar "as propriedades e comportamento da informação, as forças que regem o fluxo da informação e os meios de processamento da informação para um máximo de acessibilidade e uso" (Borko, 1968, tradução nossa) - objetivo mais ambíguo, mas também mais ambicioso do ponto de vista epistemológico, na medi- 
da em que agrega uma dimensão social e humana, "qualitativa", ao processamento tecnológico e instrumental da informação.

Apesar do recorte feito, os autores estão em linha com a vocação interdisciplinar das definições das conferências do Georgia Institute of Technology (1961/62) (Shera \& Cleveland, 1977) e de Harold Borko (1968), indicando, com precisão, aquelas com as quais se relacionam estreitamente (apresentam, para tanto, uma figura que não é a famosa "flor" de Le Coadic (1996), nem os diagramas de Silva e Ribeiro (2002) e Silva (2006), mas parece cumprir uma função similar: a CI está no centro e à sua volta figuram, como disciplinas vizinhas, as Ciências da Computação, a Economia, a Biblioteconomia, a Linguística (ramo Computacional), a Pedagogia e a Ciência da Ciência (ou Sociologia da Ciência / Comunicação Científica). Temos, assim, um círculo interdisciplinar estreito que choca, sobretudo, por várias ausências e evidencia a presença forte das Ciências e da Tecnologia, centradas no processamento e na recuperação lógica e computacional da informação. Há, assim, uma preferência clara pelo diálogo com disciplinas que contribuem diretamente para o que os Autores chamam as "sub-disciplinas" da $\mathrm{CI}$ ou, talvez mais apropriadamente, facetas do seu objeto de estudo:

(1) Recuperação da Informação;

(2) Representação do Conhecimento;

(3) Gestão de Conhecimento e Literacia da Informação;

(4) Pesquisa no interior da Sociedade da Informação e dos Mercados da Informação;

(5) Infometria, incluindo Ciência da Web (ou Webmetria).

Estas facetas decorrem do sentido plasmado na definição, e os Autores tiveram o cuidado de explicar, com algum detalhe, os elementos nela usados:

- Representação: o conhecimento contido nos documentos. Tal como os documentos em si (a saber: artigos científicos, livros, paten- 
tes ou publicações corporativas, mas também websites ou postagens em microblogues), condensado através de curtas descrições textuais e etiquetas com importantes termos e conceitos tendo em vista a filtragem de informação (Stock \& Stock, 2015, p. 3-4);

- Armazenamento e "serviço": os documentos são processados de tal maneira que possam ser idealmente estruturados, mais facilmente recuperáveis e legíveis e armazenados em locais digitais, a fim de serem geridos (Stock \& Stock, 2015, p. 4);

- Busca ou pesquisa: a CI observa como os utilizadores satisfazem as suas necessidades de informação, analisa as formulações da resposta a questões postas em ferramentas de busca e analisa ainda o modo como eles utilizam a informação encontrada (Stock \& Stock, 2015, p. 4);

- Recuperação: os pontos focais da CI são os sistemas para pesquisa de conhecimento, de que avultam como exemplos proeminentes os motores de busca na internet e também os catálogos de biblioteca;

- Relevância: o objetivo não é encontrar "qualquer velha" informação, mas somente a espécie de conhecimento que ajuda o utilizador a satisfazer as suas necessidades informacionais (Stock \& Stock, 2015, p. 4);

- Predominância digital: desde o advento da internet e da informação comercial e industrial, amplas áreas do conhecimento humano estão acessíveis digitalmente, mas apesar de a informação digital ser o tema nuclear ou "o core" da CI, há ainda espaço para as coleções de informação não-digital (Stock \& Stock, 2015, p. 4);

- Documentos: são textos e objetos não textuais (por exemplo, imagens, música e vídeos, mas também factos científicos, objetos económicos, objetos em museus e galerias, factos em tempo real e pessoas), sempre físicos (Stock \& Stock, 2015, p. 4); e

- Conhecimento: na CI o conhecimento é visto como qualquer coisa estática, fixada num documento e armazenada numa memória, armazenamento que pode ser digital (a $W W W$ - World Wide Web), material (uma Biblioteca) ou física (o cérebro dos "funcionários 
de uma empresa"), ao passo que a informação sempre contém um elemento dinâmico, pois alguém informa (ativo) ou é informado (passivo), e como a produção e o uso do conhecimento estão profundamente embebidos no processo social e cultural, a CI tem um forte contexto cultural (Stock \& Stock, 2015, p. 4).

Para complementar esta sinóptica explicação, vejamos a estrutura da obra que é muito expressiva e se desenvolve apenas em dois eixos (a infometria, embora considerada uma das subdisciplinas da CI, não é abordada no manual de forma destacada): (1) a recuperação da informação; e (2) a gestão do conhecimento.

O primeiro estende-se por um conjunto articulado e equilibrado de "capítulos": história, fundamentos e tipologia da recuperação de informação; processamento de linguagem natural; sistemas booleanos de recuperação; modelos clássicos de recuperação; recuperação de informação na web; problemas especiais da recuperação; e investigação empírica nesta área através da análise infométrica, de ferramentas e métodos analíticos, do perfil de utilizador e uso na pesquisa e avaliação dos sistemas de recuperação.

O segundo, por sua vez, compreende um capítulo "introdutório" sobre a origem e a evolução desta área, seguindo-se os metadados, as folksonomias, os sistemas de organização do conhecimento, os métodos de texto-orientado em organização de conhecimento, a indexação, a elaboração de sumários e a investigação empírica na área através da avaliação dos sistemas de organização do conhecimento e da avaliação da indexação e da elaboração de sumários.

Atendendo bem à matéria e ao propósito formativo do Handbook of Information Science (Stock \& Stock, 2015) constata-se que esta versão redutora não preenche, nem deve determinar, a natureza da CI. Esta disciplina científica pode enriquecer-se, na perspetiva evolutiva, com legados disciplinares práticos que a precederam e com a vigorosa componente tecnológica, para se desenvolver doravante e efetivamente como uma ciência social aplicada. 
Por fim, o último equívoco parece demasiado pueril, mas por muito incrível que pareça é bastante comum e persistente. Por razões corporativas e de reconhecimento social confunde-se facilmente profissão com atividade científica. A ciência em si é um processo de indagação e de descoberta teórico-prática, focada em problemas que tendem a ser explicados e resolvidos, mas é, ao mesmo tempo, um modo de vida, uma forma de trabalho remunerado, ou seja, uma profissão. No entanto, não há uma convergência natural entre estes dois planos: há profissões baseadas essencialmente no senso comum e não num corpus científico bem identificado. A aposta numa CI trans e interdisciplinar representa, de facto, um esforço sério de assunção de um paradigma onde se concretize um modus operandi realmente científico, através de uma reformulação e uma ampliação do objeto de estudo e da adoção de um autêntico método.

\section{A Ciência da Informação e seus paradigmas}

Se regressarmos ao tópico, atrás focado, das duas perspetivas que orientam o debate epistemológico em CI podemos, facilmente, desembocar na análise dos paradigmas, de início dois, tendo sido mais recentemente acrescentado um terceiro:

- o paradigma custodial, historicista, patrimonialista e tecnicista;

- o paradigma pós-custodial, informacional e científico;

e possivelmente ainda

- o paradigma político-ideológico e sociocultural.

Antes de caraterizar esses paradigmas é importante perceber que:

$1^{\circ}$ A natureza científica de uma disciplina é avaliada levando-se em conta a dimensão institucional e académico-profissional (realização de eventos, promoção de cursos de graduação e pós-graduação, revistas, livros, etc.) e o lado teórico-metodológico (negligenciado a partir dos anos sessenta do século XX por conta da influência estruturalista e pós-moderna); 
$2^{\circ}$ Os paradigmas propostos têm uma estreita relação com as três modalidades de construção e operacionalização da atividade científica.

Com a ajuda da filósofa das ciências, Olga Pombo (2004), compartilhamos a caraterização de cada uma das três modalidades de posicionamento científico:

\section{Pluri / multidisciplinaridade:}

Apenas parceria disciplinar;

Compartilhando objetivos comuns;

Multiplicidade de métodos;

Existência de uma fronteira disciplinar.

\section{Interdisciplinaridade:}

Linguagem parcialmente comum;

Coesão entre conhecimento;

Integração disciplinar;

Compartilhando objetivos comuns;

Transferência de problemas, conceitos e métodos;

Multiplicidade de métodos;

Limite disciplinar discreto.

\section{Transdisciplinaridade:}

Linguagem, estrutura, fundamentos e mecanismos comuns;

Coesão entre o conhecimento e integração disciplinar máxima;

Compartilhando objetivos comuns;

Transferência de problemas, conceitos e métodos;

Falta de limites disciplinares;

Multiplicidade de métodos;

Visão unificada e sistémica de um setor.

Voltando à presença dos paradigmas na área da Informação/ Documentação, temos a possibilidade de enumerar os seus principais traços definidores. O paradigma custodial, bistoricista, patrimonialista e tecnicista é apresentável assim: 
- sobrevalorização da custódia ou guarda, conservação e restauro do suporte como função basilar da atividade profissional de arquivistas e bibliotecários;

- identificação do serviço / missão custodial e público de Arquivo e de Biblioteca com a preservação da cultura "erudita" ou "superior" (as artes, as letras, a ciência) de um Povo em antinomia mais ou menos explícita com a cultura popular, "de massas" e os "produtos de entretenimento";

- enfatização da memória como fonte legitimadora do Estado-Nação e da cultura como reforço identitário do mesmo Estado, sob a égide de ideologias de pendor nacionalista;

- importância crescente do acesso a "conteúdo" através de instrumentos de pesquisa (guias, inventários e catálogos) de documentos percecionados como objetos patrimonializados, permanecendo, porém, mais forte o valor patrimonial do documento que o imperativo informacional;

- prevalência da divisão e assunção profissional decorrente da criação e desenvolvimento dos serviços / instituições Arquivo e Biblioteca, indutora de um arreigado espírito corporativo que fomenta a confusão entre profissão e ciência (persiste a ideia equívoca de que a profissão de arquivista ou bibliotecário gera, naturalmente, disciplinas científicas autónomas como a Arquivística e a Bibliotecologia) (Silva, 2006, p.19-20).

Em contraponto, o paradigma pós-custodial, informacional e científico evidencia diferentes caraterísticas ajustadas às demandas da Era da Informação, em que estamos imersos:

- valorização da informação enquanto fenómeno humano e social, sendo a materialização num suporte um epifenómeno (ou derivado informacional);

- constatação do incessante e natural dinamismo informacional oposto ao "imobilismo" documental, traduzindo-se aquele no trinómio criação-seleção natural-acesso/uso e o segundo na antinomia efémero-permanente; 
- prioridade máxima concedida ao acesso à informação por todos mediante condições específicas e totalmente definidas e transparentes, pois só o acesso público justifica e legitima a custódia e a preservação;

- imperativo de indagar, compreender e explicitar (conhecer) a informação social, através de modelos teórico-científicos cada vez mais exigentes e eficazes, em vez do universo rudimentar e fechado da prática empírica composta por um conjunto uniforme e acrítico de modos/regras de fazer, de procedimentos só aparentemente "asséticos" ou neutrais de criação, classificação, ordenação e recuperação;

- alteração do atual quadro teórico-funcional da atividade disciplinar e profissional por uma postura diferente sintonizada com o universo dinâmico das Ciências Sociais e empenhada na compreensão do social e do cultural, com óbvias implicações nos modelos formativos dos futuros profissionais da informação; e

- substituição da lógica instrumental, patente nas expressões "gestão de documentos" e "gestão da informação", pela lógica científico-compreensiva da informação na gestão, isto é, a informação social está implicada no processo de gestão de qualquer entidade organizacional e, assim sendo, as práticas informacionais decorrem e articulam-se com as conceções e práticas dos gestores e atores e com a estrutura e cultura organizacionais, devendo o cientista da informação, em vez de estabelecer ou impor regras operativas, compreender o sentido de tais práticas e apresentar dentro de certos modelos teóricos as soluções (retro ou) prospetivas mais adequadas (Silva, 2006, p. 21-22).

A presença desses dois paradigmas tem determinantes geográficos e culturais e, portanto, o conhecimento que temos da realidade formativa e profissional nos países da América do Sul, especialmente no Brasil, leva-nos a admitir como possível o paradigma político-ideológico e sociocultural, cujas caraterísticas essenciais são:

- substituição da égide científica da História, da Filologia e das Humanidades pela Sociologia e a Antropologia; 
- alteração no tipo de mediação praticado, que deixa de ser passivo, custodial e elitista para se tornar ideológico e sociocultural, interventivo com base na premissa neo-marxista de colocar a cultura ao serviço de uma sociedade emancipada do capital e sem classes;

- desvalorização da mediação técnica assente nos instrumentos de pesquisa e olhar crítico face às novas Tecnologias da Informação e Comunicação, usadas preferencialmente para a animação sociocultural;

- aposta prioritária na Biblioteca Pública e no Museu (sobretudo regional e local) e em estratégias de rede centradas tanto na Leitura Pública, como na Memória Coletiva, em detrimento do papel dos Arquivos (vistos lucidamente como "reservas logísticas" do(s) Poder(es)) e dos Centros de Documentação Científica e Tecnológica (Silva, 2016, p. 86).

No paradigma pós-custodial, a CI é uma ciência social que investiga os problemas, as questões e os casos relacionados com o fenómeno infocomunicacional percetível e cognoscível através da confirmação das propriedades inerentes à génese do fluxo, organização e comportamento informacional. Uma ciência que estuda todo um processo desde a origem, passando pela coleta, organização, armazenamento, recuperação, interpretação, transmissão, transformação e uso da informação (Silva, 2006, p. 141).

Para tanto, a CI precisa de um método comum às Ciências Sociais, que garanta uma atividade de pesquisa adequada. Desde 1999, a proposta metodológica dos belgas Paul De Bruyne, Jacques Herman e Marc De Schoutheete $(1974,1977)$ foi aplicada à CI. Foi muito possivelmente uma "encomenda" do filósofo das Ciências, Jean Ladrière, e constitui um método no sentido pleno (caminho para) baseado em quatro pólos que interagem entre si de forma elíptica e nunca linear, como acontece com o Método Experimental das Ciências Naturais:

Polo epistemológico - as modalidades de abordagem, paradigmas e vigilância crítica; 
Polo Teórico - a formulação do problema, a hipótese ou escolha da teoria, conceitos operativos, bem como a elaboração de um modelo possível;

Polo Técnico - todas as operações ou procedimentos que permitem coletar evidências relacionadas com um assunto, um problema ou um caso de estudo; e

Polo morfológico - a saída ou publicação dos resultados que alimentam todos os pólos anteriores.

A importância dos conceitos operacionais levou à publicação on-line, em 2008, do Dicionário Eletrónico em Terminologia da Ciência da Informação (DeltCI), onde aparece a definição de informação que seguimos, articulada com as de documento e de comunicação:

Informação - conjunto estruturado (da unidade de representação simples à combinação complexa) de representações mentais e emocionais codificadas de forma social, capaz de ser registada em qualquer tipo de suporte e comunicada de forma assíncrona e multidireccional (DeltCI, 2008).

Com esta definição, dois objetivos são atingidos: caraterizar um fenómeno; e construir um objeto científico. A informação confunde-se com a cultura porque se refere claramente à capacidade simbólica e sígnica do Homo Sapiens. Ernest Cassirer definiu o homem como "animal simbólico" e o conceito de informação tem uma conexão inescapável com a dimensão cultural da Humanidade. No entanto, o conceito de Cultura hoje é muito vasto e sujeito a grande usura ou desgaste e o da informação pode ser empregue com maior precisão. Na definição, três secções ou módulos podem ser identificados: $1^{\circ}$ - a raiz cognitiva do fenómeno sempre articulado com o contexto social; $2^{\circ}$ - a materialização que significa a concretude indiscutível do documento, ou seja, a tendência para a materialização; e $3^{\circ}$ - a possibilidade de ser comunicada, isto é, de uma comunhão ou partilha de significado(s).

Destes três módulos derivaram, pelo menos, duas consequências diretas: a evidência de que a informação tem uma raiz cognitiva e 
emocional, tendo um sentido ou significado produzido e descodificado no contexto humano e social; e se é verdade que a informação aparece aos nossos sentidos em forma de documento, considerar a informação documental como o objeto da CI é enfatizar o suporte em detrimento do conteúdo como verdadeiro foco dessa disciplina. Questões relacionadas com a produção e o comportamento informacional são estudadas levando em consideração assuntos, pessoas e não apenas documentos.

Aceitar a redução da informação ao aparato documental como o núcleo primacial da CI consiste em ignorar o reaparecimento da palavra em foco, a partir de meados do século XIX, com várias apropriações ou conceitos como, por exemplo, podemos encontrar no livro de Luciano Floridi, Information: a very short introduction: informação matemática, informação semântica, informação física, informação biológica e informação económica (Floridi, 2010). Todos eles representam o processo de apropriação que diferentes disciplinas ou ciências fizeram da palavra e cunharam um conceito operacional. É uma apropriação legítima e natural, como é natural e legítimo que a CI exclua como operacionais todos os conceitos, exceto informação semântica, que não representam a dimensão humana e social.

Também é importante distribuir todas as linhas de pesquisa que foram mapeadas e enumeradas por grupos ou áreas maiores do objeto de estudo em CI:

Produção Informacional ou génese de informação pelo sujeito da ação (individual ou coletivo) e sua correlação com o contexto;

Organização e Representação que é tudo o que tem a ver com a mediação de informação por metadados, classificação, indexação e todos os tipos de visualização informacional; e

Comportamento Informacional, ou seja, estudo das formas de busca, de acesso e de uso da informação por todos os tipos de utilizadores nos respetivos contextos. 
E transversal às três grandes áreas do objeto da CI emerge, no plano prático ou da atividade profissional, a gestão da informação.

É bom ter em mente a premissa de que os paradigmas nascem e se desenvolvem por meio da investigação e da formação. Quanto a essa dimensão, existe uma vasta gama de linhas de pesquisa que pode ser distribuída pelas três áreas do objeto.

No que diz respeito à formação, tem a ver com a conceção mais ou menos integrada que é adotada e com o tipo de currículo que é concebido. Na Universidade do Porto, no ano letivo de 2001/2002, iniciou-se uma profunda alteração de conceção do programa curricular, partindo da Licenciatura e evoluindo depois, em 2008, para o Mestrado ${ }^{3}$, como veremos no ponto seguinte.

\section{O Gestor de informação de base científica}

As múltiplas consequências teórico-práticas da fundamentação teórico-espistemológica antes exposta afetam diretamente as profissões tradicionais de arquivista e de bibliotecário, que não podem continuar a ser aqueles que guardam, conservam e organizam documentos, mas terão de se assumir como gestores de informação produzida e usada em qualquer contexto orgânico. Ser gestor de informação passa a ser um desafio difícil, mas aliciante, pois urge repensar toda uma herança empírica milenar e questionar o sentido da profissão, já não num quadro de atividades de salvaguarda do património, mas sim numa perspetiva de acesso e conservação da informação, elemento essencial da memória identitária do respetivo organismo produtor.

3 Para um conhecimento detalhado dos currículos da Licenciatura e do Mestrado, ver: https://sigarra.up.pt/flup/pt/cur_geral.cur_planos_estudos_view?pv_plano_id=13961\&pv_ ano_lectivo=2018\&pv_tipo_cur_sigla=L\&pv_origem $=$ CUR; https://sigarra.up.pt/flup/pt/ cur_geral.cur_planos_estudos_view?pv_plano_id $=2503 \& p v \_a n o \_l e c t i v o=2018 \& p v \_t i p o \_$ cur_sigla=M\&pv_origem=CUR (acesso em 10-10-2018). 
Além disso, ao gestor de informação da era pós-custodial compete também o exercício de contribuir para redesenhar as fronteiras de uma disciplina que faz da Informação não a sua matéria-prima, mas o seu objeto central de estudo e de pesquisa.

Ao serem impelidos para um mesmo objeto e para metodologias comuns por força da revolução tecnológica da informação, o arquivista, o bibliotecário, o documentalista, o museólogo e o especialista em informática de gestão tendem a fundir-se num novo profissional que sintetiza as diversas competências adstritas a todos eles e se assume como um estruturador do fluxo informacional que corre no seio das organizações e alimenta o funcionamento e a capacidade decisória das mesmas.

Qual a formação adequada para os profissionais de informação e documentação?

Parece óbvio que se deverão distinguir duas modalidades de intervenção teórico-prática, sendo uma de matriz essencialmente técnica - formação média, para um nível técnico-profissionalizante, que possa ser assegurada por escolas profissionais ou escolas do ensino secundário - e outra de nível mais compreensivo e explicativo - um saber fazer fundado no estudo e na pesquisa mono, inter e multidisciplinar, tomando as Ciências Sociais como eixo central e ponto de derivação para cruzamento com outras disciplinas científicas, a qual deve ser acometida às instituições de ensino superior (Universidades e Institutos Politécnicos).

A formação dos técnicos profissionais, a cujas aptidões e competências não pode hoje faltar um adequado treino informático, responde a exigências práticas que a gestão da informação (em sentido lato e transversal a todos os setores da atividade humana e social) coloca e colocará cada vez mais, numa perspetiva essencialmente operativa.

A formação superior (iniciada na licenciatura, mas com progressão no mestrado e no doutoramento) segundo a fundamentação exposta nos pontos anteriores serviu de suporte à criação, em 2001, 
do Curso de Licenciatura em Ciência da Informação, ministrado em parceria pela Faculdade de Letras e pela Faculdade de Engenharia da Universidade do Porto (Silva \& Ribeiro, 2002), e em 2008 ao Curso de Mestrado em Ciência da Informação, que substituiu o Mestrado em Gestão da Informação, a funcionar na Faculdade de Engenharia da Universidade do Porto desde 1997.

A Licenciatura em CI surgiu como um modelo de formação alternativo ao Curso de Especialização em Ciências Documentais, apresentando, desde logo, duas diferenças fundamentais: a de se tratar de uma formação ao nível da licenciatura e a de ter abolido a designação tradicional de "Ciências Documentais" para assumir o nome de "Ciência da Informação", o que pressupõe uma perspetiva mais abrangente e integradora de diversas áreas disciplinares afins (Silva \& Ribeiro, 2003).

A visão integrada foi assumida em plenitude, não havendo diferenças de formação em função dos perfis profissionais que os licenciados podem assumir. Assim, o design do plano de estudos anulou separações artificiais entre "ramos" ou "variantes" de Arquivo e de Biblioteca e Documentação, como acontecia no modelo formativo anterior, e que conduziam a uma visão redutora e desagregada de conteúdos que devem ser apreendidos de forma global. A título de exemplo, pode-se referir o caso das operações de representação da informação (a descrição, a indexação ou a classificação), que deixaram de ser ensinadas de forma compartimentada, em unidades curriculares distintas consoante se trate dos arquivos ou das bibliotecas ou dos museus, para passarem a ser trabalhadas de modo integrado, numa abordagem conceptual una e coerente.

A perspetiva unitária subjacente a este modelo formativo procura também uma complementaridade com a área dos chamados Sistemas de Informação, que vem ensaiando uma progressiva autonomização face à Informática e Computação tradicionais, direcionando o seu campo de trabalho e de profissionalização para as Organizações em geral. 
Com base nos pressupostos referidos, o modelo formativo em CI da Universidade do Porto concentra na área científica nuclear - CI - um conjunto de unidades curriculares que asseguram uma componente teórica e metodológica una e, a par delas, outras unidades curriculares que se centram nas especificidades dos diversos tipos de sistemas ou serviços de informação, direcionadas, por isso, para as componentes aplicadas da própria Ciência da Informação (Arquivística, Biblioteconomia, Museologia, Sistemas Tecnológicos de Informação).

Este "núcleo duro" do curriculum está, evidentemente, aberto à interdisciplinaridade, incluindo unidades curriculares de outras áreas do saber, com caráter de obrigatoriedade umas, de opção outras, mas sempre complementando as matérias da área científica nuclear.

Enunciemos alguns exemplos de unidades curriculares que integram o plano de estudos, ilustrando o seu amplo caráter interdisciplinar:

- do vasto campo das Ciências Sociais e Humanas é incluído o imprescindível conhecimento histórico das instituições (História da Administração Pública) e das práticas culturais (História da Cultura); o apoio instrumental da Paleografia e Diplomática; o contributo da Filosofia em matérias como a Lógica ou a Ética da Informação; o uso instrumental de competências linguísticas (Técnicas de Expressão e Comunicação) ou de línguas estrangeiras, designadamente o Inglês Técnico;

- da área da Informática e da Computação emanam saberes que se plasmam em unidades curriculares diversas como Sistemas Computacionais e de Comunicação, Informação para a Internet, Bases de Dados e Tecnologia Multimédia;

- a relação com as ciências da Gestão e da Administração, englobando um espetro largo que inclui o Direito, manifesta-se pela presença de unidades curriculares como Fundamentos de Gestão, Organização e Gestão de Empresas, Sistemas de Apoio à Decisão e Direito Administrativo. 
Este modelo formativo pretende, sobretudo, ilustrar a transposição de uma fundamentação epistemológica desenvolvida a montante para a estruturação curricular do curso. Não se discute, como questão de princípio, quais os níveis de formação desejáveis para preparar profissionais capazes de gerir informação, coordenar e gerir serviços ou mesmo conceber sistemas de informação. O modelo que perfilhamos começou por ser implementado há alguns anos num curso de licenciatura ( $1 .^{\circ}$ ciclo) e evoluiu alguns anos depois para o nível de mestrado ( $2 .^{\circ}$ ciclo). Se partirmos do pressuposto de que há "espessura" científica na Ciência da Informação para justificar, por um lado, uma formação profissionalizante com o necessário complemento de aplicações práticas (estágios ou projetos) e, por outro, o desenvolvimento da vertente de investigação, indispensável à formação dos próprios formadores e à consolidação científica desta área do saber, ainda considerada por muitos como uma ciência emergente, então os diferentes ciclos de estudos têm pleno sentido e as condições para criar "escola" e "massa crítica" no seio da universidade estarão criadas e prontas a frutificar.

Neste novo paradigma, a formação não se reduz à aquisição de conhecimentos, mas passa a significar conhecer, analisar, interpretar e explicar e não apenas descrever recorrendo a normas acriticamente aplicadas. Do mesmo modo, investigar em CI é uma atividade essencialmente aplicada e, como tal, traduz-se numa prática profissional com novas formas de intervenção.

Vejamos, então, como se pode concretizar, na prática do gestor de informação de base científica, esta nova abordagem e quais os traços fundamentais que a caraterizam:

- Eleger a Informação (à luz da Teoria Sistémica) como objeto de trabalho e de estudo obriga a olhar este fenómeno de uma forma completamente diferente do que até agora tem sido feito com o Documento (unidade física que se classifica, se descreve e se arruma, atribuindo-se-lhe uma cota para posterior localização). Perceber 
a informação implica, antes de mais, conhecer o seu contexto de produção, o que é algo anterior ao seu registo material num suporte físico. E implica também conhecer o uso que foi ou é dado a essa informação, ou seja, quem são os seus utilizadores, com que fim a usam, como a pesquisam, com que frequência, etc. Pensar sistemicamente a informação significa, pois, que, mais do que estruturar serviços (bibliotecas, arquivos...) dentro das organizações, é importante perceber de forma holística os contextos da sua produção e uso, numa visão integrada que não separa (nem gere) artificialmente informação de arquivo, ou de biblioteca, ou digital, mas sim analisa, numa visão integrada e como um sistema, todas as suas componentes.

- Entender o trabalho do profissional da informação como um processo investigativo que visa conhecer e representar com rigor a realidade informacional em análise tem, igualmente, consequências várias, pois ele deixa de atuar como um simples técnico que aplica normas e procedimentos uniformes com vista à produção de instrumentos, mais os menos standard, para viabilizar o acesso à informação e passar a assumir o papel do cientista da informação que apresenta resultados validados por uma metodologia científica, questionando (problematizando, formulando hipóteses) a própria atuação, sempre em referência a paradigmas e teorias que estão em permanente validação (ou revisão).

- Aplicar o método de investigação quadripolar põe a tónica na análise orgânico-funcional, requisito indispensável para se chegar a um conhecimento rigoroso da estrutura do sistema e das funções/competências dos variados setores que compõem essa mesma estrutura, pois só assim é possível caraterizar com rigor o contexto da produção informacional em análise.

- Procurar conhecer as relações sistémicas internas e externas e seu reflexo na produção informacional obriga a uma investigação sistemática para se chegar à identificação de eventuais subsistemas 
de informação ou para perceber as relações entre, por exemplo, os vários sistemas que formam, entre si, um supersistema de informação.

- Analisar a componente funcional do sistema leva a que determinadas operações tenham de ser implementadas como medidas "profiláticas" regulares destinadas a otimizar o funcionamento do próprio sistema de informação; conta-se, neste caso, por exemplo, a avaliação retro/prospetiva, operação fundamental que permite detetar redundâncias e "desperdícios" informacionais.

- Entender as operações técnicas de descrição, classificação e indexação como o resultado natural de todo o processo de conhecimento desencadeado a montante e não com o objetivo redutor de proporcionar o acesso pelo acesso à informação é também fundamental para que os instrumentos de pesquisa (catálogos, índices, inventários, bases de dados...) produzidos garantam uma representação adequada da realidade informacional objeto de análise.

Em suma, pensar a CI à luz do novo paradigma na era pós-custodial, implica uma visão integrada, em que não faz sentido organizar serviços de informação com uma finalidade meramente instrumental, separando, artificialmente, as várias componentes de um todo - a informação é gerada num determinado contexto organizacional pelos variados agentes que atuam nesse mesmo contexto, seja na área administrativa, seja na área técnica ou na área científica -, mas sim conceber sistemas de informação em que a componente funcional se concretiza na estruturação de serviços agregadores de todas as componentes informacionais.

\section{Referências Bibliográficas}

BORKO, H. (1968). Information Science, what is it? American Documentation, 19(1), 3-5. CAPURRO, R. (2003). Epistemologia e Ciência da Informação. In Informação, conhecimento e transdisciplinaridade: anais. Disponível em: http://www.capurro. de/enancib_p.htm Acesso em 20-12-2018. 
LE COADIC, Y.-F. (1996). A Ciência da Informação. Brasília: Briquet de Lemos Livros. ISBN 85-85637-08-0.

DE BRUYNe, P., HERMAN, J., \& DE SCHOUTHEETE, M. (1974). Dynamique de la recherche en sciences sociales de pôles de la pratique méthodologique. Paris : P.U.F.

DE BRUYNE, P., HERMAN, J., \& DE SCHOUTHEETE, M. (1977). Dinâmica da pesquisa em Ciências Sociais: os polos da prática metodológica. Rio de Janeiro: Livraria Francisco Alves Editora.

DeltCI: Dicionário Eletrônico em Terminologia da Ciência da Informação (2008). Disponível em: http://web4.letras.up.pt/cicdigitalporto/?page_id=245 Acesso em 20-12-2018.

FLORIDI, L. (2010). Information: a very short introduction. Oxford: Oxford University Press. ISBN 978-0-19-955137-8.

MOREIRO GONZALEZ, J. A. (2005). Conceptos introductorios al estúdio de la información documental. Salvador: EDUFBA; Lima: Pontificia Universidad Católica del Peru. ISBN 85-232-0353-2.

OTLET, P. (1934). Traité de Documentation: le livre sur le livre. Bruxelles: Éditiones Mundaneum.

POMBO, O. (2004). Interdisciplinaridade: ambições e limites. Lisboa: Relógio d'Água. ISBN 972-708-814-7.

SALDANHA, G. S. (2017). Épistémologie historique des sciences de l'information et de la communication: la méthode architecturale de Viviane Couzinet entre les "concepts-artefacts» et les "artefacts conceptuels». In P. Fraysse, C. Gardiès, I. Fabre (dir.), Sur les sciences de l'information et de la comunication: contributions hybrides autour des travaux de Viviane Couzinet (p. 43-59). Toulouse: CépaduèsÉditions. ISBN 978.2.36493.600.3.

SHERA, J. H., \& CLEVELAND, D. B. (1977). History and foundations of Information Science. Annual Review of Information Science and Technology, 12, 249-275.

SILVA, A. M. da (2006). A Informação: da compreensão do fenómeno e construção do objecto científico. Porto: Edições Afrontamento. ISBN 978-972-36-0859-6.

SILVA, A. M. da (2016). Arquitetura da Informação e Ciência da Informação: notas de (re)leitura à luz do paradigma pós-custodial, informacional e científico. Prisma. Com, 32, 62-104. Disponível em: http://ojs.letras.up.pt/index.php/prismacom/ article/view/2214 Acesso em 25-10-2018.

SIlVA, A. M. da, \& RIBEIRO, F. (2002). Das "Ciências" Documentais à Ciência da Informação: ensaio epistemológico para um novo modelo curricular. Porto: Edições Afrontamento. ISBN 972-36-0622-4.

SILVA, A. M. da, \& RIBEIRO, F. (2003). Um Modelo sintético de licenciatura para uma Ciência da Informação consolidada: o caso português. In Informação, conhecimento e transdisciplinaridade: anais. Belo Horizonte: Escola de Ciência da Informação da UFMG.

STOCK, W. G., \& STOCK, M. (2015). Handbook of Information Science. Berlin; Boston: De Gruyter Saur. ISBN 978-3-11-037364-6. 


\title{
LA CIENCIA DE LA INFORMACIÓN DOCUMENTAL: UNA DIS C I P LINA TRANSDISCIPLINAR
}

\author{
A Cî́NCIA DA INFORMAÇÃO DOCUMENTAL: \\ UMA D I S C I PLINA T RANSDISCIPLINAR
}

THE DOCUMENTARY INFORMATION SCIENCE:

A TRANSDISCIPLINARY DISCIPLINE

\begin{abstract}
Miguel Ángel Rendón Rojas
Instituto de Investigaciones Bibliotecológicas y de la Información. Universidad Nacional Autónoma de México

marr@unam.mx ORCID: https://orcid.org/0000-0002-9206-6511
\end{abstract}

RESUMEN - Se afirma que las disciplinas informativo-documentales - Archivística, Bibliotecología, Ciencia de la Información, Documentación, Museología - después de un desarrollo disciplinar autónomo, evolucionan dentro de un contexto transdisciplinar, donde bajo el común denominador de información, documento, usuario, profesional de la información documental e institución de la información documental, convergen en una nueva realidad disciplinar, pero en una relación dialéctica de unidad-multiplicidad, en la que al mismo tiempo conservan sus atributos específicos que las diferencia.

PALABRAS CLAVE - Transdisciplina; Epistemología de la Ciencia de la Información Documental. 


\begin{abstract}
It is affirmed that the informative-documentary disciplines - Archival Science, Library Science, Information Science, Documentation, Museology - after an autonomous disciplinary development, evolve within a transdisciplinary context, where under the common denominator of information, document, user, professional of documentary information and institution of documentary information, converge in a new disciplinary reality, but in a dialectic relation of unity-multiplicity, in which at the same time they preserve their specific attributes that differentiate them. KEYWORDS - Transdiscipline; Epistemology of Documentary Information Science.
\end{abstract}

RESUMO - Afirma-se que as disciplinas informativo-documentais - Arquivística, Biblioteconomia, Ciência da Informação, Documentação, Museologia - depois de um desenvolvimento disciplinar autónomo, evoluem dentro de um contexto transdisciplinar, onde sob o comum denominador de informação, documento, utilizador, profissional de informação documental e instituição de informação documental, convergem numa nova realidade disciplinar, mas numa relação dialética de unidade-multiplicidade, na qual, ao mesmo tempo, preservam os seus atributos específicos que as diferenciam.

PALAVRAS CHAVE - Transdisciplina; Epistemologia da Ciência da Informação Documental.

\title{
1. Lo uno y lo múltiple en la historia de la ciencia
}

Si analizamos el devenir de la ciencia, podemos constatar que las disciplinas científicas se mueven en espiral de la unidad a la especialización y de ésta, una vez más hacia la convergencia y unidad. En efecto, desde que un grupo de primates se desprendió del reino 
de lo inconsciente y la inmediatez factual y obtuvo la chispa de la razón, surgió el deseo de explicar la realidad, de comprenderla, de desentrañar los qué, por qué, cómo y para qué de lo que le rodeaba y acontecía.

Para satisfacer esa necesidad de conocimiento, empezó a buscar respuestas sobre el origen, la estructura, el funcionamiento y la finalidad del universo, de la naturaleza, de la vida, de ellos mismos. En un principio, en un proceso que abarca decenas, tal vez centenas de miles de años durante la larga noche obscura y difícil de la prehistoria, utilizó el mito como herramienta para conseguir ese propósito. Más tarde, en la aurora de la historia, cuando aprendió a plasmar en documentos escritos esos relatos construidos y trasmitidos de generación en generación, es que aparecen las primeras obras cosmogónicas que conocemos, como por ejemplo el Enuma Elish (2014), el Génesis (Biblia, 1967) o el Popol Vuh (2012), en las que se narran el origen del mundo y del ser humano gracias a la intervención de los dioses.

Sin embargo, su desarrollo continuó avanzando y empezó a realizar actividades prácticas más complejas como la construcción, la agricultura, la medicina, la navegación, las cuales exigían cada vez más, conocimientos empíricos y técnicos más o menos seguros, lo que provocó el desarrollo de capacidades inquisitivas más rigurosas; al mismo tiempo, creció la insatisfacción ante explicaciones mitológicas, por lo que apareció otro tipo de conocimiento que cumplió con el mismo cometido que los mitos pero cuyo fundamento era la razón discursiva. Así nació la filosofía como respuesta a esa inquietud de encontrar respuestas racionales a la realidad.

Ahora bien, dentro de ese conocimiento racional, en un todo, se encontraban, de manera incipiente, las ciencias particulares: la Matemática con Tales de Mileto, Pitágoras y los pitagóricos, Platón; la Física, Astronomía, Psicología, Política con Aristóteles; la Botánica, la Geología con Teofrasto; la Lógica, Lingüística, 
Semiótica con Aristóteles, la escuela de Megara, los estoicos. En ese momento nos encontramos en la etapa de lo uno, la unidad en la historia de la ciencia.

Muchos siglos después, se formó una razón especializada, guiada por un método sistemático y riguroso caracterizado por ser matemático, empírico y lógico, por consecuencia que exige la demostración y comprobación del conocimiento; que encontró su fundamentación epistemológica en la filosofía de Descartes, Bacon y su culmen en el positivismo. Esa razón es la razón moderna, con ayuda de la cual se van desprendiendo de la filosofía especulativa y apareciendo con identidad y autonomía propia diferentes ciencias particulares. De este modo, surgen en primer lugar, durante la revolución científica de los siglos XVI-XVII, la Física y la Astronomía, posteriormente en el siglo XVIII, la Química, en el siglo XIX, la Biología, para terminar con el ya conocido desarrollo científico que tuvo lugar a finales de ese siglo decimonónico y todo el XX. La Psicología, Lingüística, Sociología y una larga lista de disciplinas científicas que aparecieron y se desarrollaron. Es la etapa de la especialización, de lo múltiple.

Sin embargo, principalmente durante la segunda mitad del siglo pasado se empezó a observar el movimiento contrario, cuando ciencias particulares tienden a integrarse, a cooperar entre sí para estudiar fenómenos más complejos que no podían ser investigados por una sola ciencia. Así por ejemplo, aparecen la Cibernética, la Limnología1 ${ }^{1}$, la Biofísica, Bioquímica, y otro grupo de ciencias que giran en torno a un objeto que puede ser estudiado desde diferentes perspectivas y así tenemos las ciencias de la tierra, las ciencias del mar, las ciencias del deporte, entre otras. Es el periodo del regreso a la unidad en otro nivel.

1 Estudio de los ecosistemas acuáticos epicontinentales como lagos, embalses, ríos y humedales. 
Así pues, es posible sistematizar el anterior proceso con el siguiente esquema que muestra la direccionalidad del devenir histórico de las ciencias:

Unidad $\rightarrow$ Diferenciación $\rightarrow$ Integración: nueva Unidad

\section{Lo uno y lo múltiple en la historia de las disciplinas informativo-documentales}

Ese mismo camino seguido por las ciencias, que acabamos de describir, lo podemos encontrar en el desarrollo histórico de las disciplinas informativo-documentales.

Hemos señalado el despertar de la razón como uno de los momentos distintivos en que el ser humano se desprende del mundo animal. Pero junto a ello, también se puede indicar la presencia del lenguaje articulado que siempre acompaña al pensamiento y a toda la cultura, la cual representa el hábitat, el ecosistema construido de manera secundaria que es donde vive, y sólo en él puede vivir, ese ser humano con todas sus realidades espirituales (ideas, religión, moral, arte, lenguaje, sistemas de organización: social, económica, política, jurídica, educativa, etc.) Gracias a ese lenguaje construye esa cultura, ese mundo humano. En un inicio fue un lenguaje oral, que precisaba de mnemotecnia para no olvidarse, pero que ulteriormente se vio ayudado por unos signos perdurables (pictogramas, ideogramas, alfabetos), grabados en materiales perdurables (piedra, arcilla, papiro), que lo representaban. Era el nacimiento de la escritura, tan importante que se le atribuía un origen divino, sólo un dios pudo haberlo inventado y por su magnanimidad se lo regaló a los humanos: dicho dios fue identificado como Namú entre los sumerios, Thot en los egipcios, Hermes en los griegos o Itzamná en los mayas. Al contar con esos preciosos instrumentos que resguardaban al principio transacciones comerciales, des- 
pués momentos históricos de trascendencia para la comunidad, y finalmente su memoria, su cultura, su identidad, se procedió a recopilar los documentos más significativos, conservarlos y resguardarlos en un sitio especial bajo el cuidado de personajes también especiales. Es en ese momento que situamos el origen de manera incipiente, precientífico, de tres de esas disciplinas: archivística, bibliotecología y museología, y que corresponde a la primera etapa en la historia de esas disciplinas caracterizada por la unidad.

A semejanza de las ciencias particulares que formaban un todo y se encontraban dentro de la filosofía, aunque no como las conocemos actualmente, sino como protociencias (ejemplo claro son la Física y Psicología aristotélicas que distan mucho de la Física y Psicología contemporáneas), las mencionadas disciplinas informativo-documentales también aparecen en esa etapa no como ciencias autónomas, sino como una serie de actividades realizadas, como ya se mencionó, en instituciones especializadas donde se reunían, resguardaban, conservaban y consultaban ciertos documentos, principalmente administrativos e históricos, aunque también los había de carácter religioso, literario y de otros tipos de conocimientos de su época. Es obvio que los encargados de trabajar en esas instituciones para garantizar su funcionamiento tuvieron que idear y emplear algunas herramientas que permitieran reunir, identificar, organizar y recuperar esos documentos.

Es ya del todo conocidos los archivos-bibliotecas de la antigua Mesopotamia con una antigüedad de cerca de cinco milenios, como la de Ebla, o un poco posterior, como la de Asurbanipal; o las Casas de la Vida en el antiguo Egipto, a las que posteriormente en el periodo helénico se les unirá el museo, por lo que en un mismo recinto se encontraban archivo, biblioteca y museo. 


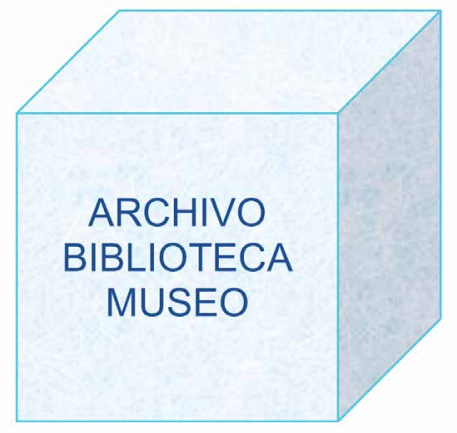

La etapa de diferenciación empieza cuando se rompe esa unidad institucional y cada una de esas entidades toma un camino diferente.

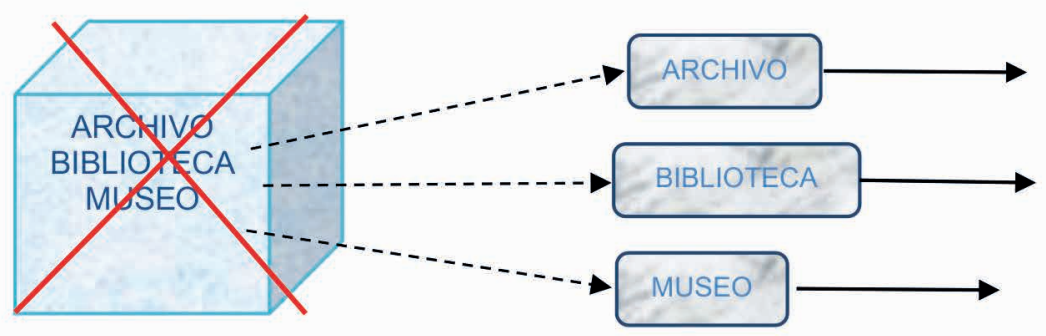

Ese proceso de diferenciación continúa cuando se van formando unas áreas práctico-teóricas particulares ${ }^{2}$ para el estudio de la respectiva institución (archivo, biblioteca, museo), los acervos que contiene (colecciones, fondos) y las técnicas utilizadas para trabajar con esos acervos en esa institución, esto es, el centro de interés recaía en los objetos y su tratamiento; además de que el afán teleológico era la conservación.

Finalmente, como resultado de ese esfuerzo práctico-teórico y de la misma manera que en el caso de las otras ciencias particulares

2 En este caso el orden de las palabras sí tiene importancia, lo práctico es primero y lo teórico va detrás de él. 
que se desprendieron de la filosofía bajo la influencia del pensamiento positivista y de la modernidad, aparecen la Archivística o Archivología o Archivonomía; la Bibliotecología o Biblioteconomía; y la Museología. ${ }^{3}$

Existe el consenso general, más como un hecho simbólico que como una fecha exacta de nacimiento, que con la publicación por Muller, Feith, y Fruin (1898) del "Manual para la organización y descripción de los archivos: diseñado en nombre de la Asociación de Archivistas de los Países Bajos" (comúnmente conocido como Manual holandés) en el siglo XIX, que la Archivología o Archivonomía adquiere carta de identidad como ciencia autónoma dedicada al estudio del archivo.

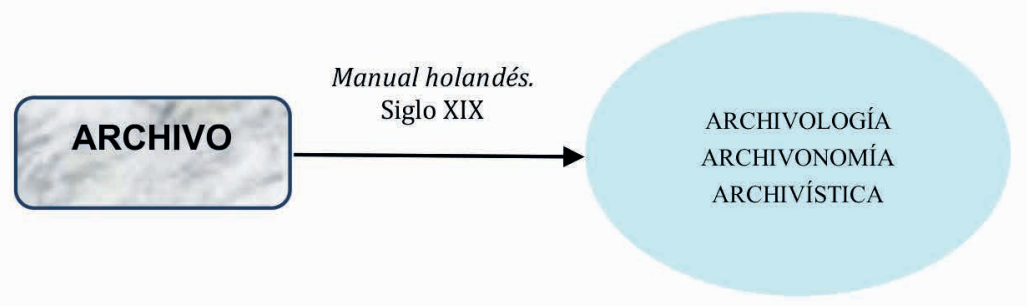

De forma paralela, en otro campo que giraba alrededor de la biblioteca, gracias a los trabajos A. Panizzi (1841), M. Dewey (1876), Ch. Cutter (1875) y S. R. Ranganathan $(1931,1937)$ surge la Biblioteconomía o Bibliotecología.

3 Existe una discusión sobre las diferencias que connotan las terminaciones "logos" y "nomos" en las respectivas terminaciones de bibliotecología y biblioteconomía; así como en archivología y archivonomía. En general se reconoce que el logos señala más a lo teórico, mientras que el nomos lo hace a lo administrativo. Lo mismo aplica a la distinción entre museología (teoría) y museografía (más práctica). Esa discusión rebasa los objetivos de este trabajo. Para nuestros fines basta constatar que aparecen áreas de conocimiento que estudian campos fenoménicos determinados y diferenciados. 


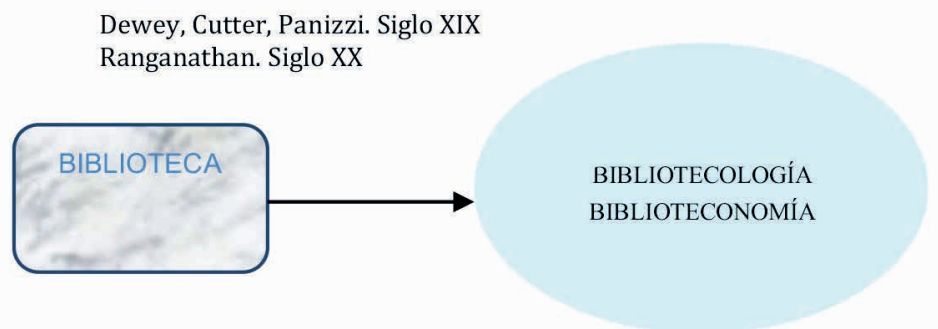

A su vez, el museo y las actividades que se realizaban en él, también fueron objeto de reflexión, lo que generó un área especializada sobre esa problemática. Se recuperan principalmente dos tradiciones, una eminentemente estética derivada del Museo de Louvre que contribuye a la formación de la concepción del museo de arte; y otra, con una visión histórica y científica, proveniente del Museo Británico. Gracias al trabajo de Jiri Neustupny con su obra Questions de muséologie moderne (1950) así como a los estudios promovidos por el Consejo Internacional de los Museos (ICOM) y principalmente por el Comité Internacional para la Museología (ICOFOM) que realiza esas investigaciones en concordancia con uno de sus objetivos, ya que "tiene a su cargo la investigación, estudio y difusión de las bases teóricas de la Museología como disciplina científica independiente y analiza las principales tendencias de la museología contemporánea" (2017).

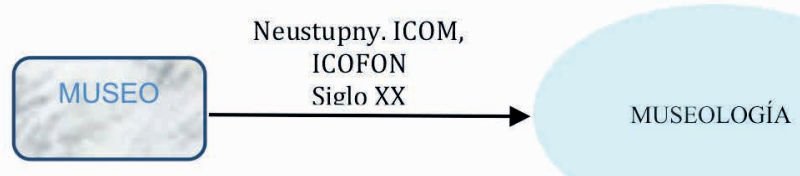

Ahora bien, en el siglo XX siempre bajo el auge del positivismo, aparece otra disciplina informativo-documental que, por un lado, se encuentra guiada por la idea de universalidad y orden en el mundo de los documentos, y por otro, trata de convertirse en un 
instrumento al servicio del desarrollo de la ciencia. Así pues, P. Otlet (1934) crea la Documentación que tiene como objeto de estudio el documento en general, ya que el conocimiento humano se encuentra plasmado no sólo en libros, sino en otro tipo de obras, desde los artículos científicos hasta tesis, actas y memorias de reuniones científicas o profesionales, reportes de investigación, patentes, a los que se agregarían audios, videos, etc. por lo que escapaban del campo de la Biblioteconomía tradicional. ${ }^{4}$

Algunas décadas posteriores, después de la Segunda Guerra Mundial y en el contexto de la nueva confrontación entre las dos superpotencias vencedoras (EEUU y URSS) que luchaban en todas las esferas, incluidas la ciencia y la tecnología, surgió una nueva disciplina que ayudaba al desarrollo en esas áreas prioritarias. En occidente denominaron a esa disciplina Ciencia de la Información, ligada a nombres como Taylor (1962), Borko (1968), Saracevic (1970), cuya finalidad era proporcionar a los científicos información previamente detectada y analizada. ${ }^{5}$ Mientras tanto, en el bloque

4 La Documentación es una ciencia general que tiene por objeto el estudio del proceso de adecuación y transmisión de las fuentes para la obtención de nuevo conocimiento". (López Yepes, 1995, p. 322) Es ciencia para la ciencia (López Yepes, 1978)

5 La Ciencia de la Información investiga la estructura, propiedades y procesos de la transmisión de la información utilizando métodos de otras ciencias como psicología, lógica, neurofisiología y matemática. Como rama de la técnica: se relaciona con los medios de procesamiento de la información que aseguran su acceso y uso. Emplea métodos de la técnica de la computación, la bibliotecología, sistemas de investigación y la ciencia administrativa (Taylor, 1962, p. VI). La ciencia de la Información es el "conjunto de conocimientos relacionados con el origen, colección, organización, almacenamiento, recuperación, interpretación, transmisión, transformación, y utilización de la información. Incluye la investigación de las representaciones de información en los sistemas naturales y artificiales, la utilización de códigos para la transmisión eficiente del mensaje, el estudio de instrumentos y técnicas de procesamiento de la información, tales como computadoras y sistemas de programación. Es una ciencia interdisciplinaria relacionada con la matemática, lógica, la lingüística, la psicología, la biblioteconomía, la administración... que investiga las propiedades y comportamiento de la información, las fuerzas que gobiernan el flujo y el uso de la información y las técnicas, tanto manuales como mecánicas, para procesarla, a fin de obtener el óptimo almacenamiento, recuperación y diseminación” (Borko, 1968, p. 3-5). 
opuesto, dicha ciencia se denominó Informátika y fue desarrollada por Mijáilov, Chernii y Guiliarevskii (1973). ${ }^{6}$

Así pues, en la segunda mitad del siglo pasado estaban presentes en la palestra científica, cinco disciplinas informativo-documentales claramente identificadas: Archivística, Bibliotecología, Ciencia de la Información (Informátika en el campo socialista que no tuvo ulterior desarrollo), Documentación y Museología.

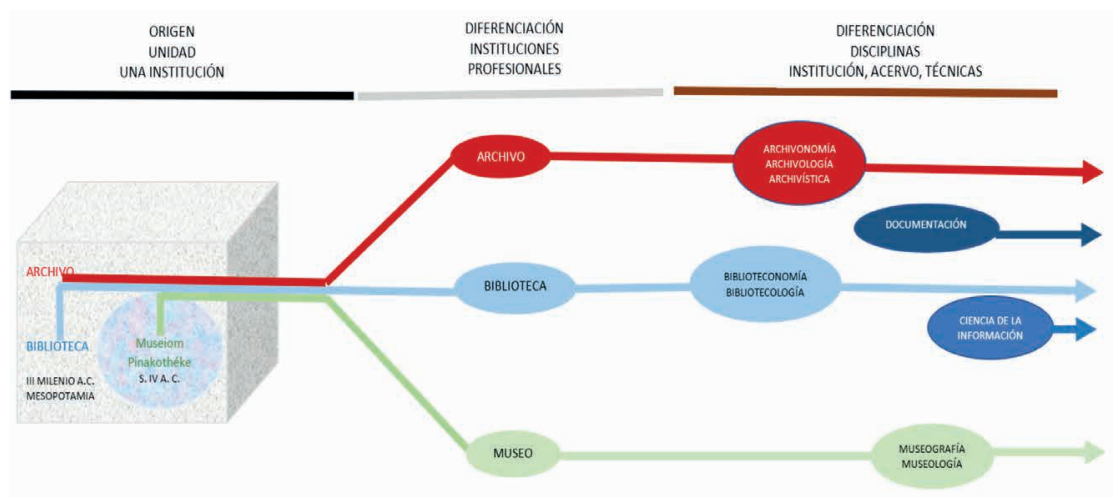

\section{Hacia la transdisciplina}

Sin embargo, ese estado de cosas no fue estático. La diferenciación, identidad y autonomía de las ciencias informativo-documentales no fueron absolutos y definitivos. Cada una de ellas continuó desarrollándose, lo que las hizo acercarse a lo que he denominado relación transdisciplinar.

La diferencia entre la forma en que concebimos la transdisciplina con la inter y multidisciplina consiste en lo siguiente. La multi-

6 La Informátika es la disciplina que estudia la estructura y las propiedades (y no el contenido específico) de la información científica, así como las leyes que rigen la actividad científico-informativa, su teoría, historia, metodología y organización. Cuyo objetivo es elaborar métodos y medios óptimos de presentación (registro), recolección, procesamiento analítico-sintético, almacenamiento, búsqueda y diseminación de la información científica (Mijáilov, Chernii, Gilyarevskii, 1973, p. 57). 
disciplina representa el estudio de un problema desde diferentes enfoques disciplinares, cada uno de ellos por separado. Por ejemplo, investigar una comunidad particular de un pueblo originario (pongamos por caso estudiar la población "Pótam", situada en el estado mexicano de Sonora y que es habitado por el pueblo yaqui). Dicha investigación se realizará desde diferentes puntos de vista: económico, político, social, religioso, estético, de salud, lingüístico, moral (usos, costumbres), histórico, entre otros; y cada especialista en una de esas ramas realizará su análisis y al final proporcionará sus conclusiones y recomendaciones por separado.

Por su parte, la interdisciplina consiste en el estudio de un problema por un conjunto de ciencias, pero no cada una por separado como ocurre con la multidisciplina, sino en completa cooperación y diálogo, entrelazando, complementando, cosubordinando sus conocimientos. Siguiendo con el ejemplo anterior, el estudio de esa localidad desde un punto de vista interdisciplinario serviría para elaborar la propuesta y aplicación de una política integral de desarrollo. Las conclusiones no serían presentadas por separado para cada área, sino sería un solo documento en el que se incluirían las recomendaciones en las que con un sincretismo gnoseológico cada parte del todo incluiría a las demás partes. Por ejemplo, lo económico forzosamente debería considerar lo político, lo religioso, los usos y costumbres (moral), lo histórico, lo geográfico, los hábitos alimenticios, las prácticas para preservar y recuperar la salud, lo religioso y sus festividades (para incrementar el turismo cultural, por ejemplo), las manifestaciones de su arte, etc. Por su parte, lo político debería integrar lo económico, religioso, estético, de salud, lingüístico, moral (usos, costumbres), histórico, etc. A su vez, las cuestiones de salud no se entenderían sin lo moral, lo histórico, lo geográfico, incluso lo lingüístico, etc. Y así en cada una de las esferas estudiadas influyen las demás. 
Finalmente, la transdisciplina representa una relación entre disciplinas, en la cual, gracias a la convergencia de esas disciplinas, aparece un campo nuevo de conocimiento que se encuentra más allá de los que tradicionalmente cada una de ellas estudia. Precisamente el prefijo latino trans cuyo significado es "al otro lado de", "del lado de allá de", "por encima de" (Diccionario ilustrado latino-español, 1964, p. 517) otorga el sentido de trascender la disciplina, ir más allá de ella. Así por ejemplo, Tejada Moreno, explica la aparición de la biología molecular como una ciencia transdisciplinar que surge:

del matrimonio de la bioquímica con la genética molecular [...] con toda libertad epistemológica [...] como solución a problemas que las dos ciencias que le dieron a luz no habían - ni hubieranresuelto. (Tejada Moreno, 1996, p.143-144)

Por lo tanto, es claro que la transdisciplina no consiste en que, al converger dos o más disciplinas, una de ellas absorba, "colonice" a las demás; sino que, como resultado de esa convergencia, se forma un nuevo campo de conocimiento que ninguna de las disciplinas participantes podría estudiar por separado.

Así pues, a continuación, explicaremos cómo se manifiesta ese movimiento a la transdisciplina en el mundo informativo-documental. En el apartado anterior ya se estableció que a través del tiempo fueron apareciendo distintas disciplinas informativo-documentales, cada una de las cuales presentaba diferencias específicas que les proporcionaba identidad propia y centraban su atención en un campo específico dado por la institución en la que se manifestaba ese campo, los acervos que contenían esas instituciones y las actividades, principalmente técnicas, que los profesionales que trabajaban en esas instituciones realizaban para el tratamiento de esos acervos. Identificamos cinco de esas 
disciplinas: Archivística, Bibliotecología, Ciencia de la Información, Documentación y Museología. ${ }^{7}$

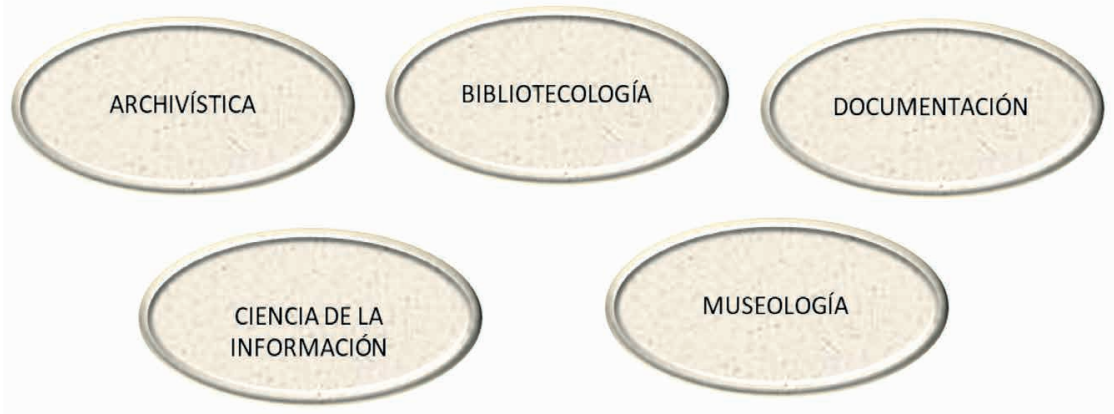

Desde un inicio se observa una relación muy estrecha entre esas disciplinas, principalmente entre la Bibliotecología, la Ciencia de la Información y la Documentación. Así, por ejemplo, podemos encontrar afirmaciones como que la Ciencia de la Información es una ciencia interdisciplinaria derivada de y relacionada con campos [entre otros] como la Bibliotecología (Library Science); además que la Blioteconomía (Librarianship) y la Documentación son aspectos aplicados de la Ciencia de la Información. (Borko, 1968 , p. 3) En ese mismo tenor, Taylor suscribe que la Ciencia de la Información emplea métodos [entre otros] de la Bibliotecología. (Taylor, 1962, p. VI).

Posteriormente, se observa, precisamente por factores que analizaremos más adelante y son lo que contribuyeron a la transdisciplina, un acercamiento e interacciones cada vez mayores.

7 Existen además otras disciplinas que han aparecido, pero no tuvieron éxito en la lucha por la supervivencia que sostuvieron con las otras ciencias. Tal es el caso de la ya mencionada Informátika, o de la Ingeniería de la Información, Informatología, Ingeniería del conocimiento, entre otras. 


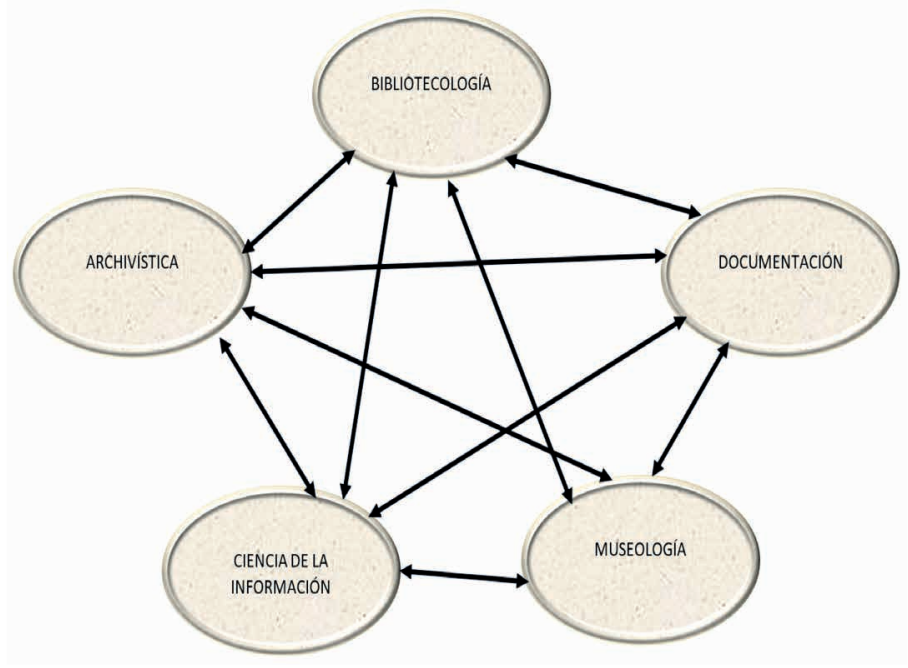

Pero como ya constatamos líneas arriba, ese acercamiento no desemboca en que una de ellas engulla a las restantes. En ocasiones, se cree que la Ciencia de la Información es la que cumple ese papel de absorber a las otras y evidentemente aflora un sentimiento de inconformidad y resistencia de parte de los otros especialistas, principalmente archivistas, bibliotecólogos y museólogos.

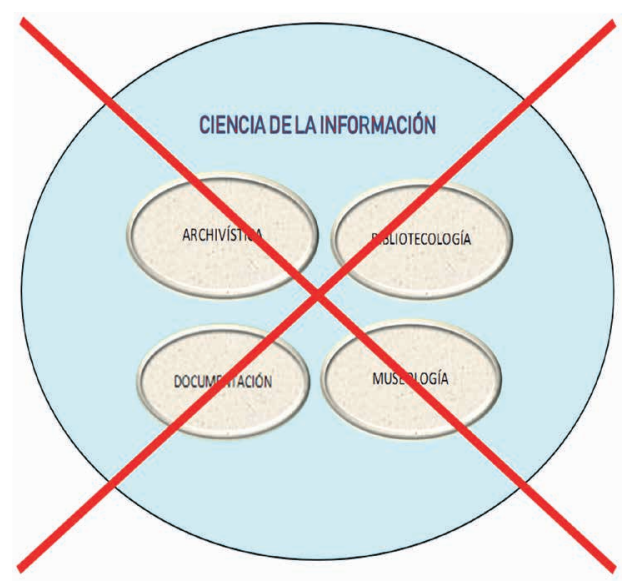


Por el contrario, lo que acontece es el surgimiento de un nuevo campo de conocimiento informativo-documental al converger esas disciplinas:

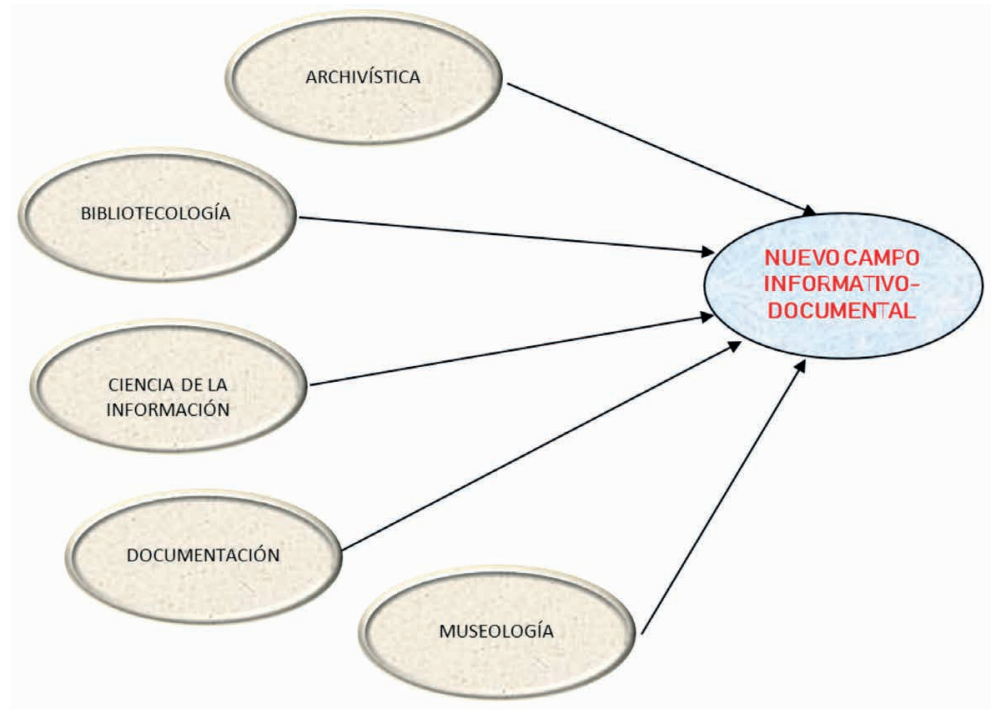

Ahora bien, los factores que determinan esa convergencia son variados, los hay de carácter estrictamente epistemológico (precisión de objeto de estudio y depuración de cuerpo teórico); otros filosóficos (reconocimiento de diferentes tipos de saberes); unos más, de tipo social (intencionalidad dirigida al servicio), que a su vez se encuentran condicionados por cuestiones económicas y tecnológicas (sociedad de la información).

Desde el punto de vista epistemológico, una de las causas de la convergencia de las disciplinas informativo-documentales radica en el hecho de que se superó la concepción que elevaba a la institución que albergaba los acervos como objeto de estudio. Así, por ejemplo, se afirmaba que la Archivística, en inglés Archival Science, es "la ciencia de los archivos (...) estudia la naturaleza de los archivos, los principios de su conservación y organización y los medios para su utilización" (Heredia, 1991, p. 29); que la Bibliotecología, su mismo 
nombre en inglés (Library Science) o alemán (Bibliothekswissenshaft) lo indica, es la ciencia de la biblioteca (Schrettinger, 1829, p.16, Butler, 1933; Cronin, 2004); y la Museología es la ciencia del museo (Rivièri, 1993, p. 105).

Sin embargo, el conocimiento científico versa sobre lo abstracto y general, por consecuencia el objeto de estudio debe ser un constructo abstracto y no identificarlo con un objeto concreto y particular, como lo son las instituciones informativo-documentales (archivo, biblioteca, museo). Esa tendencia conlleva a una visión muy estrecha de la disciplina, ya que cada institución informativo-documental va cambiando a través del tiempo, adquiriendo o perdiendo ciertas características de acuerdo con los avances tecnológicos, a intencionalidades políticas, económicas, sociales, ideológicas que se vayan presentando; y por consecuencia, si se hace ciencia a partir de ellas, también esas ciencias se irán transformando con el paso del tiempo, sin que se llegue a obtener una identidad.

Una posición crítica a esa concepción de "ciencias de instituciones" la podemos encontrar en varios autores, quienes al mismo tiempo no pierden la oportunidad para ironizar al respecto. Así por ejemplo, Wersig escribe: "Mientras no existan disciplinas como "ciencia del hospital" [hospital science] o "ciencia de la cárcel" [jailhouse science], algo así como "ciencia de la biblioteca" [library science] no es muy convincente (Wersig, 1992, p. 202).

De manera semejante, pero ahora aplicado a la Museología, el croata Tómislav Šola afirma que la museología no es una ciencia de los museos, lo cual es tan claro como que la novela Moby Dick no es un manual sobre la caza de ballenas; ¿si en el teatro, que tiene una historia más larga, nadie llama "teatrólogo" a un actor o a un director de escena, por qué se le llama museólogo a quien trabaja en el museo? (Šola, 1988, p. 13-14). El también museólogo Peter van Mensch, basándose en Šola, expresa la misma idea al escribir en su tesis doctoral que varios autores han dejado en claro que el 
museo no puede ser objeto de conocimiento ya que éste es sólo un marco de referencia organizacional. También hace mención de la analogía que con frecuencia se utiliza de que la Pedagogía no es la ciencia de la escuela [science of the school] y la Medicina no es la ciencia del hospital [science of hospital]. Y citando a Šola, insiste en que, así como no existe ninguna ciencia como la 'escuela-logía' [school-ology] o iglesialogía [churchology], tampoco puede existir la 'museo-logía [museum-ology] (Mensch,1992, s.p.) ${ }^{8}$.

Años más tarde, el checo Stránský también resalta la imposibilidad de que el museo sea el objeto de estudio de la Museología: "Me he referido sobre este aspecto en otros campos, por ejem. [sic] la Pedagogía, que tampoco es la ciencia de la 'escuela' o la Teatrología, la ciencia 'del teatro'” (Stránský, 2005, p. 111)9.

En efecto, una institución social, al no ser una realidad natural, sino cultural, es creada a posteriori por la actividad humana, cargada de intencionalidad en su origen, mantenimiento, funcionalidad, estructura. El querer elevar esa realidad cultural como objeto de estudio, es equipararla a un objeto de la naturaleza que "está ahí" y el investigador voltea su mirada hacia él para estudiarlo; pero el archivo, la biblioteca, el museo "no han estado ahí" por siempre, sino que son creaciones humanas, son ontológica, epistemológica y axiológicamente posteriores a la acción. Son según Mensch (1992) citando a Jahn I. un 'Sekundarprodukt' (Jahn in Arbeitsgruppe Museologie 1981, p. 49). Por nuestra parte, hemos afirmado que el profesional de la información documental es quien crea el mundo informativo documental en el cual posteriormente se encuentra y

8 Cabe hacer la observación que el trabajo de Šola que cita Mensch, es el mismo que nosotros hemos citado líneas arriba What is Museology? aunque el año de publicación que proporciona Mensch: 1989 no corresponde a la publicación que nosotros recuperamos (1988), además que no encontramos la cita entrecomillada a la que se hace referencia.

9 En checo en original: Odkazoval jsem v této souvislosti i na jiné obory, naprr. pedagogiku, která také není vědou "o škole" nebo teatrologie vědou "o divadle". 
actúa, pero también estudia e investiga. (Rendón, Herrera, 2010, p. 49) Por lo tanto, la institución se encuentra inmersa en un marco referencial más general, que es lo que se debe investigar como objeto de estudio. En un inicio, el fenómeno respectivo aparece en esas instituciones, pero después llega a rebasarla.

El mismo problema de caer en singularidades sin la posibilidad de elevarse a la teorización, sucede cuando en disciplinas pragmáticas, como lo son las informativo-documentales, se utilizan normas (reglas de catalogación, sistemas de clasificación, RDA, respeto al principio de procedencia y orden original) en lugar de leyes y el cómo sustituye al por qué. Ese mismo error lo encontramos cuando en el cuerpo teórico de la disciplina, en lugar de utilizar conceptos, se emplean representaciones de objetos concretos que por su misma naturaleza contingente van adquiriendo o perdiendo ciertas características, lo que, a su vez, desorienta a los especialistas en ese campo. Por ejemplo, si se concibe el "libro" con el referente empírico inmediato; ${ }^{10}$ cuando su materialidad cambia (de papel pasa a electrónico y en el futuro tal vez bioquímico u otro que no conozcamos aún); su simbolización pasa de un alfabeto con grafías a otro binario de 0,1 , o a uno cuaternario cuyas letras son moléculas orgánicas; esas transformaciones hacen pensar que lo estudiado hasta ese momento ya no es válido, porque obviamente no funciona en la nueva realidad y se plantea la necesidad de la construcción de una nueva ciencia. Lo anterior también es válido para ideas como 'documento' o 'documento de archivo'.

Podemos, con ayuda de las comparaciones arriba citadas de que no hay una ciencia del hospital, o ciencia de la escuela, aclarar porqué un objeto cultural concreto, no puede ser el objeto de estudio de

10 Conjunto de hojas o un material semejante que, impresas o manuscritas, al estar encuadernadas, forman un volumen, y agregaría la UNESCO, con un mínimo de 49 páginas (UNESCO, 1964). 
una ciencia. No podemos afirmar que la Ingeniería es la ciencia de los puentes o la Arquitectura es la ciencia de los edificios, porque puentes y edificios precisamente son el resultado de la Ingeniería y la Arquitectura, y lo que es necesario estudiar, es cómo gracias a esas ciencias se construyeron.

Ante esa situación, los especialistas han buscado objetos de estudio más abstractos, como es el caso de la Archivística integral donde, como objeto de estudio aparece la información (Thomassen 2001, p. 382) y más concretamente la información archivística (Fonseca 2005, p. 59); el proceso de comunicación para la Documentación (López Yepes, 2015); El sistema informativo documental para la Bibliotecología (Rendón Rojas, 2005); para la Museología será lo museal, concepto abstracto que se aleja tanto de la institución como de las colecciones o exposiciones concretas (Desvallées y Mairesse, 2010, p. 48).

Otro elemento que propició la convergencia de las disciplinas documentales es de carácter más filosófico y consiste en la crítica al pensamiento moderno que sólo consideraba al conocimiento científico como el único y verdadero, despreciando otros tipos de saberes. Sin embargo, poco a poco se fue afianzando la idea de que lo mítico, religioso, estético, ideológico, el propio de pueblos ancestrales, también son saberes y son valiosos para el desarrollo de la sociedad y de los individuos. De esta manera, ya no siempre se busca que el usuario construya conocimiento, tener una "ciencia para la ciencia", (López Yepes, 1995, p. 35), y se reconoce que los contenidos de conciencia no se reducen a ideas, sino también incluyen emociones, deseos, valores, creencias. Por lo que la Bibliotecología, la Ciencia de la Información y la Documentación empezaron a trabajar con otras colecciones (fonotecas, fototecas, videotecas, pinacotecas) también atendidas por la Archivística y la Museología.

Por consiguiente, se transita de una ciencia para la ciencia a una ciencia social y humana; de una gestión de la información a una mediación cultural que implica intencionalidad y diálogo. 
Finalmente, otra serie de factores derivados del desarrollo actual de la sociedad, a la que se ha denominado "sociedad de la información" intervienen en la convergencia de las disciplinas informativo-documentales. Como características principales de esa sociedad, todas ellas interconectadas, hemos identificado: A) Relaciones muy cambiantes y dinámicas en el funcionamiento de la sociedad, en todas las actividades y esferas, por lo que es necesario estar actualizados en lo que acontece y poder tomar decisiones adecuadas; B) La globalización como una nueva configuración en la economía y sociedad mundial, donde se intensifican los niveles de interacción, interconexión e interdependencia entre los Estados; lo que sucede en alguna región del mundo repercute en todas partes, por lo que la información fluye sin importar las barreras geográficas. C) La tecnología presenta instrumentos cada vez más desarrollados para realizar todo tipo de actividades, principalmente en la esfera de la computación y comunicación, lo que a su vez permite la rapidez del cambio, la globalización, la aceleración de la producción, flujo, transmisión y consumo de la información. D) El mercado adquiere un papel preponderante en esta sociedad neoliberal, pero no sólo un mercado tradicional en las esferas productiva, de comercio, financiera, de servicios, sino que esa noción de juego económico se amplía al mercado político, científico, educativo, tecnológico, militar, etc. por lo que es necesario tener información confiable, precisa y siempre disponible, para poder competir en ese juego (Rendón Rojas, 2001, p. 13-14).

Es claro inferir que esas características motivan, si el sujeto quiere sobrevivir y trabajar en esa sociedad, a centrar la atención en el flujo de la información y en el sujeto que crea, consume, transforma esa información; a ofrecer servicios de información a organizaciones e individuos, más que a conservar documentos; a transitar de lo estrictamente elitista científico a lo social. Cada 
una de las disciplinas informativo-documentales experimentó ese cambio por lo que se acercaron. Ribeiro así lo explica:

Al ser empujados, bajo el impulso de la revolución tecnológica de la información, hacia un mismo objeto y metodologías comunes, el archivista, el bibliotecario, el documentalista y el especialista en informática de la gestión tienden a fundirse en un nuevo profesional que sintetiza las diversas competencias adscritas a todas ellas y se asume como un especialista que estructura el flujo informacional que fluye dentro de las organizaciones y alimenta el funcionamiento y la capacidad para tomar decisiones de las mismas (Ribeiro, 2017, p. 41).

La historia de la Ciencia de la Información muestra ese camino, ya es muy conocido la distinción de los tres paradigmas en el desarrollo de esa ciencia propuesta por Capurro (2003): el físico, cognitivo y social. De ser una disciplina casi ingenieril de transmisión de mensajes independientemente de su significado (Shannon y Weaver, 1949) pasó a una etapa intermedia donde se tenía la idea de la información como factor que influye en la capacidad cognitiva del sujeto (Brookes, 1980) y terminó en una ciencia que consideraba el contexto social como un elemento esencial para poder comprender ese fenómeno, como en los estudios de "regímenes de información", (Frohmann, 1995; González de Gómez, 2012); de "análisis de dominio" (Hjørland \& Albrechtsen, 1995, Hjørland, 2002) o de "prácticas informacionales" (Savolainen, 1995; Mckenzie, 2003).

Ese mismo camino de convergencia lo señalan Ribeiro y Silva (2008), denominándolo cambio del paradigma tecnicista-conservacionista al paradigma científico de la Ciencia de la Información.

Igual evolución se presentó en las otras disciplinas informativo-documentales, como la Archivística integrada, la Archivística posmoderna, el estudio de los archivos personales, la mediación archivística, la mediación bibliotecaria, la competencia informacional, 
la biblioteca 2.0 y la nueva Biblioteconomía, la nueva Museología, las reflexiones sobre lo museal, las interacciones sociotécnicas en los museos, el estudio del patrimonio inmaterial, etc. (Araújo y Tanus, 2018) que propició ese acercamiento entre todas ellas.

Nuestra propuesta es que el punto de convergencia es lo que hemos denominado Sistema Informativo Documental (SID), el cual consideramos, siguiendo las ideas de Lakatos (1983) sobre los Programas de Investigación Científica, como núcleo duro del Programa de Investigación de las Ciencia de la Información Documental. (Rendón Rojas, 2005) Dicho sistema está integrado por la información, el documento, el usuario, el profesional de la información documental, la institución informativa documental, todos ellos en interrelación e interdependencia, formando una unidad. Ahora bien, si analizamos cada una de las disciplinas informativo-documentales encontramos que todas ellas giran en torno a ese sistema informativo documental.

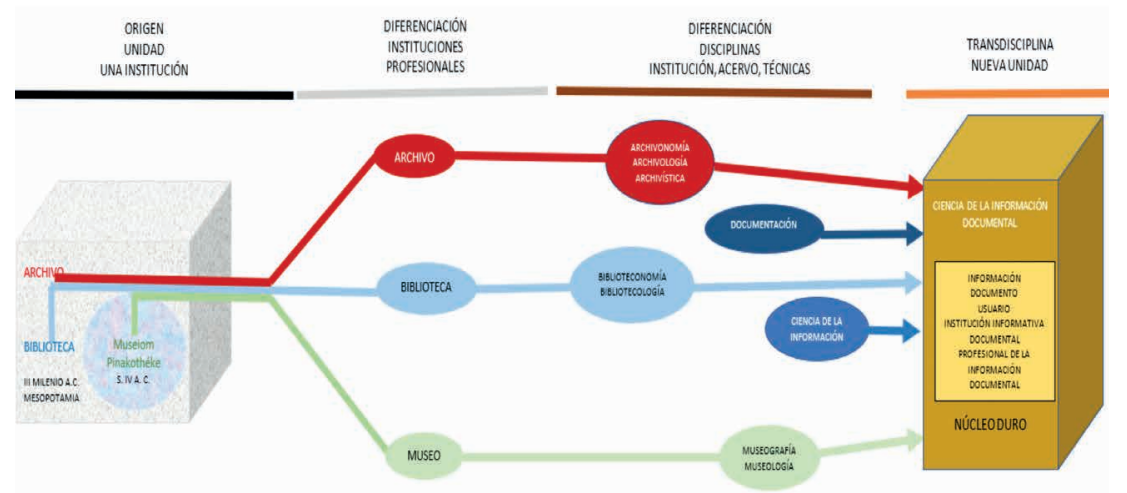

Sin embargo, simultáneamente cada disciplina informativo-documental sigue presentando sus particularidades, una forma específica de trabajar sus documentos, organizarlos, presentarlos a sus usuarios, esto es, existe lo general y lo particular; la unidad y la multiplicidad. 


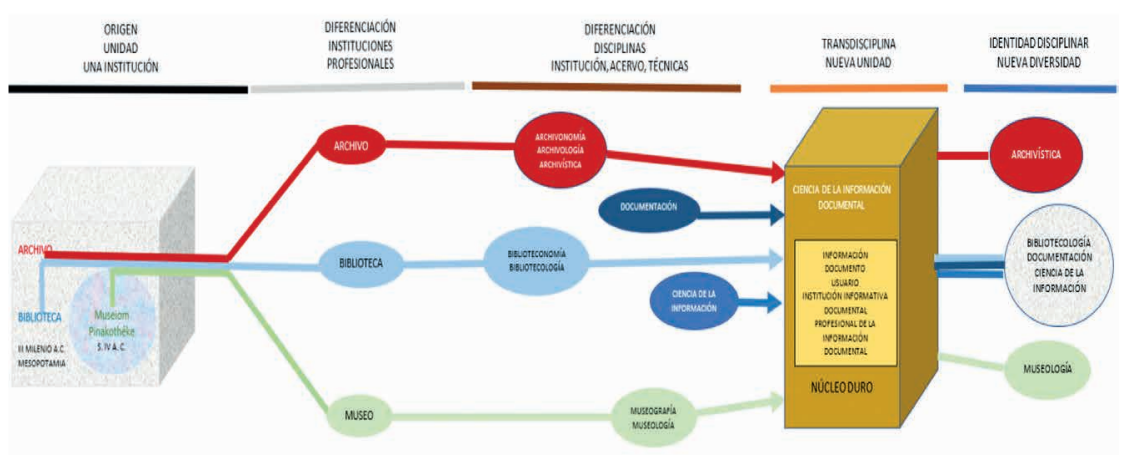

\section{Reflexiones Finales}

A lo largo del trabajo hemos acompañado los cambios experimentados en los campos del conocimiento de la Archivística, Bibliotecología, Ciencia de la Información, Documentación y Museología; y constatamos su movimiento de la unidad a la diversidad para luego regresar nuevamente a la unidad en un contexto transdisciplinar. Existen varios momentos que necesitan ser resaltados.

En primer lugar, el hecho de que epistemológicamente, si su visión continúa ligada a objetos concretos, ya sea como objeto de estudio o dentro de su aparato teórico; o a normas que indican el cómo realizar acciones, no es posible desarrollar teóricamente esas ciencias; por lo que resulta indispensable construir conceptos y buscar el qué y porqué que permitan explicar o comprender esas realidades estudiadas.

En segundo lugar, se debe dejar en claro que ninguna de esas disciplinas tiene un papel preponderante en su convergencia, esto es, ninguna absorbe a las demás, sino que cada una de ellas va evolucionando, transformándose hasta encontrarse con las otras y conformar un nuevo fenómeno. Esto es importante resaltar, porque en países donde prevalece la denominación "Ciencia de la Información" para este campo de conocimiento, parecería que es esa ciencia la que "coloniza" a la Archivística, la Bibliotecología, la Documentación y la Museología. En realidad, la disciplina trans- 
disciplinar resultante es muy diferente a la Ciencia de la Información original, y por ese motivo decidimos proponer otro nombre, el de Ciencia de la Información Documental.

En tercer lugar, ya en Rendón Rojas (1996) habíamos indicado el cambio de visión que se gestaba en la Bibliotecología y que denominamos pragmático, en cuanto el sujeto se tornaba centro de ese campo de conocimiento. La misma tendencia fue observada por Capurro en 2003 para la Ciencia de la Información, quien señaló el paso hacia un paradigma social. Por su parte, Ribeiro y Silva destacaron la convergencia de las disciplinas informativo-documentales con base en la preponderancia de la información, siempre dinámica, frente al documento, estático por antonomasia; del servicio a organizaciones e individuos, en contraposición a la conservación; de la investigación científica, en contraste con el mero tecnicismo. Consideramos que la aportación que nosotros presentamos ante lo dicho anteriormente reside en identificar las causas de esas transformaciones en las disciplinas, principalmente por cuestiones epistemológicas, filosóficas y de carácter económico, ligadas a lo que se denomina "sociedad de la información".

Finalmente, en quarto lugar, todo lo expuesto influye en la educación y profesionalización de esta disciplina. Es recomendable superar las delimitaciones feudales entre las disciplinas que colocan fronteras infranqueables entre ellas y en su lugar ofrecer una educación integral, recordar lo que en su momento la UNESCO (1984, 1987a, 1987b) llamó armonización de las ciencias informativo-documentales.

Un ejemplo de esto último son los programas de estudio de la licenciatura en Ciencias de la Información Documental que ofrece la Universidad Autónoma del Estado de México (UAEMex, 2018) y de Ciencia de la Información de la Universidad de Porto (U. Porto, 2018) que forman profesionales de la información capaces de trabajar en diferentes ámbitos: archivos, bibliotecas, centros de documentación, empresas privadas de servicios de información 
para empresas, organizaciones o individuos particulares. Pero al mismo tiempo sin olvidar que existen diferencias en el tratamiento de la información y documentos en distintas áreas, en la forma de organizarlos y ofrecerlos a sus usuarios. Manifestándose de esta manera en la práctica lo que mostramos en lo teórico: la unidad y diversidad de las disciplinas informativo-documentales.

\section{Referências Bibliográficas}

Araújo, C. A. Á. y Tanus, G. F. (2018). La intencionalidad como elemento transversal de la triada "información, mediaciones y cultura". En M. A. Rendón Rojas. (Coord.) La intencionalidad en la ciencia de la información documental. México: UNAM-IIBI.

Biblia de Jerusalén. (1967) Bruxelles, Belgium: Desclée de Brouwer.

Borko, H. (1968). Information Science. What is it? American Documentation, 19 (1), 3-5.

Brookes, B. C. (1980). The foundations of information science: part I: philosophical aspects. Journal of Information Science, 2, 125-133.

Butler, Pierce. (1933). An Introduction to Library Science. Chicago: University of Chicago Press.

Capurro, R. (2003). Epistemologia e ciência da informação. In Encontro Nacional de Pesquisa em Ciência da Informação. Belo Horizonte: Associação Nacional de Pesquisa e Pós-Graduação em Ciência da Informação e Biblioteconomia.

Cronin, B. (2004). Pierce Butler's an Introduction to Library Science: a tract for our times? A review article. Journal of Librarianship and Information Science, 36 (4), 183-188.

Cutter, C. A. (1875). Rules for a printed dictionary catalogue. Washington: Govt. Print. Off.

Desvallées, A. y Mairesse, F. (2010). Conceptos claves de museología. Paris: Armand Colin, ICOM.

Dewey, M. (1876). A classification and subject index for cataloguing and arranging the books and pamphlets of a library. Amherst, Mass.

Diccionario ilustrado latino-español. (1964) Madrid: Spes.

Dorado Santana, Y. y Mena Mugica, M. M. (2009). Evolución de la ciencia archivística. Acimed, 20 (1). Recuperado de: http://bv.s.sld.cu/revistas/aci/vol20_1_09/aci0 [Consultado: septiembre 2018]

Enuma eliš y otros relatos babilónicos de la creación. (2014) Madrid: Editorial Trotta.

Fonseca, M. O. (2005). Arquivologia e ciência da informação. Rio de Janeiro: FGV.

Frohmann, B. (1995). Taking information policy beyond information science: applying the actor network theory. In Annual Conference of The Canadian Association For Information Science, 23. Toronto: Canadian Association for Information Science. 
González de Gómez, M. N. (2012). Regime de informação: construção de um conceito. Informação \& Sociedade: Estudos, 22 (3), 43-60.

Heredia, A. (1991). Archivística general: teoría y práctica. (5ª. ed.) Sevilla: Excma. Diputación de Sevilla.

Hjørland, B. (2002). Domain analysis in information science. Eleven approaches: traditional as well as innovative. Journal of Documentation, 58 (4), 422-462.

Hjørland, B. \& Albrechtsen, H. (1995). Toward a new horizon in information science: domain analysis. Journal of American Society for Information Science, 46 (6), 400-425.

Lakatos, I. (1983). La metodología de los programas de investigación científica. Madrid: Alianza Editorial.

López Yepes, J. (2015). La ciencia de la información documental. El documento, la disciplina y el profesional en la era digital. México: Universidad Panamerica.

López Yepes, J. (1978). Teoría de la documentación. Pamplona: EUNSA

López Yepes, J. (1995). La documentación como disciplina. Teoría e historia. España: EUNSA.

Mckenzie, P. (2003). A model of information practices in accounts of everyday-life information seeking. Journal of Documentation, 59 (1), 19-40.

Mensch, P. van (1992). Towards a methodology of museology. Tesis de Doctorado. Universidad de Zagreb.

Mijáilov, A. I., Chernii, A. I., Gilyarevskii, R. S. (1973). Fundamentos de la Informática. Moscú-La Habana: Nauka, Academia de Ciencias de Cuba, Instituto de Documentación en Información Científica y Técnica. V. 1.

Muller, S., Feith, J. \& Fruin, R. (1898). Handleiding voor het ordenen en beschrijven van archieven: ontworpen in opdracht van de Vereeniging van Archivarissen in Nederand / door Mrs. S. Muller Fz., J.A. Feith en R. Fruin Th. Az. - Groningen: Erven B. van der Kamp. - iv, 156 p. Existe traducción al inglés: Muller, S., Feith, J. \& Fruin, R. (2003). Manual for the arrangement and description of archives. Society of Amer Archivists. ( ${ }^{\mathrm{a}}$ ed.) Chicago : H. W. Wilson.

Neustupny, J. (1950). Questions de muséologie moderne. Praga.

Otlet, P. (1934). Traité de documentation: le livre sur le livre, théorie et pratique. Bruxelles: Editeurs-imprimeurs D. van Keerberghen \& Fils. Existe traducción al español: Otlet, P. (1996). El tratado de documentación: el libro sobre el libro: teoría y práctica. Murcia: Universidad de Murcia.

Panizzi, A. (1841). 91 Rules for Compilation of the Catalogue. In The Catalogue of Printed Books in the British Museum, Volume 1, p. v-ix,. London: J. H. Nichols and Son, Printers, 25, Parliament street.

Popol Vub: las antiguas historias del quiché. (2012) Tercera edición. México: Fondo de Cultura Económica.

Ranganathan, S. R. (1931). The five laws of Library Science. Madras: The Library Association; London: Edward Goldston Ltd.

Ranganathan, S. R. (1937). Prolegomena To Library Classification. Madras: The Library Association; London: Edward Goldston Ltd.

Rendón Rojas, M. A. (1996). Hacia un nuevo paradigma de la bibliotecología. Transinformaçã̃. 8 (3), 17-31. 
Rendón Rojas, M. A. (2001). "Un análisis del concepto de la sociedad de información desde el enfoque histórico”. Información, cultura y sociedad, 4, 9-22.

Rendón Rojas, M. A. (2005). Bases teóricas y filosóficas de la bibliotecología. Segunda Edición. México: UNAM-CUIB.

Rendón Rojas, M. y Herrera Delgado, L. B. (2010). El profesional de la información documental. Eidos-noúmeno-identidad versus-skia-fenómeno-imagen. Revista Mexicana de Ciencias de la Información, 1(2) 40-52.

Ribeiro, F. (2017). "La era poscustodial: implicaciones en el campo de la ciencia de la información”. En M. A. Rendón Rojas. (Coord.) La archivística y la ciencia de la información documental. autonomía e interdependencias (p.33-48). México: UNAM-IIBI.

Rivière, G. H. (1993). Museología. Madrid: Akal.

Savolainen, R. (1995). Everyday life information seeking: approaching information seeing in the context of way of life. Library and Information Science Research, 17, 259-294.

Saracevic, T. (1970). Introduction to information Science. New York: R. R. Bowker Co.

Schrettinger, M. (1829). Versuch eines volltändigen lehrbuchs der bibliothekswissenscaft oder Anleitung zur vollständigen Geschäftsführung eines Bibliothakars. München: J. Lindauer.

Shannon, C. E. y Weaver, W. (1949). The mathematical theory of communication. Urbana, il: University of Illinois Press.

Silva, A. M. da y Ribeiro, F. (2008). Das "ciências" documentais à ciência da informação: ensaio epistemológico para um novo modelo curricular. Porto: Edições Afrontamento.

Šola, T. (1988). What is museology? Papers in museology 1 Report from two symposia at the Departamnet of museology, Umea University. Acta Universitatis Umensis. Umeå Studies in the Humanities, (1992) 108, 10-19.

Stránský, Z. Z. (2005). Archeologie a muzeologie. Brno: Masarykova Univerzita.

Taylor, R. (1962) Glossary of terms frequently used in scientific information. Seattle.

Tejada Moreno, A. (1997). Filosofía y ciencia: convergencias y divergencias. La Ciencia y el hombre, 26, 139-150. Recuperado de: http://cdigital.uv.mx/bitstream/123456789/5 395/2/199726P143.pdf [Consultado en agosto de 2017]

Thomassen, T. (2001). A First Introduction to Archival Science. Archival Science, 1, 373-385.

UNESCO (1964). Recomendación sobre la Normalización internacional de las Estadísticas relativas a la Edición de Libros y Publicaciones Periódicas. 19 de noviembre de 1964. Recuperado de: http://portal.unesco.org/es/ev.php-URL_ ID $=13068 \&$ URL_DO=DO_TOPIC\&URL_SECTION=201.html [Consultado en agosto de 2018]

UNESCO (1984). International Symposium on harmonisation of education and training programmes in information science, librarianship and archival studies. Paris. 
UNESCO (1987a). General Information programme Harmonisation of training in librarianship, information sciences and archives. Paris.

UNESCO (1987b). "The UNESCO/IFLA/FID/ICA International Colloquium on the Harmonization of Education and Training Programmes for Library, Information and Archival Personal, Resolution. London 9-15 august 1987". IFLA Journal, Official Quarterly Journal of the International Federation of Library Associations and Institutions. London. Vol. 13. N. 4, p. 378-387.

Universidad Autónoma del Estado de México (2018). Facultad de Humanidades. Ciencias de la Información Documental. Recuperado de: http://humanidades.uaemex.mx/ ciencias-de-la-informacion-documental/ [Consultado en septiembre de 2018]

Universidade de Porto (2018). Licenciatura em Ciência da Informação. Recuperado de: https://sigarra.up.pt/flup/pt/cur_geral.cur_view?pv_origem=CAND\&pv_curso_ $\mathrm{id}=454$ [Consultado en septiembre de 2018]

Wersig, G. (1992). Information Science and theory: a weaver bird's perspective. In P. Vakkari \& B. Cronin (Eds), Conceptions of library and information science: Historical, empirical and theorical perspectives, (201-217). 
(Página deixada propositadamente em branco) 


\title{
CIÊNCIA DA INFORMAÇÃO： FUNDAMENTOS E PERSPETIVAS DA ÁREA CIENTÍ́IICA
}

\author{
I NFORMATION SCIENCE: FOUNDATIONSAND \\ PERSPECTIVES OF THE SCIENTIFIC AREA
}

\section{Liliana Esteves Gomes}

Universidade de Coimbra, Faculdade de Letras/ CITCEM

liliana.gomes@fl.uc.pt ORCID: https://orcid.org/0000-0003-3786-2942

RESUMO - A Ciência da Informação (CI), nos seus mais de 50 anos de evolução, tem propiciado o surgimento de discussões que vão desde o seu estatuto e autonomia científicos, passando pelo objeto de estudo, por problemas terminológicos até às suas conexões interdisciplinares. Como objetivo deste capítulo, pretende-se identificar e analisar os fundamentos (século XX) e as perspetivas (século XXI) desta área científica. Para alcançar esse desiderato, optou-se por uma abordagem qualitativa de natureza exploratória traduzida na revisão da literatura. Dos resultados obtidos destaca-se: a diversidade de perceções acerca da CI, sobre a sua identidade e as suas fronteiras, assinalando-se a falta de consenso científico sobre o próprio campo disciplinar; o quão fundamental é compreender-se a sua trans e interdisciplinaridade. Conclui-se que, embora sendo diversa a fundamentação teórica que sustenta a CI, a nova realidade desta ciência social no século 
XXI resulta da convergência (e não da fusão ou assimilação) de disciplinas, que evoluíram dentro de um contexto transdisciplinar. PALAVRAS-CHAVE - Ciência da Informação; Interdisciplinaridade; Transdisciplinaridade; Epistemologia da Ciência da Informação.

ABSTRACT - In its more than 50 years of evolution, Information Science has led to the emergence of discussions ranging from its scientific status and autonomy, through the object of study, through terminological problems and even to their interdisciplinary connections.

The objective of this chapter is to identify and analyze the foundations (20th century) and the perspectives (21st century) of this scientific area.

To reach this goal, a qualitative approach of an exploratory nature, translated in the literature review, was adopted.

From the results obtained is highlighted: the diversity of perceptions about the IS, its identity and its borders, indicating the lack of scientific consensus about the field itself; how fundamental is to understand its trans and interdisciplinarity.

It is concluded that, although the diferent theoretical foundation behind IS, the new reality of this social science in the 21 st century results from the convergence (not fusion or assimilation) of disciplines that evolved within a transdisciplinary context. KEYWORDS - Information Science; Interdisciplinarity; Transdisciplinarity; Epistemology of Information Science.

\section{Introdução}

As mudanças sociais, económicas e culturais, incitadas pelo desenvolvimento da tecnologia digital vieram, sem dúvida, atenuar muitas das distinções entre os responsáveis pela criação/receção, 
organização, preservação, transmissão e utilização de informação arquivistas, bibliotecários, documentalistas e museólogos.

No momento atual, em que diferentes perspetivas coexistem, perfila-se a necessidade de um aprofundamento continuado dos pressupostos epistemológicos e teóricos da Ciência da Informação (CI).

Enquanto fenómeno humano e social, a Informação é suscetível de ser conhecida cientificamente, pois constitui-se como objeto de uma ciência social, a CI. O seu estudo metódico centra-se nas propriedades do objeto/fenómeno e no processo em que o fenómeno se transforma quando há criação, comunicação e uso.

Assim, analisar o processo genético, a evolução e a afirmação da CI, não obstante as posições diversas surgidas e consolidadas por autores, instituições e organizações (cujas disposições, mesmo controversas, constituem um contributo fundamental) permite aprofundar e ampliar o conhecimento sobre questões prementes relacionadas com a sua própria essência no séc. XXI.

\section{Origens, identidade e fronteiras}

Sobre as origens e evolução da CI, pode consultar-se os trabalhos de diversos autores, entre os quais se destacam: Borko, 1968; Shera \& Cleveland, 1977; Vickery, 1994; Saracevic, 1996; Rayward, 1996 e 1997; Williams, Whitmire, \& Bradley, 1997; Le Coadic, 1997; FayetScribe, 1997; Buckland \& Hahn, 1997; Hapke, 1998; Silva \& Ribeiro, 2002; Bawden \& Robinson, 2012.

Em contraposição, nesta área científica não há jornais ou revistas que se dediquem, em exclusivo, à sua história; no entanto, assinalam-se como fontes relevantes para o este estudo o "Bulletin of the American Society for Information Science", o "Journal of the American Society for Information Science", o "Documentaliste" e o "Journal of Documentation". A "Encyclopedia of library and information Science" 
e o "Dictionnaire encyclopédique de l'information et de la documentation" (Cacaly, 1997), também devem ser mencionados neste contexto.

A CI, no seu campo de estudo e de labor profissional, desenvolveu-se e herdou a tradição documental e prática no domínio das disciplinas nucleares que estão na sua génese - Arquivística e Biblioteconomia - gradualmente desenvolvidas desde a Revolução Francesa, e a Documentação.

A designação Information Science surgiu em finais da década de cinquenta do século XX; contudo, tal expressão tem as suas origens no conceito da Documentação e no legado teórico-prático de Paul Otlet e Henri La Fontaine (Robredo, 2003, p. 39-49; Rayward, 1997, p. 289-300; Rieusset-Lemarié, 1997, p. 301-309).

É bastante consensual a ideia de que houve uma linha de continuidade entre a CI e a Documentação ${ }^{1}$, que à luz da teorização de Otlet (1996), foi definida como "ciencia general, auxiliar de todas las demás y que les impone sus normas desde el momento en que ellas transmiten sus resultados en forma de documentos" (López Yepes, 1995, p. 80). Do início do século XX até à II Guerra Mundial, a Documentação afirma-se na Europa e nos EUA com base num associativismo bem estruturado em torno de grandes organizações ${ }^{2}$.

Num contexto marcado pelo desenvolvimento da pesquisa nas áreas científico-técnicas, associada a um crescimento significativo da produção de informação e a uma diversificação de suportes e

1 (...) "a opinião generalizada é que a partir do conceito da documentação e de sua evolução progressiva surgiu a 'Information Science', e isso apesar de algumas correntes remanescentes, principalmente na Europa, que continuaram a defender o caráter científico da documentação (Robredo, 2003, p. 53). López Yepes e outros autores espanhóis, na linha da herança de Otlet e La Fontaine, consideram que a Ciência da Documentação é uma ciência para a Ciência, existe e desenvolve-se a criar condições e facilidades indispensáveis para a prossecução do trabalho científico.

2 Em França, foi fundado em 1899 o Bureau Bibliographique de France; em 1932, a Union Française des Organismes de Documentation; em 1936, a Association pour le Développement de la Lecture Publique. Nos EUA, foi criada em 1909 a Special Libraries Association (SLA); em 1937, o American Documentation Institute (ADI) (Williams, Whitmire, \& Bradley 1997; Fayet-Scribe, 1997). 
formatos, esta nova área disciplinar materializou-se, nos EUA, em ambiente profissional, de bibliotecários especializados (special librarians) e de documentalistas. Estes profissionais tratavam informação (focalizando toda a sua atenção no conteúdo dos documentos), em todo o tipo de suporte, incluindo a de origem organizacional (ex. correspondência), com recurso ao uso da tecnologia para o seu processamento, prestando serviços aos utilizadores baseados no fornecimento da própria informação, tornando ultrapassada a fronteira tradicional entre biblioteca e arquivo (Silva \& Ribeiro, 2002, p. 48-49).

Capurro (2003) enuncia, com clareza, as raízes dessa ciência:

La ciencia de la información tiene por así decirlo dos raíces: una es la biblioteconomia clásica o, en términos más generales, el estudio de los problemas relacionados com la trasmisión de mensajes, siendo la outra la computación digital. La primera raíz nos lleva a los orígenes mismos, por cierto oscuros, de la sociedad humana entendida como un entretejido o una red de relaciones (...). Es claro que esta raíz de la ciencia de la información (...) está ligada a todos los aspectos sociales y culturales propios del mundo humano. La outra raíz es de carácter tecnológico reciente y se refiere al impacto de la computación en el proceso de producción, recolección, organización, interpretación, almacenamiento, recuperación, diseminación, transformación y uso de la información y en especial de la información científica fijada en documentos impresos.

Quando se procura delinear a evolução da CI afigura-se, manifestamente, o problema da ambiguidade terminológica na sua designação: nomes como Biblioteconomia e Ciência da Informação, Ciência da Informação (Information Science), Ciência da Biblioteca (Library Science), e Library and Information Science, denominação que aparece como mais utilizada nos últimos anos na literatura desta 
área, ou ainda o par Informação e Documentação ou Documentação e Informação, no nome de alguns graus, podem ser mencionados.

Para se acompanhar a evolução verificada no domínio da CI, ao longo da segunda metade do século XX, é necessário ter presentes dois marcos: o ano de 1958 - realização da International Conference on Scientific Information, em Whashington - facto que se assumiu como referência na transformação da Documentação em Ciência da Informação; e os anos de 1961 (outubro) - 1962 (abril) - conferências ${ }^{3}$ do Georgia Institute of Technology - onde se debateu intensamente e se fez a caraterização do que é ou devia ser a CI.

$\mathrm{Na}$ verdade, na literatura científica publicada não existe consenso acerca do surgimento da expressão Information Science. Hans Wellisch (Shera \& Cleveland, 1977, p. 266) afirma que foi, pela primeira vez, usada em 1959 a expressão Information Science; Laurence B. Heilprin (1989) acredita que o termo CI tenha sido criado cerca de 1960, a partir do estudo da produção, processamento e uso da informação como atividade predominantemente humana; Anthony Debons (1986, p. 355) indica ter sido em 1962, no Second International Congress on Information System Sciences (Hot Springs - Virginia).

Contudo, pode afirmar-se que por meados dos anos sessenta do século XX, a designação estava definitivamente consolidada nos EUA:

La Ciencia de la Información investiga la estructura, propiedades y procesos de la transmisión de la información utilizando métodos de otras ciencias como psicología, lógica, neurofisiología y matemática. Como rama de la técnica: se relaciona con los medios de procesamiento de la información que aseguran su acceso y uso. Emplea métodos de la técnica de la computación, la bibliotecología, sistemas de investigación y la ciencia administrativa (Taylor, 1962, p. VI, cit. por Mikhailov; Chernyi \& Gilyarevskyi, 1973, p. 46).

3 Definição de Information Science incluída em Shera \& Cleveland (1977, p. 265). 
Na União Soviética, fruto da raiz de carácter tecnológico associada ao surgimento da CI, em 1966 foi publicado no periódico Nauchno-Tekbnicheskaya Informatsiya o artigo intitulado "Informatika4: um novo nome para a teoria da informação científica”.

"Pocos años después de fundamentarse y desarrollarse en Estados Unidos la "Information Science", aparecía en la Unión Soviética y en los países de su influencia el concepto de Informatika para referirse al mismo ámbito teórico-práctico" (Moreiro González, 1995, p. 173).

São diversos os artigos e outros escritos com propostas de definição em torno da fundamentação teórica desta área disciplinar. Para ilustrar a diversidade de perceções acerca da CI, sobre a sua identidade e as suas fronteiras, apresenta-se seguidamente uma amostra indicativa das diversas visões (tabela 1).

\begin{tabular}{|c|c|c|}
\hline Autor(es) & Definição & Perceções \\
\hline $\begin{array}{l}\text { MIKHAILOV, } \\
1967 ; \\
\text { MIKHAILOV, } \\
\text { CHERNYI, e } \\
\text { GILYAREVSKYI, } \\
1967,1969, \\
1980\end{array}$ & $\begin{array}{l}\text { (...) é a disciplina científica que estuda a estrutura } \\
\text { e as propriedades (não especificamente o } \\
\text { conteúdo) da informação científica, assim como as } \\
\text { leis que regem as atividades ligadas à informação } \\
\text { científica, sua teoria, história, metodologias } \\
\text { e organização. O objetivo da Informatika é } \\
\text { desenvolver métodos e meios eficientes de } \\
\text { registro, processamento analítico sintético, } \\
\text { armazenamento, recuperação e disseminação da } \\
\text { informação científica (Mikhailov, 1967, p. 241). } \\
\text { Informática é uma disciplina social, uma vez } \\
\text { que estuda fenómenos e regularidades inerentes } \\
\text { apenas à sociedade humana (Mikhailov, Chernyi, } \\
\text { \& Gilyarevskyi, 1980, p. 72-73). }\end{array}$ & $\begin{array}{l}\text { Informática - } \\
\text { disciplina social } \\
\text { que estuda a } \\
\text { informação } \\
\text { científica }\end{array}$ \\
\hline
\end{tabular}

4 Sobre o conceito soviético "Informatika" (contexto histórico de surgimento e evolução, fundamentação e razões que determinaram a sua debilidade concetual e aplicada) ver Moreiro González (1995, p. 173-182). 


\begin{tabular}{|c|c|c|}
\hline $\begin{array}{l}\text { ZUNDE e } \\
\text { GEHL, } 1972\end{array}$ & $\begin{array}{l}\text { "É o estudo da natureza da informação como } \\
\text { ela própria se manifesta, em seus vários } \\
\text { fenômenos, relacionados à geração, transmissão, } \\
\text { transformação, acumulação, armazenagem e } \\
\text { outros processos" (Zunde \& Gehl, 1972, p. } 68 \text {; cit. } \\
\text { por Pinheiro, 1999, p. 106). }\end{array}$ & $\begin{array}{l}\text { Disciplina } \\
\text { empírica }\end{array}$ \\
\hline BRAGA, 1973 & $\begin{array}{l}\text { "A Ciência da Informação, como ciência em si, } \\
\text { possui aspectos básicos (orientados para a teoria) } \\
\text { e aplicados (orientados para os sistemas, técnicas } \\
\text { e equipamentos). Embora estes últimos tenham } \\
\text { sido bem mais enfatizados que os primeiros, } \\
\text { a Ciência da Informação não é uma disciplina } \\
\text { pragmática: dispõe de teorias próprias - embora } \\
\text { ainda inadequadas - que desenvolveram-se } \\
\text { gradualmente a partir das pesquisas efetuadas } \\
\text { na Teoria da Informação. Gradualmente outras } \\
\text { teorias (Behavioristas, Semânticas, Sintáticas etc.) } \\
\text { e diversas leis foram sendo incorporadas à nova } \\
\text { ciência" (Braga, 1973, p. 10). }\end{array}$ & $\begin{array}{l}\text { Ciência - possui } \\
\text { aspetos básicos } \\
\text { e aplicados }\end{array}$ \\
\hline GOMES, 1974 & $\begin{array}{l}\text { "No caso da ciência da informação, verifica-se } \\
\text { que é uma disciplina científica interdisciplinar, } \\
\text { como as demais. Aproveita-se ela da contribuição } \\
\text { da tecnologia moderna, como atividade-meio, } \\
\text { enquanto os aspectos sociais e de comunicação } \\
\text { constituiriam a sua atividade-fim..." (Gomes cit. } \\
\text { por Pinheiro \& Loureiro, 1995, p. 48). }\end{array}$ & $\begin{array}{l}\text { Disciplina } \\
\text { científica } \\
\text { interdisciplinar }\end{array}$ \\
\hline $\begin{array}{l}\text { WERSIG e } \\
\text { NEVELLING, } \\
1975\end{array}$ & $\begin{array}{l}\text { "Information Science or Informatics is a } \\
\text { problem-oriented discipline, concerned with } \\
\text { specific social objectives". (...) "This science is } \\
\text { based on the notion of the information needs } \\
\text { of certain people involved in social labour, } \\
\text { and of concern with the study of methods of } \\
\text { organization of communication processes in } \\
\text { a way which meets these information needs" } \\
\text { (Wersig \& Nevelling, 1975, p. 128). }\end{array}$ & $\begin{array}{l}\text { Disciplina } \\
\text { orientada para } \\
\text { a resolução de } \\
\text { problemas, com } \\
\text { objetivos sociais } \\
\text { específicos }\end{array}$ \\
\hline $\begin{array}{l}\text { BELKIN e } \\
\text { ROBERTSON, } \\
1976\end{array}$ & $\begin{array}{l}\text { (...) "information science is a problem-oriented } \\
\text { discipline concerned with the effective transfer } \\
\text { of desired information from human generator to } \\
\text { human user (...)" (Belkin \& Robertson, 1976, p. } \\
197) \text {. }\end{array}$ & $\begin{array}{l}\text { Disciplina } \\
\text { orientada para } \\
\text { a resolução de } \\
\text { problemas }\end{array}$ \\
\hline
\end{tabular}




\begin{tabular}{|c|c|c|}
\hline FOSKETT, 1980 & $\begin{array}{l}\text { (...) "a disciplina que surge de uma fertilização } \\
\text { cruzada de idéias que incluem a velha arte da } \\
\text { biblioteconomia, a nova arte da computação, as } \\
\text { artes dos novos meios de comunicação e aquelas } \\
\text { ciências como psicologia e linguística, que em } \\
\text { suas formas modernas têm a ver diretamente } \\
\text { com todos os problemas de comunicação - a } \\
\text { transferência do pensamento organizado. O ponto } \\
\text { chave para as implicações no ensino da Ciência } \\
\text { da Informação como disciplina emergente, é, } \\
\text { portanto, que devemos deixar de considerar } \\
\text { nossa disciplina como uma coleção de técnicas } \\
\text { de estudo e operação válidas por si; elas devem } \\
\text { estar sujeitas ao exame minucioso à luz da função } \\
\text { social que desempenham" (Foskett, 1980, p. 24). }\end{array}$ & $\begin{array}{l}\text { Disciplina } \\
\text { emergente }\end{array}$ \\
\hline $\begin{array}{l}\text { MACHLUP e } \\
\text { MANSFIELD, } \\
1983\end{array}$ & $\begin{array}{l}\text { "Sabemos que muitos autores de trabalhos em } \\
\text { Ciência da Informação possuem sentimento de } \\
\text { culpa sobre o fato de que esta disciplina não } \\
\text { descobriu novas leis nem inventou novas teorias } \\
\text { e, além disso, não obteve reconhecimento como } \\
\text { ciência. Este complexo de inferioridade é o } \\
\text { resultado de uma doutrinação com um modelo } \\
\text { de filosofia da ciência que contém definições } \\
\text { persuasivas de ciência e do método científico. } \\
\text { (...) nós não nos importamos se a Ciência } \\
\text { da Informação, Biblioteconomia, Ciência da } \\
\text { Computação ou qualquer outra disciplina, são ou } \\
\text { não ciências" (Machlup \& Mansfield, 1983, p. 12). }\end{array}$ & $\begin{array}{l}\text { Disciplina, } \\
\text { não obteve } \\
\text { reconhecimento } \\
\text { como ciência }\end{array}$ \\
\hline BOYCE, 1985 & $\begin{array}{l}\text { A Ciência da Informação pode ter princípios } \\
\text { empíricos que têm o "(...) "status" de quase- } \\
\text { teorias ou talvez teorias partilhadas com outras } \\
\text { disciplinas, mas vemos nossa disciplina como } \\
\text { primeiramente prática e tecnológica. Nossa } \\
\text { disciplina está mais relacionada com a facilitação } \\
\text { dos processos de comunicação do que com a } \\
\text { sua explanação. Qualquer explanação que ocorra } \\
\text { vem, primeiramente, da aplicação de teorias e } \\
\text { modelos desenvolvidos em algum outro lugar } \\
\text { para outros propósitos" (Boyce, 1985, p. 165, cit. } \\
\text { por Pinheiro, 1999, p. 107). }\end{array}$ & $\begin{array}{l}\text { Disciplina } \\
\text { prática e } \\
\text { tecnológica }\end{array}$ \\
\hline YUEXIAO, 1988 & $\begin{array}{l}\text { (...) "a Ciência da Informação não é uma } \\
\text { Metaciência, mas uma interdisciplina" (Yuexiao, } \\
\text { 1988, p. 488). }\end{array}$ & Interdisciplina \\
\hline
\end{tabular}




\begin{tabular}{|c|c|c|}
\hline $\begin{array}{l}\text { HEILPRIN, } \\
1989\end{array}$ & $\begin{array}{l}\text { "although many laws, hypotheses, and } \\
\text { speculations about information have been } \\
\text { proposed, adequate scientific and epistemic } \\
\text { foundations for a general science of information } \\
\text { have not yet appeared" (Heilprin, 1989, p. } \\
343 \text { ). Acrescenta que as fundações da CI são } \\
\text { "multidisciplinares e, de alguma maneira, } \\
\text { intratáveis, até que os muitos campos envolvidos } \\
\text { estabeleçam uma síntese" (Heilprin, } 1989 \text { cit. por } \\
\text { Pinheiro, 1999, p. 103). }\end{array}$ & Interdisciplina \\
\hline $\begin{array}{l}\text { SARACEVIC, } \\
1991\end{array}$ & $\begin{array}{l}\text { "Ciência da Informação é um campo dirigido à } \\
\text { investigação científica e à prática profissional } \\
\text { relacionada aos problemas de efetiva } \\
\text { comunicação de conhecimento e registros de } \\
\text { conhecimento, entre humanos, nos contextos } \\
\text { de uso social, institucional e/ou individuais e de } \\
\text { necessidades de informação" (Saracevic, 1991, } \\
\text { cit. por Pinheiro, 1999, p. 106). }\end{array}$ & $\begin{array}{l}\text { Ciência pura e } \\
\text { aplicada }\end{array}$ \\
\hline WERSIG, 1993 & $\begin{array}{l}\text { Vê a CI "não como uma ciência clássica, mas } \\
\text { como o protótipo de uma nova ciência" (1993: } \\
\text { 44). Regista obstáculos no seu estudo devido } \\
\text { ao seu "fracionamento em inúmeras disciplinas, } \\
\text { obrigando o cientista a lidar com dados } \\
\text { fragmentados de natureza empírica e teórica. } \\
\text { Se a Ciência da Informação existe, qualquer } \\
\text { que seja a denominação dada a esse campo, } \\
\text { ela não possuirá uma teoria, mas uma estrutura } \\
\text { proveniente de um amplo conceito científico ou } \\
\text { modelos e conceitos reformulados" (Wersig cit. } \\
\text { por Pinheiro, 1999, p. 103). }\end{array}$ & $\begin{array}{l}\text { Nova ciência, } \\
\text { fragmentada } \\
\text { em inúmeras } \\
\text { disciplinas }\end{array}$ \\
\hline $\begin{array}{l}\text { LE COADIC, } \\
1996\end{array}$ & $\begin{array}{l}\text { A ciência da informação, com a preocupação } \\
\text { de esclarecer um problema social concreto, } \\
\text { o da informação, e voltada para o ser social } \\
\text { que procura informação, coloca-se no campo } \\
\text { das ciências sociais (das ciências do homem } \\
\text { e da sociedade), que são o meio principal } \\
\text { de acesso a uma compreensão do social e } \\
\text { do cultural. (...) Os problemas de que trata } \\
\text { cruzam as fronteiras históricas das disciplinas } \\
\text { tradicionais, e o recurso a várias disciplinas } \\
\text { parece ser evidente. Essa colaboração chama- } \\
\text { se interdisciplinaridade. (...) De prática de } \\
\text { organização, a ciência da informação tornou- } \\
\text { se, portanto, um ciência social rigorosa que se } \\
\text { apóia em uma tecnologia também rigorosa. Tem } \\
\text { por objeto o estudo das propriedades gerais da } \\
\text { informação (natureza, gênese, efeitos) (...)" (Le } \\
\text { Coadic, 1996, p. 21, 22, 26). }\end{array}$ & $\begin{array}{l}\text { Ciência social } \\
\text { interdisciplinar }\end{array}$ \\
\hline
\end{tabular}




\begin{tabular}{|l|l|l|}
\hline PINHEIRO, & $\begin{array}{l}\text { "É perceptível, nas palavras de inúmeros } \\
\text { especialistas da área, que é uma tarefa quase } \\
\text { impossível classificar a Ciência da Informação } \\
\text { dentro dos critérios e padrões que integram } \\
\text { o modelo científico dominante". (..) "O } \\
\text { entendimento da Ciência da informação como } \\
\text { Ciência do PE [Paradigma Emergente] permite que } \\
\text { não somente ela, como outras ciências, encontrem } \\
\text { um espaço de ordem mais adequado às suas } \\
\text { necessidades e ao seu desenvolvimento" (Pinheiro, } \\
\text { 1999, p. 102, 107). }\end{array}$ & $\begin{array}{l}\text { Ciênerigma } \\
\text { emente }\end{array}$ \\
\hline HAWKINS, & $\begin{array}{l}\text { "An interdisciplinary field concerned with the } \\
\text { theoretical and practical concepts, as well as the } \\
\text { technological, laws, and industry dealing with } \\
\text { knowledge transfer and the sources, generation, } \\
\text { organization, representation, processing, } \\
\text { distribution, communication, and uses of } \\
\text { information, as well as communications among } \\
\text { users and their behavior as they seek to satisfy } \\
\text { their information needs" (Hawkins, 2001, p. 45). }\end{array}$ & $\begin{array}{l}\text { Ciência } \\
\text { interdisciplinar }\end{array}$ \\
\hline RODRÍGUEZ & $\begin{array}{l}\text { Ciencia de la documentación - "su carácter } \\
\text { de metadisciplina o de interdisciplina, pues } \\
\text { presta su apoyo a otras ciencias además de } \\
\text { trascenderlas para desarrollarse como ciencia } \\
\text { propia, (...) no tiene un objeto en exclusividad; } \\
\text { da igual que pensemos en el documento o en la } \\
\text { información: nuestra ciencia se ocupa de algunos } \\
\text { de sus aspectos, no de todos" (Rodríguez Bravo, } \\
\text { 2002, p. 17-18). }\end{array}$ & $\begin{array}{l}\text { Ciência da } \\
\text { documentação - } \\
\text { interdisciplinar }\end{array}$ \\
\hline
\end{tabular}

Tabela 1: Conceções acerca da identidade e/ou fronteiras da CI Fonte: Elaboração própria (Gomes, 2016).

Da amostra colhida, não exaustiva, ressalta, por um lado, a falta de um consenso mínimo indispensável acerca das origens e da natureza da CI e, por outro, constata-se que a referida falta de consenso traduziu-se numa incapacidade de assumir posições epistemológicas claras.

O desenvolvimento da produção informacional (informação em geral, científica e técnica) e de sistemas tecnológicos de informação tornou necessária uma ciência que tivesse por objeto de estudo a informação. Consequentemente surgem as questões sobre as relações entre a CI, a Tecnologia da Informação e a Sociedade (Buckland, 2012). Corroborando esta afirmação: 
We may best understand information science as a field of study, with human recorded information as its concern, focusing on the components of the information chain, studied through the perspective of domain analysis, in specific or general contexts. Its particular focus of interest is those aspects of information organization, and of human information-related behaviour, which are invariant to changes in technology. It also has a role as a science of evaluation of information understood as semantic content with respect to qualitative growth of knowledge, and change in knowledge structures in domains (Robinson \& Karamuftuoglu, 2010).

Hjørland acrescenta:

Information science is sometimes confused with information technology and with computer science and is seen by some people as being primarily about information technology and computers. One indication of this is that, in the year 2000, the American Society for Information Science decided to add "and Technology" to its name. Another is the tendency to merge departments of library and information science with departments of computer science. A third indication is that a core subfield, information retrieval, is dominated by the computer science community (Hjørland, 2014, p. 213).

Apesar das múltiplas definições propostas, a que surgiu nas conferências do Georgia Institute of Technology, aperfeiçoada mais tarde por Harold Borko, permanece como uma das mais consensuais.

Ciência da Informação é a que investiga as propriedades e comportamento da informação, as forças que regem o fluxo da informação e os meios de processamento da informação para um máximo de acessibilidade e uso. O processo inclui a origem, disseminação, coleta, organização, armazenamento, recuperação, interpretação 
e uso da informação. O campo deriva ou relaciona-se com a matemática, a lógica, a linguística, a psicologia, a tecnologia computacional, as artes gráficas, as comunicações, a biblioteconomia, a gestão e alguns outros campos (Shera \& Cleveland, 1977, p. 265).

Sobressaem desta definição duas tendências diferentes, todavia complementares: a delimitação de um objeto específico de estudo e a presença de uma disciplina científica com identidade própria, gerada e aberta à interdisciplinaridade.

Para Harold Borko, no clássico artigo Information Science what is it?, a "information science is that discipline that investigates the properties and behavior of information, the forces governing the flow of information, and the means of processing information for optimum accessibility and usability" (Borko, 1968, p. 3).

Trata-se, segundo Borko, de uma ciência interdisciplinar derivada e relacionada com vários campos, com uma componente de ciência pura e de ciência aplicada que abrange todo o fluxo da informação e desenvolve serviços e produtos. Identifica a Biblioteconomia e a Documentação como aspetos/componentes aplicados(as) da CI. Na mesma linha, e considerando a CI uma ciência social rigorosa, Le Coadic (1996, p. 22) afirma:

A ciência da informação é uma dessas novas interdisciplinas, um desses novos campos de conhecimentos onde colaboram entre si, principalmente, a psicologia, a linguística, a sociologia, a informática, a matemática, a lógica, a estatística, a eletrônica, a economia, o direito, a filosofia, a política e as telecomunicações.

Silva (2006) afirma tratar-se de uma ciência social trans e interdisciplinar, dotada de um corpo teórico-metodológico próprio "que investiga os problemas, temas e casos relacionados com o fenómeno info-comunicacional" e se centra no estudo do ciclo informacional 
na sua plenitude: "origem, coleta, organização, armazenamento, recuperação, interpretação, transmissão, transformação e utilização da informação" (Silva, 2006, p. 140-141).

Ao longo dos últimos cinquenta anos, a CI identificou e delimitou o seu objeto e os problemas fundamentais de pesquisa: estudo das propriedades gerais da informação e dos processos e sistemas de construção/criação, comunicação e uso dessa informação.

The one discipline that has information as its sole object of interest is information science. (...) Information science concerns itself with all aspects of the organization and communication of recorded information, with the information and digital literacies needed to make use of it, and with associated ethical issues. (...) information science as a broad and inclusive field of study; only such a holistic approach can do justice to the issues that emerge when information takes center stage in society" (Buckland, 2017, p. x[10]).

Nas duas últimas décadas, a existência de uma CI (e não de várias) surge claramente dominada, por um lado, por uma perspetiva social centrada no estudo "das propriedades do objeto/fenómeno [informação] e do processo em que o fenómeno se transforma quando ocorrem situações marcadas pela dinâmica sócio-comunicacional" (Silva \& Ribeiro, 2002, p. 43). Por outro, temos a CI de cariz acentuadamente tecnológico, centrada no processamento e na recuperação computacional da informação: "studies the representation, storage and supply as well as the search for and retrieval of relevant (predominantly digital) documents and knowledge (...)" (Stock \& Stock, 2015, p. 4).

Ora, o processo evolutivo desta ciência não foi linear, em particular quanto ao seu objeto e perfil identitário. Recorde-se a afirmação de Heilprin (1989, p. 335): “although many laws, hypotheses, and speculations about information have been proposed, adequate scien- 
tific and epistemic foundations for a general science of information have not yet appeared". E, dezassete anos depois, Zins concluíu:

Apparently, there is not a uniform concept of "information science". The field seems to follow different approaches and traditions; for example, objective approaches vs cognitive approaches, the library tradition vs the documentation tradition vs the computation tradition, and so on. The concept has different meanings. Different meanings imply different knowledge domains. Different knowledge domains imply different fields. Nevertheless, all of them are represented by the same name, "information science". No wonder that even scholars and practitioners are subject to confusion (Zins, 2006, p. 447).

Importa, pois, elencar o essencial sobre a conceção da CI que se assume: uma ciência social, trans e interdisciplinar, com um objeto científico (a informação) que vai sendo construído e que constitui um fenómeno humano e social - o fenómeno infocomunicacional.

\section{Uma Ciência pluri, inter e/ou transdisciplinar?}

Não é, portanto, consensual, ainda hoje, no início da terceira década do século XXI, o entendimento de que a CI constitui um campo disciplinar com plena identidade e com caráter de cientificidade inquestionável, como o testemunham os trabalhos de autores como Hawkins (2001), Webber (2003) e Robinson (2009), dedicados em particular, à visão geral desta importante questão.

$\mathrm{Na}$ verdade, a CI tem sido considerada uma metaciência, uma interciência, uma ciência pós-moderna, uma ciência superior, uma ciência do conhecimento ou um campo multidisciplinar de estudo (Robinson, 2009). 
Outra questão que não está resolvida é a que se refere à relação existente entre a CI e outras disciplinas, com incidência particular na discussão sobre a conexão com a Arquivística, a Biblioteconomia, os Sistemas Informáticos ou Tecnológicos de Informação e a Museologia.

Em face das divergências e controvérsias conhecidas, assinala-se a dificuldade que reside no estabelecimento de um consenso científico sobre o próprio campo disciplinar, e este está relacionado com diversos aspetos plasmados na literatura da área, como sejam os que se enumeram seguidamente:

- Pensar a prática conduziu à afirmação disciplinar da Arquivística, da Biblioteconomia e da Documentação, "a teoria seguiu a prática, não a dirigiu nem a guiou” (Delgado López-Cózar, 2002, p. 24). Foi o exercício profissional que estimulou a reflexão sobre a praxis e fez surgir a necessidade de uma formação adequada;

- Na sequência do ponto anterior, a teorização e os trabalhos de investigação foram essenciais para a construção do conhecimento científico em torno do objeto de estudo;

- A construção científica da CI não ocorreu simultaneamente e da mesma forma em todos os países e contextos, o que torna muito variável o seu grau de desenvolvimento;

- Não havendo um consenso científico sobre a unidade epistemológica da área, surgem posições de entendimento da CI como uma interdisciplina;

- Subsistem, também, visões alicerçadas pelo paradigma tradicional, que aceita apenas a Informação registada (Documentação) como objeto de estudo (López Yepes, 1995, 1996, 2004);

- No âmbito do paradigma científico-informacional, regista-se a posição em favor de uma CI assumida como um campo de saber uno e transdisciplinar, o qual congrega e dá suporte teórico a diversas disciplinas aplicadas, desde a Arquivística e a Biblioteconomia/ Documentação aos Sistemas Tecnológicos de Informação (Silva \& Ribeiro, 2002, p. 80); 
- A CI assumida como um campo de saber uno e transdisciplinar, inscrito na vasta área das ciências sociais e humanas, evidencia uma clara dimensão transdisciplinar e, em simultâneo, as suas relações interdisciplinares com outras áreas do conhecimento (Silva, 2006, p. 28).

Perante esta multiplicidade diferenciada de posicionamentos, o debate sobre se a CI é uma ciência social pluridisciplinar, interdisciplinar e/ou transdisciplinar ${ }^{5}$ é bastante atual.

A questão basilar consiste na tarefa difícil de se conseguir delimitar bem conceitos próximos, todavia distintos - pluridisciplinaridade, interdisciplinaridade e transdisciplinaridade ${ }^{6}$. Olga Pombo (2003) apresenta a seguinte proposta de entendimento face à flutuação de conceitos:

(...) Quando estivéssemos a falar de pluridisciplinaridade ou de multidisciplinaridade, estaríamos a pensar naquele primeiro nível que implica pôr em paralelo, estabelecer algum mínimo de coordenação. A interdisciplinaridade, pelo seu lado, já exigiria uma convergência de pontos de vista. Quanto à transdisciplinaridade, ela remeteria para qualquer coisa da ordem da fusão unificadora, solução final que, conforme as circunstâncias concretas e o campo específico de aplicação, pode ser desejável ou não (Pombo, 2003, p. 5-6).

5 O prefixo pluri aponta para uma lógica de multiplicidade, o prefixo inter remete para a convergência, a complementaridade, o cruzamento, o prefixo trans aponta para a aspiração à homogeneização. Concordando com Pombo (2003, p. 4-5), "é à etimologia dos prefixos que, em cada caso, antecedem a palavra disciplina que, a meu ver, há que recorrer. (...) [Assim] há a possibilidade de avançar uma proposta terminológica assente em dois princípios fundamentais: a) aceitar estes três prefixos: multi ou pluri, inter e trans (digo três e não quatro porque, do ponto de vista etimológico, não faz sentido distinguir entre pluri e multi) enquanto três grandes horizontes de sentido e, b) aceitá-los como uma espécie de continuum que é atravessado por alguma coisa que, no seu seio, se vai desenvolvendo."

6 Todas as palavras têm uma mesma raiz: disciplina. E, "esse comum radical, ao invés de funcionar como elemento de aproximação, constitui um novo procedimento de dispersão de sentido. Na verdade, na sua equivocidade, a palavra disciplina pode ter, pelo menos, três grandes significados. Disciplina como ramo do saber (...). Disciplina como componente curricular (...). Finalmente, disciplina como conjunto de normas ou leis que regulam uma determinada actividade ou o comportamento de um determinado grupo (...)" (Pombo, 2003, p. 4). 
Naturalmente há inúmeras definições entre os principais especialistas. Para lá de todas as diferenças, a interdisciplinaridade é o conceito primeiramente invocado perante a definição dos limites de uma área de conhecimento, face a uma nova disciplina ou diante de problemas complexos, cuja solução exige múltiplas e diferentes perspetivas.

A presença de uma ampla interdisciplinaridade na génese e evolução da CI não parece ter sido suficiente para a tornar consensual.

A definição a que se chegou nas conferências do Georgia Institute of Technology, aperfeiçoada depois por Borko (1968), influenciou inquestionavelmente a conceção unitária e interdisciplinar enunciada por Yves Le Coadic: "A interdisciplinaridade traduz-se por uma colaboração entre diversas disciplinas, que leva a interações, isto é, uma certa reciprocidade, de forma que haja, em suma, enriquecimento mútuo" (Le Coadic, 1996, p. 22).

Esta aposta na interdisciplinaridade da CI, aparece subscrita por vários autores (Robredo, 2003, p. 62 e seg.), para além de Le Coadic (1996) e de Blanca Rodríguez Bravo (2002).

Há, contudo, visões opostas, como a de Guy A. Marco (1996, p. 11) que, partindo da análise de várias definições de CI, apresenta "two false beliefs about information science: that there is a distinct discipline of information science; and that librarians need to study it". Uma das questões que sustenta o seu discurso critico e redutor é precisamente a interdisciplinaridade, afirmando que a "information science is no more than a gathering of findings from communication, computer science and librarianship - it is not interdisciplinary, since it uses only products of the other fields, not their principles and methods".

Por sua vez, Holland (2008, p. 9), considera que a "interdisciplinary research has longer-term benefits for information science, but multidisciplinary research can also fulfil valid collaborative roles in information science". Sobre a natureza multidisciplinar e interdisciplinar da CI acres- 
centa que as inconsistências na aplicação dos termos tem impacto na prática profissional, todavia há uma distinção clara entre ambos.

Para o conceito multidisciplinar Holland segue a proposta de Joe Moran (2010), afirmando que "o trabalho multidisciplinar refere-se à justaposição de duas ou mais disciplinas ligadas pela sua proximidade, mais do que pelo esforço transformador para produzir novas formas de conhecimento". Sobre estas duas abordagens considera que, por norma, a colaboração entre diversas áreas de conhecimento verifica-se a um nível multidisciplinar, todavia o mais útil, construtivo e enriquecedor para a CI seria o trabalho sob a perspetiva interdisciplinar ${ }^{7}$.

De acordo com Nicolescu (2000, p. 15), a interdisciplinaridade é a transferência de métodos de uma disciplina para outra, que pode ocorrer em três graus: a) de aplicação; b) epistemológico; c) geração de novas disciplinas. A pluridisciplinaridade diz respeito ao estudo do objeto de uma disciplina por várias disciplinas ao mesmo tempo. A transdisciplinaridade está relacionada com o que está ao mesmo tempo entre as disciplinas, através das diferentes disciplinas e além de qualquer disciplina.

Enquanto a pluridisciplinaridade remete para a convergência plural de disciplinas convocadas para a solução de um problema, a transdisciplinaridade remete para o estudo de um objeto análogo. Assumindo-se a transdisciplinaridade da CI, esta congrega e dá suporte teórico a disciplinas como a Arquivística, a Biblioteconomia, a Documentação ou os Sistemas Tecnológicos de Informação. Quanto à sua interdisciplinaridade, pode situar-se em dois níveis:

[A nível central ou nuclear a CI precisa] do contributo directo da Lógica e da Matemática, das Neurociências, da Cibernética,

7 "I take interdisciplinarity to mean any form of dialogue or interaction between two or more disciplines: the level, type, purpose, and effect of this interaction remain to be examined" (Moran, 2010, p. 14). 
da Inteligência Artificial (com incidência na pesquisa avançada sobre a interacção homem - máquina), da Psicologia (com especial destaque para a Psicologia Cognitiva, a Psicolínguística, a Psicologia Social e a Psicologia da Comunicação), da Sociologia (das Organizações, da Cultura e da Comunicação), da Semiologia e da Medialogia (acha-se, neste elenco, o core das denominadas Ciências da Comunicação ${ }^{8}$ ). O intercâmbio com estas disciplinas faz-se, na óptica da C.I., através da assimilação de resultados, metodologias e teorias que têm a ver directamente com o objecto info-comunicacional que a C.I., estuda (...); e, em troca, essas disciplinas recebem o produto contínuo desta abordagem específica e, num plano mais aplicacional, lucram com os dispositivos que agilizam o fluxo informacional para proveito operacional de cada pessoa, grupo ou instituição (...). [A nível complementar, a CI desenvolve práticas interdisciplinares] com ciências que ajudam a contextualizar quer a informação produzida quer o correlativo processo comunicacional ou de recuperação/uso - a História, a Administração e o Direito, a Gestão e Economia e a Auditoria e Contabilidade. As questões relacionadas com a preservação do suporte material simples ou o dispositivo tecnológico de registo/ processamento dos conteúdos (informação) implicam relações com ciências naturais (Física e Química) e com a engenharia electrotécnica e informática (Silva, 2006b, p. 28-29).

Portanto, a interdisciplinaridade e transdisciplinaridade da CI não corresponde ao somatório ou à justaposição de diversas disciplinas que estudam um fenómeno de natureza complexa, partilhado por várias áreas do conhecimento. Sendo a Informação um fenómeno cuja génese está no cérebro humano, em estreita relação com a

8 Ciências da Comunicação (Sociologia, Semiótica, Psicologia e Informática, Inteligência Artificial e Multimédia). 
ação de cada sujeito socialmente contextualizada, o seu estudo não pode deixar de remeter para abordagens cognitivistas e sociológicas, numa evidente interdisciplinaridade com a CI.

A CI tem, portanto, uma natureza interdisciplinar flagrante, porque necessita do contributo de outras ciências, humanas e sociais (ex. Sociologia, História, Gestão e Economia, Direito), exatas e naturais (ex. Matemática, Física e Química, Informática), e simultaneamente exige delas um intercâmbio, no que toca a metodologias, teorias e resultados que se relacionam com o estudo do fenómeno infocomunicacional.

Uma vez que a transdisciplinaridade remete para o estudo de um objeto análogo, a evolução em contexto transdisciplinar da Arquivística, Biblioteconomia, Documentação, Museologia (Gomes, 2016, p. 93-128) e CI converge, agora, para uma nova realidade disciplinar.

Nesta perspetiva, afirma-se que a CI não corresponde ao somatório de disciplinas que operam entre si (interdisciplina) ou em conjunto (pluridisciplina) para se assumir como um campo trans e interdisciplinar, em relação com outros domínios científicos.

\section{Notas finais}

Partindo de uma síntese dos fundamentos, progressos e principais linhas de força do desenvolvimento e consolidação da CI, desde 1958 até à atualidade, constata-se que o seu processo evolutivo não foi linear.

Até 1958, o termo CI raramente surgiu na literatura especializada, conquanto se possa estabelecer uma origem mais longínqua, recuando ao final do século XIX e aos estudos de Otlet e La Fontaine que determinaram a afirmação da Documentação. Apesar de a literatura publicada sobre a CI ter florescido ao longo da última metade do século XX, na verdade assistiu-se a profundas e intensas discussões em redor do seu caráter científico. 
O indispensável rigor epistemológico e concetual, bem como outras necessidades relativas a disciplinas suscetíveis de integração ou convergência na/para a CI, ou de estabelecimento de relações interdisciplinares, comprovam o projeto de construção científica em torno desta ciência recente.

A interdisciplinaridade genética da CI permite-lhe, hoje, ter uma relação dinâmica com outras áreas científicas, mais ou menos próximas (Ciências Humanas e Sociais, Ciências Exatas e Naturais).

Afirma-se que a disciplina transdisciplinar CI do século XXI é muito diferente da CI "original". A atual, não absorveu no seu campo científico a Arquivística, a Biblioteconomia, a Documentação, a Museologia ou a CI "original", pois as distintas áreas disciplinares evoluíram e transformaram-se, num sentido divergente inicialmente, e agora no sentido da convergência.

\section{Referências Bibliográficas}

BAWDEN, D. \& ROBINSON, L. (2012). Introduction to information science. London: Facet Publishing. ISBN 9781856048101.

BELKIN, N. J. \& ROBERTSON, S. E. (1976). Information Science and the phenomena of information. Journal of the American Society for Information Science, 27(4), 197-204.

BORKO, H. (1968). Information science: what is it? American Documentation, 19(1), 3-5.

BRAGA, G. M. (1973). Relações bibliométricas entre a frente de pesquisa (research front) e revisões da literatura: estudo aplicado a ciência da informação. Ciência da Informação, 2(1), 9-26. Consult. 12 Jan. 2019. Disponível em: http://revista. ibict.br/ciinf/article/view/20

BUCKLAND, M. (2012). What kind of science can information science be?, Journal of the American Society for Information Science and Technology, 63(1), 1-7.

BUCKLAND, M. (2017). Information and society. Cambridge, MA: MIT Press. ISBN 9780262533386.

BUCKLAND, M. K. \& HAHN, T. B. (Eds.) (1997). Special Topic Issue: history of Documentation and Information Science. Journal of the American for Information Science, April 48(4), 285-379; September 48(9), 773-842. ISSN: 0002-8231.

CACALY, S. et al. (1997). Dictionnaire encyclopédique de l'information et de la documentation. Paris: Éditions Nathan. ISBN 2-09-190528-3.

CAPURRO, R. (2003). Epistemologia y ciencia de la información. Consult. 12 Jan. 2019. Disponível em: http://www.capurro.de/enancib.htm 
DEBONS, A. (1986). Information science. In ALA world encyclopedia of library and information services. Chicago: American Library Association. ISBN 0-8389-0427-0.

DELGADO LÓPEZ-CÓZAR, E. (2002). La Investigación en biblioteconomía y documentación. Gijón: Ediciones Trea. ISBN 84-9704-041-4.

FAYET-SCRIBE, S. (1997). The cross-fertilization of the U.S. Public Library Model and the French Documentation Model (IIB, French Correspondent of FID) through the French Professional Association between World War I and World War II. Journal of the American for Information Science, 48(9), 782-793.

FOSKETT D. J. (1980). Informática. In H. E. Gomes (Org.), Ciência da informação ou Informática (p. 5-51). Rio de Janeiro: Calunga.

GOMES, L. I. E. (2016). Gestão da informação, holística e sistémica, no campo da Ciência da Informação: estudo de aplicação para a construção do conhecimento na Universidade de Coimbra. Tese de doutoramento, Universidade da Corunha. Disponível em: http:// ruc.udc.es/dspace/handle/2183/18287; https://estudogeral.sib.uc.pt/handle/10316/43201

HAPKE, T. (1998). History of scholarly information and communication: a review of selected german literature. Journal of the American for Information Science. Forthcoming. ISSN: 0002-8231.

HAWKINS, D. T. (2001). Information science abstracts: tracking the literature of information science. Part 1: definition and map. Journal of the American Society for Information Science and Technology, 52, 44-54.

HEILPRIN, L. B. (1989). Foundations of information science re-examined. Annual Review of Information Science and Technology, 24, 343-372.

HJØRLAND, B. (2014). Information science and its core concepts: levels of disagreement. In F. Ibekwe-SanJuan \& T. M. Dousa (Eds.), Theories of information, communication and knowledge: a multidisciplinary approach, 205-235. New York, NY: Springer.

HOLLAND, G. A. (2008). Information science: an interdisciplinary effort? Journal of Documentation, 64(1), 7-23. DOI: http://dx.doi.org/10.1108/00220410810844132

LE COADIC, Y.-F. (1996). A Ciência da Informação. Brasília: Briquet de Lemos.

LE COADIC, Y.-F. (1997) Science de l'information. Dictionnaire encyclopédique de l'information et de la documentation, 516-523. Paris: Nathan.

LÓPEZ YEPES, J. (1995). La Documentación como disciplina: teoría e historia. $2^{\text {a }}$ ed. actualizada y ampliada. Pamplona: Ediciones Universidade de Navarra.

LÓPEZ YEPES, J. (1996). El concepto de ciencia de la documentación: unidad en la diversidad o diversidad en la unidad. Investigación Bibliotecológica, 10 (21), 4-6. Consult. 05 Jun. 2018. Disponível em: http://www.ejournal.unam.mx/ibi/vol1021/IBI001002101.pdf

LOPÉZ YEPES, J. (2004). Características de la Documentación y su reflejo en la formación de los profesionales e investigadores de la disciplina. In Congresso Nacional de Bibliotecários Arquivistas e Documentalistas - Nas encruzilhadas da informação e da cultura: (re)inventar a profissão: actas (p. [1-20]). Consult. 05 Jun. 2018. Disponível em: http://www.bad.pt/publicacoes/index.php/ congressosbad/issue/view/13

MACHLUP, F. \& MANSFIELD, U. (1983). The study of information: interdisciplinary messages. New York: John Wiley \& Sons. 
MARCO, Guy A. (1996). Two false dogmas of information science. New Library World, 97(7), 11-14. doi: http://dx.doi.org/10.1108/03074809610148766

MIKHAILOV, A. I. (1967). Informatics - A Scientific Discipline. Documentação e Informação Científica, 10(53), 239-242.

MIKHAILOV, A. I., CHERNYI, A. I. \& GILYAREVSKY, R. S. (1980). Estrutura e principais propriedades da informação científica. In GOMES, H. E. (Org.), Ciência da informação ou informática? Rio de Janeiro: Calunga.

MIKHAILOV, A. I., CHERNYI, A. I., \& GILYAREVSKY, R. S. (1969). Informatics: Its scope and methods. In FID/RI. International Federation for Documentation. Study Committee Research on Theoretical problems of Informatics, 7-24. Moscow: ALL-Union for Scientific and Technical Information.

MIKHAILOV, A. I., CHERNYI, A. I., \& GILYAREVSKY, R.S. (1967). Development of Information Science in the USSR. Automatic Documentation and Mathematical Linguistics, 1(5), 18-26.

MIKHAILOV, A. I.; CHERNYI, A. I. \& GILYAREVSKYI, R. S. (1973). Fundamentos de la informatica. La Habana: IDICT/Academia de Ciencias de Cuba.

MORAN, J. (2010). Interdisciplinarity. 2nd edition. London; New York: Routledge. ISBN 0-203-86618-5.

Moreiro González, J. A. (1995). ¿Qué fue del concepto soviético de "Informatika"? Documentación de las Ciencias de la Información, 18, 173-182. Consult. 11 Jun. 2018. Disponível em: https://dialnet.unirioja.es/servlet/articulo?codigo $=51376$

NICOLESCU, B. (2000). Um novo tipo de conbecimento - transdisciplinaridade. Brasília: UNESCO.

OTLET, P. (1996). El tratado de documentació: el libro sobre el libro: teoría y práctica. 2. ${ }^{a}$ ed. Murcia: Universidad de Murcia, Servicio de Publicaciones.

PINHEIRO, L. V. R. \& LOUREIRO, J. M. M. (1995). Traçados e limites da ciência da informação. Ciência da Informação, 24(1). Consult. 12 Dez. 2018. Disponível em: http://revista.ibict.br/ciinf/article/view/609

PINHEIRO, L. V. R. (Org.) (1999). Ciência da informação, ciências sociais e interdisciplinaridade. Brasília/Rio de Janeiro: Instituto Brasileiro de Informação em Ciência e Tecnologia.

POMBO, O. (2003). Epistemologia da Interdisciplinaridade. In Colóquio Interdisciplinaridade, Humanismo e Universidade, Porto. Consult. 11 Jun. 2016. Disponível em: http:// webpages.fc.ul.pt/ ommartins/investigacao/portofinal.pdf

RAYWARD, W. B. (1996). The History and Historiography of Information Science: some reflections. Information Processing \& Management, 32(1): 3-18.

RAYWARD, W. B. (1997). The Origins of information science and the International Institute of Bibliography / International Federation for Information and Documentation (FID). JASIS - Journal of the American Society for Information Science, 48(4), 289-300.

RIEUSSET-LEMARIÉ, I. (1997). P. Otlet's Mundaneum and the international perspective in the history of documentation and information science. JASIS - Journal of the American Society for Information Science, 48(4), 301-309.

ROBINSON, L. \& KARAMUFTUOGLU, M. (2010). The nature of information science: changing models. Information Research, 15(4). Consult. 16 Nov. 2018. Disponível em: http://www.informationr.net/ir/15-4/colis717.html 
ROBINSON, L. (2009). Information Science: communication chain and domain analysis. Journal of Documentation, 65(4), 578-591.

ROBREDO, J. (2003). Da ciência da informação revisitada aos sistemas humanos de informação. Brasília: Thesaurus/SSRR Informações.

RODRÍGUEZ BRAVO, B. (2002). El documento: entre la tradición y la renovación. Gijón: Ediciones Trea.

SARACEVIC, T. (1996). Ciência da informação: origem, evolução e relações. Perspectivas em Ciência da Informação, 1, 41-62.

SHERA, J. H. \& CLEVELAND, D. B. (1977). History and foundations of information science. Annual Review of Information Science and Technology, 12, 249-275.

SILVA, A. M. \& RIBEIRO, F. (2002). Das "ciências"documentais à ciência da informação: ensaio epistemológico para um novo modelo curricular. Porto: Edições Afrontamento.

SILVA, A. M. da (2006). A informação: da compreensão do fenómeno e construção do objecto científico. Porto: Edições Afrontamento e CETAC.COM. ISBN 972-36-0859-6.

SILVA, A. M. da (2006b). Informação e Comunicação: as duas faces de Jano. Prisma. com, 2, 3-32. Consult. 11 Jan. 2019. Disponível em: http://ojs.letras.up.pt/index. $\mathrm{php} / \mathrm{prismacom} /$ article/view/2134

STOCK, W. G., \& STOCK, M. (2015). Handbook of Information Science. Berlin; Boston: De Gruyter Saur. ISBN 978-3-11-037364-6.

VICKERY, B. C. (Ed.) (1994). Fifty Years of Information Progress: A Journal of Documentation Review. London, England: Aslib. ISBN: 0-85142-327-2.

WEBBER, S. (2003). Information science in 2004: a critique. Journal of Information Science, 29(4), 311-30.

WERSIG, G., \& NEVELING, U. (1975). The phenomena of interest to information science. The Information Scientist, 9(4), 127-140.

WILLIAMS, R. V., WHITMIRE, L. \& BRADLEY, C. (1997). Bibliography of the History of Information Science in North America, 1900-1995. Journal of the American Society for Information Science, 48, 373-379.

YUEXIAO, Z. (1988). Definitions and sciences of information. Information Processing E Management, 24(4), 479-491.

ZINS, C. (2006). Redefining information science: from "information science" to "knowledge science". Journal of Documentation, 62(4), 447-461. DOI 10.1108/00220410610673846 
(Página deixada propositadamente em branco) 
PARA UMA CI ÊNCIA DA INFORMAÇÃO SOCIAL E HUMANA: ANÁLISE CRÍTICA DAS TENDENCIAS DA FORMAÇÃO EM INFORMATION SCIENCE E CI ÊNCIA DA INFORMAÇÃO NAS “25 MELHORES UNIVERSIDADESDOMUNDO"

\author{
TOWARDSA SOCIALAND HUMAN INFORMATION \\ SCIENCE: CRITICALANALYSIS OF INFORMATION \\ SCIENCE TRENDS AND TRAINING AT THE “25 \\ BESTUNIVERSITIES IN THE WORLD”
}

Maria Beatriz Marques Universidade de Coimbra, Faculdade de Letras/ CITCEM/ CEGOT beatrizmarques35@gmail.com ORCID: https://orcid.org/0000-0002-0088-0429

RESUMO - A conjuntura geo-política, económica, social e cultural da Era da Informação implica o desenvolvimento de um pensamento critico em relação a fenómenos emergentes que podem contribuir para acentuar as assimetrias, as desigualdades, "a brecha humana" e, em última instância, para ameaçar a sobrevivência da humanidade e a sustentabilidade do planeta. Este contexto afigura-se-nos altamente favorável para o desenvolvimento/consolidação de uma Ciência da Informação (CI) de matriz social e humana. Assim, o objetivo principal deste capítulo é o de contribuir para o debate epistemológico e para a afirmação/reposicionamento do seu objeto de estudo. 
A metodologia mista utilizada, partiu da análise quantitativa dos dados publicados pelo QS World University Rankings, e do seu enquadramento no movimento ou consórcio internacional das Information Schools ou iSchools. Posteriormente, desenvolveu-se uma análise qualitativa de natureza exploratória da oferta formativa das " 25 melhores universidades do mundo" no domínio da Library and Information Science.

Conclui-se sobre a importância de uma perspetiva trans e interdisciplinar da CI com outras áreas científicas, nomeadamente as Ciências da Computação / Informática / Matemática, a Gestão, a Comunicação, a Educação, etc., e, em simultâneo, sobre a urgência de um debate epistemológico no domínio do estabelecimento de um "consenso possível" sobre o objeto, o método e a linguagem da CI, na sua matriz europeia de natureza social e humana e do necessário esclarecimento das suas relações disciplinares. PALAVRAS-CHAVE - Ciência da Informação; Epistemologia da Ciência da Informação; Oferta formativa; iSchools.

ABSTRACT - The geo-political, economic, social and cultural conjuncture of the Information Age implies the development of critical thinking in relation to emerging phenomena that can contribute to accentuate asymmetries, inequalities, "the human gap" and, ultimately, to threaten the survival of humanity and the sustainability of the planet. This context seems to us to be highly favorable for the development / consolidation of an Information Science (IS) of social and human matrix. Thus, the main objective of this chapter is to contribute to the epistemological debate and to the affirmation / repositioning of its object of study.

The mixed methodology used was based on the quantitative analysis of data published by QS World University Rankings, and its fit in the international movement or consortium of Information Schools or iSchools. Subsequently, an exploratory qualitative 
analysis of the " 25 best universities in the world" in the field of Library and Information Science was developed.

It concludes on the importance of a trans and interdisciplinary perspective of IS with other scientific areas, namely Computer Science / Informatics / Mathematics, Management, Communication, Education, etc., and, simultaneously, on the urgency of an epistemological debate in the field of establishing a "possible consensus" on the object, method and language of the IS, in its European matrix of social and human nature and the necessary clarification of its disciplinary relations.

KEYWORDS - Information Science; Epistemology of Information Science; Educational offer; iSchools.

\section{Introdução}

Ao longo dos últimos anos assistimos, em Portugal, a uma mudança paradigmática no domínio da formação dos doravante designados "Cientistas da Informação" (Marques, 2016). Alguns deles, outrora designados de Arquivistas, Bibliotecários, Documentalistas ou Guardiães... partilham as mesmas funções ancestrais de recolha, preservação/conservação e difusão de uma "matéria prima" cada vez mais abundante e, ao mesmo tempo, cada vez mais desperdiçada ou mal utilizada.

Este "novo" profissional, é capaz de produzir, selecionar, avaliar, classificar, organizar e recuperar informação, para além de avaliar o seu impacto e contribuir, direta e indiretamente, para a criação de conhecimento.

Mas, na nossa perspetiva, a vantagem competitiva do "Cientista da Informação”, em relação a outras áreas profissionais (arquivista, bibliotecário, documentalista, museólogo, informático, analista de dados, gestor de sistemas tecnológicos de informação, etc.), e domínios científicos que com ele partilham o mesmo objeto de es- 
tudo, é a sua formação Social e Humanista, que lhe acrescenta um elevado valor, dotando-o das designadas competências "soft" que lhe permitem atuar na mediação entre a informação e as pessoas que a produzem e/ou consomem.

Todavia, a investigação desenvolvida ao nível da análise dos diversos paradigmas formativos existentes, permite-nos confirmar que este não é um tema consensual ao nível da epistemologia da Ciência da Informação $(\mathrm{CI})^{1}$.

A revisão da literatura efetuada e o estudo que levamos a cabo, permitem-nos identificar várias tentativas, que surgiram após os anos 60 do século passado, para definir a CI (Borko, 1968, p. 3; Goffman, 1970; Saracevic, 1996, p. 47; Silva, 2006, p. 140-141), as quais, e apesar de todos os esforços desenvolvidos, confirmam a opinião de Zins (2006, p. 447), quando afirma que:

\begin{abstract}
"apparently, there is not a uniform concept of 'information science'... The concept has different meanings. Different meanings imply different knowledge domains. Different knowledge domains imply different fields. Nevertheless, all of them are represented by the same name, information science. No wonder that even scholars and practitioners are subject to confusion".
\end{abstract}

Assim, o objetivo geral deste capítulo é o de analisar, descrever, perceber, explicar e enquadrar os diversos modelos formativos nos seus devidos espaços geográficos, políticos, económicos, sociais e culturais e, sobretudo, olhar para a informação não apenas como

1 Sobre a perspetiva epistemológica da CI ver os projetos Cranfield (1957 e 1963) e as Conferências do Georgia Institute of Technology (1961 e 1962) que estiveram na origem das suas primeiras definições (Taylor, 1963; Borko, 1968), a análise crítica de Shera e Cleveland e a Copenhagen Conference Theory and Application of Information Research, em 1977. 
uma matéria prima, mas como o objeto de estudo de uma CI de matriz Social e Humanista, com um campo próprio e promissor.

A pergunta de partida a que se pretende acrescentar valor é a de saber o que se espera de um "Cientista da Informação" na Sociedade do Conhecimento: um fornecedor/facilitador do acesso à informação ou um mediador entre o acesso à informação e a produção de conhecimento? Por outras palavras, aquilo que pretendemos confirmar ou infirmar através deste estudo é a natureza conjuntural ou estrutural das tendências da oferta formativa no domínio da CI.

No âmbito deste contexto, convém relevar que o fenómeno da explosão de informação, aliado a uma redução drástica do tempo disponível para a processar, conduziu a humanidade a um novo tipo de analfabetismo, designado por analfabetismo funcional ou iliteracia, o qual tem de ser combatido rapidamente, nomeadamente pelo efeito "mortal" que advém do aparecimento de uma realidade aparentemente nova, que corresponde às chamadas "Fake News".

Ora, consideramos que o "fator novidade desta realidade", restringe-se apenas à designação em si e à rapidez e amplitude da sua propagação, pois serve para caraterizar as notícias falsas que já na Idade Média eram "transportadas e transmitidas" de terra em terra pelos almocreves... e que no século XXI circulam de uma forma torrencial pelas diversas redes sociais, com objetivos de manipulação individual e coletiva muito específicos e sem qualquer tipo de controle ou gestão.

De acordo com esta perspetiva, e, sobretudo, a partir da década de 90 do século passado, a Sociedade em geral assistiu a uma liberalização, também apelidada de "revolução tecnológica", no acesso à informação... processo que idealmente permitiria estreitar laços entre os povos, através de uma redefinição das noções de tempo e de espaço e da construção de pontes de inclusão social.

Neste pressuposto, considerava-se que o livre acesso à informação conduziria a uma maior felicidade e bem estar do ser humano, porquanto conduziria ao seu eficiente e eficaz processamento e, por 
conseguinte, ao aumento da criatividade, da inovação e da produtividade, entendidas como consequências diretas da libertação do homem das tarefas rotineiras e mecânicas, permitindo-lhe aumentar os seus níveis de conhecimento e a sua inerente capacidade de olhar o mundo através de novas lentes.

Assim, pensava-se que o poder de decisão oriundo da possibilidade maciça de acesso à informação, outrora na mão de uma minoria, seria doravante partilhado pela comunidade em geral e transmitido sem restrições ou descriminações de nacionalidade, raça, religião, condição social, etc. Os arautos da Sociedade da Informação viram no desenvolvimento das tecnologias da informação e da comunicação, uma oportunidade para a criação de uma consciência critica social que conduziria ao desenvolvimento sustentável da humanidade.

Ora, pese embora estas boas intenções do século passado, o ser humano rapidamente dominou a máquina e passou a "atirar muita areia para os olhos" dos chamados "nativos digitais" ... seja lá o que isso for... Dessa forma, reinventou novas formas de controlar o poder e de o reduzir a uma nova minoria de privilegiados através da administração autocrática da informação a partir das "torres de marfim" do Silicon Valley americano ou do Shenzhen chinês.

Assim, e contrariamente ao que era suposto, assistiu-se apenas a uma mudança de agentes ou protagonistas, sendo que o valor atribuído pela sociedade industrial ao capital material, deu lugar à valorização do chamado capital informacional, levando ao surgimento de novos grupos de privilegiados que passaram a dominar o poder através do controle da informação e da contra-informação disponibilizada e manipulada.

Mas, e tal como no passado, nunca a importância de recolher, preservar/conservar e difundir informação útil, atualizada, suficiente, original, etc., foi tão crucial como nos dias de hoje e é neste contexto que surge o "Cientista de Informação" entendido como um agente da evolução e desenvolvimento do ser humano. 
Ao segredo profissional de proteção das fontes imposto, por exemplo aos jornalistas e a outros profissionais da Comunicação Social através dos seus Códigos de Ética e Deontologia profissional, os Cientistas da Informação têm como dever proteger os seus autores, os seus produtores, os dados produzidos e, sobretudo, os seus consumidores, doravante designados como Prossumidores ${ }^{2}$, ou seja, os seres humanos ou consumidores da era pós-moderna, ou pós-custodial ou era da informação, que assumem um novo papel na tomada de decisão, na governança e no domínio da produção e da compra de bens e serviços, através de uma participação cidadã consciente, ativa e crítica.

\section{Quais são as propostas dos "melhores" centros de formação em Information Science e CI?}

Não sendo objetivo deste trabalho refletir sobre a missão das Universidades enquanto "agências de emprego", sobre o conceito de determinação de valor, sobre o caráter subjetivo da avaliação ${ }^{3}$, sobre os conceitos de valor absoluto ou relativo dos Rankings, sobre os critérios subjacentes à eleição dos indicadores de avaliação, não podemos deixar de assinalar que na sua base estão sempre questões conjunturais de natureza geográfica, política, económica, social e cultural que determinam a natureza dos inputs, outputs, outcomes, impacts, values ${ }^{4}$ destes instrumentos de medição e da atribuição dos adjetivos de melhor, pior, boa, má... para classificar as universidades, os curricula, etc.

2 Do neologismo originado no inglês Prosumers. Sobre este conceito, ver os trabalhos de Alvin Toffler e de Alvin e Heidi Toffler - "A Terceira Onda" e "A Revolução da Riqueza".

3 Sobre estes conceitos ver Marques, 2012 e 2013.

4 Entradas, Saídas (Base dos modelos de avaliação da década de 80 do século XX), Resultados (Base dos modelos de avaliação da década de 90 do século XX), Impactos ou Benefícios e Valores (Base dos modelos de avaliação a partir da $1^{\text {a }}$ década do século XXI). 


\subsection{QS5 TOP 25 UNIVERSITIES - Movimento das iSchools}

Uma análise detalhada deste ranking permite-nos concluir que 18 destas 25 "melhores" universidades para estudar Library and Information Science enquadram-se no chamado movimento das Information Schools ou iSchools ${ }^{6}$, surgido nos EUA, o qual, apesar de alavancado, inicialmente, na definição de CI de Borko (1968), tem sido bastante "adulterado" ao longo da sua evolução e desenvolvimento nas universidades dos 3 continentes, onde tem uma elevada implantação (Ásia e Oceânia - 23; Europa $-29^{7}$ e América do Norte e do Sul - 48).

5 "The QS World University Rankings by Subject ranks the world's top universities in individual subject areas, covering 48 subjects. The rankings aim to help prospective students identify the world's leading schools in their chosen field in response to high demand for subject-level comparisons". Informação disponível em: https://www. topuniversities.com/subject-rankings/methodology

6 Ver Anexo I - a Bold estão assinaladas as universidades que fazem parte do QS TOP de 2018 e de 2019. De acordo com Larsen (2008), confirma-se a origem norteamericana deste movimento - "iSchools member institutions are listed below by level, followed by senoirity with the organization. These membership levels indicate each school's commitment of support to the organization, and are self-selected. ischools Membership levels": iCaucus (36 - 28 dos EUA, 4 da China, 2 do Canadá, 1 do Reino Unido e 1 da Alemanha); Enabling; Sustaining (6 - 1 dos EUA, 2 das Suécia, 1 da Dinamarca, 1 da Filândia e 1 da Noruega); Supporting ( $4-2$ dos EUA, 1 do Reino Unido e 1 da Coreia do Sul); Basic ( $44-6$ do Reino Unido, 5 dos EUA, 3 da Austrália, 3 da Coreia do Sul, 3 de Espanha, 3 de Portugal, 2 do Canadá, 2 da China, 2 de Taiwan, 1 do Japão, 1 de Hong Kong, 1 da Malásia, 1 da Tailândia, 1 da Nova Zelândia, 1 da Colômbia, 1 do Uganda, 1 de Israel, 1 da República Checa, 1 da Turquia, 1 da Alemanha, 1 de França, 1 da Irlanda, 1 da Holanda, 1 da Dinamarca); Associate (10 - 7 dos EUA, 1 da China, 1 das Filipinas e 1 do Japão). "The Associate category is for schools that are new or may not yet meet the requirements for other levels". Informação disponível em: https://ischools.org/Directory

7 Fazem parte deste movimento ou consórcio internacional 100 universidades, das quais 3 são portuguesas: a Universidade Nova de Lisboa - Information Management School; a Universidade do Minho - ALGORITMI Center School of Engineering e a Universidade do Porto - Faculty of Engineering in cooperation with the Faculty of Arts. 
10 países

23 Universidades

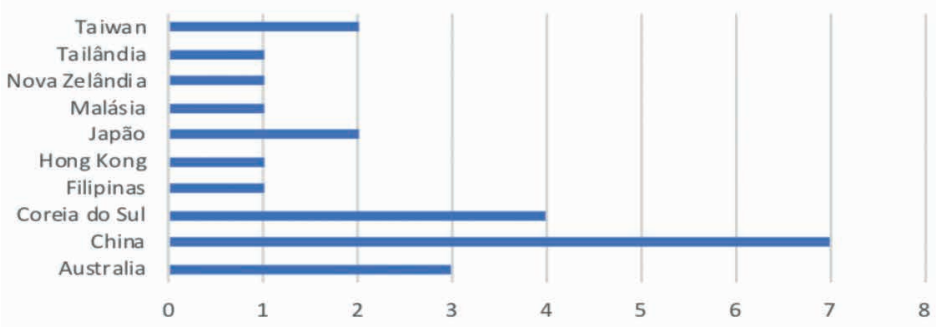

Fig. 1 - iSchools da Ásia e Oceânia

De referir que a Austrália e a nova Zelândia (Oceânia) são países que, neste diretório, estão "associados" à região da Ásia.

15 países

29 Universidades

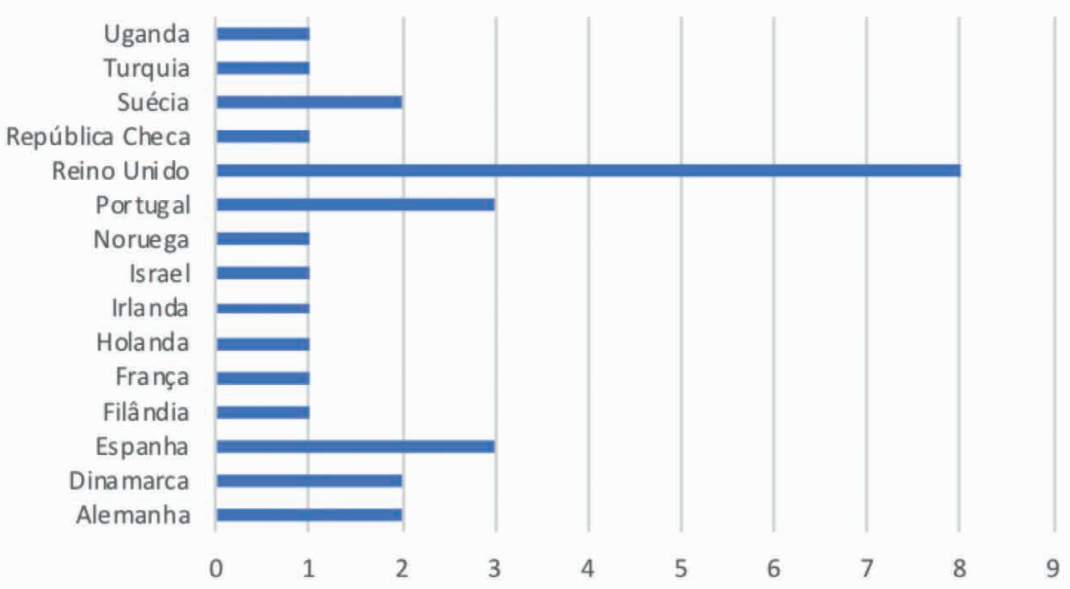

Fig. 2 - iSchools da Europa

De referir que o Uganda (único país do continente africano que pertence a este movimento) e Israel (Ásia) são países que, neste diretório, estão "associados" à região da Europa. 


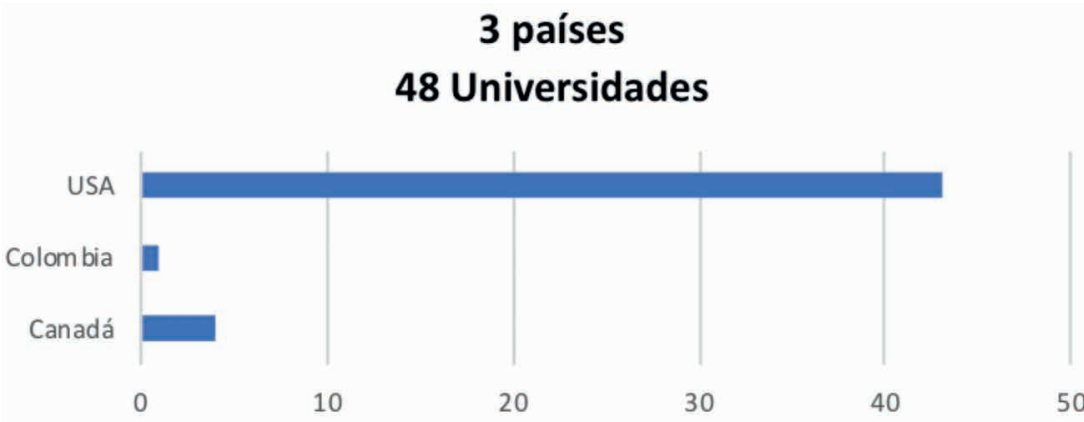

Fig. 3 - iSchools da América do Norte e do Sul

De referir também que a Colômbia (único país da América do Sul que pertence a este movimento) está, neste diretório, associado à região da América do Norte.

Uma das conclusões mais significativas da análise das fig. 4 e 5, que deve ser devidamente assinalada, é a presença do monopólio dos EUA e das universidades norte-americanas na visão da CI de base Tecnológica ou como uma "ciência social rigorosa" (Le Coadic, 1996, p. 22), ilustrada neste movimento das iSchools.

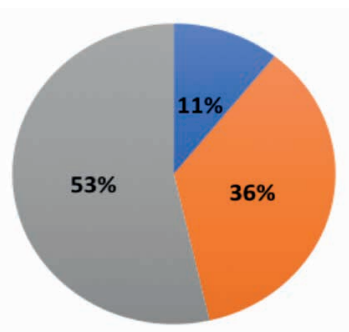

- América do Norte e do Sul

Ásia e Oceania

Europa

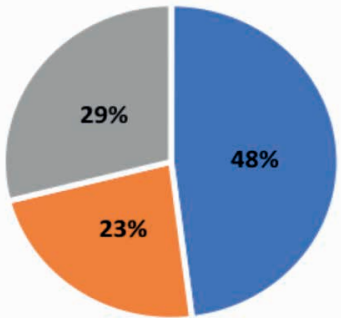

- América do Norte e do Sul

- Ásia e Oceania

- Europa

Fig. 4 e 5 - Representatividade percentual dos países/universidades no movimento das iSchools 
Assim, e se analisarmos comparativamente estes dois gráficos, facilmente concluimos sobre a predominância do "paradigma físico" (Capurro, 2003) ou tecnológico da CI, vigente na grande maioria das universidades norte-americanas que fazem parte deste movimento, em "relação contrária" às eventuais tendências da investigação desenvolvida nas universidades europeias.

Pois, e apesar de se verificar uma maior representatividade, em termos quantitativos, de países europeus neste movimento, a sua grande dispersão, torna pouco significativa a amostra dos modelos formativos da CI na Europa. Acresce o facto de, e a título de exemplo, não encontrarmos nenhuma universidade italiana neste movimento, e do monopólio europeu se centrar em universidades inglesas e do norte da Europa.

Por outro lado, e passível de confirmação, também pode dar-se o caso da pouca adesão das universidades europeias a este movimento das iSchools resultar do facto de desenvolverem os seus modelos formativos em CI com base no paradigma Humanista e Social.

Importante será assinalar que esta proposta de fundamentação da formação em CI com uma forte componente tecnológica, que aposta no saber fazer, em detrimento do conhecer o quê, o porquê, o como, o para quê e para quem se faz, poder confundir e criar diversos equívocos concetuais porquanto aplicada a realidades que, e tal como refere Williams (1987/1988), são substancialmente diferentes, e têm implicações diretas no conceito de Gestão da Informação:

"(...) information science brings together and uses the theories, principles, techniques and technologies of a variety of disciplines toward the solution of information problems. Among the disciplines brought together in this amalgam called information science are computer sciences, cognitive science, psychology, mathematics, logic, information theory, electronics, communications, linguistics, 
economics, classification science, systems science, library science and management science. They are brought to bear in solving the problems with information - its generation, organization, representation, processing, distribution, communication and use" (p. 17-19).

Por conseguinte, não devemos concluir que o paradigma da CI de base tecnológica é "o melhor" ou, tão pouco, corresponde a um desenvolvimento e afirmação estratégica deste domínio científico. Pelo contrário, devemos contextualizar e desenvolver uma análise crítica deste movimento das iSchools, surgido nos EUA ${ }^{8}$ no âmbito de um contexto altamente concorrencial e de uma visão essencialmente pragmática, de origens remotas, e que sempre privilegiou o saber fazer, o bom desempenho das "tarefas", em detrimento do conhecer ${ }^{10}$ e que nos parece ter tido como objetivo prioritário o de alargar o horizonte profissional do mercado de trabalho dos tradicionais Arquivistas e Bibliotecários através do "estabelecimento de relações entre informação, tecnologia e pessoas".

Ora, é exatamente esta ordem pré estabelecida por este movimento, que não nos parece acidental, que vai determinar as suas prioridades e que pode conduzir ao chamado Capitalismo Informacional... tão criticado por Casttels (1999).

8 Desde 2005, "the iSchools consortium seeks to explore critical information issues in contemporary society and now consists of more than 90 members worldwide, including the North America, Europe, Asia Pacific. The iSchools consortium hosts its annual meeting, iConference, providing researchers, faculty, and students with opportunities for sharing their research results that focused on the concepts of "information," "technology," and "people." Informação disponível em: https://www.lis. ntu.edu.tw/english/?p=737

9 Sobre as raízes do modelo de pensamento administrativo americano ver Taylor, F. W. (1911). Principles of Scientific Management. Nova Iorque: Harper \& Row.

10 Uma leitura atenta dos princípios desta visão pragmática das organizações e da organização racional das tarefas do Taylorismo, nomeadamente o seu conceito de homem máquina, permitenos avançar com algumas considerações sobre o futuro deste tipo de formação em Ciência da Informação... nomeadamente o esvaziamento ou enfraquecimento do seu objeto, método e linguagem e a sua asfixia por outras áreas científicas, como a Informática. 


\subsection{QS TOP 25 UNIVERSITIES - 2018}

Pese embora as ressalvas assinaladas anteriormente, de acordo com os dados de 2018 do QS TOP UNIVERSITIES ${ }^{11}$, as 25 melhores universidades do mundo para estudar Library and Information Science situam-se, maioritariamente, no mundo anglo-saxónico. Os indicadores avaliados neste Ranking são: a reputação da universidade; o reconhecimento das entidades empregadoras; as citações por artigo; o índice de citações ${ }^{12}$.

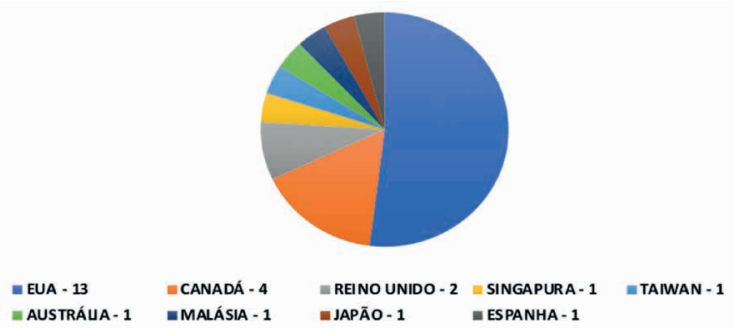

Fig. 6 - QS TOP 25 UNIVERSITIES 2018

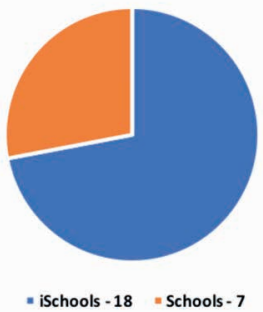

Fig. 7 - Representatividade das iSchools no QS TOP 25 UNIVERSITIES 2018

11 Disponível em: https://www.topuniversities.com/university-rankings/universitysubject-rankings/2018/library-information-management

12 "Each of the subject rankings is compiled using four sources. The first two of these are QS's global surveys of academics and employers, which are used to assess institutions' international reputation in each subject. The second two indicators assess research impact, based on research citations per paper and h-index in the relevant subject. These are sourced from Elsevier's Scopus database, the world's most comprehensive research citations database. These four components are combined to produce the results for each of the subject rankings, with weightings adapted for each discipline". Informação disponível em: https://www.topuniversities.com/subject-rankings/methodology. 
18 melhores iSchools do mundo para estudar $\mathrm{Cl}$

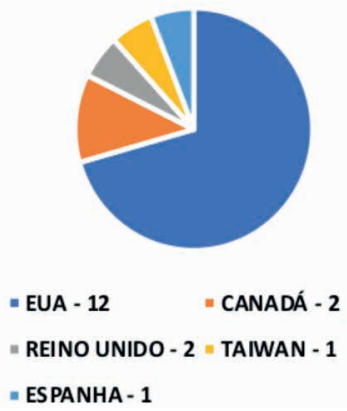

7 melhores Schools do mundo para estudar $\mathrm{Cl}$

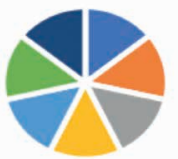

- EUA - 1

- REINO UNIDO - 1

= SINGAPURA-1 1 AUSTRÁUA-1

- CANADÁ - 1 = JAPÃO - 1

- MALÁSIA - 1

Fig. 8 e 9 - Análise das iSchools e das Schools no QS TOP 25 UNIVERSITIES 2018

\subsubsection{RANKING - 25 UNIVERSITIES - $2018^{13}$}

\section{University of Sheffield - www.sheffield.ac.uk/is}

A Universidade inglesa de Sheffield, não oferece cursos de licenciatura nesta área científica. Ao nível da oferta de pós-graduação a Escola de Informação, integrada na Faculdade de Ciências Sociais, disponibiliza vários cursos de mestrado - https://www.sheffield. ac.uk/is/pgt/courses - de pendor predominantemente tecnológico, supervalorizando a informação de natureza digital e estabelecendo uma clara distinção entre a Information Science e a Biblioteconomia. Oferece um Curso de doutoramento com diversos tópicos ou linhas de investigação ${ }^{14}$.

$\mathrm{Na}$ análise efetuada não se localizou nenhuma informação sobre propostas de formação em Arquivologia.

13 Encontram-se sublinhadas as Universidades que não fazem parte do movimento das iSchools.

14 Consultar: https://www.sheffield.ac.uk/is/pgr/apply/phdtopics 
= 1. University of North Carolina, Chapel Hill: School of Information and Library Science - www.sils.unc.edu

A School of Information and Library Science da Universidade norte-americana de North Carolina, Chapel Hill, oferece uma formação que pretende resolver os problemas relacionados com a criação, o fluxo e o uso da informação:

“(..) our graduates then design and develop systems and services to help people find information and create new knowledge in a variety of settings. Information professionals help people filter vast arrays of data and information that streams to them every minute and evaluate the usefulness of information sources. Information professionals manage collections of text, code, imagery and other forms of data in large and small organizations and businesses.”

Afirmando-se como um Mix de Humanidades e Tecnologias, esta universidade oferece formações nos 3 ciclos de estudo: licenciatura, mestrado e doutoramento. Ao nível da licenciatura, é visível, através das oportunidades de carreira previstas para os titulares deste grau académico, a sua orientação científica:

"Graduates assume a variety of job titles, including: Business Analyst; UX (User Experience) Architect; Database Designer; Information Security Specialist; Software Engineer; Systems Manager; Web Developer; Technology Consultant.”

O mesmo se verifica ao nível dos programas de mestrado e de doutoramento, nomeadamente no Master of Science in Library Science (MSLS) e no Master of Science in Information Science (MSIS), onde, para além de estabelecerem uma clara distinção entre Biblioteconomia e Information Science e de incluirem as compe- 
tências em Arquivos neste "chapéu"15, têm como pré-requisitos de admissão as competências em Tecnologias da Informação.

Também ao nível dos mestrados, e apesar da multiplicidade de necessidades do mercado que pretende satisfazer, é visível, através das oportunidades de carreira previstas para os titulares deste grau académico, a mesma orientação científica ${ }^{16}$.

O ponto forte do MSLS parece-nos residir nas especializações previstas:

"Academic Libraries; Adult Services in Public Libraries; Archives and Records Management; Children and Youth Services; Digital Libraries; Organization of Information and Materials ; Reference ; School Library Media Coordinator; Special Libraries and Knowledge Management".

Só ao nível do doutoramento em Information and Library Science é que assistimos ao anunciado Mix entre as Humanidades e as Tecnologias, mantendo-se todavia a distinção entre o que é a Information Science (de natureza tecnológica) e a Library Science (de natureza mais Social e Humanista).

15 A formação em Arquivos é apresentada como uma área de formação concentrada que não confere o grau de mestre, ainda que permita o acesso a um destes 2 Mestrados - "Preparation for a career in archives and records management is not associated specifically with either one of the master's degrees at SILS. Job titles of recent graduates who completed the ARM concentration: Library and Archives Manager/Chief Archivist, Nantucket Historical Association; Metadata Specialist for Digital Indy Grant; Archives Technician at National Archives and Records Administration; Program Coordinator/Digital Collections Specialist in Learning Sciences, Vanderbilt University; Archivist, City of Vancouver; Digital Archivist/Assistant Professor, University of Montana; Digital Archivist, Apollo Theater, New York; Digital Archivist at North Carolina Department of Natural and Cultural Resources; Reference, Instruction and Digital Services Librarian at John J Burns Library, Boston College; Project Cataloger at Folger Shakespeare Library".

16 "Job titles of recent MSLS graduates" disponível em: https://sils.unc.edu/programs/ graduate/msls 


\section{University of Illinois at Urbana-Champaign:}

\section{School of Information Sciences - https://ischool.illinois.edu}

A School of Information Sciences da Universidade norte-americana de Illinois at Urbana-Champaign, apenas oferece cursos de licenciatura na área das Bibliotecas Escolares e que permitem, a par de outras formações, o acesso ao mestrado na mesma área de especialização.

Apesar da maior flexibilidade do seu Currículum, a perspetiva desta escola, é muito próxima das anteriores: oferece 2 mestrados e um doutoramento na área da CI - MS in Library and Information Science; MS in Information Management e PhD in Library and Information Science.

Mantêm-se uma visão dicotómica entre a Biblioteconomia, a Information Science e a Gestão da Informação. Esta visão é patente nos nichos do mercado a que se destinam os dois mestrados. O primeiro a Archivist, Children's Librarian, Competitive Intelligence Analyst, Information Architect, Information Technology Manager, Library Director, Reference Librarian, Rights and Reproductions Coordinator, User Experience Designer, Web Developer, e o segundo a Cybersecurity Analyst, Data Scientist, Digital Content Manager, Director of Information Services, Information Consultant, Knowledge Manager, Senior Digital Product Manager, Strategic Research Consultant, Taxonomist/Ontologist, User Experience Researcher.

Estas duas formações oferecidas ao nível do mestrado têm estruturas semelhantes, mas especialidades totalmente distintas ${ }^{17}$.

17 O "MS in Library and Information Science" assenta em 2 áreas obrigatórias "Information Organization and Access" e "Libraries, Information, and Society" e várias disciplinas opcionais: "Archival and Special Collections, Youth and K-12, Information Organization and Management, Research and Information Services, Data and Asset Management e Knowledge Management and Competitive Intelligence". O "MS in Information Management" assenta em 3 áreas obrigatórias - "Information Modeling (IS 561)", "Data, Statistical Models and Information (IS 542)", and "Sociotechnical Information Systems (IS 543)" e várias opcões: "Data Science and Analytics, Privacy, Trust, Security, and Ethics, Information Architecture and Design e Knowledge Management and Information Consulting”. 
Ao nível do doutoramento em Library and Information Science, esta escola recebe alunos de várias formações académicas e propõe-se "responds to new social and technological opportunities for producing, disseminating, and accessing information".

O doutoramento oferece 2 cursos semestrais obrigatórios: um em History and Foundations of LIS e o outro em Research Design in LIS. Mais uma vez, e de acordo com as ofertas do mercado de trabalho ocupadas por estes graduados podemos verificar a linha de orientação científica privilegiada:

Faculty members at institutions such as the University of Michigan, Florida State University, University of Washington, University of Texas-Austin, and UCLA; Research and development professionals at Microsoft and Google; Academic library professionals at Princeton University, the University of Chicago, and the University of Missouri at Columbia; Digital Asset Managers and Strategists; Digital Scholarship Librarians; Data Scientists; Research Scientists; Research Consultants.

\section{University of British Columbia:}

The School of Library, Archival \& Information Studies (UBC) - https://www.grad.ubc.ca/prospective-students/ graduate-degree-programs

A grande mais valia desta Universidade canadiana parece-nos ser o facto de incluir, explicitamente, a formação em Arquivos, nomeadamente através da sua própria designação - Escola de Arquivos, Bibliotecas e Informação da Faculdade de Artes da Universidade de British Columbia. Também não oferece o grau de licenciatura, recomendando como possibilidade de acesso ao grau de mestre, a licenciatura em Media Studies. Este programa 
independente de estudos em Arquivologia, é considerado por muitos como o melhor do Canadá e um dos melhores do mundo.

Em relação a ofertas de segundo ciclo de estudos, e de acordo com a informação disponível na sua página web, ela é muito diversa e flexível, permitindo o desenho de várias oportunidades de carreira.

Este é o primeiro programa de mestrado em Arquivos da América do Norte e foi oferecido pela UBC a partir de 1981. O mestrado em Archival Studies com 48 ECTS, tem um programa bastante especializado - Archival Diplomatics (3 credits); Arrangement And Description Of Archival Documents (3 credits); Management of Current Records (3 credits); Archival Systems and the Profession (3 credits); Archival Diplomatics (3 credits).

Oferece também um mestrado em Library and Information Studies, com 6 áreas de especialização, Librarianship, "First Nations Curriculum Concentration, Data services, Community and culture, Information interaction and design, Designing for People" e o designado Dual degree MAS/LIS que dura 28 meses e é um programa interdisciplinar "in which students complete two graduate degrees within an accelerated timeframe". Oferece ainda um mestrado em Children's Literature.

Assim, verifica-se ao nível da oferta formativa dos segundos ciclos de estudo, uma clara distinção entre Arquivos e Bibliotecas, o que, para além de ser uma visão muito tradicional... ou custodial da CI, também nos parece pouco consentânea com os pressupostos do consórcio das iSchools onde está integrada, assumindo-se como uma das poucas exceções neste movimento.

O doutoramento em Libray, Archival and Information Studies, foi criado muito recentemente. Tem uma duração de 4 anos e 5 áreas de especialização "human information interaction and design, knowledge organization, digital archives/media, language processing, data and more". 


\section{Indiana University Bloomington:}

\section{School of Informatics, Computing, and Engineering - https://www.indiana.edu}

Esta Universidade norte-americana ${ }^{18}$, oferece um mestrado e um doutoramento em Information Science, ministrado pela School of Informatics, Computing, and Engineering, onde está sediado o Departamento em Information and Library Science.

O mestrado em Library Science tem diversas especialidades: Archives and Records Management; Art Librarianship; Children's and Young Adult Services; Data Science; Digital Curation; Digital Humanities; Digital Libraries; Information Architecture: Music Librarianship; Rare Books and Manuscripts.

Também é oferecido por esta universidade um curso de especialista em Library and Information Science (SP.L.I.S.), de 30 ECTS.

\section{University of California, Berkeley (UCB): School of Information - https://www.berkeley.edu}

A Escola de Informação desta Universidade norte-americana oferece um mestrado e um doutoramento em Information Management and Systems (MIMS), um mestrado em Information and Data Science (MIDS) e outro em Information and Cybersecurity (MICS).

Os 2 primeiros prevêm como outcomes a intersecção entre a "technology, people, and information", todavia, as competências adquiridas por estes estudantes situam-se em domínios muito especializados como "data analysis and modeling, machine learning, product management, data visualization, user experience research,

18 A título de curiosidade, esta universidade norte-americana, oferece uma licenciatura, um mestrado e um Doutoramento em Língua Portuguesa. 
user interface design, policy and legal research, cybersecurity, software development, business strategy, information organization and retrieval, and entrepreneurship".

Apesar do doutoramento aceitar candidatos com diversos perfis, "some will be technically educated, some educated in the humanities and social sciences", uma breve análise das teses produzidas e dos conteúdos previstos, permite-nos concluir sobre a sua tendência altamente tecnológica e muito longe da CI, tal como a entendemos (Marques, 2017 e 2018) - "Major and minor areas include: HumanComputer Interaction; Information Economics and Policy; Information Law and Policy; nformation Organization and Retrieval; Information Systems Design; Social Aspects of Information; Information and Communication Technologies and Development."

O MIDS tem como áreas nucleares "Research Design; Data Cleansing; Data Engineering; Data Mining and Exploring; Data Visualization; Information Ethics and Privacy; Statistical Analysis; Machine Learning."

\section{University of Washington: The Information School - https://ischool.uw.edu}

Esta Universidade oferece uma grande e diversificada oferta formativa, todavia a Information Science também não é considerada uma Ciência Social e Humana. A Escola de Informação da Universidade de Washington oferece várias formações, cujo teor é paradigmático do que entendem por Information Science: licenciatura em Informatics, mestrados em Library and Information Science e Science in Information Management, um doutoramento em Information Science.

De acordo com a informação disponível na sua página web, o mestrado em Library and Information Science pretende fornecer 
competências "to thrive in any knowledge-intensive industry".... tendo como foco do curriculum "emphasizes knowledge organization theory and design thinking and creates a framework on which you can build throughout your career. Courses provide a foundation on how information is organized, stored, searched and used, along with important technological, policy, research, management and design concepts”.

Mais uma vez, o denominador comum entre as ofertas formativas da maioria das Universidades norte-americanas é a preocupação em fazer a ponte entre a formação ministrada e o mercado de trabalho. Assim, e através deste denominador, é possível verificar o acentuado pendor tecnológico e o espírito pragmático da formação ministrada ao nível do mestrado, presencial ou online:

Archives and Special Collections Librarian; Digital Librarian; Learning Resource Center Librarian; Reference Librarian; School Librarian; Research Librarian; Adult or Youth Services Librarian; University Library Director; Metadata Specialist; Competitive Intelligence Analyst; Consultant; Business Analyst; Information Architect; Web Content Manager; Digital Literacy Specialist; Knowledge Management Specialist; Project Manager; Senior Program Manager; Taxonomist.

Relativamente ao mestrado em Information Science, os objetivos são também muito claros: A master's in information management can specialize in data science, information security $\&$ other areas of expertise. Offered in full-time and mid-career modes.

No que diz respeito ao doutoramento oferecido, são várias as áreas de especialização:

Data, People, Decisions (DPD); Digital Youth; Information Literacy; Information Management; Information Technology for Social 
Change (IT/Social Change); Information, Values, Policy, Ethics; Knowledge Organization; Libraries and Librarianship; Social Impact and Evaluation; Social Media; User Experience and Human Computer Interaction (UX/HCI).

\section{Loughborough University - https://www.lboro.ac.uk}

A Universidade inglesa de Loughborough, é a primeira Universidade deste Ranking que não faz parte do movimento das iSchools. Foi considerada como a Universidade do Ano pelo The Times and Sunday Times University Guide 2019.

É curioso observar que, e pela primeira vez neste Ranking, a oferta formativa no domínio da CI, está concentrada na área das Ciências Humanas e Sociais, maioritariamente, na School of Business and Economics, nomeadamente na licenciatura em Information Management and Business, no mestrado em Information Management and Business Technology e no doutoramento em Information Science - que managing business relationships, IT systems, data science and information architecture to name a few. It is designed to develop you into a 'bybrid' manager who is able to bridge the gap between technical and managerial perspectives and is equipped with the technical, professional and management knowledge and skills needed by employers.

De acordo com esta perspetiva, o Doutor em Information Science é alguém que combina as necessidades das organizações no domínio da condução racional das suas atividades, com as ferramentas tecnológicas, muitas delas desenvolvidas na área das Ciênciaa da Computação, nomeadamente na licenciatura em Information Technology Management for Business, em que permitem a agilização dos processos com o objetivo de aumentar a sua eficiência e eficácia: 
We take pride in teaching you how relevant and inspiring research can be used in practice to solve real world problems. The use of guest lecturers from industry and not-for-profit organisations belps to embed this real-world perspective. You should also be able to demonstrate knowledge and understanding in the following areas:

The principles and practice of information and business technology management.

The relationship between traditionally technology-independent areas of an organisation and non-technical business areas.

Assim, o doutoramento do Centro de Information Management da School of Business and Economics pretende to undertake internationally recognised research for the benefit of the individual, organisations, government and society. In particular the Centre aims to evidence the significance and value of information; challenge thinking and practice around information management; and improve performance through analysis, interpretation and judgement of information.

\section{University of Pittsburgh: School of Computing and Information - https://www.pitt.edu}

Esta Universidade norteamericana, e mais uma vez, concentra toda a formação em Library and Information Sciences na School of Computing and Information. A oferta formativa abrange os três Ciclos de Estudo: a licenciatura, o mestrado e o doutoramento em Information Science e o mestrado e o doutoramento em Library and Information Science.

A licenciatura, tem 4 áreas de estudo determinantes: MAKING IT SECURE; COMPUTING WITH A HUMAN FOCUS; THE CHALLENGE OF BIG DATA e THE WIRELESS WORLD e seis especializações - General, 
Big Data Analytics, Dtabase and Web Systems, Geoinformatics, HumanCentered Computing, Information Security e Telecommunications and Distributed Systems.

Apesar de considerarem que os Profissionais da Informação are the buman element that connects people, information, and technology, e de afirmarem que Our graduates have careers not only in the library, archive and museum settings, but in government, corporate, non-profit, and entrepreneurial environments as well... uma análise detalhada dos conteúdos do mestrado oferecido em Library and Information Science, na modalidade presencial e online, permite-nos concluir sobre o seu foco central:

LIS 2020 Lifecycles of Data and Information (to be taken in the first term) LIS 2030 Data and Information in Systems (to be taken in the first term) LIS 2040 The Information Professional in the Community (to be taken in the third term)

The Design Methods Sequence to be taken in three consecutive terms (Fall, Spring, Summer):

LIS 2021 Identifying Information Needs of Knowledge Organizations LIS 2022 Implementing Solutions for Knowledge Organizations LIS 2023 Integrating Solutions for Knowledge Organizations

De acordo com as competências adquiridas propõem que $M L I S$ graduates will be able to:

Identify and communicate the ethical and historical foundations and core values of the information professions, data professions, and related disciplines.

Apply principles of the management of information and organizations to various functions in data and information environments. Select, plan, implement, and apply information technology using creative, contextualized, and ethical approaches. 
Design, plan, implement, evaluate, and advocate for information services that embody a commitment to inclusion and dedication to underrepresented and marginalized users and communities.

Understand and apply research in library, archival, museum studies, information science, data science, and stewardship, as well as other disciplines.

Develop and advance the contribution of the information professions to society through advocacy, continuing education, and lifelong learning for information professionals and the communities they serve.

Pelo exposto, e apesar de anunciarem que Aside from the required core courses that all students must take, there is flexibility to personalize a program of study that meets a particular area of interest. There are certain thematic areas for which faculty advisors may suggest appropriate courses. Samples of some of these potential thematic areas have been provided. It not necessary to follow any one of these suggested clusters of courses... são facilmente percetíveis as prioridades desta oferta formativa.

A novidade deste programa reside no facto de fazerem uma distinção clara, nos 2 mestrados e doutoramentos oferecidos, entre a Information Science e a Library and Information Science. A título de exemplo, no caso do doutoramento em LIS, são contempladas as seguintes oportunidades:

Archives and Information Science: For doctoral students interested in pursuing academic careers in the archives area, with a focus on digital preservation or curation and archival ethics, accountability, and appraisal issues.

Information Behavior: For doctoral students who seek to understand how people plot a course through complex information ecologies including digital environments, and how such ecologies 
can respond to their ways of thinking, feeling, and valuing. A special emphasis is placed on behaviors of children and youth. Health Information Behavior and Health Education Interventions: For doctoral students who wish to investigate the information practices and behaviors of health professionals, patients, caregivers, and consumers.

Social Information Systems: For doctoral students who will investigate issues related to the design and use of social information systems, focusing on the impact of social media on people's information behavior. Web-based Information Systems: For doctoral students interested in studying, designing, and implementing web-based systems for representing, retrieving, extracting, and disseminating relevant information.

School Librarianship: For doctoral students interested in teaching, research, and administrative experience in a top-ranked, competency-based School Library Certification Program designed for school librarians and school library supervisors.

\section{University of California, Los Angeles (UCLA): Graduate School of Education and Information Studies - http://www.ucla.edu}

Apesar de pertencer ao movimento das iSchools, esta universidade parece-nos representar uma das poucas exceções da realidade norteamericana que consta neste Ranking.

Tem um Departamento específico de Estudos da Informação integrado na Escola de Educação e Estudos de Informação, a qual visa repensar as relações entre a tecnologia e a cultura e pretende que os Graduates of our programs are making the world a better place by improving the ways in which information is preserved, accessed, and used. 
Oferece a number of courses that provide undergraduate students with a blend of conceptual and theoretical knowledge and practical, hands-on laboratory experiences, com diversas áreas de especialização, entre as quais se encontram: Information and Power; Fiat Lux Freshman Seminars; Digital Cultures and Societies; Internet and Society; Honors Seminars; Variable Topics in Information Studies; Student Research Program...

Oferece também um mestrado e um doutoramento em Library and Information Science totalmente independentes da área da Informática e das Tecnologias da Informação.

O mestrado é orientado para a prática profissional e tem 5 áreas de especialização: Archival Studies; Informatics; Library Studies; Media Archival Studies; Rare Books e Print and Visual Culture.

Os objetivos do programa de doutoramento parecem-nos muito claros:

Researchers in information studies seek to understand the ways in which information in all its forms is produced, recorded, organized, preserved, retrieved, communicated, managed, and used, and the ways in which people's information-related activity shapes - and is shaped by - information technologies, information structures, and information institutions such as libraries, archives, and museums. The answers to the research questions posed in information studies help to improve information systems and services, to guide information policy, and to enrich life in today's information society.

Neste contexto, os cursos oferecidos por este programa doutoral são muito diversificados e, em nossa opinião, muito completos, verificando-se uma identificação muito rigorosa da natureza Trans e Interdisciplinar da CI:

"inquiry in the theory and methodology of information studies, focusing on information-related artifacts (e.g., documents, texts, 
images, records, collections), agents (e.g., producers, managers, seekers), contexts (e.g., cultural, economic, legal, social, technological), institutions (e.g., organizations, professions, disciplines), practices (e.g., production, design, recording, representation, organization, replication, preservation, retrieval, communication, management, interpretation, use, destruction, policymaking), properties (e.g., authenticity, authorship, identity, reliability, trustworthiness, truth), values (e.g., aesthetic, ethical, functional), and related phenomena (e.g., data, evidence, heritage, knowledge, memory, and misinformation).

\section{McGill University, Montreal: School of Information Studies https://www.mcgill.ca}

Esta Universidade canadiana, que também faz parte do movimento das iSchools, tem uma Escola de Estudos de Informação, totalmente autónoma da Escola de Ciências da Computação, com uma oferta formativa muito diversificada e que denota uma identificação muito rigorosa da natureza Trans e Interdisciplinar da CI:

Master of Information Studies with areas of specialization in Library Studies, Knowledge Management, Information and Communication Technology, and Archival Studies/Records Management; a PhD in Information Studies; and several Graduate Certificates - Graduate Certificate in Digital Archives Management; Graduate Certificate in Information Architecture; Graduate Certificate in Information $\mathcal{E}$ Knowledge Management e um Graduate Certificate in Library $\mathcal{E}$ Information Studies.

O programa do mestrado, para além de permitir a não obrigatoriedade de elaboração de uma dissertação, admite a possibilidade da realização de 18, dos 48 ECTS noutras áreas científicas, incluindo, 
ainda que a título de exceção, noutras Universidades do Quebec. Desta forma, os alunos podem escolher, verdadeiramente, a sua área de especialização, de acordo com os seus interesses individuais.

No que diz respeito ao doutoramento, os alunos têm algumas unidades obrigatórias como GLIS 701 Comprehensive Examination (O credits); GLIS 702 Seminar in Information Studies (3 credits); GLIS 703 Research Paradigms in IS (3 credits); GLIS 704 Research Design in IS (3 credits) e GLIS 705 Readings in IS (3 credits). Tal como acontece no mestrado, os doutorandos podem escolher áreas de especialização fora da Universidade ou da escola, nomeadamente:

REDM 610 Writing Science Articles 1 (3 credits). Offered by: Redpath Museum, Faculty of Science. Administered by: Graduate Studies REDM 710 Writing Science Articles 2 (3 credits). Offered by: Redpath Museum, Faculty of Science. Administered by: Graduate Studies EDPH 689 Teaching and Learning in Higher Education (3 credits). Offered by: Educational \& Counselling Psychology, Faculty of Education. Administered by: Graduate Studies.

= 11. University of Toronto: Faculty of Information - https:// www.utoronto.ca

Esta Universidade canadiana, também tem uma Faculdade de Informação e uma visão mais Social e Humana da CI. Oferece um mestrado e um doutoramento em Informação, cujas áreas de concentração são:

\section{- MESTRADO}

Archives and Records Management (ARM)

Critical Information Policy Studies (CIPS)

Culture and Technology (CET)

Information Systems and Design (ISD) 
Knowledge Management and Information Management

(KMIM)

Library and Information Science (LIS)

User Experience Design (UXD)

\section{- DOUTORAMENTO}

Archives and Records Management

Critical Information Policy Studies

Cultural Heritage

Information Systems and Design

Knowledge Management and Information Management

Library and Information Science

Philosophy of Information

Tem como particularidade um grande espírito pragmático, patente no facto de oferecer Diplomas de pós-graduação para quem não quiser fazer a dissertação de mestrado e Diplomas em Estudos Avançados no Estudo da Informação para os mestres e que se destinam a quem deseje aprofundar os estudos, mas não pretenda fazer o doutoramento:

Human Values in Data Science

Special Topics in Information Studies: Ethics, Vulnerable

Population and Information Science

Experimental Design for Data Science

Introduction to Statistics for Data Science

Global Cultures and Museums

Special Topics in Museum Studies: The Digital Museum: From

Strategy to Implementation (OSC)

Modules of Knowledge Media Design

Fundamentals of User Experience

Introduction to Computational Thinking 
Special Topics in Information Studies: Program Evaluation and Measurement

Special Topics in Information Studies: Designing for Knowledge

Work

Constructing and Curating Digital Heritage

Cooperative Education Placement III

Cooperative Education Placement II

Cooperative Education Placement I

Special Studies

Seminar in Identity, Privacy and Security

Technologies for Knowledge Media

Special Topics in Information Studies: Archival Leadership

The Photographic Record

Uma outra curiosidade desta Faculdade de Informação e que nos pode conduzir à perspetiva holística e à visão sistémica da informação que advogamos, é o facto de ter a particularidade de também oferecer estudos de mestrado em Museologia, o que é, ou pode ser, de per se, significativo da sua visão da CI.

\section{Rutgers, The State University of New Jersey: School of Communication and Information - https://comminfo.rutgers.edu}

Esta universidade norteamericana tem uma Escola de Comunicação e Informação, o que é, ou também pode ser, de per se, significativo da sua visão da $\mathrm{CI}$, no que diz respeito à sua aproximação à Ciência da Comunicação. Pretende preparar alunos interessados em organizational communication, social and new media, library and information science, and information technology for a top 
career in today's digital workplace. É constituída por 3 Departamentos: Communication, Journalism and Media Studies e Library and Information Science (DLIS).

Esta escola oferece 3 licenciaturas - Comunicação, Tecnologia da Informação e Informática (oferecida pelo DLIS, tendo The ITI major unites theories drawn from the humanities and social sciences with practical computer-based competencies) e Jornalismo e Estudo dos Media -, e 2 Menores interdisciplinares - Comunicação Digital, Informação e Media e Género e Media.

O DLIS, oferece também um mestrado em Informação, de natureza muito eclética e com um curriculum bastante flexível, e que tem como áreas de especialização: Library and Information Science; School Librarianship; Data Science: Informatics and Design Technology, Information and Management; and Archives and Preservation 19 .

O doutoramento em Library and Information Science tem também várias áreas de especialização: Human Information Behavior; Information Retrieval, Language and Communication; Information Agencies and Artifacts; Learning, Youth, Information and Technology; and Social and Community Informatics ${ }^{20}$.

\section{Syracuse University: School of Information Studies - https://www.syracuse.edu}

Esta universidade é formada por 13 escolas e colégios. A Escola de Estudos da Informação prepara os estudantes for a fast-paced digital future by teaching the technological, communication, man-

19 Ver https://comminfo.rutgers.edu/academics/graduate/master-information/ program-information/master-information-program-concentrations

20 Ver https://comminfo.rutgers.edu/academics/graduate/phd-program/areasand-concentration/phd-lis-concentration 
agement, and design skills necessary to develop solutions for any industry or to launch your own startup.

Oferece uma licenciatura em Information Management and Technology com diversas áreas de concentração que, e apesar da possibilidade permitida aos alunos de fazer um menor noutras áreas científicas, permitem-nos identificar novamente uma ligação direta com as Ciências da Computação - Information Security, Project Management, Network Management, Web Design and Management, Data Analytics e Digital Retail Strategie. Os estudantes são educados to understand the value of information to society, organizations, and individual professionals. Students are prepared to analyze the information needs of individuals and organizations and to design and manage information systems that meet specific needs.

Oferece 5 mestrados que também podem ser frequentados em regime de eLearning ${ }^{21}$ : o de Library and Information Science (LIS) que se centra no estudo on the users of library and information services. Keeping the needs of users-and potential users-of library and information services in the foreground is a fundamental value of librarianship; Use technology to provide exemplary library and information services. Librarians need to be able to use technology effectively to provide quality library and information services; Manage information services and systems. Librarians in the 21st century must be competent managers of information, capable of innovation, efficiency, and leadership to meet the needs of their clientele; o de Library and Information Science with a specialization in School Media; e os de Information Management, Applied Data Science e Enterprise Data Systems com ligações diretas com as Ciências da Computação.

Oferece também 7 cursos de especialização/atualização, para os estudantes que não pretendam seguir para o doutoramento, sendo

21 Ver https://ischool.syr.edu/academics/graduate/masters-degrees/ 
quase todos, eventualmente com uma exceção - School Media -, direcionados para a área das Tecnologias da Informação e Comunicação.

O doutoramento em Information Science and Technology diz-se como sendo human-centered, rather than computer science and computer engineering, and more technologically-oriented than most programs in psychology, sociology, communications and business, todavia as 10 áreas de especialização têm todas subjacente o paradigma físico ou tecnológico da CI. ${ }^{22}$

\section{University of Texas at Austin: School of Information - https://www.utexas.edu}

Esta Universidade também tem uma Escola de Informação que oferece um Menor em CI com várias especializações: HCI/UX Design; Digital Humanities; Information Security; Information Policy; Library and Information Science; Archives and Records Management.

Tem também diversos cursos de pós-graduação: UX Research; UX Design; Archives; Interactive Design; Web Development; Business Analysis; Knowledge Management; Librarianship; Information Architecture; Digital Asset Management; Digital Humanities; Curation and Preservation; Health Informatics.

Os alunos têm 7 possibilidades de programas duplos de mestrado em Estudos de Informação ${ }^{23}$, um mestrado em Identity Management and Security e outro mestrado em Information Science, com diversas áreas de especialização: Archival Studies; Digital Libraries; HumanComputer Interaction \& Information Architecture; Organization and Retrieval of Knowledge and Information; Preservation and Conservation of Physical and Digital Artifacts; Development,

22 Ver https://ischool.syr.edu/research/faculty-research-areas/

23 Ver https://www.ischool.utexas.edu/programs/dual_degrees 
Management, and Evaluation of Collections and Services; Cultural Heritage Development and History and Management of the Cultural Record; Information Policy, Ethics, and Advocacy; User Behavior; Health Informatics; Information Work and Workers; Social Informatics.

O doutoramento em Estudos de Informação tem 3 áreas de especialização:

Organization: To have value for humans and organizations, the vast array of information resources must be organized and managed. From the creation of organizational schemata and catalogs to the analysis of structures in language and data, information specialists have developed techniques and tools to support the location, management, and use of information. This area is designed so that students may learn the intellectual foundations of information organization and the technical skills required to analyze collections of both textual and nontextual materials for buman use;

Interaction: People interact with information resources through a variety of technologies and through other people. Creating meaningful and effective interaction requires an understanding of how people think and reason, how they behave in specific contexts, and how the interfaces between people and information can best be designed. This area is designed so that students may learn to understand human needs and dispositions in information contexts and develop the methodological skills needed to belp develop information interfaces that work well for all people;

Curation: Information resources require careful stewardship to ensure their long-term preservation. This process involves assessing the value of information to future users and ensuring appropriate 
interventions for quality control and the migration of collections across technological platforms and over time. This area is designed so that students may learn how to appraise records, how archives and other collections are created and managed, and how best to preserve physical and digital records ${ }^{24}$.

\section{University of Michigan: School of Information - https://umich.edu}

A Universidade de Michigan tem 19 escolas e colégios ${ }^{25}$. Esta Universidade também tem uma escola de informação que oferece uma licenciatura e um mestrado em Information Science e um doutoramento em Informação.

O objeto de estudo nesta escola é a informação em sentido lato - bealth care, education, libraries, finance, government, the automotive industry, communication, entertainment-pretty much any field you can imagine.

Uma análise detalhada dos Curricula e do mercado de trabalho dos licenciados com esta formação, permite-nos concluir que a oferta é direcionada, na sua quase totalidade, para a formação no domínio da informática: analista de dados, de Tecnologias da Informação, etc.

Também no que diz respeito ao mestrado em Information Science, são apresentadas como referência de colocação dos Mestres, empresas como a Microsoft, a Hewlett-Packard...o Google, o Facebook... Bibliotecas Nacionais... e Arquivos Digitais... studies/

24 Ver http://catalog.utexas.edu/graduate/fields-of-study/information/information-

25 Como curiosidade podemos realçar o facto de ter disponível, na sua página Web, alguma informação em língua portuguesa. 
Entre as 3 áreas de interesse propostas aos alunos deste mestrado encontra-se Digital Archives and Library Science / Preservation: Specialists in these fields must address the problems of online access, digital preservation and electronic records management. They evaluate what cultural artifacts are worth preserving, what policies apply, and what resources and funding are available for the preservation of information.

Ora, após a análise detalhada dos Curricula e, apesar de preverem ao nível das ofertas de carreira Academic Librarian, Archivist, Assessment Librarian, Data Librarian, Digital Curator, Digital Preservation Manager, Digital Projects Librarian / Digital Projects Archivist, Health Sciences Librarian / Health Informationist, Information and Records Manager / Electronic Records Manager, Instructional Librarian / Archivist, Knowledge Management Specialist / Knowledge Management Consultant, Learning Technology Specialist, Metadata Specialist, Public Librarian, não nos parece crível que esta oferta formativa disponibilize os conceitos básicos para os alunos poderem trabalhar, por exemplo, numa Bibioteca Pública.

Para além deste mestrado, esta escola oferece também um mestrado em Informática da Saúde e outro, ministrado em regime de elearning, em Applied Data Science.

O doutoramento em Information tem a mesma linha de orientação, tendo como áreas de investigação:

Accessibility and Computing, Archives and Digital Curation, Collective Intelligence and Organizational Technology, Critical Studies of Design and Computing, Data Science, Analytics, and Visualization, Educational Technology and Learning Analytics, Health Informatics, Human Computer Interaction (HCI), ICTs and Social Change, Information Economics, Library and Information Science, Privacy, Science, Technology, and Society, Social Media and Social Computing, Ubiquitous Computing. 


\section{University of Southern California - https://www.usc.edu/}

Esta Universidade norteamericana ${ }^{26}$, em Los Angeles, é constituída por 22 escolas, e não faz parte do movimento das iSchools. Assim, e tal como já se verificou na Loughborough University, que também não faz parte deste movimento, a formação em Information Science está associada à Escola de Negócios - USC Marshall School of Business.

Oferece um mestrado, criado em 2013, em Management in Library and Information Science, que explores leadership and management strategies - as well as business operations - to prepare students for high-level careers in the library and information science fields.

Mais uma vez verificamos o caráter instrumental, e não dominante, da componente tecnológica, a qual é considerada como uma ferramenta de apoio e não como o core da oferta formativa pois afirmam claramente que To succeed in today's world of library and information fields, you should have a strong understanding of how the field has evolved and a leadership philosophy that reflects those changes.

Oferece também um Curso de Especialização pós mestrado online, de caráter profissionalizante em Library and Information Management, que enables students who already have a master's in library and information science to advance their career into high-level leadership with expert knowledge and confidence.

É muito interessante e promissora a visão desta escola sobre as Bibliotecas e os Bibliotecários:

26 A título de mera curiosidade, é nesta Universidade norteamericana que dá aulas de psicologia, filosofia e neurologia, o português António Damásio. 
Libraries are no longer cold, quiet, impersonal data rooms. Today, these spaces are transforming into vibrant learning hubs, creating a demand for industry professionals who are ready to lead their organizations into a new era of librarianship. Modern librarians are engaging and instructive, with a firm understanding of digital media. They are tutors, teachers, mentors and business professionals. They are managers of resources, including individuals. With the wide range of career opportunities for librarians, this is a wonderful time to be a librarian.

\section{Nanyang Technological University, Singapore (NTU) - http://www.wkwsci.ntu.edu.sg}

Esta Universidade também não faz parte do movimento das iSchools, havendo uma nítida distinção e complementaridade entre o que são os Sistemas de Informação...e o que são os Sistemas Tecnológicos de Informação ${ }^{27}$ e uma consciência clara da natureza Trans e Interdisciplinar da CI, para além de, e tal como verificamos anteriormente na Rutgers, The State University of New Jersey: School of Communication and Information, exista uma aproximação da CI à Ciência da Comunicação.

Tem uma escola especializada nesta área - Wee Kim Wee School of Communication and Information, e pretende ministrar uma holistic education involving multi-disciplinary research and the cultivation of soft skills, adequately preparing them for research-intensive careers. Esta escola oferece quatro programas de mestrado designados de Programmes by Coursework em Communication, Knowledge Management, Information Studies e Information Systems e um programa de mestrado designado Master by Research Programme

\footnotetext{
27 Sobre esta distinção Ver Fernández Marcial, Gomes e Marques., 2015.
} 
em Comunicação, onde são oferecidos conteúdos de CI, nomeadamente Conceptual Foundations of Information; Independent Study in Information; Advanced Quantitative and Qualitative Research Methods in Communication and Information e 2 doutoramentos: um em Comunicação e outro em Informação que tem como áreas principais: Human computer interaction, games and gamification, information retrieval and analytics, social media, mobile and ubiquitous computing, information behaviour, information literacy, knowledge organization, knowledge management applications and practices.

\section{National Taiwan University (NTU): \\ Graduate Institute of Library and Information Studies - https://www.lis.ntu.edu.tw/english/}

Universidade que data de 1961, com o seu Departamento de Library Science, só passou a fazer parte do movimento das iSchools muito recentemente, em 2018. É constituída por 11 colégios.

A formação em CI é oferecida pelo Department of Library $\mathcal{E}$ Information Science do College of Liberal Arts. Oferece uma licenciatura, um mestrado (1980) e um doutoramento (1989), tornando-se the first department of library and information science in Taiwan to have a complete educational system.

Este Departamento, estabelece relações muito fortes com o Department of Computer Science and Information Engineering, the Department of Information Management, the Department of Business Administration and the Department of Bio-Industry Communication and Development in order to jointly establish inter-disciplinary programs on knowledge management, creative business start-up, and communications, and to cultivate the diverse talents needed in today's information society. 
Os objetivos do DGILIS traduzem-se na criação de competências em:

1. Basic knowledge of library and information science

2. Ability to provide reader services and reference services

3. Ability to use and manage information resources

4. Ability to organize information and knowledge

5. Ability to manage and utilize information technologies

6. Ability to disseminate information

7. Ability to provide information literacy education

8. Ability to manage a library or an information center

9. Ability to solve various information problems and to conduct fundamental research

São várias as áreas dos cursos ministrados:

B.A.

1. Basic courses

2. Information organization

3. Information resources and services

4. Information and Communication technologies

5. Management of information institutions

6. Special topics in information \& documentation studies

M.A.

1. Prerequisite basic courses/Required core courses

2. Information organization

3. Information resources and services

4. Information and Communication technologies

5. Management of information institutions

6. Special topics in information \& documentation studies 
Ph.D.

1. Prerequisite basic courses

2. Information organization

3. Information resources and services

4. Information and Communication technologies

5. Management of information institutions

6. Special topics in information \& documentation studies

As informações sobre as possibilidades de Unidades Curriculares disponíveis, demonstram, de uma forma inequívoca, a grande diversidade e riqueza da oferta formativa desta Universidade.

\section{RMIT University - https://www.rmit.edu.au}

Esta Universidade australiana não faz parte do movimento das iSchools. Assim, toda a formação está integrada nos programas da área científica da Business and Administration.

Oferece uma licenciatura (de 5 anos) que se desenvolve ao longo de 4 cursos - The Digital Information Environment; Information Discovery; Information Organization; Information Provision - e um mestrado em Gestão da Informação (de 2 anos), acreditados pela Australian Library and Information Association (ALIA). Este mestrado pretende dotar os estudantes das skills required to work as a librarian, archivist or records manager and manage information-based products and services e desenvolve-se em 5 eixos principais: Information management, Digital curation, Electronic publishing, Records management, Archives administration, que se desenvolvem ao longo de 4 cursos: Management 1 - Managing People; Business and Government in the Global Context; Global Business and Social Technology: A Case Study Approach; Accounting for Management Decisions. 


\section{The University of Western Ontario - http://welcome.uwo.ca/index.html}

Universidade canadiana que também não faz parte do movimento das iSchools. Toda a formação em CI é ministrada na Faculty of Information \& Media Studies.

Oferece uma licenciatura em Media, Information $\&$ Technoculture (MIT), um mestrado em Health Information Science e um mestrado em Library $\&$ Information Science cujo programa provides a strong foundation in traditional librarianship together with an opportunity to engage with innovative ideas and new information technologies. Este mestrado tem 5 eixos fundamentais: Information Organization, Curation and Access; Information Policy; Connecting People with Information; Information and communication Technology; Managing and working in information Institutions.

Ao nível dos estudos de doutoramento mantêm estas 2 linhas de investigação no domínio dos estudos da Informação. O Doutoramento em Library \& Information Science oferece 2 campos de especialização: Information \& Society e Information Organization \& Technologies.

\section{Universidad Carlos III de Madrid(UC3M): Departamento de} Biblioteconomía y Documentación, Facultad de Humanidades, Comunicación y Documentación - http://portal.uc3m.es/ portal/page/portal/biblioteconomia_documentacion

Universidade que integra as iSchools. Tem uma escola de Hum anities, Communication and Library Science e um Departamento de Library and Information Science que oferece 2 licenciaturas de 4 anos (Management of Information and Digital ContentsNew 2017/2018; Library and Information), um mestrado em Libraries, Archives and Digital Continuity e um doutoramento em Documentation: Archives and Libraries in a Digital Context. 
Não localizamos, ou não está disponível, a Informação sobre o mestrado. Em relação ao doutoramento, ele é constituído por alguns Seminários sobre Metodologia. As teses podem ser desenvolvidas no âmbito das linhas de investigação previstas nos 3 grupos existentes:

Research Group 1

Scientific \& Technological Systems

Planning \& Management of Science

Scholarly Communication and social impact of Science

Research Evaluation

Bibliometrics/Scientometrics

Informetrics

Research Group 2

Digital Humanities

Print/Written Culture: Books and Documents through the History Archival Science \& Record Management

Historiography

Diplomatics, conservation, restoration and preservation

Information Sources and Bibliography

Information Systems and Information Policy

Planning \& Management of Libraries \& Information Centers

Information Management in Intelligence Units

Knowledge Society metrics

Digital Divide

Information Literacy

Learning Resources Centres

Networking and educational virtual content

Libraries and citizen empowerment processes

Collection management

Training and profession

Research Group 3 
Systems, Representations and Knowledge Organization

Structures and semantics relationships in vocabularies

Linguistics

Information Technology

Information Retrieval Systems

Digital Libraries

Open Science

Linked Data

Digital Imaging

XML Standards

Human Computer Interaction

\section{The University of Tokyo - https://www.u-tokyo.ac.jp/en/ academics/grad_interdisciplinary.html}

Esta universidade não faz parte do movimento das iSchools. É constituída por 10 faculdades e 15 escolas, entre as quais encontramos a Graduate School of Information Science and Technology e a Graduate School of Interdisciplinary Information Studies. É nesta última que podemos localizar a formação em CI:

Master's degrees:

Socio-information and Communication Studies Course:

M.A. (Socio-Information and Communication Studies)

Other courses:

Master of Arts and Sciences (Information Studies

Doctoral degrees:

Socio-information and Communication Studies Course:

Ph.D. (Socio-Information and Communication Studies)

Other courses:

Ph.D. (Information Studies 


\section{Universiti Malaya (UM) - https://www.um.edu.my}

Esta Universidade é constituída por 2 academias, 12 Faculdades, 5 Institutos e 6 Centros. Os cursos de mestrado em Information Science, são oferecidos pela Faculdade de Computer Science and Information Technology e permitem o acesso às carreiras de Information Scientist, Librarian, Documents Manager, Knowledge Manager, Academic Staff, Bibliometrician/Webometrician, Strategic Analyst; Scientific Information Provider. Um dos mestrados é constituído por um curso de Metodologia no $1^{\circ}$ ano do curso e pela realização de uma dissertação. O outro prevê a frequência de um curso, com 4 UC obrigatórias e várias opções e a realização de uma dissertação. Por último, existe ainda um mestrado que não implica a realização de uma dissertação, apenas a frequência de um Curso com 8 UC obrigatórias e várias opções. Também oferece um doutoramento em Information Science, sem ano curricular, sendo constituído por um curso de Metodologia no $1^{\circ}$ ano do curso e pela realização de uma tese.

\section{The University of Arizona: School of Information - https://ischool.arizona.edu}

Nesta Universidade, a formação em CI é oferecida pelo College of Social and Behavioral Sciences, o qual tem uma escola de Information Resources and Library Science e uma outra escola de Information. Oferece um mestrado em Arts in Library and Information Sciences e um mestrado e um doutoramento em Informação.

Apesar de pertencer ao movimento das iSchools, o mestrado em Arts in Library and Information Science parece-nos uma formação muito diversificada que oferece specialization in archives and preservation, digital librarianship, heath information, digital information, management and systems, law librarianship, legal in- 
formation, as well as academic and public librarianship. Students prepare for careers in libraries, museums, and archives, as well as government and business information centers.

No entanto, o mestrado e o doutoramento em Science in Information têm uma vertente tecnológica dominante.

\subsection{QS TOP 25 UNIVERSITIES - 2019}

Os dados relativos ao ano de 2019 na mesma categoria, recentemente publicados pelo QS World University Rankings TOP UNIVERSITIES, ${ }^{28}$ apresentam ligeiras alterações em relação ao ano transato relativamente às 25 "melhores" universidades do mundo para estudar Library and Information Science.

Mantêm-se o monopólio do mundo anglo-saxónico, ainda que tenha aumentado a representação europeia, através da entrada de novos países, para além da habitual presença maioritária do Reino Unido.

Estes novos dados mantêm o número das 13 Universidades nos EUA (ainda que tenha saído a Universidade do Arizona, $25^{\mathrm{a}} \mathrm{em}$ 2018, e que em 2019 passa para o $44^{\circ}$ lugar e tenha entrado para este Ranking a Universidade Buffalo Suny, que nem sequer figurava no Ranking das 50 melhores universidades em 2018, e que agora passa a figurar em $20^{\circ}$ lugar), 4 no Canadá, 2 em Inglaterra, 1 em Singapura, 1 em Taiwan, 1 na Austrália, e, pela primeira vez, 1 na Nova Zelândia (que em 2018 figurava em $40^{\circ}$ lugar e que agora figura em $24^{\circ}$ ), 1 na Holanda (que em 2018 figurava em $26^{\circ}$ lugar) e 1 na Bélgica (que em 2018 figurava em $38^{\circ}$ lugar).

A primeira mudança a assinalar é o facto da Universidade da Malásia, que, em 2018, ocupava o $24^{\circ}$ lugar neste ranking, cair 7

28 Ver: https://www.topuniversities.com/university-rankings/university-subjectrankings/2019/library-information-management 
lugares em 2019, passando a ocupar o $31^{\circ}$ lugar. Mas, as grandes alterações situam-se ao nível da Universidade Carlos III de Madrid (22 ${ }^{\mathrm{a}}$

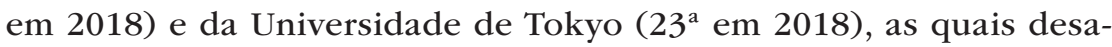
parecem do TOP alargado às 50 melhores Universidades do Mundo.

Ora, a Universidade Carlos III de Madrid é, conjuntamente com a Universidade Aberta da Catalunha e a Universidade Politécnica de Valência, uma das três Universidades espanholas que fazem parte do movimento das iSchools, daí alguma estranheza pela quebra abrupta e pelas razões que lhe podem estar subjacentes.

Neste contexto, as Universidades Espanholas deixaram de estar representadas no Top das 25 melhores, sendo a Universidade de Barcelona, que não pertence ao movimento das iSchools, a única a figurar neste Ranking, ainda que em $27^{\circ}$ lugar.

Uma análise detalhada, permite-nos concluir que, em 2019, 17 destas 25 universidades enquadram-se no chamado movimento das Information Schools ou iSchools, pelo que houve uma redução desta representação em uma Universidade.

Ora, apesar do pouco significado desta mudança, que nos impede de retirar conclusões, este pode ser um sinal de alguma nova tendência, ainda que muito pouco claro.

\section{5 melhores universidades do mundo para estudar $\mathrm{Cl}$}

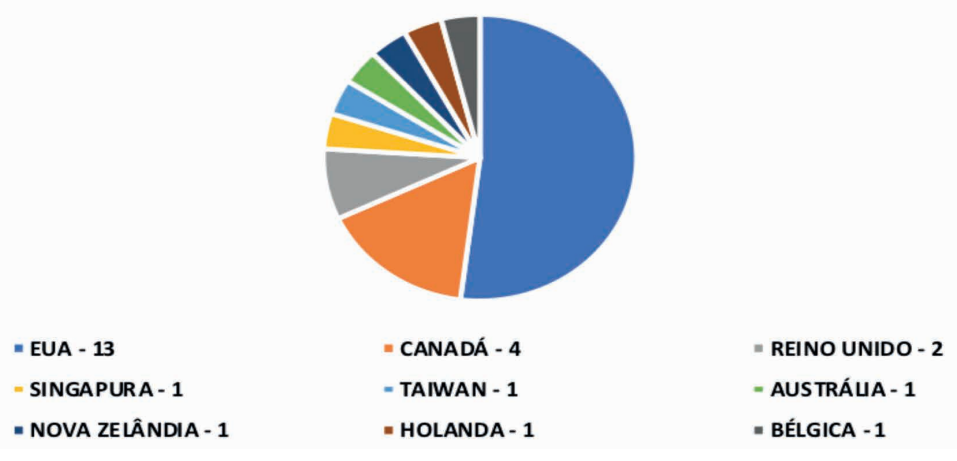

Fig. 10 - QS TOP 25 UNIVERSITIES 2019 


\section{5 melhores universidades do mundo para estudar $\mathrm{Cl}$}

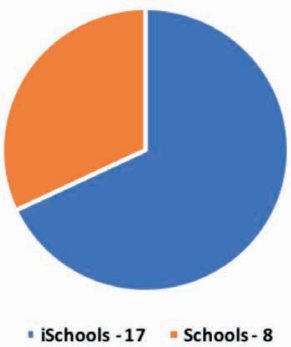

Fig. 11 - Representatividade das iSchools no QS TOP 25 UNIVERSITIES 2019

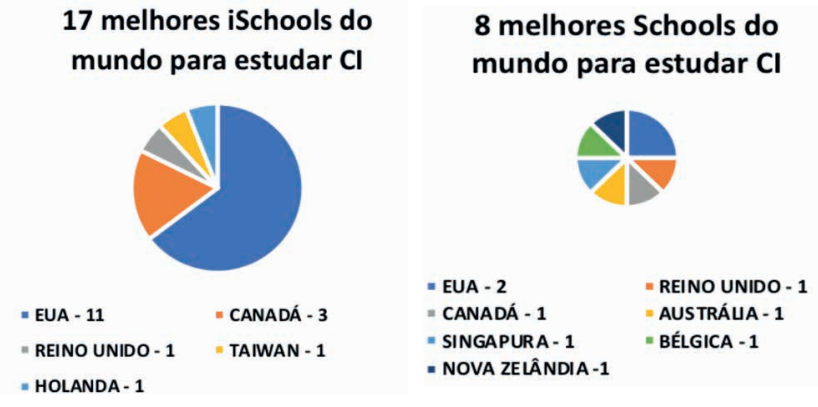

Fig. 12 e 13 - Análise das iSchools e das Schools no QS TOP 25 UNIVERSITIES 2019

\subsubsection{RANKING - 25 UNIVERSITIES - 2019}

Para além das mudanças assinaladas anteriormente, verifica-se a alteração, em alguns casos significativa, do lugar ocupado no Ranking, e a entrada de novas Universidades para este TOP de 25 Universidades $^{29}$ :

1. University of British Columbia (4)

2. University of Sheffield (1)

3. University of Toronto (11)

29 Entre parênteses está o lugar ocupado no mesmo Ranking em 2018. 
4. University of Illinois at Urbana-Champaign (3)

5. University of North Carolina, Chapel Hill (1)

6. Syracuse University (14)

7. University of Washington (7)

8. Indiana University Bloomington (5)

9. Loughborough University (8)

10. University of California, Berkeley (UCB) (6)

11. Rutgers University-New Brunswick (13)

12. McGill University (11)

13. University of California, Los Angeles (UCLA) (10)

$=13$. The University of Western Ontario (21)

15. University of Pittsburgh (9)

16. University of Michigan (16)

17. University of Texas at Austin (15)

18. Nanyang Technological University, Singapore (NTU) (18)

19. University of Amsterdam, Netherlands: Graduate School of Humanities, Archives and Information Studies - https://www.uva. nl/en (26)

Esta Universidade holandesa, que também faz parte do movimento das iSchools, é constituída por 7 Faculdades. A Faculdade de Humanidades oferece 2 licenciaturas de 3 anos na área da CI, uma em Media and Culture e outra em Media and Information:

A $1^{a}$, offers inspiring career prospects: aside from careers in the academic field, graduates go on to work at production companies for film, television, new media, in advertising and in the creative industries, as researchers, producers, directors, creative editors, and journalists. They may also bold positions as project managers, advisors, curators and programmers at distributors, broadcasting networks, festivals, museums, libraries, archives and other cultural institutions, or commercial companies. 
A $2^{a}$, Strong ties with the thriving Amsterdam community of new media companies, digital art institutions, creative industries, game and app developers, archives, and museums; Impressive career prospects: Graduates go on to work in journalism, advertising, and media sectors, and bold positions as project managers, data analysts, and developers in museums, libraries, archives, the creative industry, and other commercial companies.

Oferece também 2 mestrados em Archival and Information Studies, cujo programme consists of a theoretically-based first semester in which you will critically analyse core information and archival theories. Ambos têm como disciplinas comuns - The Information Society and its Infrastructures (12 ECTS) e Information Analytics and Digital Humanities (12 ECTS) e como opções especializadas da $1^{\mathrm{a}}$ variante Specialist Archival Appraisal: Concepts and Practices (6 ECTS) e Digital Memory and Sovereignty (6 ECTS) e da $2^{\text {a }}$ variante Digital Curation (6 ECTS) e Digital Memory and Sovereignty (6 ECTS).

A Faculdade de Ciências, oferece também um mestrado em Information Studies, de natureza predominantemente tecnológica que is a broad and interdisciplinary field, primarily concerned with the analysis, collection, classification, manipulation, storage, retrieval and dissemination of information. It examines the interaction between people, organisations and any existing information systems, with the aim of creating, replacing, improving or understanding information systems... it focuses on understanding information problems from the perspective of the stakebolders nvolved, and then applying technologies as needed. Not only aspects of computer science are incorporated, but also aspects of research fields like cognitive science, commerce, communications, management, philosophy, public policy, and the social sciences.

Este mestrado tem duas variantes, a de Data Science e a de Information Systems. 


\title{
20. Universidade Buffalo Suny: Department of Information Science (não fazia parte das 50 elencadas em 2018) - http://ed.buffalo.edu/information.html
}

Esta Universidade de Nova Iorque é a premier public research university in the Northeastern United States e teve uma ascensão meteórica neste Ranking. É constituída por 13 Schools and Colleges.

O Departamento de Information Science ${ }^{30}$ da Graduate School of Education oferece um menor de 2 a 3 semestres (18 ECTS), 100\% online em Library \& Information Studies que focuses on the policy, management, security, and learning potential of information. The engineer, the artist, and the community organizer all need to know how to best use information to achieve maximal success in their future endeavors. The program offers a way for students to master the information skills and knowledge that can best help them in whatever their major is. The Information Studies minor is appropriate for undergraduate students who are interested in a wide range of careers in any field, in the for-profit, non-profit, or governmental sectors. It is open to all majors.

Este menor destina-se a formar:

\author{
archivists \\ information analysts \\ intelligence analysts \\ bealth information specialists \\ librarians \\ marketing analysts
}

30 Até janeiro de 2019, a designação era de Department of Library and Information Studies. A alteração reflects changes in the field of library and information science over the past 20 years... "The focus on 'libraries' as a physical setting or entity has been replaced by a focus on 'information' as a phenomena, which is relevant to libraries, but more importantly is explored in a range of organizational contexts, workplace contexts and individuals' daily life contexts," the resolution states. 
metadata specialists

records managers

researchers in all environments

search engine optimizers

school library media specialists

system administrators

web designers

É muito interessante analisar os conteúdos ministrados neste Menor:

LIS 200 Introduction to Information Studies

LIS 205 Information and Society

LIS 405 Information Seeking and Use (prerequisite LIS 200)

At least 9 credits (3 electives) chosen from the following electives:

LIS 425 Applied Information Management

LIS 426 Psychology of Information

LIS 427 Information Ethics, Privacy and Policy

LIS 428 History of Information

LIS 430 Decision Making and Story Telling

LIS 499 Special Topics in Information Studies

Oferece também 2 mestrados, em regime de elearning. Um em Information and Library Science e outro em School Librarianship.

$\mathrm{O}$ mestrado em Information and Library Science focuses on enabling you to seek professional employment in a wide range of information careers in the United States and around the world e inclui specialized degree program options including music librarianship and law librarianship; and practicums, special projects and directed study courses to gain real-world experience.

Destinado a profissionais que pretendem trabalhar quer em Bibliotecas tradicionais, quer na Gestão da Informação das organizações, é também muito interessante a análise do pro- 
grama deste mestrado, que prevê uma enorme rotatividade e diversidade de conteúdos ${ }^{31}$ :

LIS 507 Information Life Cycle

LIS 508 Information Users and Uses

LIS 575 Introduction to Research Methods

Concentrations are available within this program. You can prepare to be generalists or choose courses with concentrations in one or more areas:

Information management

Information organization

Information services

Information storage and retrieval

Law librarianship, with a concurrent MS in information and library science and JD degrees

Music librarianship, which combines MS in information and library science and master's of music

Public or academic libraries

Special libraries including those serving business, museums and law firms

Este mestrado permite a obtenção de dois duplos graus pois está também associado ao master of arts (MA) degree in music with a concentration in either music history or music theory e à School of Law, you can earn two degrees: a master of science degree (MS) and a doctor of law (JD) degree, both in information and library science que provides training in information studies and law, essential for advancement in the profession of academic law librarianship, and prepares you for new opportunities in publishing

31 Ver http://ed.buffalo.edu/content/dam/ed/information/docs/LIS-Course-RotationSchedule.pdf 
and the legal information industry, através da formação de law librarians e legal information professionals.

O mestrado em School Librarianship, totalmente online, funciona anualmente em regime de co-regência entre a School of Education e a School of Law e focuses on preparing you to teach in a 21st century school library. All courses include the latest research-based, best practices occurring in the school library field. You will be exposed to strategies and techniques for teaching information literacy, based on new standards of practice as outlined in the Common Core Learning Standards and the Annual Professional Performance Review.

Consideramos que a análise do seu programa é vital no domínio do estudo das tendências da CI:

LIS 507 Information Life Cycle

LIS 508 Information Users and Use

LIS 518 Reference Sources and Services

LIS 524 School Media Center Field Experience

LIS 525 School Media Center Practicum ${ }^{1}$

LIS 532 Curriculum Role of the Media Specialist ${ }^{2}$

LIS 534 Resources and Services for Children

LIS 535 Resources and Services for Young Adults

LIS 538 Pedagogy for School Librarians

LIS 568 Computer Applications in the School Library Media Center

LAI 574 Teaching the Exceptional Learner in the Regular Education Classroom

LIS 575 Introduction to Research Methods

LIS 585 Management of School Library Media Centers

Esta Universidade oferece também um doutoramento em CI que tem uma componente Social e Humana muito acentuada - will give you the opportunity to develop sophisticated quantitative and 
qualitative research skills to equip you to delve into the complex information problems facing humanity and contemporary organizations. As buman interaction and cultural expression continue to be facilitated digitally, the workings of digital technologies, their impact and their uses need to be understood. Our doctoral degree in information science will provide the opportunity to study these issues in depth. The information field is changing rapidly, and offering myriad opportunities for future scholars of information science.

De acordo com as informações disponibilizadas através da sua página Web, it is one of only two online information science doctoral programs in North America e destina-se a formar Faculty/scholar of information science at a university; Researcher at a profit or nonprofit organization; Senior manager of a large public library; Senior manager of a university campus library. Existem apenas 5 Core Courses (15 credits):

LIS 601 Qualitative Methods in Information Science LIS 602 Quantitative Methods in Informtion Science LIS 603 Theoretical Foundations of Information Science LIS 604 Statistics I LIS 605 Statistics II

O mestrado em information science, information studies, librarianship or a cognate discipline is a program pre-requisite. Upon accceptance into the doctoral program, you are allowed to transfer entre 30 -36 credits from your master's degree program.

\section{University of Southern California (17)}

\section{National Taiwan University, Singapore (NTU) (19)}




\section{Universidade Católica de Leuven - KU (38) - https://www.kuleuven.be/english/}

Esta Universidade é constituída por 15 faculdades. A Faculdade de Artes oferece um mestrado em Arquivística: Património e Gestão de documentos que é um programa interuniversitário da KU Leuven, da Universidade de Antuérpia (UA), da Universidade de Gante (UGent) e da Vrije Universiteit Brussel (VUB).

O curso é uma extensão do mestrado em História, mas os outros alunos da Universidade também se podem inscrever após um programa de transição. Para além da conceção clássica de arquivos, também são ministrados outros conteúdos dirigidos a possibilitar a carreira em arquivos empresariais.

Esta Faculdade também oferece um mestrado em Humanidades Digitais que tem como objetivos...Also, graduates from Humanities and Behavioural Sciences programs enter a professional world in which digitization becomes the standard, be it in publishing, arts, libraries, teaching and many others.

A Faculdade de Economia e Gestão oferece um mestrado em Gestão da Informação em que The emphasis lies on the efficient and effective application and management of information technology in various business contexts (e.g. finance, marketing, $H R$, production and logistics)... The key focus is the preliminary design needed to develop and set up an information system. In completing your Master's thesis, you can apply these skills within a specific business context.

Este mestrado tem uma componente tecnológica muito acentuada, visível através das suas 3 linhas gerais: Data Science, Software Engineering e Management e nas oportunidades previstas de carreira - Our graduates pursue careers as information analysts, project leaders, and information technology strategists. 


\section{Universidade de Victoria (40) - http://www.victoria.ac.nz/ international}

Esta Universidade é constituida por 8 Faculdades e uma escola especializada. Oferece um Professional Specialization Certificate em Collections Management, destinado prioritariamente à formação de Museólogos, tem uma oferta diversificada, e também pode ser oferecido a Arquivistas dado que, entre outras UC, prevê a UC de Managing Archival Collections que focuses on archives as an important component of museum collections and develops your understanding of ways in which archival materials should be organized, managed, preserved and shared. Os conteúdos programáticos são bastante interessantes:

- the nature of archival materials

- theories, principles, and practices governing archival management

- legal, administrative, and professional frameworks

- appraisal, acquisition, and accessioning of archives

- archival arrangement and description, including the application of archival descriptive standards

- physical processing and storage

- the importance of preventive conservation

- reference services and access issues

- using archives to enhance exhibits, educational offerings, and outreach initiatives

- the impact of digital technologies on the management of records and archives

- the role of archives in culture, heritage and society.

A Faculdade de humanidades oferece também um Menor em Professional Communication, que permite o acesso à profissão de Bibliotecário e Arquivista e é partilhado por várias áreas de 
interesse da Universidade Business, Economics and LawFine Arts and Digital Media.

A Faculdade de Desenvolvimento Humano e Social, em conjunto com a escola de Health Information Science oferecem uma licenciatura, um mestrado e um doutoramento em Health Information Science com uma forte componente tecnológica.

25. RMIT University (20)

1.4 ANÁlise GLOBAL DOS DADOS DO QS TOP 2018 - 2019

\subsubsection{QS TOP - $1^{\circ}$ - $25^{\circ}$ - ESCOLAS QUE NÃO PERTENCEM ÀS iSCHOOLS}

\begin{tabular}{|l|l|}
\hline $\mathbf{2 0 1 8}$ & $\mathbf{2 0 1 9}$ \\
\hline 8. Loughborough University & 9. Loughborough University \\
17. University of Southern California & 13. The University of Western Ontario \\
18. Nanyang Technological University, & 18. Nanyang Technological University, \\
Singapore (NTU) & Singapore (NTU) \\
20. RMIT University & 21. University of Southern California \\
21. The University of Western Ontario & 22. Nanyang Technological University, \\
23. The University of Tokyo & Singapore (NTU) (19) \\
24. Universiti Malaya (UM) & 23. Universidade Católica de Leuven - KU (38) \\
& 24. Universidade de Victoria (40) \\
& 25. RMIT University \\
\hline
\end{tabular}

Fig. 14 - Escolas que não pertencem ao consórcio das iSchools - QS TOP 25 UNIVERSITIES 2018/2019. A bold estão assinaladas as Universidades que saíram e entraram no Ranking no ano de 2019

\subsubsection{QS TOP $-25^{\circ}-50^{\circ}$}

Nas restantes 25 Universidades do Top 50 - 2018: 4 são dos EUA, 3 são chinesas, 2 da Coreia do Sul, 2 de Taiwan, 1 australiana, 1 canadiana, 1 japonesa, 1 da Nova Zelândia, e apenas 10 são europeias: 5 do Reino Unido $\left(32^{\circ}, 35^{\circ},=43^{\circ}\right.$ e $\left.49^{\circ}\right)$; 1 holandesa $\left(26^{\circ}\right)$; 1 italiana $\left(33^{\circ}\right) 1$ alemã $\left(35^{\circ}\right)$; 1 belga $\left(38^{\circ}\right)$ e 1 filandesa $\left(50^{\circ}\right)$. 
Nas restantes 25 Universidades do Top 50 - 2019: 4 são dos EUA, 4 são chinesas (mais uma do que em 2018), 2 canadianas (mais uma do que em 2018), 2 australianas (mais uma do que em 2018), 1 da Coreia do Sul, 1 da Malásia, 1 de Taiwan (menos uma do que em 2018) e apenas 10 são europeias: 3 alemãs (mais 2 do que em $2018-29^{\circ}, 33^{\circ}$ e $42^{\circ}$ ); 2 do Reino Unido (menos 3 do que em $2018-31^{\circ}$ e $48^{\circ}$ ); 2 italianas (mais 1 do que em $2018-43^{\circ}$ e $\left.50^{\circ}\right)$; 1 espanhola $\left(27^{\circ}\right) ; 1$ Holandesa $\left(37^{\circ}\right)$ e 1 Irlandesa $\left(38^{\circ}\right)$.

\subsubsection{QS TOP - TENDÊNCIAS DA FORMAÇÃO EM INFORMATION SCIENCE E CIÊNCIA DA INFORMAÇÃO NAS "25 MELHORES UNIVERSIDADES DO MUNDO"}

A determinação das tendências formativas em CI foi aferida quer em termos quantitativos, quer qualitativos e, porquanto, foi feita a partir do seu enquadramento institucional e da análise dos diversos conteúdos programáticos previstos, sempre que eram oferecidos, nos seus 3 Ciclos de Estudo - licenciatura, mestrado e doutoramento:

TENDÊNCIAS FORMATIVAS 2018

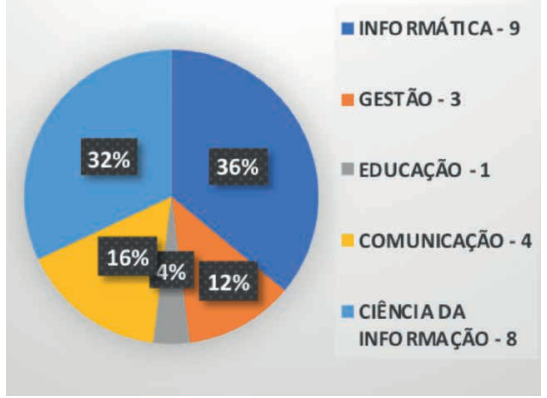

TENDÊNCIAS FORMATIVAS 2019

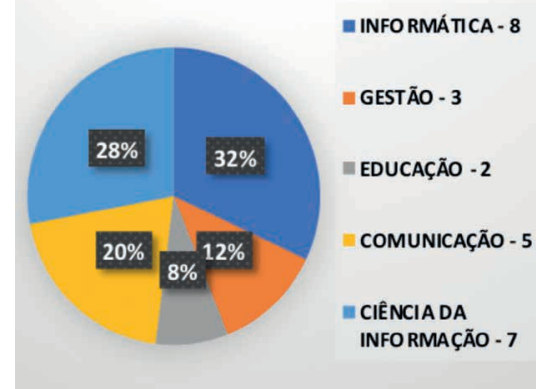

Fig. 15 - Tendências formativas do QS TOP 25 UNIVERSITIES 2018/2019 
A análise desenvolvida permite-nos concluir que a tendência da oferta formativa em Information Science, apesar de diversificada, concentra-se, na sua maioria, em escolas de Ciências da Computação e Tecnologias da Informação ${ }^{32}$ que formam profissionais na área da programação, da análise e recuperação de grandes volumes de dados (data analytics, data science, etc.).

Convém também referir que esta situação verifica-se, quase exclusivamente, em Universidades norteamericanas, sendo a Universidade de Sheffield, no Reino Unido, a única exceção geográfica, e todas pertencerem ao movimento das iSchools.

A CI, tal como a entendemos, de matriz europeia, onde a tecnologia tem um valor "meramente Instrumental", e desempenha o papel de ferramenta de apoio à produção, organização e representação da informação, aparece imediatamente a seguir, ainda que se comece também a notar nestas escolas, agora de vários países, uma tendência para reduzir os conteúdos ligados às Ciências Humanas e Sociais e aumentar o peso das Tecnologias. Talvez o facto de, com exceção da universidade canadiana de Western Ontario, todas pertencerem ao consórcio das iSchools possa contribuir para esta situação.

Todavia, a análise comparativa efetuada, permite-nos confirmar uma tendência, ainda que muito pouco significativa, ao nível da implantação e desenvolvimento da CI de matriz social e humana, pois nota-se uma redução do número destas escolas e a oferta formativa começa a aumentar em escolas de Comunicação, de Educação e de Gestão, sendo de salientar que neste último caso, Southern California dos EUA, RMIT da Austrália e Loughborough do Reino Unido, nenhuma pertence ao movimento das iSchools.

32 A título de exemplo, e tal como se pode verificar através da descrição anterior, as Universidades norteamericanas de Indiana e Pittsburgh, concentram toda a sua oferta formativa em CI na School of Informatics, Computing, and Engineering e na School of Computing and Information. 


\section{VISÕES E PERSPETIVAS}

$\mathrm{Na}$ tentativa de acrescentar valor à pergunta inicial consideramos que, e apesar da amostra em análise, um "Cientista da Informação" não pode ser "equiparado" a um informático e os Sistemas de Informação não podem ser tendencialmente reduzidos a uma perspetiva tecnológica que, em última instância, vê na inteligência artificial o futuro para a excelência das organizações em geral e do Ser Humano em particular.

Esta visão redutora da CI, para além de contrariar o seu caráter trans e interdisciplinar, parece-nos muito perigosa e arriscada para o desenvolvimento estrutural de uma ciência ainda muito recente e pouco sustentada no contexto das chamadas hard sciences.

Perigosa, pois pode conduzir-nos a um retrocesso epistemológico da CI e Arriscada, pois, e em última instância, pode acantoná-la, ou reduzir a CI, tal como a entendemos enquanto Ciência Social Aplicada, com uma componente cognitiva e emocional muito acentuada, a uma mera disciplina auxiliar das Ciências da Computação. Assim, e tal como refere Saracevic:

"Information science is the science and practice dealing with the effective collection, storage, retrieval, and use of information. It is concerned with recordable information and knowledge, and the technologies and related services that facilitate their management and use. More specifically, information science is a field of professional practice and scientific inquiry addressing the effective communication of information and information objects, particularly knowledge records, among humans in the context of social, organizational, and individual need for and use of information. The domain of information science is the transmission of the universe of human knowledge in recorded form, centering on manipulation (representation, organization, and retrieval) of information, rather than knowing information". 
Neste contexto, e tendo em conta os resultados do nosso estudo, partilhamos de uma forma muito consciente e preocupante, todas as dúvidas epistemológicas anunciadas, há mais de vinte anos, por Saracevic (1996: 43):

\begin{abstract}
"apesar de os Estados Unidos desempenharem o papel mais proeminente no desenvolvimento da CI. . . nem os problemas informacionais nem a CI são americanos em sua natureza".
\end{abstract}

Tal como refere (Fondin, 2005: 4 e 8), consideramos que a visão da "CI americana", a qual tinha como objetivos criar as condições "pour que les États-Unis deviennent la mémoire du monde, ce qui leur permettra ultérieurement de dominer dans le secteur des banques de données documentaires, dans l'industrie de l'information, et, avec l'Internet, dans la fourniture d'information en ligne. . Ils imposent une certaine vision de l'activité. Ils exportent leur vocabulaire"33 é mais uma nova forma de colonização do século $\mathrm{XXI}^{34} \ldots$ do que uma questão de natureza epistemológica.

Esta visão da CI é questionada, logo a partir da década de 90 do século passado, inclusive por americanos como John M. Budd e pelo dinamarquês Birger Hjorland. Assim, apesar deste investimento claro dos anos 60 e 70, Buckland (2012: 8) afirma que:

"information retrieval and bibliometrics, both very useful, are quantitative and technical but not scientific in the normative sense because they are based on ill-defined foundations".

33 De acordo com Fondin (2005: 4), "en 1951, l'Américain Calvin N. Mooers introduit la notion de Information Retrieval, c'est à dire la récupération organisée des documents pertinents conservés dans un fonds documentaire.", que é determinante para algumas tendências que pretendem tornar a CI numa "Ciência hard, robusta, de natureza tecnológiaca".

34 Ver sobre estas novas formas de colonização moderna Marques e Gomes, 2014. 
É que delas estão ausentes todos os elementos de turbulência de natureza subjetiva, designadamente o elemento humano.

No âmbito do novo contexto geo-político, económico, social e cultural da segunda década do século XXI, consideramos que "enquanto ciência social de caráter transdisciplinar a CI tem evoluído no sentido de demonstrar, ao nível do seu objeto de estudo, a 'falência' do determinismo tecnológico e a 'ascensão' da componente social e humanística." 35

Assim, a questão que se coloca em 2019, é substancialmente diferente da que se colocava nos finais da década de 50 do século passado $^{36}$. A dimensão social e humanista da CI, referencialmente associada à designada Library and Information Science, que se desenvolve em diversos contextos organizacionais e que "cobre" a Arquivística, a Biblioteconomia, a Documentação, a Museologia..., afigura-se-nos como crucial para o desenvolvimento de uma Ciência que se pretende trans e interdisciplinar.

Tal como referiu Capurro em 1992, a informação é uma dimensão essencial da existência humana:

\begin{abstract}
"But information, taken as a dimension of human existence, is nothing substantial. Instead of asking: 'what is information?' we should ask 'what is information science for? The change over to the second question means a change of perspective which takes as a starting point the 'cognitive turn' but goes beyond it in search of a pragmatic and rhetorical perspective."
\end{abstract}

Nesta perspetiva e fazendo uma analogia com outras Ciências de raízes e fundamentos bastante sólidos... tal como a Medicina não é o estudo do coração, do fígado, dos ouvidos, do nariz e da

\footnotetext{
35 Ver sobre este assunto, Marques, 2015.

36 Ver Bates, 1999.
} 
garganta... mas o estudo dos doentes, ou das formas de diagnosticar, prevenir ou tratar as doenças do corpo humano, uma "Ciência de debelar ou atenuar as doenças", a CI, tal como a entendemos, de natureza cognitiva e emocional, não tem como objeto de estudo os arquivos, as bibliotecas, os museus...e muito menos a informação automática, os sistemas tecnológicos de informação ou as ferramentas informáticas desenvolvidas...ou a desenvolver pelo ser humano...para agilizar todas as tarefas mecânicas e rotineiras de uma organização ou de um indivíduo...

A visão que temos do objeto de estudo da CI, desloca a ênfase da Informação, entendida como matéria prima e, porquanto, passível de ser automatizada e traduzida em bits e bytes... para o ser humano, enquanto entidade individual e/ou coletiva que produz e consome informação, em função da satisfação das suas necessidades, expetativas e desejos e da sua afirmação e distinção em relação aos outros elementos da natureza.

Esta visão holística da informação social, poderá ajudar-nos a clarificar algumas inconsistências verificadas no contexto de alguns países e universidades, onde as formações iniciais de graduação ou licenciatura se desenvolvem através do estudo das disciplinas aplicadas tradicionais da Arquivística e da Biblioteconomia, entendidas como as bases do Saber Fazer, e da Gestão da Informação em geral, e que evoluem, ao nível de estudos graduados de mestrado ou de doutoramento para uma Ciência de Informação de base tecnológica.

\section{CONCLUSÃo}

Após a análise de todas as propostas de formação para 2018 e 2019 destas " 25 melhores universidades do mundo para estudar Library and Information Science", assinalamos 3 grandes marcos referenciais: em relação à Arquivologia e aos Arquivistas, a oferta 
formativa prevista nos Currícula é, por razões geográficas, sociais e culturais facilmente percetíveis, muito escassa; há uma forte componente tecnológica associada a todos os Ciclos de estudo; e, finalmente, há uma distinção clara entre Ciência das Bibliotecas, ou Biblioteconomia - Librarianship - e Ciências da Computação ou Informática - Information Science.

A primeira conclusão a retirar do que foi dito é a impossibilidade de vivermos como entidades autónomas numa sociedade em rede, composta por diversas variáveis que interagem permanentemente e modificam o estado original dos diversos sistemas;

A segunda conclusão é a inevitabilidade dos sistemas abertos enfrentarem harmoniosamente a sua natural entropia e "combaterem" a sua natureza tendencialmente homeostática;

Decorrente das conclusões anteriores surge uma terceira que implica a assunção definitiva do imperativo categórico da trans e interdisciplinaridade da investigação científica e, em particular, da CI, o que implica um diálogo permanente, construtivo e alheio a qualquer pressuposto de natureza corporativa ou profissional;

Uma quarta conclusão é a necessidade de um debate epistemológico sobre a natureza da CI, evitando os constantes equívocos com outras áreas científicas e disciplinas aplicadas e, sobretudo, entendendo e clarificando de uma forma unívoca o seu objeto de estudo, o seu método e a sua linguagem, considerados como determinantes para o seu enquadramento claro no âmbito das Ciências Sociais e Humanas.

Finalmente, e não menos importante, consideramos que é determinante a necessidade de assumirmos o posicionamento da CI na Sociedade atual ou futura. No âmbito de uma perspetiva proativa em relação ao futuro da CI e da Humanidade em geral temos de encontrar um ponto de equilíbrio entre os chamados por Humberto Eco (1993) de apocalípticos e/ou integrados, quiçá através da "Inteligência Informacional", i.e, olhando sempre para o desenvolvimento científico e tecnológico como uma consequência direta 
do desenvolvimento humano e não o inverso, reduzindo o ser humano a uma máquina e profetizando os benefícios da Inteligência Artificial em detrimento da Inteligência Emocional.

Em jeito de súmula, consideramos determinante o aparecimento de estudos similares para outras realidades europeias, nomeadamente, em relação aos países onde a formação em Arquivística e Biblioteconomia tem uma tradição ancestral, França, Espanha, Itália...e para outros países como a India, e ainda outros de "formação recente", da América do Sul, como o Brasil, o México, o Perú e de África, como Angola, Moçambique, etc.

\section{Referências Bibliográficas}

Bates, M. J. (1999). The Invisible Substrate of Information Science. Journal of the American Society for Information Science, 50 (12): 1043-1050.

Bates, M. J. (1999). A tour of information Science through the pages of JASIS. Journal of the American Society for Information Science, 50 (11): 975-993.

Borko, H. (1968). Information science: What is it? American Documentation, 19 (1): 3-5.

Brookes, B. C. (1980). The foundations of Information Science: part I: philosophical aspects. Journal of Information Science, 2 (3-4): 125-133.

Buckland, M. (2012). What kind of science can information science be?. Journal of Information Science and Technology, 63 (1): 1-7.

Budd, J. M. (1997). A critique of customer and commodity. College and Research Libraries. Vol. 58: 310-321.

Capurro, R. (1992). What is information science for? A philosophical reflection. In: Pertti Vakkari, Blaise Cronin (Eds), Conceptions of Library and Information Science. Historical, empirical and theoretical perspectives, (p. 82-98). London: Taylor Graham.

Capurro, R. (2003). Epistemologia e Ciência da Informação. In: ENCONTRO NACIONAL DE PESQUISA EM CIÊNCIA DA INFORMAÇÃO, 5, Belo Horizonte. Anais eletrônicos... Disponível em: <http://www.capurro.de/enancib_p.htm>. Acesso em: 08 maio. 2019.

Castells, M. (1999). Information Technology, Globalization and Social Development. UNITED NATIONS RESEARCH INSTITUTE FOR SOCIAL DEVELOPMENT. UNRISD Discussion Paper. $\mathrm{N}^{\circ} 114$, September.

Castells, M. (1999). A sociedade em rede - a era da informação: economia, sociedade e cultura. v. 1. São Paulo: Paz e Terra.

Eco, U. (1993). Interpretación e superinterpretación. São Paulo: Martins Fontes. 
Fernández Marcial, V.; Gomes, L. I. E.; Marques, M. B. P. S. M. (2015). Perspetiva teórica e metodológica em sistemas de informacão complexos. Páginas $a \xi b$ : arquivos e bibliotecas. Lisboa. $\mathrm{N}^{\mathrm{o}}$ 4: 3-21.

Fondin, H. (2005). La Science de l'information ou le poids de l'histoire. GRESEC | Les Enjeux de l'information et de la communication: 35-54.

Goffman, W. (1970). Information science: discipline or disappearance. ASLlB Proceedings, 22 (12): 589-596.

Hjorland, B. (2002). Epistemology and the socio-cognitive perspective in information science. Journal of the American Society for Information Science and Technology, 5 (4): 257-270.

Larsen, R. L. (2008). History of the iSchools. University of Pittsburgh, School of Information Sciences.

Le Coadic, Y.-F. (1996). A Ciência da Informação. Brasília: Briquet de Lemos.

Marques, M. B. P. S. M. (2012). A satisfação do cliente de Serviços de Informação: As bibliotecas públicas da região centro. Tese de Doutoramento. Disponível em: https://estudogeral.sib.uc.pt/handle/10316/20462?mode=full

Marques, M. B. P. S. M. (2013). The value of information and information services in knowledge society. In Rethinking the conceptual base for new practical applications in information value and quality. Pennsylvania, USA: IGI Global. Cap. 7, p. 134-161.

Marques, M. B. P. S. M. (2015). Informação, comunicação e conhecimento: os desafios da sociedade do século XXI. In Congresso da Associação Portuguesa de Ciências da Comunicação - SOPCOM (Sociedade Portuguesa de Comunicação), $9^{\circ}$, Coimbra, 12-14 novembro de 2015, vol. 1, p. 48-62

Marques, M. B. P. S. M. (2016). O paradigma formativo do arquivista em Portugal. Boletim do Arquivo da Universidade de Coimbra. Coimbra. $\mathrm{N}^{\circ} 29$, p. 323-346. http://dx.doi.org/10.14195/2182-7974_29_6

Marques, M. B. P. S. M. (2017). Gestão da Informação em Sistemas de Informação Complexos. Pesquisa Brasileira em Ciência da Informação e Biblioteconomia. João Pessoa, 12 (2): 60-76.

Marques, M. B. P. S. M. (2018). O fenómeno e o processo de construção da memória organizacional na Sociedade do Conhecimento. In Narrativas Mediáticas e Comunicação: Construção da Memória como Processo de Identidade Organizacional, João Figueira e Ana Teresa Peixinho (Editores). Coimbra: Imprensa da Universidade de Coimbra. (Investigação).

Marques, M. B. P. S. M. \& Gomes, L. I. E. (2014). A comunicação da produção científica em Ciência da Informação: um estudo das publicações em línguas ibéricas indexadas na WoS (Web of Science) e na Scopus. In CONGRESSO MUNDIAL DE COMUNICAÇÃO IBERO_AMERICANA - CONFIBERCOM (Confederação Iberoamericana de Associações Científicas e Académicas de Comunicação), $2^{\circ}$, Braga, 13 a 16 de abril- atas, p. 468-484.

Saracevic, T. (1996). Ciência da informação: origem, evolução e relações. Perspectivas em Ciência da Informação, 1 (1): 41-62. Belo Horizonte.

Shera, J. H.; Cleveland, D. B. (1977). History and foundations of Information Science. Annual Review of Information Science and Technology, 12: 249-275. 
Silva, A. M. da (2006). A Informação: da compreensão do fenómeno e construção do objecto científico. Porto: Edições Afrontamento; CETAC.COM.

Silva, A. M. da; Ribeiro, F. (2008). Das "ciências" documentais à ciência da informação: ensaio epistemológico para um novo modelo curricular. 2. ed. Porto: Edições Afrontamento.

Toffler, A. (1981). The third wave. New York: Bantan Books.

Toffler, A.; Toffler, H. (2006). La revolución de la riqueza. Barcelona: Debate.

Zins, C. (2006). Redefining information science: from "information science" to "knowledge science". Journal of Documentation, 62(4), 447-461.

Williams, M. E. (1987/1988). Defining information science and the role of ASIS. Bulletin of the American Society for Information Science. 14 (2), 17-19.

\section{Anexos}

ANEXO 1 - Information Schools ou iSchools

\section{iCaucus}

Drexel University: College Computing \& Informatics (USA, North America Region)

University of Pittsburgh: School of Computing and Information (USA, North America Region)

Syracuse University: School of Information Studies (USA, North America Region)

University of Michigan: School of Information (USA, North America Region)

University of Washington: The Information School (USA, North America Region)

Florida State University: College of Communication and Information (USA, North America Region)

University of Illinois at Urbana-Champaign: School of Information Sciences(USA, North America Region)

Indiana University: School of Informatics, Computing, and Engineering (USA, North America Region)

University of North Carolina at Chapel Hill: School of Information and Library Science (USA, North America Region)

University of Texas: School of Information (USA, North America Region)

University of California, Berkeley: School of Information (USA, North America Region)

University of California, Irvine: Donald Bren School of Information and Computer Sciences (USA, North America Region)

University of California, Los Angeles: Graduate School of Education and Information Studies (USA, North America Region)

Georgia Tech: College of Computing (USA, North America Region)

University of Maryland: College of Information Studies (USA, North America Region) 
The Pennsylvania State University: College of Information Sciences and Technology (USA, North America Region)

Rutgers, The State University of New Jersey: School of Communication and Information (USA, North America Region)

University of Toronto: Faculty of Information (Canada, North America Region)

Carnegie Mellon University, Heinz College: School of Information Systems and Management School of Public Policy and Management (USA, North America Region)

Humboldt-Universität zu Berlin: Berlin School of Library and Information Science (Germany, Europe Region)

Wuhan University: School of Information Management (China, Asia Pacific Region)

University of Maryland, Baltimore County: Department of Information Systems(USA, North America Region)

University of North Texas: College of Information (USA, North America Region)

The University of Sheffield: Information School (UK, Europe Region)

University of British Columbia: The School of Library, Archival \& Information Studies (Canada, North America Region)

University of Kentucky: College of Communications and Information(USA, North America Region)

University of Wisconsin-Milwaukee: School of Information Studies (USA, North America Region)

University of Missouri: School of Information Science and Learning Technologies (USA, North America Region)

The University of Tennessee: School of Information Sciences (USA, North America Region)

University of Arizona: School of Information (USA, North America Region)

Cornell University: Faculty of Computing and Information Science (USA, North America Region)

Kent State University: School of Information (USA, North America Region)

Renmin University of China: School of Information Resource Management(China, Asia Pacific Region)

Peking University: Department of Information Management (China, Asia Pacific Region)

San Jose State University: School of Information (USA, North America Region)

Central China Normal University: School of Information Management (China, Asia Pacific Region)

\section{Enabling}

There are currently no members at this level.

\section{Sustaining}

University of Copenhagen: Department of Information Studies (Denmark, Europe Region) 
University of Tampere: School of Information Sciences (Finland, Europe Region)

University of Boras: The Swedish School of Library and Information Science(Sweden, Europe Region)

Oslo Metropolitan University: Department of Archivistics, Library and Information Science (Norway, Europe Region)

Indiana University-Purdue University Indianapolis: School of Informatics and Computing (USA, North America Region)

Linnaeus University: Information Institute (Sweden, Europe Region)

\section{Supporting}

Northumbria University: Department of Computing and Information Sciences(UK, Europe Region)

Michigan State University: Department of Media and Information (USA, North America Region)

Sungkyunkwan University: Library and Information Science and Data Science(Korea, Asia Pacific Region)

University of South Carolina: School of Library \& Information Science (USA, North America Region)

\section{Basic}

University College, Dublin: School of Information and Communication Studies(Ireland, Europe Region)

University College London: Department of Information Studies (UK, Europe Region) Nanjing University: School of Information Management (China, Asia Pacific Region)

University of Amsterdam: Graduate School of Humanities, Archives and Information Studies (Netherlands, Europe Region)

Open University of Catalonia: Faculty of Computer Science, Multimedia and Telecommunications (Spain, Europe Region)

University of Glasgow: Humanities Advanced Technology and Information Institute (UK, Europe Region)

University of Melbourne: Department of Computing \& Information Systems(Australia, Asia Pacific Region)

University of Porto: Faculty of Engineering in cooperation with the Faculty of Arts (Portugal, Europe Region)

University of South Australia: School of Information Technology \& Mathematical Sciences (Australia, Asia Pacific Region)

University of Tsukuba: Graduate School of Library, Information, and Media Studies (Japan, Asia Pacific Region)

Polytechnic University of Valencia: School of Informatics (Spain, Europe Region)

IMT Atlantique: Department of Logic Uses, Social Sciences and Information(France, Europe Region) 
Charles Sturt University: School of Information Studies (Australia, Asia Pacific Region) Universidade Nova de Lisboa: Information Management School (Portugal, Europe Region) Universtiät Siegen: School of Media and Information (Germany, Europe Region)

University of Strathclyde: Computer and Information Sciences (UK, Europe Region)

University of Wisconsin-Madison: School of Library and Information Studies (USA, North America Region)

McGill University, Montreal: School of Information Studies (Canada, North America Region)

Seoul National University: Graduate School of Convergence Science and Technology (Korea, Asia Pacific Region)

Simmons, Boston: School of Library and Information Science (USA, North America Region)

Sun Yat-sen University, Guangzhou: School of Information Management(China, Asia Pacific Region)

Yonsei University: Library and Information Science (Korea, Asia Pacific Region)

Bar-Ilan University: Department of Information Science (Israel, Europe Regio

Universidad Carlos III de Madrid: Departamento de Biblioteconomía y Documentación, Facultad de Humanidades, Comunicación y Documentación(Spain, Europe Region)

Charles University Prague: Institute of Information Studies and Librarianship, Faculty of Arts (Czech Republic, Europe Region)

Robert Gordon University: Department of Information Management of Aberdeen Business School (UK, Europe Region)

Hacettepe University: Department of Information Management, Faculty of Letters (Turkey, Europe Region)

Makerere University: The College of Computing and Information Sciences(Uganda, caucuses with Europe Region)

University of Hong Kong: Division of Information and Technology Studies(Hong Kong, Asia Pacific Region)

Universidade do Minho: ALGORITMI Center School of Engineering (Portugal, Europe Region)

Oxford Digital Information Group (UK, Europe Region)

National Taiwan Normal University, Graduate Institute of Library and Information Studies (Taiwan, Asia Pacific Region)

University of Waikato: Faculty of Computing and Mathematical Sciences (New Zealand, Asia Pacific Region)

Dominican University: School of Information Studies (USA, North America Region)

Long Island University: Palmer School of Library \& Information Science (USA, North America Region)

University of Montréal: Université de Montréal École de bibliothéconomie et des sciences de l'information (Canada, North America Region)

Aalborg University: Department of Communication and Psychology (Denmark, Europe Region) 
University at Albany: College of Emergency Preparedness, Homeland Security and Cybersecurity(USA, North America Region)

Manchester Metropolitan University: Information and Communications (UK, Europe Region)

Universiti Teknologi MARA: Faculty of Information Management (Malaysia, Asia Pacific Region)

Pontificia Universidad Javeriana: Departamento de Ciencia de la Información(Colombia, caucuses with North America Region)

National Taiwan University: Department and Graduate Institute of Library and Information Science (Taiwan, Asia Pacific Region)

Khon Kaen University: Faculty of Humanities and Social Sciences, Department of Information Science (Thailand, Asia Pacific Region)

Kyungpook National University: Department of Library and Information Science (Korea, Asia Pacific Region)

\section{Associate}

National Chengchi University: Graduate Institute of Library Information and Archival Studies (China, Asia Pacific Region)

University of Colorado: Boulder: Department of Information Science (USA, North America Region)

University of the Philippines: School of Library and Information Studies(Philippines, Asia Pacific Region)

Pratt Institute, School of Information (USA, North America Region)

University of South Florida: School of Information (USA, North America Region)

Texas A\&M University - Kingsville: Department of Electrical Engineering \& Computer Science (USA, North America Region)

State University of New York at Buffalo: Department of Information Science(USA, North America Region)

Wayne State University: School of Information Sciences (USA, North America Region)

Kyushu University: Department of Library Science, Graduate School of Integrated Frontier Sciences (Japan, Asia Pacific Region)

University of Oklahoma: School of Library and Information Studies (USA, North America Region)

\section{ANEXO 2 - Índice de Figuras}

Fig. 1 - iSchools da Ásia e Oceania

Fig. 2 - iSchools da Europa

Fig. 3 - iSchools da América do Norte e do Sul 
Fig. 4 e 5 - Representatividade dos Países/Universidades no movimento das iSchools Fig. 6 - QS TOP 25 UNIVERSITIES 2018

Fig. 7 - Representatividade das iSchools no QS TOP 25 UNIVERSITIES 2018

Fig. 8 - Análise das iSchools no QS TOP 25 UNIVERSITIES 2018

Fig. 9 - Análise das Schools no QS TOP 25 UNIVERSITIES 2018

Fig. 10 - QS TOP 25 UNIVERSITIES 2019

Fig. 11 - Representatividade das iSchools no QS TOP 25 UNIVERSITIES 2019

Fig. 12 - Análise das iSchools no QS TOP 25 UNIVERSITIES 2019

Fig. 13 - Análise das Schools no QS TOP 25 UNIVERSITIES 2019

Fig. 14 - Escolas que não pertencem ao consórcio das iSchools - QS TOP 25 UNIVERSITIES 2018/2019

Fig. 15 - Tendências formativas do QS TOP 25 UNIVERSITIES 2018/2019 
(Página deixada propositadamente em branco) 


\title{
CIENCIAS DE LA DOCUMENTACIÓN EN ESPAÑA: SITUACIÓN Y CAMBIOSA NIVEL DE ESTUDIOS D E G R A D O
}

\author{
DOCUMENTATION SCIENCES IN SPAIN: CURRENT \\ SITUATION AND CHANGESAT THE LEVEL OF \\ DEGREESTUDIES
}

\begin{abstract}
CI ÊNCIAS DA DOCUMENTAÇÃO EM ESPANHA: SITUAÇÃO ATUAL E MUDANÇAS AO NíVEL DOS ESTUDOS DE GRADUAÇ ÃO
\end{abstract}

Sara Martínez Cardama

Universidad Carlos III de Madrid smarti1@bib.uc3m.es ORCID: https://orcid.org/0000-0001-7035-5884

Mercedes Caridad Sebastián Universidad Carlos III de Madrid mercedes@bib.uc3m.es ORCID: https://orcid.org/0000-0001-7486-8353

RESUMO - Se presenta una reflexión sobre la situación de las Ciencias de la Documentación en España. Se debate sobre su situación conceptual, sus límites y retos. El texto se estructura en dos apartados, en primer lugar, uno dedicado a debatir el estado actual de la disciplina en cuanto a sus límites teóricos. 
Se reflexiona sobre el papel de la tecnología en la disciplina, así como el reto que supone cómo afrontar su interdisciplinaridad y la definición de las competencias core en este nuevo entorno. En la segunda parte, se plasma la situación actual de los planes de estudio de grado en España, y cómo se ha afrontado la crisis de nuestros estudios mediante la formación de dobles grados y la creación de títulos universitarios nuevos.

PALABRAS CLAVE - Ciencias de la Documentación; Planes de estudio; Educación.

ABSTRACT - A reflection about the situation of the Documentation Science in Spain is presented. There is a debate about its conceptual situation, its limits and challenges. The text is structured in two sections, first, one dedicated to discussing the current state of the discipline in terms of its conceptual limits. It reflects the role of technology in the discipline as well as the challenge of how to deal with its interdisciplinary and the definition of core competencies in this new environment. In the second part, the current situation of curriculum in Spain is presented, and how the crisis of our studies has been tackled through the creation of double degrees and the creation of new university degrees. KEYWORDS - Documentation Sciences; Study plans; Education.

RESUMO - Apresenta-se uma reflexão sobre a situação das Ciências da Documentação em Espanha. Debatem-se os aspetos conceptuais, os seus limites e desafios. O texto está estruturado em duas partes, uma dedicada à discussão do estado atual da disciplina, no que respeita aos seus limites teóricos. Reflete-se sobre o papel da tecnologia na disciplina, bem como o desafio de como enfrentar a sua interdisciplinaridade e a definição de competências essenciais nesse novo cenário. Na segunda parte, analisa-se a situação atual dos planos de estudo de graduação 
em Espanha, e como se enfrentou a crise dos nossos estudos através da formação de graus duplos e da criação de novos títulos universitários.

PALAVRAS-CHAVE - Ciências da Documentação; Planos de estudo; Educação.

\section{Introducción}

El estudio de las Ciencias de la Documentación en España, bajo el nombre de Biblioteconomía y Documentación para los estudios de primer ciclo, Documentación para los de segundo ciclo, y, posteriormente bajo el tándem de Información y Documentación tras la adaptación al proceso de Bolonia ha pasado por varias etapas hasta la situación actual. La realidad de estudio siempre es compleja, aún si bien esta lo es más, dado a las fuertes interconexiones de la Documentación como Ciencia, que la dota de un carácter interdisciplinar.

Los inicios de la formación reglada a nivel de grado se dieron con la Diplomatura en los años 80, alcanzando su máximo histórico de alumnado en el curso 1997/1998 (Ortiz-Repiso, Calzada y Aportela, 2013).Tras esta, los modelos de estudios de segundo ciclo implantados en los años 90, la demanda de digitalización de las empresas, la necesidad de dotar de recorrido a las enseñanzas

de primer ciclo, así como el auge de las plazas y proyectos en el sector público, entre otras causas, auparon nuestros estudios alcanzando un buen número de alumnos y grupos de enseñanza numerosos. No obstante, con la llegada del nuevo milenio comenzó, pese a los buenos datos de matrícula de la Universidad española en general, una caída y sangría del alumnado marcada a tenor de autores como Delgado-López-Cózar (2007) en factores endógenos más que exógenos, atribuidas a la configuración de los estudios 
y visibilidad de la disciplina. En 2008, comenzó a implantarse el Grado en Información y Documentación, con el fin de adaptarse al proceso de Bolonia, pero también para dar respuesta a la reciente caída de la demanda de estudiantes, así como para adaptarse a un mercado laboral incipiente en el que la ausencia del empleo público comenzaba a hacer mella. La adaptación al nuevo entorno tecnológico y el aprendizaje de estas competencias fueron clave en la mutación. La transformación de los títulos se originó en el Libro Blanco (Aneca, 2004) que guio el diseño de los grados. La implantación de estos estudios, como puede verse en Ortiz-Repiso, Calzada y Aportela (2013), funcionó los primeros cursos. A la vez, fue visto de manera positiva ya que constituía un avance hacia nuevas competencias más orientadas a la actualidad del mercado laboral y el sector privado y convergentes con nuevas tendencias internacionales marcadas por consorcios internacionales como la de Ischools, que pivota sobre tres elementos clave: la información, la tecnología y las personas.

No obstante, en la actualidad y desde cursos recientes, los modelos de grado actuales en España han sido ampliamente debatidos y cuestionados. Las soluciones implantadas han sido varias: desde la aparición de nuevas titulaciones hasta la formación de dobles grados, que comenzaron con disciplinas como Periodismo o Comunicación, para extenderse por el panorama nacional como una opción formativa más atractiva.

En el presente texto se pretende presentar las principales transformaciones a nivel de grado en el ámbito de las Ciencias de la Documentación. Dado que el debate en España se ha forjado fundamentalmente en este nivel académico, se descartan los estudios de Máster o Doctorado. Asimismo, se realiza un recorrido por los retos conceptuales de la Documentación en la actualidad y se reflexiona sobre si los cambios recientes en los planes de estudio afectarán a la configuración de la disciplina. 


\section{Retos conceptuales para la Ciencia de la Documentación}

Uno de los retos fundamentales de la disciplina como tal, es conocer qué somos, definir nuestro núcleo y límites conceptuales. Esto constituye un reto a la hora de definir planes de estudio.

Un primer punto en el que debemos pararnos es, la ausencia de un bagaje teórico fuerte en Documentación (o Library and Information Science). Durante años fue notoria la ausencia de un corpus teórico sólido en el ámbito de la Biblioteconomía y Documentación. Esta ausencia de "Teorías" fue puesta de manifiesto por Hjørland (1998). Pettigrew y Mackechnie concluyeron, no obstante, en 2001, una no desdeñable presencia de $34.1 \%$ del uso de teorías en artículos en el área LIS, con una marcada tendencia ascendente. Sin embargo, reconocen un escaso debate y citación de estas aportaciones teóricas en los 1160 artículos analizados.

El nacimiento de la Documentación como Ciencia auxiliar, conlleva la natural interdisciplinaridad en su formulación. Como recogen Martínez Cardama y Caridad Sebastián (2017) los ejemplos de la interdisciplinariedad son la base para muchas disciplinas, así, por ejemplo, Teorías económicas van de la mano de postulados filosóficos (teoría de la Racionalidad, la Teoría de juegos, la Incertidumbre...). En cuanto al ámbito de la Biblioteconomía y Documentación su estructura es en sentido amplio interdisciplinar (Saracevic, 1995) señalándola Nolin y Aström (2010) como "una naturaleza fragmentada". Algo que estos autores consideran como un elemento de valor añadido, frente a características anteriormente negativas como: el difícil establecimiento de límites y la ausencia de un núcleo disciplinar claro.

García Marco (2013) llama a la necesidad de clarificar la misión, el nicho ecológico y objetivos estratégicos de nuestra disciplina, y más concretamente de nuestros estudios. Esto ha de realizarse de forma teórica, intentando sistematizar su dominio, límites y relaciones con 
otras ciencias, y empírica, esto es de manera práctica, analizando qué se investiga y qué interesa a los profesionales de la información.

En cuanto a lo primero, el espacio transdisciplinar que constituye la "Información" puede analizarse desde diferentes primas. A tenor de García Marco (2013), tres son los aspectos esenciales:

La comprensión de la realidad a través del concepto de información (science of information), el espacio específico de la vida social como preservación e intercambio de conocimiento (social information science) y la inserción e invención de las tecnologías en el marco de las unidades sociales especializadas en esas funciones.

En cuanto al primer punto, el concepto de Información está fuertemente marcado por el de complejidad (Martínez Cardama y Caridad Sebastián, 2017). Estas autoras recogen cómo en el área de la Information Science, Bawden y Robinson (2015) sitúan la Información dentro de una perspectiva compleja, enmarcándola en conceptos como el orden y la organización, pero también el caos y la entropía. Este mismo autor en 2007 , había ya estudiado el concepto unificado de información como sistema autoorganizativo complejo en los dominios de la Física, la Biología y las Ciencias Humanas. La complejidad le ayuda a ofrecer una definición de información que sea un puente entre varias disciplinas, y que, a su vez la Information Science pueda servir de nicho conceptual a otros campos de conocimiento.

Esta conexión con otras disciplinas, también se percibe en la práctica laboral en las unidades de información, donde la convivencia con profesionales de distinto bagaje formativo hace que la práctica laboral de la Documentación se vuelva particularmente compleja y difícil de delimitar.

En este espacio, hemos de definirnos en un espacio conjunto con profesionales del ámbito de la Informática o la gestión. Esta 
conexión, es enriquecedora debido a la constante colaboración entre disciplinas, puede volverse en contra a efectos laborales o de definición de la disciplina.

A nivel académico, Delgado-López Cózar (2008) ya apuntó que la ausencia de la disciplina de Documentación como materia básica en los nuevos grados, es decir aquellas de carácter elemental en la formación inicial del estudiante, fue una oportunidad perdida para los estudios, dado su carácter transversal y auxiliar para otros estudios. Este hecho hubiera significado un reconocimiento social y universitario a la disciplina como saber científico. Pérez Agüera, recogía el pensamiento de López Cózar al hablar sobre la investigación en Documentación, su calidad y déficit de internacionalización como causa de este declive, ya que docencia e investigación van de la mano.

No obstante, se ha trabajado e intensificado mucho esta vía en la última década. Los requisitos de acreditación a cuerpos docentes, junto con los nuevos criterios para méritos de investigación (sexenios) exigen la publicación de resultados de investigación en revistas muy bien posicionadas (cuartiles 1 y 2 ) de los índices de calidad JCR y Scopus. Asimismo, sí se ha percibido una mejora internacional tanto en la investigación como en la inclusión de algunos departamentos de Biblioteconomía y Documentación en los rankings internacionales. Esto, no obstante, no ha conllevado una mayor visibilidad de la disciplina a nivel de estudios de grado.

En la redefinición constante de la disciplina, la aceptación de la revolución digital ha constituido un elemento clave (García Marco, 2013). Como menciona este autor, en España la configuración del grado en Información y Documentación siempre se dirigió hacia la gestión de la información, dejando en un segundo plano la apertura digital. Si retrocedemos unos años, era frecuente encontrar el debate entre los tecnófobos, defensores del perfil humanístico de la disciplina, y los digitales, que querían realizar esa transición. Hoy, sin embargo, se trata de una discusión que carece de sentido. 
La tecnología ha reformulado de manera práctica la concepción de casi todas las disciplinas, en particular de las Ciencias de la Documentación. No se entiende ya hablar de la disciplina si no es en digital. Palabras como "bibliotecas digitales" no constituyen más que un pleonasmo y un vocablo ampliamente utilizado por todos, ya que cualquier biblioteca, archivo o centro de documentación contempla la perspectiva digital.

En el debate sobre la biblioteca digital y sus significados, se justifica esta disertación debido a los cambios prácticos que fuerzan el debate conceptual. Sin embargo, es importante reflexionar sobre qué papel le queremos dar a la tecnología en la configuración conceptual de la disciplina. Se reflexiona poco sobre ello.

Martínez Cardama (2017) recoge reflexiones sobre su papel y su incidencia en la configuración conceptual de la Library and Information Science. Es preciso señalar que la Tecnología, aunque no siempre, se suele basar en la Ciencia que intenta explicar la realidad, hechos y las propiedades de los fenómenos. Sin embargo, igual que en las técnicas, las tecnologías tienen en común el usar esa información o conocimiento para transformar la materia. Así, de acuerdo con Herbert Simon, la Tecnología "no es más que otro nombre al conocimiento humano" (1973), de esta manera no reside en los artefactos sino en las personas en las que las inventan y las usan. Este último punto es especialmente relevante y adquiere gran contemporaneidad por el hecho de la posibilidad de los usuarios de constituir una fuerza productiva con una influencia directa en la elaboración, es el caso del papel que adquieren en tecnologías sociales y colaborativas.

$\mathrm{El}$ aspecto fundamental de este tema es que la tecnología no es simplemente una aplicación de la ciencia o un elemento basado en la misma. Existe conocimiento científico que no logra tener aplicación tecnológica, así que la afirmación no puede establecerse en términos absolutos. 
También resulta esencial para abrir posibilidades y crear oportunidades desde una perspectiva evolucionista de la tecnología. Este espacio (este nuevo marco social) constituye un lugar lleno de alternativas posibles, donde se puede configurar el futuro en lo que depende de la acción humana. A diferencia de las técnicas, la Tecnología es un sistema de instituciones que no ha existido siempre, es un producto de la sociedad contemporánea (Broncano, 2002).

El espacio digital se ha configurado un nuevo espacio conceptual, discursivo y con una narratividad propia. El estudio de su especificidad ya no corresponde a disciplinas de tipo tecnológico, sino que ocupa el foco de otras de corte humanístico. Así, desde las Humanidades Digitales, por ejemplo, se trata de reformular de manera académica esa conexión. Lo mismo sucede en Documentación.

Ahora que se cumplen 30 años de la web, conviene echar la vista atrás para ver cómo ha afectado esta transformación a nuestros estudios. García Marco (2013) reconoce que, en muchos aspectos, la docena de años que se sitúa entre el despegue de la World Wide Web y la crisis de 2007 fue una época dorada para la profesión en España debido al aumento de producción científica sobre la adopción de tecnología en nuestra área, así como el aumento de puestos de trabajo relacionados y formación ad hoc. No obstante, este autor, reconoce que la disciplina ha confundido los medios con los fines en la revolución digital. La interdisciplinariedad de la disciplina, junto con la adopción de las prácticas digitales, ha podido llevar a perder la esencia o competencias core de la Disciplina.

Resultados recientes (Figuerola, García Marco y Pinto, 2017) señalan un incremento de la disciplina LIS en su conjunto, gracias al auge de disciplinas tecnológicas que generan investigación más especializada. Así, estos autores mencionan el incremento en producción científica en ámbitos como las plataformas educativas online, la información para los medios de comunicación, el patrimonio digital, 
la distribución de contenido, el negocio y la gestión de conocimiento en organizaciones o la información biomédica e Informetría.

Si lo digital está transformando la ventana de publicaciones y los nichos de publicación y la transición a lo digital ya es una realidad: ¿cómo ha de volcarse en los planes de estudios?

Los nativos digitales, constituyen los nuevos egresados, y para ellos, que han nacido con la tecnología, esta no constituye una realidad laboral de manera aislada (salvando estudiantes de Ingeniería Informática, y otras asociadas). Cabe plantearse, por tanto, las vías de acción. García-Marco (2013) plantea una opción inteligente como “cuidar el núcleo y abordar la periferia”. El hecho de que en la configuración de nuevos títulos se puedan desdibujar competencias core, podría suponer perderse en la transversalidad de nuevas titulaciones y dobles grados amplios. En este sentido el autor plantea:

Hemos de aclararnos sobre si queremos estudiantes de humanidades, de sociales, de tecnología o de cualquier cosa, en qué medida, y, sobre todo, cómo arbitrar el tránsito sin estrellarnos nosotros ni sacrificarlos a ellos (García-Marco, 2013, p. 496).

En el núcleo de la disciplina todavía hay elementos que, si bien merecen ser reformulados, no pueden dejarse a un lado. Es el caso de la Catalogación y Clasificación, que si bien, adaptada al entorno digital, sigue generando demanda en puestos de trabajos y está presente en la oferta de empleo público. Otro caso sin resolver en España, y que atañe a nuestros departamentos, como menciona García-Marco (2013), son las bibliotecas escolares, sin regulación ni marco presupuestario claro. Constituye un fracaso que debe abordarse desde una perspectiva realista con los docentes y departamentos de Educación.

En cuanto a la periferia que menciona el autor, esta se está ampliando y se convierte, en el propio núcleo de muchos planes de estudio reformulados. Así, la gestión de contenidos, el marketing 
digital y la gestión de la reputación online en redes sociales constituyen ya líneas claras de formación de los nuevos grados, cuyo panorama se presenta en el nuevo epígrafe.

\section{La situación de las Ciencias de la Documentación a través de las titulaciones de grado en España}

Para abordar la situación actual de las Ciencias de la Documentación en España, lo más operativo es valorar la actual situación de los estudios en las diferentes facultades. Para ello, hemos de acudir a RUID, la red de todos los centros de departamentos universitarios españoles de Información y Documentación con el fin de compartir experiencias e iniciativas con respecto a la puesta en marcha de los nuevos planes de estudio adaptados al EEES. Este grupo tuvo su origen en el grupo de trabajo que redactó el Libro Blanco de Información y Documentación en 2004. Los centros que componen esta red son:

- Universidad Carlos III de Madrid (UC3M)

- Universidad Complutense de Madrid (UCM)

- Universidad de Alcalá de Henares (UAH)

- Universidad de Extremadura (UEX)

- Universidad de Granada (UGR)

- Universidad de León (Unileon)

- Universidad de Murcia (UM)

- Universidad de Salamanca (USAL)

- Universidad de Valencia (UV)

- Universidad de Zaragoza (Unizar);

- Universidad Politécnica de Valencia (UPV)

- Universidade de A Coruña (UDC)

- Universitat de Barcelona (UB)

- Universitat Oberta de Catalunya (UOC)

- Universitat Pompeu Fabra (UPF). 
Algunos ya no imparten la titulación, como es el caso de la Universidad de Alcalá de Henares o la Universitat Oberta de Catalunya como se mencionará posteriormente.

Ortiz Repiso, Calzada y Aportela (2013) dieron cuenta de la situación en cuanto a: - oferta de titulaciones; - matrícula y número de egresados en el último quinquenio; - tasas de abandono - participación en otras titulaciones - fortalezas y debilidades. Las conclusiones obtenidas son desalentadoras en cuanto a la baja tasa de matrícula y de abandono. Esta tendencia contrarresta la tendencia alcista de estos estudios en posgrado y Doctorado. Entre las conclusiones que se debatían en 2013 para las titulaciones, estas versaban sobre la "revisión y actualización de los planes de estudio de los grados en información y documentación, teniendo en cuenta las nuevas condiciones y enfoques profesionales en el mercado laboral" (Ortiz Repiso, Calzada y Aportela, 2013). Estas conclusiones todavía son vigentes en debates profesionales actuales, y el devenir de los grados así lo ha demostrado. Así, los datos de 2016 (De la Moneda, 2018) ya apuntaban a que este tipo de reflexiones habían originado la transformación en mayor o menor medida de los títulos universitarios.

A través de los centros que conforman la red, pueden detectarse las tendencias que configurarán los estudios y la disciplina de las Ciencias de la Documentación en los siguientes años. Se señalan tres de las tendencias detectadas: la formación de dobles grados, la formación por itinerarios y la creación de títulos nuevos.

\subsection{La formación de dobles grados}

Este es el caso de universidades como la Universidad de Salamanca, que ha optado por lanzar dobles grados con disciplinas colindantes con las Ciencias de la Documentación: 


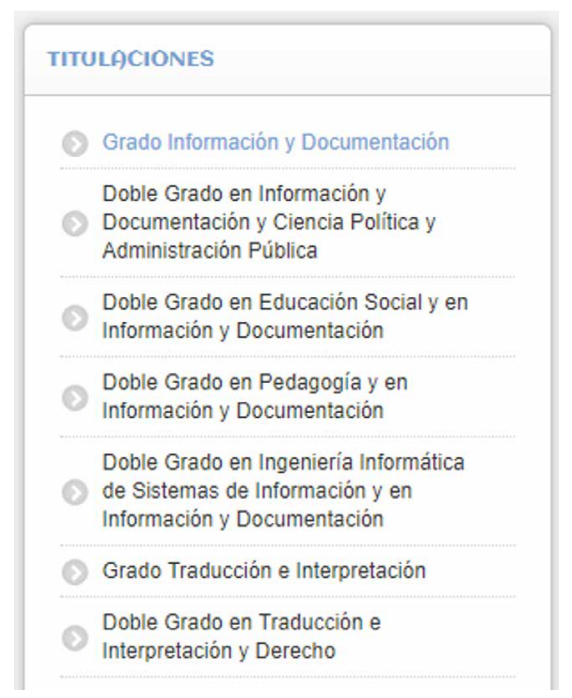

Figura 1: Oferta de grados en la Universidad de Salamanca $(2017 / 2018)$

Así, al margen de nuestro grado en solitario, este se combina con Ciencia Política y Administración Pública, Educación Social, Ingeniería Informática y Pedagogía. Estos dobles grados se orientan a la obtención de competencias transversales en ambas especialidades. Con ellos se adquiere un doble perfil que capacita al educando a desarrollar habilidades en el ámbito de la Documentación, pero también en otros campos relacionados. Al cubrir ambas competencias, constituyen planes de estudios de 6 años en vez de cuatro, en los que una vez finalizados, se obtienen ambos títulos por separado.

En este sentido, la vía que parece más natural para la formación de dobles grados, debido al origen de las Ciencias de la Documentación en España, es el ámbito competencial de INFOCOM, esto es, las propias Ciencias de la Información. Con esta Disciplina, ya sea en la rama de Periodismo o Audiovisual se tiene grandes puntos en común y, dada su popularidad entre el estudiantado, puede ayudar a incrementar la popularidad de los estudios en Información y Documentación (Abadal, 2013). 
Así, la Universidad de Barcelona plantea el doble grado precisamente bajo el epígrafe INFOCOM, en Información y Documentación y Comunicación Audiovisual. Esto se justifica debido a la estrecha relación entre ambas disciplinas. En este caso se plantea el doble itinerario para obtener los dos títulos de grado en 10 semestres, matriculando un total de 348 créditos.
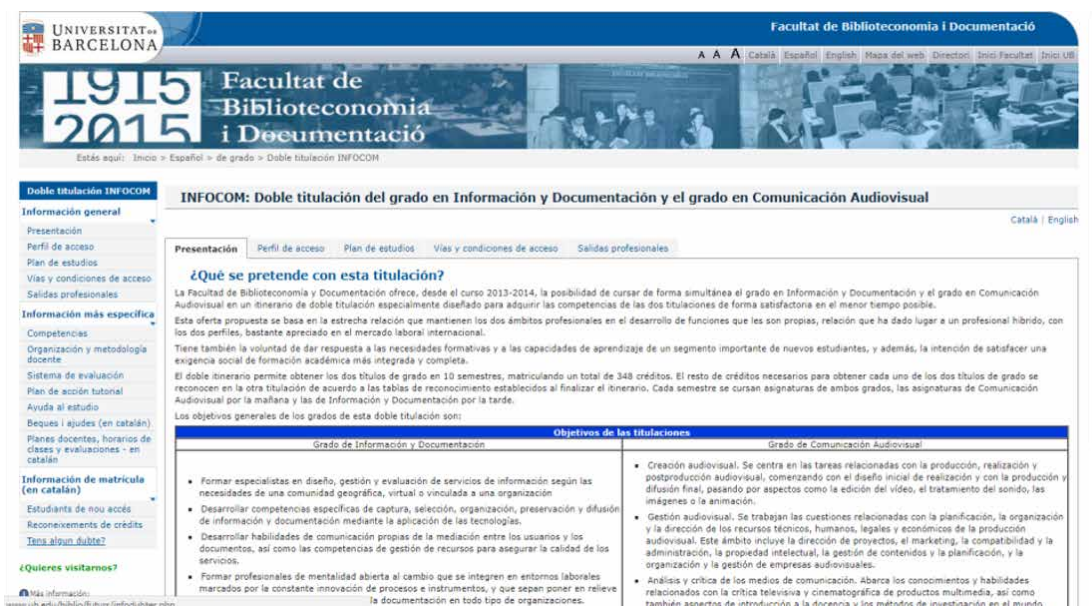

Figura 2: Doble grado en Información y Documentación y Comunicación Audiovisual en la Universitat de Barcelona

Otro caso dentro del ámbito de la Información es el grado de la Universidad de Murcia. Bajo el epígrafe "Programa de Estudios Simultáneos en Periodismo e Información y Documentación" se presenta un grado de 5 años en los que el estudiante adquirirá una "serie de competencias y habilidades estrechamente vinculadas a contenidos que se imparten habitualmente en el Grado de Información y Documentación, como es el interactuar con productores, usuarios y clientes de servicios de información digital; un conocimiento básico del marco jurídico y administrativo del uso, gestión y reutilización de la información; la identificación y evaluación de fuentes y recursos de información para el trabajo diario o la elaboración de informes; el análisis y representación de la información; el uso de sistemas gestores de contenidos 
digitales incluyendo las técnicas de organización, almacenamiento y recuperación de información" (Universidad de Murcia, 2018).

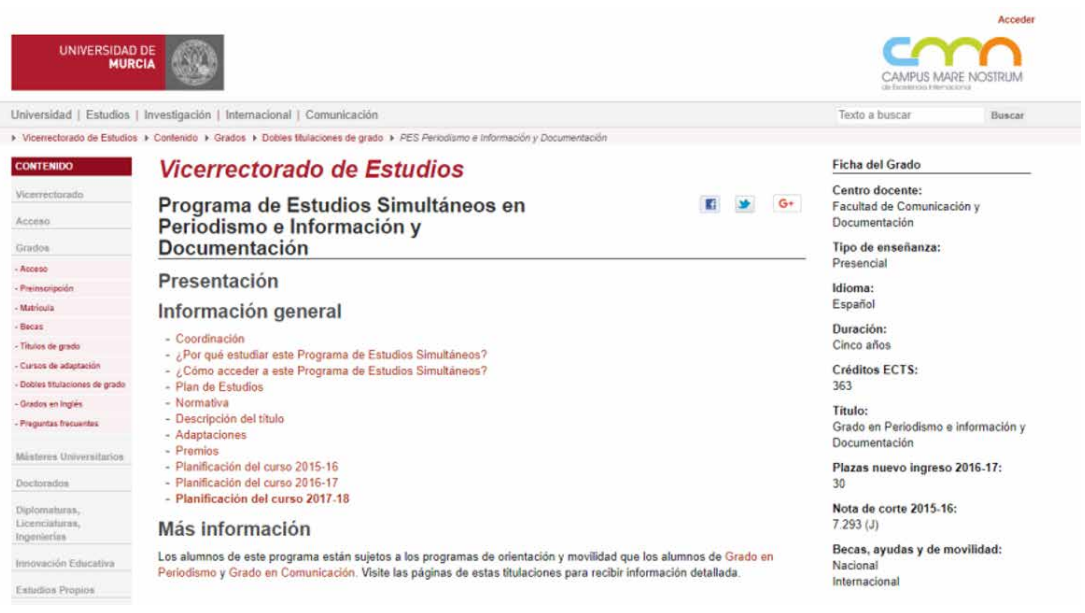

Figura 3: "Programa de Estudios Simultáneos en Periodismo e Información y Documentación" de la Universidad de Murcia

La formulación de estos dobles grados tiene como ventajas:

- Una formación más transversal a través del estudio de dos disciplinas que se complementan

- Un perfil de profesional con unas competencias más amplias y con mayor capacidad de adaptación a un entorno

- Ratios de matrícula más elevados

No obstante, plantean miedos y posibles consecuencias futuras:

- Pérdida de competencias core del ámbito de las Ciencias de la Documentación. Aunque estos estudios replican modelos formativos del grado en Información y Documentación, siempre existe la posibilidad de dar mayor carga lectiva a la otra disciplina

- Desaparición de la titulación única. Este tipo de grados, al ser dobles, pueden, por su mayor demanda de matrícula fagocitar a la titulación de Información y Documentación

- Pérdida de peso teórico de la disciplina en el entorno universitario 


\subsection{Creación de grados con itinerarios}

El buque insignia de estos estudios por itinerarios en España siempre fue la Universitat Oberta. Su grado de Información y Documentación a distancia representaba un modelo escalable con fuerte presencia de tecnología. Así, al margen de formar en archivos y bibliotecas, también lo hacían en "gestión de datos, macrodatos (big data), catalogación y metadatos, diseño de sistemas de información, documentación sanitaria, gestión documental, documentación audiovisual, gestión del conocimiento, inteligencia competitiva, transparencia, datos abiertos (open data), gestión de comunidades (community management), gestión de contenidos (content curator), repositorios documentales, SEO y analítica web, diseño centrado en el usuario, y muchos otros (Universitat Oberta, 2018).

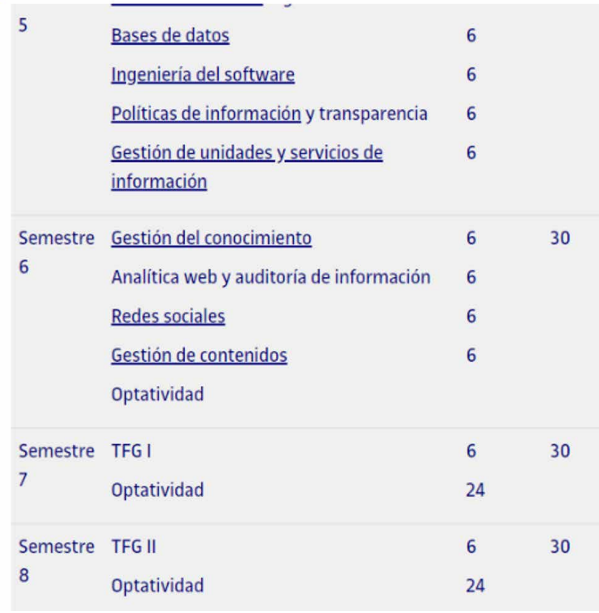

Figura 4: Programa del Grado en Información y Documentación de la Universitat Oberta

El grado en Información y Documentación sí formaba en estos contenidos, sin embargo, la peculiaridad de la UOC, era la gran optatividad conformada alrededor de 3 perfiles: Gestión de servicios de información, Inteligencia y estrategia empresarial y Experiencia 
de usuario. A pesar de su modelo, en 2018 se anuncia un calendario de extinción para el mismo y la imposibilidad de ofertarse de nuevo.

\subsection{Creación de nuevos títulos}

La última de las opciones que encontramos en el escenario nacional es la creación de títulos nuevos que se adapten más a las nuevas necesidades del mercado. Es el caso de la Universidad Carlos III con la creación e implantación del nuevo grado "Grado en Gestión de la Información y Contenidos digitales" en el curso 2017/2018. Para su elaboración, al margen de la oferta laboral y estudios prospectivos de la profesión se tuvieron en cuenta informes sobre la necesidad de profesionales formados en perfiles digitales nuevos, por ejemplo, el "Libro Blanco para el Diseño de Titulaciones Universitarias en el Marco de la Economía Digital" (2015) que demandaba programas transversales con fuerte contenido tecnológico y de carácter interdisciplinar. Los perfiles más demandados se encuentran en el área del Marketing Digital, Social Media y Community Management y programación y diseño web. Este diseño responde, asimismo, al planteamiento generalista de muchos bachelors de la red de ischools que conforman grados alrededor de disciplinas como Comunicación, Medios Digitales y Computación.

García Marco (2009) apuntaba que la formación de estas escuelas:

reconoce que el fenómeno de la información en nuestros días -que como se ha dicho es resultado de la interacción de contenidos, tecnologías y usuarios- requiere un abordaje y una formación interdisciplinar, que exige atender tanto a la información como a las tecnologías pasando por las necesidades y comportamientos de las personas. Esta constatación acerca a informáticos y profesionales de la información generalistas y especializados a un espacio común. 
Asimismo, reconoce que el cambio de nombre (rebranding) hacia la Información, no es estético, sino que supone una ruptura con la Biblioteconomía. Aunque así se plantearon los grados en Información y documentación, estos, como se mencionaba en la introducción no están aportando buenos datos de matrícula en las diversas universidades del país.

El nuevo grado de la Universidad Carlos III pivota sobre la tecnología de manera transversal, muy en conexión con disciplinas como la Estadística, por ejemplo. Las principales salidas profesionales son la gestión de redes sociales y activos y marketing digital, así como la Edición web.

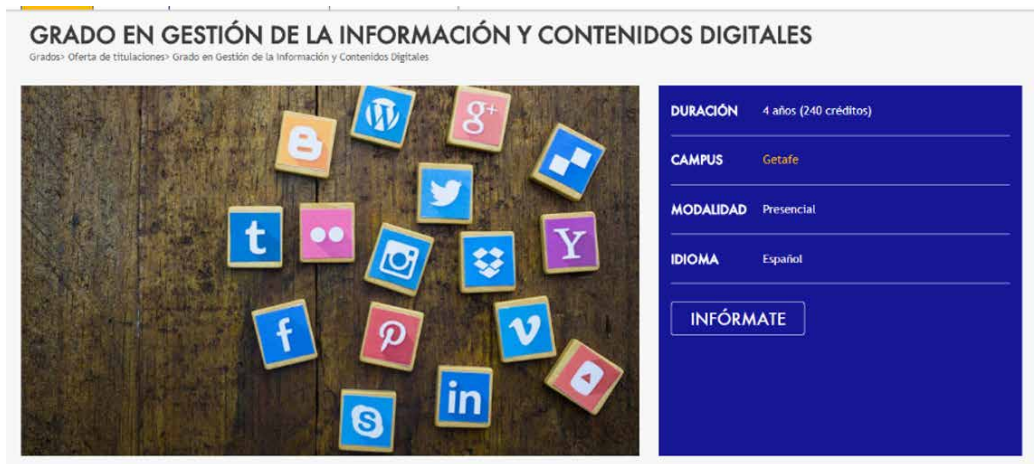

Figura 5: Grado en Gestión de la Información y Contenidos Digitales de la Universidad Carlos III

A esta iniciativa de creación de nuevos títulos se ha sumado para el curso 2019/2020 la Universidad de A Coruña con el título de "Gestión de la Información Digital en Información y Documentación" con conocimientos multidisciplinares en Information Science, Data Science, Big Data y Gestión de Contenidos, entre otros.

\section{Conclusiones}

El estado de las Ciencias de la Documentación en España a nivel académico está fuertemente influenciado por las tendencias que marcan 
los planes de estudio en las distintas universidades. Sin duda, ha habido un ocaso en las titulaciones, en cuanto a número de alumnos y la tasa de abandono. Sin embargo, nos encontramos en un momento esperanzador en el que las distintas propuestas pueden reforzar nuestros estudios.

Por un lado, dobles grados que miran directamente al ámbito de la Ciencia de la Información (nuestra cuna inicial) y que resuelve la dicotomía establecida en la literatura acerca de "Ciencia de Información "y "Ciencias de la Información". Asimismo, el acercamiento a titulaciones de informática podría aportar a nuestros alumnos de competencias más amplias, y adquirirían una mayor visibilidad en el entorno tecnológico donde ciertas funciones son desempeñados por informáticos.

La aparición de nuevos títulos que respondan a la demanda profesional es un horizonte esperanzador, aunque pueda disipar el verdadero núcleo teórico de nuestra disciplina. Asimismo, se considera importante que la formación tecnológica no solo se realice de manera instrumental, sino de manera crítica.

Las Ciencias de la Documentación deben recuperar su papel de apoyo y constituir un elemento fundamental en muchas de las disciplinas con las que compartimos nicho tanto de empleo como de investigación. Asimismo, tampoco es conveniente obviar la necesaria formación patrimonial que demandan profesionales con competencias muy definidas, y que no pueden ser obviadas en la reformulación de los títulos.

\section{Referências Bibliográficas}

Abadal, E. (2013). La biblioteconomía y la documentación en la universidad española a principios del siglo XXI. Nuovi annali della Scuola speciale per archivisti e bibliotecari. Anno XXVII, 211-228

Broncano, F. (2002). Mundos artificiales. Filosofía del cambio tecnológico, Barcelona: Paidós

De-la-Moneda, M. (2018). Las cifras de la enseñanza universitaria en Documentación en España: 2016. Anuario ThinkEPI, v. 12, 15-35.

Delgado-López-Cózar, E. (2008). El ocaso de las enseñanzas universitarias de Documentación en España. Anuario ThinkEPI, 126-129. 
García-Marco, F. J. (2013). Educación y aprendizaje de la información y la documentación: raíces, desafíos y líneas de acción. El profesional de la información, 22, (6), 489504.

García-Marco, F. J. (2009). El movimiento iSchools: posicionando los estudios de biblioteconomía y documentación en la era de la información. Anuario ThinkEPI, (1), 95-99.

Figuerola, C. G., Marco, F. J. G., \& Pinto, M. (2017). Mapping the evolution of library and information science (1978-2014) using topic modeling on LISA. Scientometrics, 112 (3), 1507-1535.

Hjørland, B. (1998). Theory and metatheory of information science: a new interpretation. Journal of documentation 54 (5), 606-621

Martínez Cardama, S. (2015). Estudio de la complejidad estructural y dinámica de la Biblioteca Digital Universitaria: un modelo de cambio basado en el Conocimiento. Universidad Carlos III de Madrid.

Martínez Cardama, S. M., \& Caridad Sebastián, M. C. (2017). La Teoría de la Complejidad en Biblioteconomía y Documentación: análisis y presencia en la investigación. Ibersid: revista de sistemas de información y documentación, 11(2), 13-22.

Nolin, J; Åström, F. (2010). Turning weakness into strength: Strategies for future LIS. Journal of Documentation 66 (1), 7-27.

Ortiz-Repiso, V.; Calzada-Prado, J., \& Aportela- Rodríguez, I. M. (2013). ¿Qué está pasando con los estudios universitarios de biblioteconomía y documentación en España?". El profesional de la información El profesional de la información, 22, (6), 505-514.

Pettigrew, K. E, \& McKechnie, L. EF (2001).The use of theory in information science research.Journal of the American Society for Information Science and Technology 52 (1), 62-73.

Saracevic, T. (1995). Interdisciplinary nature of information science. Ciência da informação 24 (1), 36-41

Simon, H.A. (1973) Technology and Environment. Management Service, 19 (10)

Universidad de Murcia (2018). Programa de Estudios Simultáneos en Periodismo e Información y Documentación. Recuperado de http://www.um.es/web/vicestudios/contenido/grados/dobles/pes-periodismo-e-informacion-y-documentacion

Universitat Oberta de Catalunya (2018). Programa de estudios en Información y Documentación. Recuperado de http://estudios.uoc.edu/es/grados/informaciondocumentacion/presentacion. 


\title{
PERCURSOS DACI ÊNCIA DA INFORMAÇÃO EM PORTUGAL E NO BRASIL
}

\author{
I N F ORMATION SCIENCE COURSE \\ I NORTUGALAND BRAZIL
}

Leonor Calvão Borges

Assembleia da República, Lisboa, Portugal

Email: leonorcborges@gmail.com ORCID: https://orcid.org/0000-0002-2316-9365

Marcelo Nogueira de Siqueira Arquivo Nacional, Rio de Janeiro, Brasil

Email: mnsiq@yahoo.com.br ORCID: https://orcid.org/0000-0003-1410-9544

RESUMO - Apresenta a Ciência da Informação em Portugal e no Brasil, focalizando os aspetos históricos, epistemológicos e seus marcos legais, do surgimento ao estágio atual, apontando os elementos contextuais de seu desenvolvimento. Analisa questões referentes à legislação, ensino, pesquisa, associativismo e produção científica, salientando o processo de sua institucionalização nos dois países. Os resultados demonstram o estado da arte da Ciência da Informação em Portugal e no Brasil e, ao final, são apresentadas algumas reflexões e persepctivas a partir dos dados analisados. PALAVRAS-CHAVE - Ciência da Informação; Portugal; Brasil; Ensino; Pesquisa; Periódicos. 


\begin{abstract}
It presents Information Science in Portugal and Brazil, focusing on the historical, epistemological aspects and their legal frameworks, from its emergence to the present stage, pointing out the contextual elements of its development. It analyzes issues related to legislation, teaching, research, associativism and scientific production, highlighting the process of its institutionalization in both countries. The results demonstrate the state of the art of Information Science in Portugal and Brazil and, at the end, some reflections and perspectives are presented based on the prevailing data.

KEYWORDS - Information Science; Portugal; Brazil; Teaching; Research; Periodicals.
\end{abstract}

\title{
Introdução
}

O presente trabalho apresenta e analisa a evolução da formação em Ciência da Informação em dois países lusófonos, Brasil e Portugal, inseridos em contextos geográficos e epistemológicos diferentes. Devedor de trabalhos já publicados sobre a matéria (Freitas \& Silva, 2009, Souza \& Ribeiro, 2009, Souza \& Stumpf, 2009 e Cardoso \& Calixto, 2010), o estudo pretende contribuir para a compreensão da evolução da conceção da Ciência da Informação nos dois países, a partir da análise diacrónica da prática e teoria ministrada em contexto formativo de nível universitário.

Para o efeito, recorreu-se à recolha da legislação criadora e promotora da formação, dos marcos históricos, bem como da análise da literatura científica sobre a matéria, identificando paradigmas subjacentes à teoria ensinada nas universidades e enquadrando o mesmo em contexto internacional.

O trabalho identifica ainda a criação de associações profissionais nos dois países e no caso do Brasil, de seus periódicos e eventos científicos, analisando o seu impacto na formação ministrada. 
Por fim, identificam-se os cursos dos vários ciclos de ensino universitário atualmente existentes.

\section{A Ciência da Informação}

A Ciência da Informação possui uma nítida caraterística interdisciplinar, sobretudo pela multiplicidade dos agentes que deram origem a esta nova área (Saracevic, 1996). Profissionais de diferentes formações, mas que nitidamente possuíam relações mais estreitas com a Biblioteconomia, a Comunicação e a Ciência da Computação (Souza, 2012), promoveram uma inegável formatação da área com elementos e metodologias incorporadas e, posteriormente adaptadas, que geraram uma nova disciplina que de acordo com Brookes (1980) passou a deter seu próprio território, não sendo "uma miscelânea incoerente de elementos oriundos de um elenco retirado de um conjunto arbitrário de disciplinas díspares”. A partir dos anos de 1940, uma série de debates no contexto anglo-saxão permitiu uma delineação da information sciencee na década de 1960, um conjunto de fatores convergentes, centrados no conceito científico de informação (trazido pela teoria matemática da comunicação), promoveu sua consolidação como ciência centrada no fluxo, na otimização dos processos de recuperação e na promoção do acesso à informação (Araújo, 2011).

Para Souza e Ribeiro (2009, p. 82) a Ciência da Informação nasceu formalmente em 1962, durante uma reunião do Georgia Institute of Technology, caraterizando-se por ser uma área científica de perspetiva epistemológica e centrada na informação, contextualizada em diferentes ambientes e serviços, como seu objeto de estudo e trabalho.

Nas décadas de 1960 e 1970, as teorias sistémicas e matemáticas delinearam a área nos Estados Unidos e na União Soviética.

A partir da década de 1980 , se estabelece um novo modo de produção científica, caraterizado por questões pragmáticas e in- 
terdisciplinares, decorrente do cenário das políticas e atividades científicas empreendidas em todo mundo, em que o mercado e os setores empresariais demandam soluções e aprimoramentos gerenciais e informacionais (Marteleto, 2009). Neste momento e em anos subsequentes, surgem novas subáreas na Ciência da Informação e outras são consolidadas, ampliando seu escopo científico e profissional.

Nos anos 1990, como Barreto (2012) destaca, a informação assumiu uma nova dimensão após a criação da internet e de sua interface gráfica, a world wide web, mais conhecida pela sigla www, transformando a relação entre usuário, informação e conhecimento, criando uma sociedade em rede, interligada, constantemente conectada e capaz de transferir, compartilhar, criar e recriar conteúdos informacionais em uma velocidade e quantidade crescente de forma exponencial, um meio de comunicação que permitiu de forma inédita a troca de informações e conhecimentos de muitos com muitos e para muitos em escala global, reestruturando atividades económicas, políticas, sociais e culturais (Castells, 2003) e fazendo com que a Ciência da Informação se aproximasse ainda mais dos aspetos tecnológicos ligados à informação e seus fenómenos.

A Ciência da Informação alheia a fronteiras disciplinares aproxima-se da teoria da complexidade de Morin e das teorias sistémicas inspiradas em Bertalanffy, bem como da visão holística de Capra (Francelin, 2004, p. 55), passando a ser compreendida por muitos como uma ciência pós-moderna em suas aceções, embora tivesse nascida condicionada por determinações tecnológicas e por interesses estratégicos (Araújo, 2011, p. 121).

Silva (2011, p. 140) entende a Ciência da Informação como "uma ciência social que investiga os problemas, temas e casos relacionados com o fenómeno info-comunicacional perceptível e cognoscível através da confirmação ou não das propriedades inerentes à génese do fluxo, organização e comportamentos informacionais." 
Para Araújo (2018) o momento contemporâneo da Ciência da Informação a faz mais atenta à complexidade dos fenómenos informacionais, manifestando-se através de um modelo sociocultural caraterizado por questões teóricas como a análise de domínio, a altmetria, a neodocumentação, a curadoria digital, os regimes de informação, as folksonomias, as questões éticas, as humanidades digitias e a cultura organizacional, dentre outros aspetos.

Em sua breve trajetória, a Ciência da Informação ganhou especificidades em determinados países, acompanhando caraterísticas e motivações locais, bem como sofrendo influências de áreas transversais, estabelecendo diálogos e promovendo simbioses. Uma ciência que nasce dos anseios urgentes do século $\mathrm{XX}$ da compreensão, gerenciamento, controle, uso e disseminação da informação e que se consolida no novo século, adaptando-se, tornando-se pluridisciplinar e atingindo novos contextos, formas e atores.

\section{A Ciência da Informação em Portugal}

A conservação de livros e documentos, bem como a instituição de arquivos e bibliotecas encontra-se bem documentada em Portugal, desde tempos recuados, sendo possível identificar práticas e mesmo algumas normas de organização e tratamento da documentação, à semelhança de outros países europeus. Assim, e como referem Silva e Ribeiro, "a prática precedeu, portanto, a reflexão e teorização e acabou guiando um saber fazer que se foi apurando" (2004).

Contudo, será no enquadramento da evolução das práticas europeias relativas às bibliotecas e arquivos, com crescimento exponencial a partir da Revolução Francesa que Portugal inicia a formação dos profissionais destes serviços através da transmissão de saberes exercida no decorrer da atividade. Como refere 
Ribeiro, tratava-se ainda de "uma via destinada ao exercício de uma profissão, mais do que a aquisição de saberes tendentes a estimular o estudo e o conhecimento numa dada área disciplinar (2002, p. 420).

Assim, entre o século XVIII e 1887, data da criação do primeiro curso de Bibliotecários e Arquivistas, surgem os primeiros estudos relativos a paleografia e diplomática ${ }^{1}$, muito influenciados pela vertente historicista que então se fazia sentir, e dos quais se destaca a Aula de Diplomática de João Pedro Ribeiro, criada na Universidade de Coimbra em 1796, cujo ensino se torna efetivo apenas a partir do alvará de 20 de Fevereiro de 1801, que o transfere para o Arquivo da Torre do Tombo, aí tornado obrigatório para o desempenho de cargos na instituição.

Também a extinção das Ordens Religiosas em 1834 obrigará à incorporação massiva de acervos em bibliotecas e arquivos. Para fazer face a essa "institucionalização das funções de recolha, armazenamento e uso dos documentos tutelados por serviços especializados" (Pinto, 2008) é criada, pelo Decreto de 29 de Dezembro de 1887, a Inspeção Geral das Bibliotecas e Arquivos Públicos. O mesmo diploma, prevê, no seu artigo $13 .^{\circ}$, a criação de um Curso superior de Bibliotecário-Arquivista, com a duração de dois anos, seguidor do modelo francês, vincadamente historicista e patrimonialista e cujo modelo dual (formação universitária em conjunto com formação técnica) se vai manter até à reforma de 1931, como veremos.

Enquanto as disciplinas base funcionam integradas no Curso Superior de Letras (para a identificação das disciplinas dos cursos lecionados entre 1887 e 1980 ver tabela 1), as de matriz técnico como a Diplomática, numismática e bibliologia funcionavam no Arquivo

1 Para a história do ensino da paleografia e diplomática em Portugal, vejam-se Coelho, Santos, Gomes e Morujão, 2001, Marques, 2011, Ribeiro, 2006, Santos, 2000. Refira-se ainda o preâmbulo do Decreto n. ${ }^{\circ} 26026$, de 1935, onde se enumeram instituições, datas e atividades referentes à matéria em apreço. 
da Torre do Tombo ou na Biblioteca Nacional, cujos profissionais se encarregavam de as lecionar $\left(\operatorname{art}^{\circ}{ }^{\circ} 14 .^{\circ}\right)$.

O curso é objeto de reformulação através do Decreto de 24 de Dezembro de 1901, regulamentado pelo Decreto de 3 de outubro de $1902^{2}$, que lhe aumenta a duração para três anos, mas mantem o regime duplo de disciplinas do Curso Superior de Letras e formação nos serviços, agora acrescida da disciplina de paleografia.

Com o advento da República, a 5 de Outubro de 1910, os serviços de Bibliotecas e Arquivos sofrem uma remodelação com a aprovação do Decreto de 18 de Março de 1911, sendo visíveis "preocupações com o acesso à informação e à leitura" (Ribeiro, 2005 , p. 4). O curso passa a integrar a recém-criada Faculdade de Letras da Universidade de Lisboa, mantendo a sua vertente dupla de formação superior com formação em serviço, como determina o Decreto de 18 de junho de 1913.

A criação, pelo Decreto n. ${ }^{\circ}$ 130, de 11 de Setembro de 1913 de um curso prático para o "pessoal a cujo cargo se encontra, ou venham a encontrar-se todos os arquivos que directa ou indirectamente dependam das Secretarias Gerais dos Ministérios" (art. ${ }^{\circ} 1 .^{\circ}$ ), a desenvolver pela Inspeção das Bibliotecas Eruditas e Arquivos, e cuja habilitação daria preferência no provimento dos lugares de arquivista dependentes do mesmo Ministério, parece indicar uma falta de profissionais nessa área, sendo a primeira vez que se cria uma formação apenas virada para a prática profissional ${ }^{3}$. O estágio decorria entre 15 de outubro de 30 de julho e tinha como disciplinas a arquivologia, paleografia e biblioteconomia.

Com a reforma introduzida pelo Decreto n. ${ }^{\circ} 4312$, de 8 de Maio de 1818, que reorganiza as Bibliotecas Eruditas e Arquivos Nacionais,

2 O estágio foi regulamentado através do Decreto n ${ }^{\circ}$ 508, de 21 de maio de 1914 .

3 Refira-se que não existem estudos sobre a frequência e aproveitamento destas formações, pelo que aqui nos limitamos a fazer a análise dos diplomas que os criam. 
a direção do curso $^{4}$ é atribuída à Faculdade de Letras. O objetivo do legislador, como refere o preâmbulo do Decreto n. ${ }^{\circ} 4885$, de 11 de Outubro de 1918, que aprova o regulamento do curso superior de bibliotecário arquivista, é o de suprir a falta de frequência do curso "sempre pouco frequentado enquanto anexo ao extinto Curso Superior de Letras", e sem frequência com a "equiparação entre as antigas disciplinas professadas naquele estabelecimento e as actuais cadeiras da Faculdade de Letras da Universidade de Lisboa" em 1913. Considera-se assim que, para o êxito do curso é necessário "reduzir o número das disciplinas de carácter teórico que o constituíam, aumentando as disciplinas de carácter prático, professadas no Arquivo da Torre do Tombo e da Biblioteca Nacional", o que é garantido com o acréscimo das disciplinas de arquivologia e biblioteconomia, que aqui surgem pela primeira vez em contexto universitário, e ainda um curso trimestral anexo à cadeira de Biblioteconomia sobre higiene das espécies biblíacas, numa nítida tendência profissionalizante.

Em 1919 a designação do curso é alterada para Curso de Biblioteconomia e Arquivística pelo Decreto n. ${ }^{\circ}$ 5618, de 10 de Maio de 1919, não existindo diferenças assinaláveis no seu conteúdo, como de resto, acontece com a aprovação do Decreto n. ${ }^{\circ} 13724$, de 27 de maio de 1927 que apresenta a novidade das disciplinas de Filosofia: noções gerais de história da filosofia e das ciências e suas classificações lógicas e Cartografia antiga.

Mas será com o Decreto ${ }^{\circ}$ 19952, de 27 de junho de 1931, "fruto de um novo contexto político centralizador e de uma reforma estrutural das bibliotecas e arquivos estatais" (Pinto, 2008) que se dá uma alteração profunda no curso, retirando-o da alçada universitária alterando-lhe a

4 O diploma, no seu preâmbilo, refere ainda que o estágio criado em 1913 "não dava nenhumas garantias para a formação do pessoal superior das bibliotecas e arquivos nacionais". 
matriz para uma vertente exclusivamente técnica, ficando as disciplinas reduzidas a essa componente. A intenção é expressa claramente no seu preâmbulo, ao referir a conveniência de se conseguir "a unidade de preparação científica e técnica do pessoal", tornada obrigatória para o recrutamento de quadros em bibliotecas e arquivos.

A frequência do curso era permitida apenas a detentores do grau de bacharel ou licenciado em histórico-filosóficas e a sua organização ficava a cargo da Inspeção Geral das Bibliotecas e Arquivos, sendo a sua duração reduzida para dois anos. Os seus conteúdos programáticos foram definidos pela Portaria n. 7261 de 16 de novembro de 1931, e, da sua leitura, referem Silva \& Ribeiro, é evidente o caráter historicista, patrimonialista e tecnicista, que caraterizava o modelo de formação (2002, p. 145).

A publicação do Decreto n. ${ }^{\circ}$ 22014, de 21 de dezembro de 1932 dá conta do sucesso desta alteração regulamentar afiançando, no seu preâmbulo, que o curso funcionou com regularidade e número de inscritos no limite fixado por lei. A prática, porém, demonstrou que os tempos letivos eram insuficientes, razão pela qual o novo diploma alarga a duração da formação e cria a disciplina de Fontes da História de Portugal.

A experiência terá curta duração, já que, três anos depois, com a aprovação do Decreto-Lei n. ${ }^{\circ}$ 26026, de 7 de Novembro de 1935, e respetiva reflexão de que "há vantagem em aliviar os serviços técnicos das bibliotecas e arquivos de funções docentes", se transfere o curso de novo para meio universitário, desta feita na Universidade de Coimbra, cujos anexos - o Arquivo e Museu de arte e a Biblioteca Geral - poderiam acolher exercícios práticos. Ao curso poderiam aceder diplomados em qualquer curso universitário, mantendo assim a sua dimensão de pós-graduação, com a duração de dois anos curriculares e um estágio de seis meses.

Sendo um curso profissionalizante, dominado pelas disciplinas técnicas, não se afasta "de uma matriz erudita e historicista, que não 
é de estranhar, dado o carácter de disciplina auxiliar da História que ainda marcava, fortemente, a Arquivística e, de forma menos acentuada, a Biblioteconomia" (Ribeiro, 2005). O curso será mantido até 1982, ano em que foi extinto.

Apesar da longevidade desta formação, a área da informação e documentação, de resto, em consonância com o que se passa na Europa e Estados Unidos, começa a sofrer influências e estímulos decorrentes da explosão da informação científica e técnica, das tecnologias da informação e das necessidades acrescidas de acesso e difusão da informação. De igual forma, também os profissionais do setor irão iniciar um ciclo de reflexões sobre a área, de onde se destacam, ainda na década de 50, as reflexões de Jorge Peixoto (1957), e, na década de 60, a publicação dos Cadernos BAD - primeira publicação periódica coordenada por profissionais da área - em 1963, e o início da realização do Encontros de Bibliotecários e Arquivistas 5 em Coimbra, 1965. Uma das conclusões deste I Encontro será mesmo a necessidade de uma "Reforma profunda do Curso de Bibliotecário-Arquivista, dando-lhea actualização necessária, e que só se possa intitular bibliotecário-arquivistao diplomado com tal curso, defendendo-o com uma legislaçãoadequada" (Cadernos, 1965).

Em 1967 com a criação, pelo Decreto-lei n. ${ }^{\circ} 47791$, de 11 de julho da Junta Nacional de Investigação Científica e Tecnológica (JNICT), assume o legislador a necessidade dos investigadores estarem "permanentemente informados acerca do que se vai descobrindo", o que implicava "ter acesso a excelentes bibliotecas e serviços de documentação". Apesar disso, Adelino Calado, considera que o diploma não encara a documentação como "factor imprescindível do rendimento da investigação", propondo "como solução para a organização documental portuguesa a criação de um centro nacional de

5 Sobre este primeiro Encontro, veja-se o Editorial dos Cadernos BAD (1965). Para uma visão de conjunto sobre todos os Encontros realizados, veja-se Vivas \& Oliveira, 2015. 
documentação" (1967). Ainda em 1967, Maria Luísa Saavedra Machado analisa um curso de arquivologia para empresas, mencionando a necessidade do Curso de Bibliotecário-arquivista contemplar estas áreas e não estar apenas vocacionado para a administração pública.

Em 1969, é criado um estágio para a preparação técnica dos bibliotecários, arquivistas e documentalistas, aprovado pelo DecretoLei . $^{\circ}$ 49009, de 16 de Maio de 1969, na dependência direta da Direção Geral do Ensino Superior e Belas Artes. O objetivo é dada a carência de técnicos, promover e acelerar uma formação em serviço $^{6}$. De realçar que esta formação prevê já no seu plano de estudos (ver tabela 1) a administração de serviços de arquivo, biblioteca e centros de documentação, sendo a primeira vez que os últimos são mencionados em contexto formativo ${ }^{7}$.

Na sequência dos Encontros e publicações dos Cadernos, a BAD é criada como associação profissional, em $1973^{8}$, seguindo um caminho de dignificação dos seus profissionais que também passava pela reflexão sobre a respetiva formação.

Não é assim de estranhar que, 1982, pelo Decreto no 87/82, de 13 de Junho, seja extinto o Curso da Universidade de Coimbra, sendo substituído por um curso de especialização em Ciências Documentais (CECD), rapidamente adotado pela Faculdade de Letras da Universidade de Coimbra (Portaria $n^{\circ} 448 / 83$ ), a que se seguiu a Faculdade de Letras da Universidade de Lisboa (Portaria n. ${ }^{\circ} 449 / 83$ ), e, dois anos mais tarde a Faculdade de Letras da Universidade do Porto (Portaria n. ${ }^{\circ}$ 852/85).

Referia o legislador no seu preâmbulo que "A transferência da informação nas suas diferentes modalidades, sendo um importante factor de desenvolvimento do País, pressupõe a criação e a dinami-

6 Mais uma vez, sublinhamos a falta de dados e estudos sobre a frequência deste Estágio, que funcionou cerca de seis anos.

7 Curiosamente, será a este modelo curricular que os futuros cursos de especialização em Ciências Documentais irão retirar as disciplinas base (ver tabela 1 e 2).

8 Para a história da BAD, veja-se Amaral, 2013. 
zação de infra-estruturas na área dos serviços de documentação, de biblioteca e de arquivo", razão pela qual se tornava indispensável "planear uma formação adequada que permita, inclusive, alargar a capacidade de utilização dos sistemas de informação já existentes a nível mundial, sendo certo que o investimento que neste campo se fizer terá um poderoso efeito multiplicador".

Contudo, e como referem Silva e Ribeiro, não há qualquer rutura face ao paradigma dominante (historicista, custodial e tecnicista) mas sim um acentuar da vertente tecnológica, dentro do quadro concetual anterior (2002, p. 148).

O curso de pós-graduação era obrigatório para os técnicos superiores de Arquivo, Bibliotecas e Documentação da administração pública, apresentando uma mudança estrutural com a separação da formação de arquivo da formação de bibliotecas e documentação: no primeiro ano era comum, sendo o $2^{\circ}$ ano constituído por duas opções (ver tabela 2).

Sendo uma pós-graduação e não existindo formação ao nível da licenciatura, tratava-se, na verdade de uma formação inicial, o que, indica Marcos, foi um dos aspetos mais controversos deste curso (2015). O facto de não haver corpo docente na área, sendo a maioria das disciplinas asseguradas por profissionais em regime de acumulação e não existir qualquer mestrado ou doutoramento na área, dificultou ainda mais a possibilidade de se criar um corpo docente habilitado a dedicar-se à investigação e ensino (Marcos, 2015).

A contestação a este modelo fez-se sentir desde cedo. Apesar disso, foi replicado em universidades públicas e privadas com sucesso, a partir de $1988^{9}$, sendo a evolução objeto de reflexão

9 Para a sua caraterização e identificação, vejam-se sobretudo, Ribeiro, 2005, Pinto, 2008. 
tanto nos estabelecimentos de ensino, como em seminários promovidos pela $\mathrm{BAD}^{10}$.

Paralelamente aos CECD, e a partir da década de 90, numa tentativa de colmatar a falha que se fazia sentir, começaram a surgir mestrados e doutoramentos em parceria com universidades estrangeiras ${ }^{11}$, tendo a Universidade do Porto aprovado a área de doutoramento em Ciências Documentais em 1989, permitindo a "instauração da carreira académica no domínio das ciências documentais (Ribeiro, Leite e Cerveira, 2003, p. 13) e criado o mestrado em Gestão da Informação na Faculdade de Engenharia. Com uma licenciatura lançada em $2001^{12}$, a Universidade do Porto era a primeira a oferecer formação nos três ciclos do ensino superior.

Com a entrada em vigor do Decreto-lei n. ${ }^{\circ} 49 / 2005$, de 3 de agosto, que definiu a Lei de Bases do Sistema Educativo, adotando em Portugal o novo modelo de organização do Ensino Superior em 3 ciclos, no chamado Processo de Bolonha, a área da CI foi repensada e reformulada. A alteração ao nível do $1^{\circ}$ e $2^{\circ}$ ciclo foi feita tendo em conta o currículo europeu em LIS e o Referencial Europeu de Competências para os Profissionais da Informação (Cardoso e Calixto, 2010; Marcos, 2015; Silva \& Ribeiro, 2004), determinando uma mudança de paradigma formativo para pós custodial e científico-informacional (Silva e Ribeiro, 2010; Ribeiro, 2017).

Marcos refere um aumento na oferta de licenciaturas, mestrados e mesmo pós-graduações tanto em universidades públicas como privadas $(2011,2015)$, que o processo de acreditação de cursos, entretanto tornado obrigatório através do Decreto-lei n. ${ }^{\circ} 369 / 2007$, de

10 A BAD promoveu em 1997, uma Conferência Nacional sobre Formação e Carreiras Profissionais BAD realizada no Minho, e em 2006, publica um número dos seus Cadernos dedicado ao Ensino Superior em Informação e Documentação e o Processo de Bolonha. De referir ainda os debates promovidos dentro das Universidades, nomeadamente as de Coimbra, do Porto e Autónoma de Lisboa.

11 Para a sua identificação veja-se Marcos, 2015.

12 Para a contextualização desta licenciatura veja-se Ribeiro, 2008. 
5 de novembro, que criou a Agência para a Acreditação e Avaliação do Ensino Superior (A3ES) estancou ${ }^{13}$.

Por esse motivo, atualmente a oferta de formação em Ciência da Informação diminuiu bastante e está geograficamente concentrado em Coimbra e Porto, que detém os três ciclos de ensino, enquanto Lisboa possui apenas oferta formativa ao nível do segundo ciclo, com o Mestrado em Ciências da Documentação e Informação da Faculdade de Letras da Universidade de Lisboa, e o Mestrado em Gestão e Curadoria da Informação, resultante de uma parceria entre a NOVA IMS e a Faculdade de Ciências Sociais e Humanas da Universidade NOVA de Lisboa (para a identificação da formação atual, ver tabela 3 - licenciaturas, tabela 4 - mestrados e tabela 5 - doutoramentos).

\section{A Ciência da Informação no Brasil}

A Ciência da Informação foi implementada no Brasil inserida no âmbito universitário na década de 1970, mas diferente de outros países não se constituiu como curso de graduação e campo profissional (Araújo, 2011, p. 7), sobretudo por haver legislação de regulamentação profissional nas áreas de Arquivologia (Lei $\mathrm{n}^{\circ}$ 6.546, de 4 de julho de 1978) ${ }^{14}$, Biblioteconomia (Lei $\mathrm{n}^{\circ} 4.084$, de 30 de junho de 1962) ${ }^{15}$ e Museologia (Lei $n^{\circ} 7.287$, de 18 de

13 Para a análise do processo de acreditação dos cursos de CI ver Marcos, 2015 e Marques, 2016.

14 A lei que regulamenta a profissão de arquivista dispõe que o exercício profissional só será permitido aos diplomados no Brasil e no exterior (com a necessidade do diploma ser revalidado no país) por cursos superiores de Arquivologia ou aos que contem, pelo menos, cinco anos ininterruptos de atividade ou dez intercalados, na data de início da vigência da lei (1978), nos campos profissionais da Arquivologia.

15 A lei que regulamenta a profissão de bibliotecário dispõe que o exercício profissional só será permitido aos portadores de diplomas expedidos por Escolas de Biblioteconomia de nível superior e aos portadores de diplomas de instituições estrangeiras que apresentem os seus diplomas revalidados no Brasil. 
dezembro de 1984) ${ }^{16}$, que conferem o exercício legal da profissão de arquivista, bibliotecário e museólogo somente aos que possuem formação específica em nível superior em cada área. Além do aspecto legal, questões de nivel corporativo das áreas citadas foram determinantes para que não houvesse sua integração dentro do escopo da Ciência da Informação. Arquivistas, bibliotecários e museólogos possuem órgão representativos próprios, como associações e conselhos, eventos acadêmicos e científicos específicos e cursos de nível superior tradicionais. Soma-se a este fator o cenário de pouco diálogo entre arquivos, bibliotecas e museus no país, sem que haja alguma política publica instituída neste âmbito ou algum órgão de gestão de englobasse tais instituições de forma integrada.

A primeira experiência acadêmica da Ciência da Informação no Brasil foi em 1955, com o Curso de Documentação Científica, uma pós-graduação lato sensu promovida pelo Instituto Brasileiro de Bibliografia e Documentação - IBBD, instituição que mais tarde daria origem ao Instituto Brasileiro de Informação Científica e Tecnológica - IBICT (Souza; Stumpf, 2009). O referido curso, o primeiro da América Latina, trouxe ao Brasil inúmeros professores estrangeiros convidados, como Jessé H. Sera, Tefko Saracevic, Frederick Lancaster dentre outros (Pinheiro, 2006). Em 1970, quinze anos após a primeira edição do Curso de Documentação Científica, foi criado o mestrado em Ciência da Informação pelo IBICT, inicialmente em comodato e posteriormente em convênio com a Universidade Federal do Rio de Janeiro - UFRJ (Pinheiro, 2017, p. 121 e 122).

16 A lei que regulamenta a profissão de museólogo dispõe que o exercício profissional só será permitido aos diplomados no Brasil e no exterior (com a necessidade do diploma ser revalidado no país) por cursos superiores e de pós-graduação em Museologia ou aos possuidores de outros diplomas de cursos superiores que contem, pelo menos, cinco anos de exercício de atividades técnicas de Museologia até a data de início da lei (1984). 
O corpo docente do mestrado era composto basicamente por professores e pesquisadores ingleses e norte-americanos que trouxeram consigo os debates acerca da crescente produção de informação técnica e científica surgida no pós-guerra, havendo uma clara preocupação com a formação de uma geração de profissionais aptos a lidar com esse novo cenário. Estes professores tiveram nítida influência na formação inicial do corpo docente em Ciência da Informação no Brasil, que por sua vez foram responsáveis pela criação de outros cursos de pós-graduação em Ciência da Informação, sobretudo os mestrados em Biblioteconomia.

Em 1972, o IBBD lançou a revista Ciência da Informação, intrinsecamente ligada às pesquisas acadêmicas do seu curso de mestrado (Souza; Ribeiro, 2009, p. 84) e ainda hoje em atividade (Marteleto, 2009, p. 30).

Na década de 1990, tais cursos, assim como muitas escolas e departamentos de biblioteconomia, passaram a assumir a denominação de Ciência da Informação e iniciaram os cursos de doutorado na área, fomentando a pesquisa, capacitando docentes para o ensino superior e formando recursos humanos especializados (Población, 1993).

De modo geral, os cursos de graduação em Biblioteconomia mantiveram sua denominação e os cursos de graduação em Arquivologia tiveram grande expanção na primeira década do século XXI, atingindo todas as regiões do país e chegando a 16 cursos oferecidos ${ }^{17}$. A Ciência da Informação no Brasil consolidou-se na pós-graduação, com forte tendência para a pesquisa acadêmica e formação docente.

Em virtude de tal cenário, torna-se fundamental compreender a estrutura e o funcionamento dos programas de pós-graduação em Ciência da Informação no Brasil, dos periódicos científicos da área e de sua associação de profissionais e pesquisadores.

17 Região Sul: UFSM, UFRGS, FURG, UEL, UFSC; Região Sudeste: UNIRIO, UFF, UFES, UNESP, UFMG; Região Centro Oeste: UNB; Região Nordeste: UFBA, UFPB, UEPB; Região Norte: UFAM, UFPA. 


\subsection{Programas de Pós-Graduação em Ciência da Informação no Brasil}

O Conselho Nacional de Desenvolvimento Científico e Tecnológico - CNPq é uma agência do Ministério da Ciência, Tecnologia, Inovações e Comunicações destinada ao fomento da pesquisa científica e tecnológica e à formação de recursos humanos para pesquisa no país ${ }^{18}$. O CNPq é responsável, dentre outras atribuições, pela Plataforma Lattes - sistema de informação que integra bases de dados referentes a currículos, grupos de pesquisa e instituições das áreas de ciência e tecnologia no Brasil, e pela elaboração da Tabela das Áreas do Conhecimento - TAC, com fins de auxílio no fomento à pesquisa. Desde sua criação o CNPq publicou três tabelas, em 1976, 1978 e 1984 e promoveu revisões na década de 1990 e no início do século XXI.

Segundo Marques (2017, p. 18) a primeira TAC traz a Ciência da Informação classificada como uma subárea da Comunicação. Na segunda TAC a área passa a se denominar "Ciência da Informação, Biblioteconomia e Arquivologia" e na terceira TAC, a Arquivologia e a Biblioteconomia são concebidas como subáreas da área Ciência da Informação, por sua vez inserida na Grande Área "Ciências Sociais Aplicadas. Em 2005, uma proposta de revisão apresentava a Ciência da Informação e Arquivologia como duas áreas distintas, inseridas na Grande Área "Ciências Socialmente Aplicáveis", mas tal revisão não foi adiante, mesmo com grande aceitação da comunidade arquivística nacional.

A Coordenação de Aperfeiçoamento de Pessoal de Nível Superior - CAPES, fundação do Ministério da Educação, é o órgão responsável no Brasil pela coordenação do Sistema Nacional de Pós-Graduação, da avaliação da pós-graduação stricto sensu, da divulgação da produção

18 Informações disponíveis em < http://www.cnpq.br/web/guest/apresentacao_ institucional/> Data de acesso: 10/09/2018. 
científica, na promoção da cooperação científica internacional e por investimentos na formação de recursos de alto nível no país e no exterior ${ }^{19}$.

A CAPES classifica os Programas de Pós-Graduação por áreas do conhecimento previamente definidas pela TAC. A Ciência da Informação está dentro na grande área das Ciências Sociais Aplicadas 1, que contempla as subáreas da Comunicação, Ciência da Informação e Museologia. A Arquivologia e a Biblioteconomia estão inseridas na Ciência da Informação.

Em 2019, 24 instituições de ensino ofereciam cursos de PósGraduação Stricto Sensu (mestrado e/ou doutorado) no país, contabilizando 27 programas com 18 cursos de mestrado acadêmico, 9 cursos de mestrado profissional e 11 cursos de doutorado. O conjunto desses cursos oferecem dezenas de linhas de pesquisa, contemplando as inumeras possibilidades e interfaces da Ciência da Informação. A CAPES avalia periodicamente esses cursos com notas de zero a sete, sendo que as notas iguais ou superiores a 3 garantem o funcionamento do curso. Aqueles recém constituídos recebem o conceito A, pois estão sob avaliação inicial (Ver Tabela 6).

\subsection{Periódicos em Ciência da Informação no Brasil}

A CAPES utiliza um conjunto de procedimentos, denominado QUALIS, para aferir a produção intelectual dos programas de pós-graduação, analisando a qualidade dos periódicos científicos. Como resultado desta análise, a CAPES disponibiliza uma classificação destes periódicos tendo por critério índices pré-estabelecidos (variedade, qualidade e fator de impacto ${ }^{20}$ dos artigos; intercâmbio

19 Informações disponíveis em <http://www.capes.gov.br/historia-e-missao > Data de acesso: 02/09/2018.

20 O fator de impacto é a principal métrica de avaliação de periódicos científicos no mundo, pois contabiliza as citações recebidas de artigos que foram publicados em periódicos indexados na Web of Science. 
de pesquisadores e instituições; periodicidade e acessibilidade dos periódicos; normas editoriais) dentro de um interstício determinado. Os periódicos são enquadrados em faixas de avaliação: A1 e A2 (de referência internacional), B1 a B5 (de referência nacional) e C (sem qualidade científica). ${ }^{21}$

Em dezembro de 2016, a CAPES disponibilizou através do Portal Sucupira $^{22}$ as avaliações referentes ao quadriênio 2013-2016. Os periódicos em Ciência da Informação estão inseridos na área "comunicação e informação".

Segundo a CAPES, alguns periódicos não constam na lista QUALIS por não terem sido indicados por nenhum programa de pós-graduação como veículo de divulgação de sua produção intelectual ou foi avaliado pela CAPES como não sendo um periódico.

Foram identificados 65 periódicos em Ciência da Informação no Brasil até 2017 , sendo que alguns foram descontinuados e outros tiveram sua linha editorial modificada. Para esta pesquisa utilizou-se as bases BRAPCI - Base de Dados em Ciência da Informação, SciElo - Scientific Eletronic Library Online, Portal de Periódicos CAPES/MEC e Google Acadêmico ${ }^{23}$. A maioria dos periódicos é ligada às Instituições Federais de Ensino Superior - IFES, em um total de 30 periódicos de 15 instituições diferentes (UFSC, UFPB, UFPR, UFMG, FURG, UFAL, UFCA, UFC, UFPE, UFBA, FIOCRUZ, UNB, UFRN, UFRJ eUFRGS), 10 periódicos são vinculados a cinco universidades públicas estaduais (UEL, UEPB, UNESP, UNICAMP e USP), nove periódicos de associações profissionais ou científicas

21 Informações disponíveis em <http://www.capes.gov.br/acessoainformacao/ perguntas-frequentes/avaliacao-da-pos-graduacao/7422-qualis> Data de acesso: 13/09/2018.

$22<$ https://sucupira.capes.gov.br/sucupira/public/consultas/coleta/veiculoPublicacaoQualis/ listaConsultaGeralPeriodicos.jsf> Data de acesso: 18/09/2018.

23 BRAPCI - www.brapci.inf.br/index.php/journal

SciELO - www.scielo.org/php/index.php

Portal de Periódicos CAPES/MEC - www.periódicos.capes.gov.br

Google Acadêmico - https://scholar.google.pt 
(AAB, AAERJ, ABDF, ABECIN, ACB, ANCIB, FEBAB, CRB/SP e CRB - $6^{a}$ Região), cinco periódicos de propriedade do IBICT (instituto de pesquisa do Ministério da Ciência, Tecnologia e Gestão), quatro periódicos de propriedade pessoal, quatro periódicos de instituições arquivísticas (Arquivo Nacional, Arquivo Público Mineiro e Arquivo Geral da Cidade do Rio de Janeiro), um periódico de universidade privada (PUC - Campinas) ${ }^{24}$ e dois periódicos de origem não identificada.

Dos 65 periódicos identificados, 41 tiveram pelo menos uma edição em 2017, data limite do levantamento de dados. (Ver Tabela 8)

Em relação a análise Qualis, seis periódicos são de referência internacional (9,2\%), 40 de referência nacional (61,6\%), 14 não foram classificados em virtude de não mais existirem ou por terem sido criados recentemente $(21,5 \%)$ e 5 foram considerados não científicos (7,7\%) (Ver Tabela 7$)$.

\subsection{Associação Nacional de Pesquisa e Pós-Graduação em Ciência da Informação}

Ao perceber o crescimento da Ciência da Informação no Brasil e sentindo uma demanda em consolidá-la, professores e pesquisadores de cursos e programas de pós-graduação na área criaram em 1989 a Associação Nacional de Pesquisa e Pós-Graduação em Ciência da Informação - ANCIB, uma sociedade civil e sem fins lucrativos, que admite sócios institucionais (Programas de Pós-Graduação em Ciência da Informação) e sócios individuais (professores, pesquisadores, profissionais e estudantes ligados à área), tendo por finalidade o acompanhamento e estímulo das atividades de ensino de pós-graduação e pesquisa em Ciência da Informação no país e

24 As siglas estão disponibilizadas em apêndice. 
fomento de debates de questões pertinentes à área. ${ }^{25}$ Para Souza e Ribeiro (2009, p. 85) o fortalecimento da Ciência da Informação no Brasil avançou consideravelmente com criação da ANCIB.

Desde que foi criada, a ANCIB vem se consolidando como representação científica e espaço político no debate das questões referentes à área de informação, tanto no país como no estrangeiro.

Desde 1994, a ANCIB realiza, em consonância e parceria com os Programas de Pós-Graduação em Ciência da Informação, o Encontro Nacional de Pesquisa em Ciência da Informação - ENANCIB que reúne pesquisadores de temas específicos da área organizados em Grupos de Trabalho, que em 2018 se constituíam em onze unidades: GT 1: Estudos Históricos e Epistemológicos da Ciência da Informação; GT 2: Organização e Representação do Conhecimento; GT 3: Mediação, Circulação e Apropriação da Informação; GT 4: Gestão da Informação e do Conhecimento; GT 5: Política e Economia da Informação; GT 6: Informação, Educação e Trabalho; GT 7: Produção e Comunicação da Informação em Ciência, Tecnologia \& Inovação; GT 8: Informação e Tecnologia; GT 9: Museu, Patrimônio e Informação; GT 10: Informação e Memória; GT 11: Informação \& Saúde. ${ }^{26}$

Até 2018 foram realizados 19 edições do ENANCIB, em oito unidades da federação. A maior parte destes eventos possuiu um tema norteador, sem que houvesse perda dos debates gerais e específicos da área (Ver Tabela 9). O Encontro Nacional de Pesquisa em Ciência da Informação de 2019, com sede na cidade de Florianópolis, Santa Catarina, teve como tema escolhido "A Ciência da Informação e a Era da Ciência de Dados" e que de acordo com a ANCIB apresenta as "inquietações e a necessidade de debater os dados e a sua ciência, que serve de base, estrutura e complemento para discussões

25 Informações disponíveis em <https://www.ancib.org.br/front-page> Data de acesso: 28/08/2018.

26 Informações disponíveis em <https://www.ancib.org.br/menu-lateral/ancib-25anos> Data de acesso: 12/09/2018. 
de acesso a informação, mineração de conteúdo, gestão e organização da informação" 27 . Os anais dos ENANCIBs realizados estão disponibilizados no portal da entidade.

A associação também promove anualmente o Prêmio ANCIB de Teses e Dissertações, em que são premiadas as melhores teses e dissertações defendidas no ano anterior nos Programas de Pós-Graduação na área.

Ao longo de seus trinta anos, a ANCIB tornou-se o principal espaço de apresentação, divulgação e debate de resultados científicos da área no país, fomentando parcerias entre investigadores e programas de pesquisa, alargando as fronteiras da Ciência da Informação e promovendo novas interfaces, contribuindo para o avanço do conhecimento científico e para a compreensão dos impactos e efeitos na sociedade dos fenômenos informacionais contemporâneos.

\section{Conclusões}

A partir dos dados analisados e das reflexões apresentadas podemos compreender a Ciência da Informação no Brasil como um campo científico constituído que demonstra um inegável amadurecimento em busca da solidez do seu estatuto científico, explicitado na expansão dos Programas de Pós-Graduação, do expressivo número de periódicos da área - sinal inequívoco da produção científica desenvolvida - e dos eventos nacionais, que são estruturados, consistentes e de periodicidade respeitada.

Souza e Stumpf (2009, p. 55) apontam ainda que a pouca representação da Ciência da Informação nas agências de fomento demonstra um processo de institucionalização lento, todavia destacam o seu reconhecimento como área do conhecimento em pesquisa e na

27 Informações disponíveis em <https://www.ancib.org.br/> Data de acesso: $22 / 06 / 2018$ 
formação científica e profissional. Pinheiro (2017, p. 121) por sua vez, ressalta a expansão e o aprofundamento dos estudos teóricos nacionais, promovendo maior densidade no estatuto científico da Ciência da Informação no país.

Outro fator de destaque é o fato da Ciência da Informação no Brasil não ser homeogênea, tendo linhas de pesquisa diversas e possuir uma amplitude de reflexões sobre temas variados, explicitados em sua literatura científica.

A análise da legislação e literatura científica permite-nos verificar que, em Portugal, a formação na área da CI acompanhou a linha evolutiva Europeia, com destaque para a criação de um curso de grau universitário ainda no século XIX. A formação seguiu o paradigma custodialista e historicizante de modelo francês, sendo, numa primeira fase constituída por disciplinas não técnicas, situação que se alterou a partir de 1913.

A formação ao longo do século XX oscilou entre a aposta em cursos universitários de índole teórica e a formação de carácter prático, com dois estágios criados para fazer face à falta de pessoal técnico nos quadros do Estado. A partir de 1982, com a criação dos cursos de pós-graduação unificou-se o sistema de ensino em Coimbra, Lisboa e Porto, modelo esse depois replicado pelas universidades particulares. O processo de Bolonha veio trazer uma clarificação na formação desta área, com a introdução dos três ciclos de ensino superior e correspondente estabilização de pessoal docente na área.

Como referem Souza e Ribeiro, a Ciência da Informação em Portugal foi simultaneamente devedora e modelada por contribuições das designadas ciências documentais, mais diretamente relacionadas com a arquivologia e a biblioteconomia (2009, p. 100), encontrando-se o país numa fase embrionária no desenvolvimento da Ciência daInformação através da formação nos três ciclos edesenvolvimento de estruturas de investigação e pesquisa. 


\section{Referências Bibliográficas}

AMARAL, A. E. M. (2013) - Apontamentos para a história da BAD: os primeiros anos(1973/1983). Cadernos BAD. $\mathrm{N}^{\circ} 1 / 2$, p. 7-15. Recuperado de http://www. bad.pt/publicacoes/index.php/cadernos/article/view/1024/pdf.

ARAÚJO, C. A. A. (2011). Arquivologia, Biblioteconomia, Museologia e Ciência da Informação: o diálogo possível. São Paulo: Abrainfo.

ARAÚJO, C. A. A. (2018). Tendências contemporâneas da Ciênca da Informação. Palestra. Universidade Federal de Pernambuco.

BARRETO, A. (2012). Uma história da Ciência da Informação. In TOUTAIN, L. M. B. B. Para entender a Ciência da Informação. Salvador: EDUFBA.

BROOKES, B. C. (1980). The Foundations of Information Science. Journal of Information Science. Amsterdam; New York. 1980. 125-133, 209-221.

CADERNOS BAD (1965) - Editorial: o I Encontro dos Bibliotecários e Arquivistas Portugueses - O Decreto-lei 46 350, de 22 de Maio de 1965 e outra legislação. Cadernos BAD, Vol. 2, $\mathrm{N}^{\circ} 3$, p. 155-160.

CALADO, A. (1967) - Investigação e Documentação ao nível nacional. Cadernos $B A D$, Vol. 4, No 4, p. 170-179.

CARDOSO, A. M. P., \& CALIXTO, J. A. (2010). Modelos de formação em Ciência(s) da Informação: estudo comparativo entre Brasil e Portugal. In Políticas de informação na sociedade em rede (p. 1-8). Guimarães: APBAD. Recuperado de: https://www.bad.pt/publicacoes/index.php/congressosbad/article/view/164/159

CARVAlHo, J. (2007). Saiba o que é Qualis Capes e quais os periódicos da CI com essa classificação. <http://biblioo.info/saiba-o-que-e-qualis-capes/> Data de acesso: 18/09/2018.

CASTELLS, M. (2003). A Galáxia da internet: reflexões sobre a internet, os negócios e a sociedade. Rio de Janeiro: Zahar.

Coelho, M. H. da C. C., SAntos, M. J. A., Gomes, S. A., \& MORUjÂO, M. do R. (2001). Estudos de Diplomática Portuguesa. Lisboa: Colibri e Faculdade de Letras da Universidade de Coimbra.

FRANCELIN, M. M. (2004). Configuração epistemológica da ciência da informação no Brasil em uma perspectiva pós-moderna: análise de periódicos da área. Ciência da Informação, v. 33, n.2, p. 49-66, maio/ago. 2004.

FREITAS, G., \& Silva, A. M. da. (2009). Identificação de paradigmas nos programas de pós-graduação em Ciência da Informação oferecidos em Portugal e no Brasil. In A Ciência da Informação criadora de conbecimento (Vol. 1, p. 69-83). Coimbra: Universidade de Coimbra.

MARCOS, I. M. (2011). As Carreiras dos profissionais da informação: estudo de caso dos técnicos superiores da administração pública portuguesa (Dissertação de mestrado). Universidad de Alcalá de Henares, Madrid.

MARCOS, I. M. (2016). Que futuro para o ensino da ciência da informação em Portugal? Páginas A\&bb, 3(5), 3-21. Recuperado de: http://ojs.letras.up.pt/index. $\mathrm{php} / \mathrm{paginasaeb/article/viewFile/1469/1263}$

MACHADO, M. L. S. (1967). Um curso de arquivologia para as empresas. Cadernos $B A D$, Vol. 4 , $\mathrm{N}^{\circ} 1$, p. $10-23$. 
MARQUES, J. (2011). A Paleografia e a Diplomática na Faculdade de Letras de Coimbra. Revista Portuguesa de História, XLII, 285-311.

https://doi.org/http://dx.doi.org/10.14195/0870-4147_42_13

MARQUES, M. B. (2016). O paradigma formativo do arquivista em Portugal. Boletim do Arquivo Da Universidade de Coimbra, XXIX, 323-346. Recuperado de: http:// impactum-journals.uc.pt/boletimauc/article/view/2737/2295

PEIXOTO, Jorge (1957) - Para uma reforma das bibliotecas e arquivos portugueses. Coimbra: AssociaçãoPortuguesa para o Progresso das Ciências.

PINHEIRO, L. V. R. (2005). Processo evolutivo e tendências contemporâneas da Ciência da Informação. Informação E Sociedade, João Pesoa, v. 15, n.1, 2005.

PINHEIRO, L. V. R. (2017). Itinerários filosóficos da Ciência da Informação no Brasil, o pioneirismo do IBICT e a propagação de idéias. Informação E Sociedade: Estudos, João Pessoa, v.7, n.3, p. 121-130, set./dez. 2017.

PINTO, M. (2008). A Formação em informação e documentação: Portugal na contemporaneidade. In Formación, investigación y mercado laboral enInformación y DocumentaciónenEspaña y Portugal = Formação, investigação e mercado de trabalho em Informação e Documentação em Espanha e Portugal. Recuperado de: https://repositorio-aberto.up.pt/handle/10216/26562

POBLACIÓN, D. A. M. A. (1993). Pesquisa e Pós-Graduação em Ciência da Informação e Biblioteconomia no Brasil: duas fases (1970/85 - 1986/92). In: Encontro Nacional dos Cursos de Pós-Graduação em Ciência da Informação e Biblioteconomia, 12., 1992, São Paulo, Anais... São Paulo: ANCIB, 1993. p. 11-23.

RIBEIRO, F. (2002). O desafio da formação profissional: novo paradigma, novo modelo formativo. Recuperado de: http://ler.letras.up.pt/uploads/ficheiros/1241.pdf

RIBEIRO, F. (2005). Formação e mercado de trabalho em Informação e Documentação em Portugal. PresentedattheColoquio Internacional de Ciencias de la Documentación, VI. Recuperado de: https://repositorio-aberto.up.pt/bitstream/10216/14003/2/ formaoemercado000073186.pdf

RIBEIRO, F. (2006). O Ensino da Paleografia e da Diplomática no Curso de BibliotecárioArquivista. In Estudos em Homenagem ao Professor Doutor José Marques (p. 47-63). Porto: Faculdade de Letras da Universidade do Porto. Recuperado de: https:// repositorio-aberto.up.pt/bitstream/10216/7741/2/4847.pdf

RIBEIRO, F. (2008). A formação dos profissionais de informação na Universidade do Porto : um modelo teórico-prático inovador assente numa perspectiva integrada. In Informação e Comunicação nos Mass Media: a produção noticiosa - actores e papéis. Recuperado de: https://repositorio-aberto.up.pt/bitstream/10216/14050/2/ formacaoup000073241.pdf

RIBEIRO, F. (2017). La era poscustodial :implicacionesen el campo de la ciencia de la información. In M. A. Rendon Rojas (Ed.), Laarchivística y la ciencia de la información documental: autonomía e interdependencias (p. 23-37). México: Universidad Nacional Autónoma de México. Instituto de InvestigacionesBibiotecológicas. y de la Información.

Ribeiro, F., LEITE, J. E. C., \& CERVEIRA, E. (2004). Memória do Curso de Especialização em Ciências Documentais: 1985-2003. In Homenagem ao Professor Doutor José Marques (p. 209-252). Porto: Universidade do Porto. Faculdade de Letras. Recuperado de: https://sigarra.up.pt/flup/pt/pub_geral.pub_view?pi_pub_ base_id=72514 
SANTOS, M. J. A. (2000). O ensino da Paleografia e da Diplomática na Faculdade de Letras da Universidade de Coimbra. In Ler e compreender a escrita na Idade Média. Lisboa: Edições Colibri e Faculdade de Letras da Universidade de Coimbra.

SARACEVIC, T. (1996) Ciência da informação: origem, evolução e relações. Perspectivas em Ciência da Informação, Belo Horizonte, v.1, n.1, p.41-62, 1996.

SILVA, A. M. da, \& RIBEIRO, F. (2002). Das "ciências" documentais à Ciência da Informação: ensaio epistemológico para um novo modelo curricular. Porto: Edições Afrontamento.

SILVA, A. M. da, \& RIBEIRO, F. (2004). Formação, perfil e competências do profissional da Informação. In Atas do $8^{\circ}$ Congresso Nacional de Bibliotecários, Arquivistas e Documentalistas. Estoril: BAD. Recuperado de: https://www.bad.pt/publicacoes/ index.php/congressosbad/article/view/622/619

SOUZA, R. F. \& STUMPF, I. R. C. (2009). Ciência da Informação como área do conhecimento: abordagem no contexto da pesquisa e da Pós-Graduação no Brasil. Perspectivas em Ciência da Informação, Belo Horizonte, v.14, número especial, p. 41-58, 2009.

SOUZA, T. B. de, \& RIBEIRO, F. (2009). Os cursos de Ciência da Informação no Brasil e em Portugal: perspectivas diacrônicas. Informação \& Informação, 14 (1), 82-102. https://doi.org/10.5433/1981-8920.2009v14n1p8 2

VIVAS, D., \& OLIVEIRA, S. R. de. (2015). Os Encontros de Bibliotecários, Arquivistas e Documentalistas (1965-1983): estudo histórico e bibliométrico. In Atas do12 ${ }^{\circ}$ Congresso Nacional de Bibliotecários, Arquivistas e Documentalistas. Évora: BAD. Recuperado de: https://www.bad.pt/publicacoes/index.php/ congressosbad/article/view/1289/pdf_79 


\section{Apêndice}

Tabela 1 - Formação em Informação e

Documentação em Portugal entre 1898 e 1982

\begin{tabular}{|c|c|c|}
\hline $\begin{array}{l}\text { Curso de } \\
\text { Bibliothecario- } \\
\text { archivista, } \\
\text { criado pelo } \\
\text { Decreto de } 29 \text { de } \\
\text { Dezembro de } 1887 \\
\left(\text { artigo } 13 .^{\circ}\right)\end{array}$ & $\begin{array}{l}\text { Curso de instrução } \\
\text { superior. Formação } \\
\text { na Faculdade } \\
\text { de Letras, } \\
\text { com algumas } \\
\text { disciplinas } \\
\text { ministradas no } \\
\text { Arquivo Nacional } \\
\text { ou Biblioteca } \\
\text { Nacional (artigo } \\
14 .^{\circ} \text { ) } \\
\text { Duração: } 2 \text { anos }\end{array}$ & 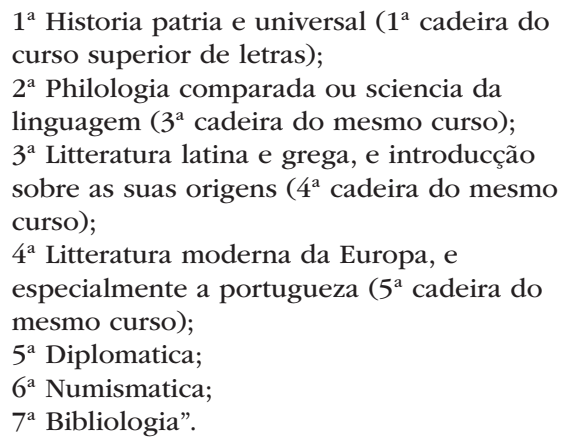 \\
\hline 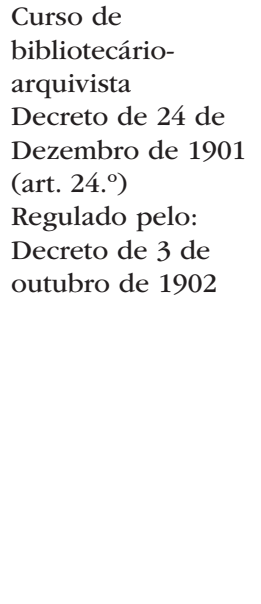 & $\begin{array}{l}\text { Curso de instrução } \\
\text { superior. Formação } \\
\text { na Faculdade } \\
\text { de Letras, } \\
\text { com algumas } \\
\text { disciplinas } \\
\text { ministradas no } \\
\text { Arquivo Nacional } \\
\text { ou Biblioteca } \\
\text { Nacional } \\
\text { Duração: } 3 \text { anos }\end{array}$ & $\begin{array}{l}1^{\circ} \text { Ano: } \\
\text { Geografia; Língua e literatura francesa; } \\
\text { Língua inglesa: História Antiga (do Curso } \\
\text { Superior de Letras); } \\
\text { Bibliologia (dada na Biblioteca Nacional); } \\
\text { Paleografia (dada na Torre do Tombo) } \\
2^{\circ} \text { Ano: } \\
\text { Geografia; Filologia Românica; Língua e } \\
\text { literatura francesa; Línguas e literaturas alemã } \\
\text { e inglesa; História da Idade Média e Moderna } \\
\text { (do Curso Superior de Letras); } \\
\text { Diplomática (dada na Torre do Tombo) } \\
3^{\circ} \text { Ano: } \\
\text { Filologia Portuguesa; Língua e literatura } \\
\text { francesa; Línguas e literaturas alemã e } \\
\text { inglesa; Literatura nacional; História Pátria } \\
\text { (do Curso Superior de Letras); } \\
\text { Numismática (dada na Biblioteca Nacional). }\end{array}$ \\
\hline
\end{tabular}




\begin{tabular}{|c|c|c|}
\hline $\begin{array}{l}\text { Decreto de } 18 \text { de } \\
\text { junho de } 1913 \\
\text {-Estabelecendo } \\
\text { a forma como } \\
\text { deve ser feita a } \\
\text { equiparação das } \\
\text { antigas cadeiras } \\
\text { do curso de } \\
\text { bibliotecário } \\
\text { arquivista com as } \\
\text { actuais cadeiras } \\
\text { da Faculdade de } \\
\text { Lisboa }\end{array}$ & $\begin{array}{l}\text { Curso de instrução } \\
\text { superior. Formação } \\
\text { na Faculdade } \\
\text { de Letras, } \\
\text { com algumas } \\
\text { disciplinas } \\
\text { ministradas } \\
\text { no Arquivo } \\
\text { ou Biblioteca } \\
\text { Nacional } \\
\text { Duração: } 3 \text { anos }\end{array}$ & $\begin{array}{l}1^{\circ} \text { Ano: } \\
\text { Filologia Portuguesa (dois semestres); } \\
\text { Língua e literatura francesa (dois } \\
\text { semestres); Língua e literatura inglesa } \\
\text { (dois semestres); Geografia geral (dois } \\
\text { semestres); Bibliologia (dada na Biblioteca } \\
\text { Nacional); Paleografia (dada na Torre do } \\
\text { Tombo) } \\
2^{\circ} \text { Ano: } \\
\text { Língua e literatura francesa (dois } \\
\text { semestres); Filologia Românica (dois } \\
\text { semestres); Língua e literatura inglesa } \\
\text { (dois semestres); Língua e literatura alemã } \\
\text { (dois semestres); História moderna e } \\
\text { contemporânea (dois semestres) (do Curso } \\
\text { Superior de Letras); Diplomática (dada na } \\
\text { Torre do Tombo) } \\
3^{\circ} \text { Ano: } \\
\text { Literatura Portuguesa (dois semestres); } \\
\text { Língua e literatura inglesa (dois semestres); } \\
\text { Língua e literatura alemã (dois semestres); } \\
\text { Geografia de Portugal, colónias (um } \\
\text { semestre); Etnologia (um semestre) (do } \\
\text { Curso Superior de Letras); } \\
\text { Numismática (dada na Biblioteca Nacional). }\end{array}$ \\
\hline $\begin{array}{l}\text { Curso de } \\
\text { bibliotecário- }^{\text {arquivista }} \\
\text { Decreto n. } \\
\text { de } 8 \text { de Maio de } \\
1818,- \\
\text { Regulado } \\
\text { peloDecreto n. } \\
\text { 4885, de } 11 \text { de } \\
\text { Outubro de } 1918\end{array}$ & $\begin{array}{l}\text { Curso de instrução } \\
\text { superior. Formação } \\
\text { na Faculdade } \\
\text { de Letras, } \\
\text { com algumas } \\
\text { disciplinas } \\
\text { ministradas } \\
\text { no Arquivo } \\
\text { ou Biblioteca } \\
\text { Nacional } \\
\text { Duração: } 3 \text { anos }\end{array}$ & $\begin{array}{l}1^{\circ} \text { Ano: } \\
\text { Filologia portuguesa, Latim medieval } \\
\text { e bárbaro, História de Portugal ( } 1^{\mathrm{a}} \\
\text { parte), Curso prático da língua francesa, } \\
\text { Paleografia ( } 1^{\mathrm{a}} \text { parte) e Bibliologia } \\
2^{\circ} \text { Ano: } \\
\text { História de Portugal ( } 2^{\mathrm{a}} \text { Parte), Curso } \\
\text { prático da língua francesa, Curso prático } \\
\text { da língua inglesa ou da língua alemã, } \\
\text { Paleografia ( } 2^{\mathrm{a}} \text { Parte), Diplomática, } \\
\text { Numismática geral e medalhística } \\
\text { Biblioteconomia, com um curso trimestral } \\
\text { anexo sobre higiene das espécies biblíacas } \\
3^{\circ} \text { Ano } \\
\text { História medieval, História moderna e } \\
\text { contemporânea, Curso prático da língua } \\
\text { inglesa ou da língua alemã, arquivologia, } \\
\text { numismática portuguesa e esfragística. }\end{array}$ \\
\hline
\end{tabular}




\begin{tabular}{|c|c|c|}
\hline $\begin{array}{l}\text { Curso de } \\
\text { Biblioteconomia e } \\
\text { arquivística,criado } \\
\text { pelo Decreto n. } \\
5618 \text {, de } 10 \text { de } \\
\text { Maio de } 1919 \\
\text { (Capítulo IV), } \\
\text { Regulado pelo } \\
\text { Decreto n. }{ }^{\circ} 6385 \text {, } \\
\text { de } 12 \text { de Fevereiro } \\
\text { de } 1920\end{array}$ & $\begin{array}{l}\text { Curso de instrução } \\
\text { superior. Formação } \\
\text { na Faculdade } \\
\text { de Letras, com } \\
\text { disciplinas } \\
\text { especiais } \\
\text { ministradas } \\
\text { no Arquivo } \\
\text { ou Biblioteca } \\
\text { Nacional } \\
\text { Duração: } 3 \text { anos }\end{array}$ & $\begin{array}{l}1^{\circ} \text { Ano: } \\
\text { História da Literatura Portuguesa, Curso } \\
\text { prático da língua francesa, História } \\
\text { de Portugal, Língua e literatura latina, } \\
\text { Bibliologia e Paleografia. } \\
2^{\circ} \text { Ano: } \\
\text { História da Literatura Portuguesa, Curso } \\
\text { prático da língua inglesa, História de } \\
\text { Portugal, Língua e literatura latina, } \\
\text { Paleografia e Iconografia } \\
3^{\circ} \text { Ano: } \\
\text { Curso prático da língua alemã, Língua e } \\
\text { literatura latina, Numismática e esfragística, } \\
\text { Diplomática, Biblioteconomia (com curso } \\
\text { trimestral anexo de Higiene dos livros) e } \\
\text { Arquivologia. }\end{array}$ \\
\hline $\begin{array}{l}\text { Decreto n. }{ }^{\circ} 13724 \text {, } \\
\text { de } 27 \text { de maio de } \\
1927 \text { - Reorganiza } \\
\text { os serviços } \\
\text { das bibliotecas } \\
\text { eruditas e } \\
\text { arquivos - Fixa } \\
\text { os programas das } \\
\text { cadeiras especiais } \\
\text { do curso superior } \\
\text { de bibliotecário } \\
\text { arquivista }\end{array}$ & $\begin{array}{l}\text { Curso de instrução } \\
\text { superior. Formação } \\
\text { na Faculdade } \\
\text { de Letras, com } \\
\text { disciplinas } \\
\text { especiais } \\
\text { ministradas } \\
\text { no Arquivo } \\
\text { ou Biblioteca } \\
\text { Nacional } \\
\text { Duração: } 3 \text { anos }\end{array}$ & $\begin{array}{l}1^{\circ} \text { Ano: } \\
\text { Filologia portuguesa ( } 1^{a} \text { parte), Literatura } \\
\text { portuguesa ( } 1^{\mathrm{a}} \text { parte), História de Portugal } \\
\text { ( } 1^{\mathrm{a}} \text { parte), Língua e literatura latina ( }{ }^{\mathrm{a}} \\
\text { parte), Francês prático, Bibliologia (curso } \\
\text { semestral), Paleografia ( } 1^{\mathrm{a}} \text { parte). } \\
2^{\circ} \text { Ano: } \\
\text { Filologia portuguesa ( } 2^{\mathrm{a}} \text { parte), Literatura } \\
\text { portuguesa ( } 2^{\mathrm{a}} \text { parte), História de } \\
\text { Portugal ( } 2^{\mathrm{a}} \text { parte), Língua e literatura } \\
\text { latina ( } 2^{\mathrm{a}} \text { parte), Grego elementar, } \\
\text { Inglês prático, Paleografia ( } 2^{\mathrm{a}} \text { parte), } \\
\text { Diplomática e esfragística. Numismática } \\
\text { geral e medalhística (curso semestral), } \\
\text { Biblioteconomia (curso semestral) } \\
3^{\circ} \text { Ano: } \\
\text { Língua e literatura latina ( } 3^{\mathrm{a}} \text { parte), } \\
\text { Filosofia: noções gerais de história da } \\
\text { filosofia e das ciências e suas classificações } \\
\text { lógicas (curso semestral), Inglês prático, } \\
\text { Arquivologia (curso semestral), Cartografia } \\
\text { antiga, Iconografia (curso semestral), } \\
\text { Numismática portuguesa. }\end{array}$ \\
\hline $\begin{array}{l}\text { Curso Superior } \\
\text { de Bibliotecário } \\
\text { Arquivista } \\
\text { Decreto n }{ }^{\circ} 19952 \text {, } \\
\text { de } 27 \text { de junho de } \\
1931\end{array}$ & $\begin{array}{l}\text { Curso profissional } \\
\text {, na dependência } \\
\text { da Inspeção das } \\
\text { Bibliotecas e } \\
\text { Arquivos } \\
\text { Duração: } 2 \text { anos }\end{array}$ & $\begin{array}{l}\text { Bibliografia (um semestre), } \\
\text { Biblioteconomia (um semestre) } \\
\text { Arquivologia e arquivo-economia (um } \\
\text { semestre) } \\
\text { Paleografia (anual) } \\
\text { Diplomática e esfragística (anual) } \\
\text { Numismática e medalhística (um semestre) } \\
\text { Iconografia e iluminura (um semestre) }\end{array}$ \\
\hline
\end{tabular}




\begin{tabular}{|c|c|c|}
\hline $\begin{array}{l}\text { Curso superior } \\
\text { de bibliotecário- } \\
\text { arquivista } \\
\text { Decreto } \text {. }^{\circ} \\
22014 \text {, de } 21 \text { de } \\
\text { dezembro de } 1932\end{array}$ & Duração: dois anos & $\begin{array}{l}1^{\circ} \text { ano: } \\
\text { Bibliologia e bibliografia } \\
\text { Arquivologia e arquioeconomia } \\
\text { Biblioteconomia } \\
\text { Paleografia ( } 1^{\mathrm{a}} \text { parte) } \\
\text { Numismática } \\
2^{\circ} \text { ano: } \\
\text { Diplomática e esfragística } \\
\text { Paleografia ( } 2^{\mathrm{a}} \text { parte) } \\
\text { Fontes de História de Portugal } \\
\text { Arqueologia artística e iconografia }\end{array}$ \\
\hline $\begin{array}{l}\text { Curso de } \\
\text { Bibliotecário- } \\
\text { arquivista, } \\
\text { Decreto-Lei n. } \\
\text { 26026, de } 7 \text { de } \\
\text { Novembro de } 1935\end{array}$ & $\begin{array}{l}\text { Curso de instrução } \\
\text { superior, dado na } \\
\text { Universidade de } \\
\text { Coimbra } \\
\text { Duração: dois anos }\end{array}$ & $\begin{array}{l}1^{\circ} \text { ano: } \\
\text { Paleografia e diplomática } \\
\text { Numismática e esfragística } \\
\text { Bibliografia e biblioteconomia } \\
2^{\circ} \text { ano: } \\
\text { Curso de aperfeiçoamento de paleografia } \\
\text { Arquivologia e arquivoeconomia }\end{array}$ \\
\hline $\begin{array}{l}\text { Decreto-Lei n. } \\
49009 \text {, de } 16 \text { de } \\
\text { Maiode } 1969 \text { - } \\
\text { Regula a prestação } \\
\text { do estágio para a } \\
\text { preparação técnica } \\
\text { dos bibliotecários, } \\
\text { arquivistas e } \\
\text { documentalistas } \\
\text { Portaria n. }{ }^{\circ} 24263 \text {, } \\
\text { de } 3 \text { de setembro } \\
\text { de } 1969 \text { - Regula } \\
\text { a admissão } \\
\text { ao estágio de } \\
\text { preparação técnica } \\
\text { dos bibliotecários, } \\
\text { arquivistas e } \\
\text { documentalistas. }\end{array}$ & $\begin{array}{l}\text { Formação } \\
\text { prática sob a } \\
\text { alçada Direção } \\
\text { Geral do Ensino } \\
\text { Superior e Belas } \\
\text { Artes, a realizar } \\
\text { em bibliotecas } \\
\text { e arquivos a } \\
\text { designar pelo } \\
\text { Ministro da } \\
\text { Educação Nacional } \\
\text { Duração: } 1 \text { ano } \\
\text { e três meses, } \\
\text { divididos em } 3 \\
\text { períodos }\end{array}$ & $\begin{array}{l}1^{a} \text { período: } \\
\text { Administração de bibliotecas } \\
\text { Catalogação - classificação I } \\
\text { Documentação I } \\
\text { Arquivística I } \\
\text { Leitura e crítica de documentos } \\
\text { Mecanização } \\
2^{\circ} \text { período: } \\
\text { Administração de arquivos } \\
\text { Catalogação - classificação II } \\
\text { Documentação II } \\
\text { Instituições Portuguesas. Seus núcleos } \\
\text { documentais } \\
\text { Leitura e crítica de documentos II } \\
3^{\circ} \text { Período: } \\
\text { Administração de centros de documentação } \\
\text { Documentação II } \\
\text { Informática } \\
\text { Sociologia da leitura e comunicação } \\
\text { Sociologia da informação }\end{array}$ \\
\hline
\end{tabular}

Fonte: Legislação citada

Elaboração própria 


\begin{tabular}{|c|c|c|}
\hline $\begin{array}{l}\text { Decreto } \mathrm{n}^{\circ} 87 / 82 \text {, } \\
\text { de } 13 \text { de Junho } \\
\text { - Cria o curso de } \\
\text { especialização } \\
\text { em Ciências } \\
\text { Documentais } \\
\text { (CECD) } \\
\text { Portaria } n^{\circ} 448 / 83 \\
\text { - Coimbra } \\
\text { Portaria no } 449 / 83 \\
\text { - Lisboa } \\
\text { Portaria } n^{\circ} 852 / 85 \\
\text { - Porto }\end{array}$ & $\begin{array}{l}\text { Curso de formação } \\
\text { superior, ao nível } \\
\text { da pós-graduação } \\
\text { Duração: } 2 \text { anos }\end{array}$ & 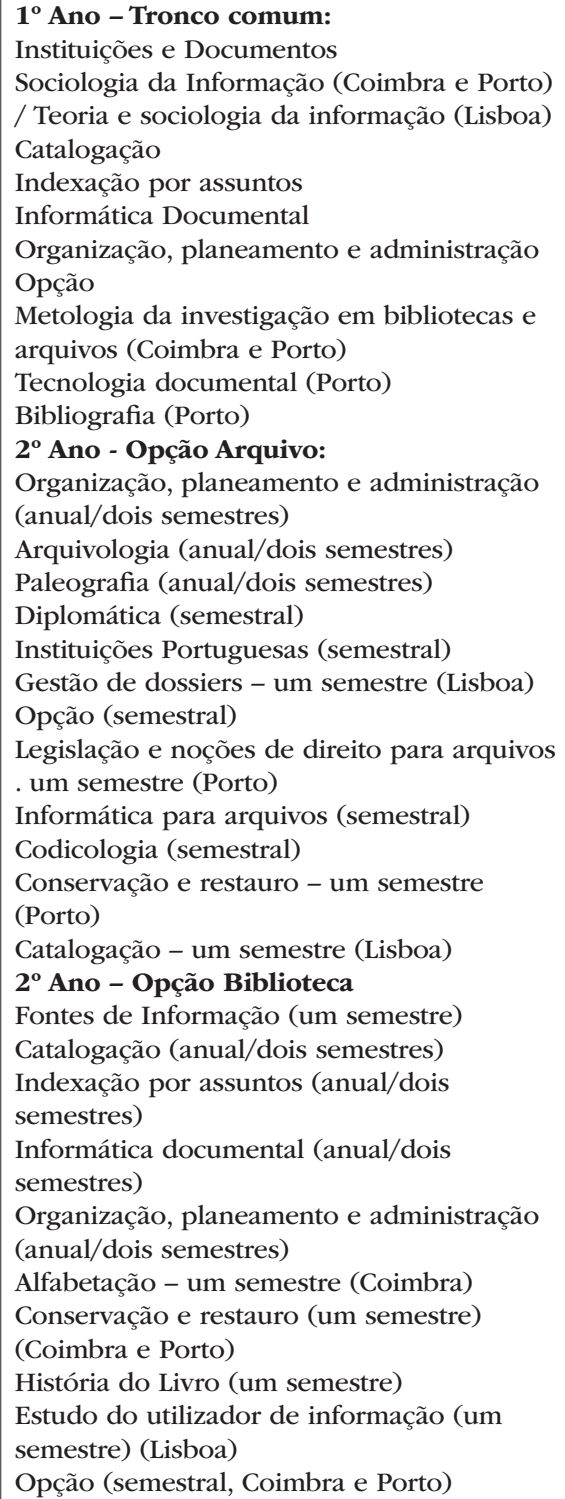 \\
\hline
\end{tabular}

Fonte: Legislação citada

Elaboração própria 
Tabela 3 - Oferta atual de formação em Ciência da Informação em Portugal - licenciaturas

\begin{tabular}{|c|c|}
\hline \multicolumn{2}{|c|}{ Licenciatura em Ciência da Informação: duração 3 anos } \\
\hline $\begin{array}{l}\text { Faculdade } \\
\text { de Letras da } \\
\text { Universidade de } \\
\text { Coimbra }\end{array}$ & 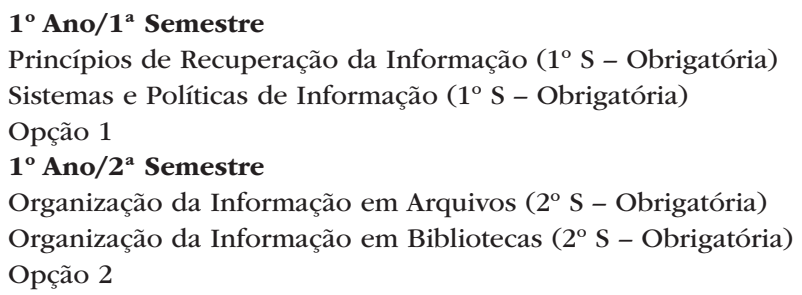 \\
\hline $\begin{array}{l}\text { Faculdade } \\
\text { de Letras da } \\
\text { Universidade do } \\
\text { Porto }\end{array}$ & 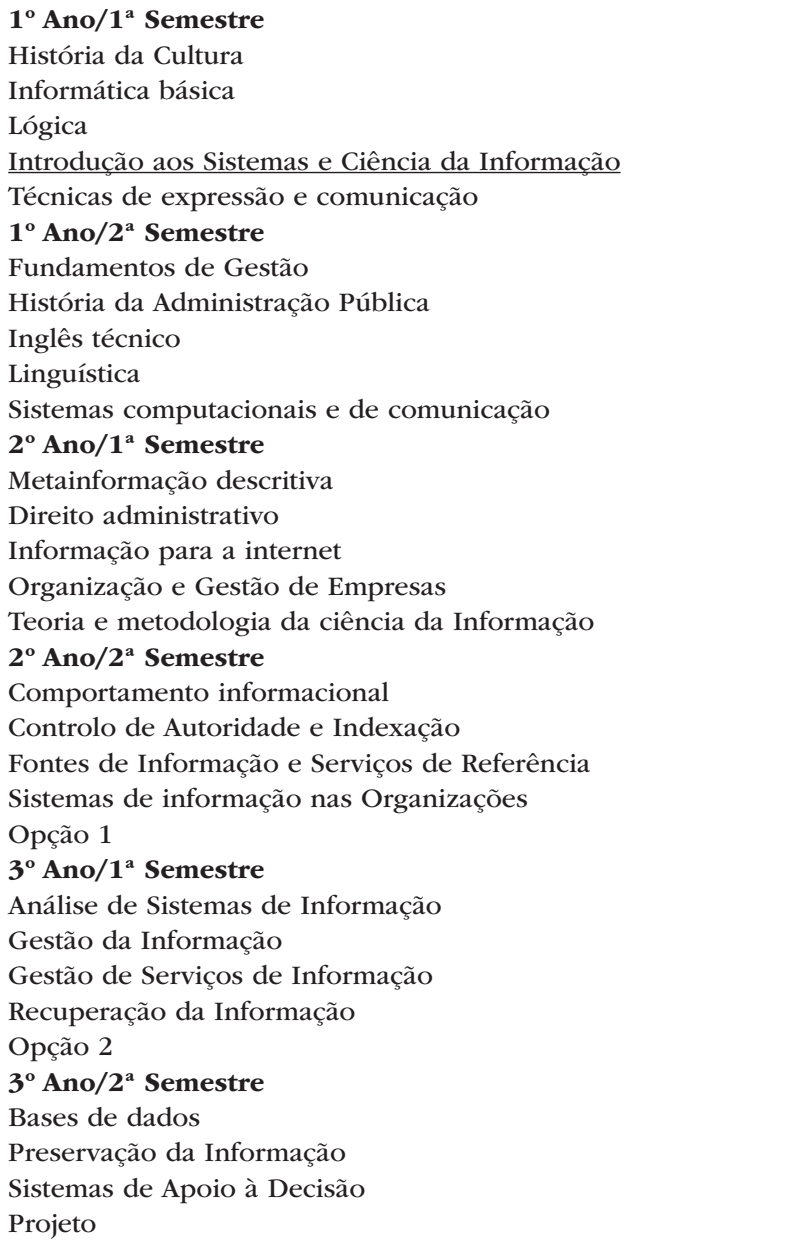 \\
\hline
\end{tabular}

Fonte: Websites das Universidades

Elaboração própria 
Tabela 4 - Oferta atual de formação em Ciência da Informação em Portugal - mestrados

\begin{tabular}{|c|c|c|}
\hline $\begin{array}{l}\text { Faculdade de } \\
\text { Ciências Sociais } \\
\text { e Humanas da } \\
\text { Universidade } \\
\text { Nova de Lisboa }\end{array}$ & $\begin{array}{l}\text { Mestrado em } \\
\text { Gestão e curadoria } \\
\text { da informação }\end{array}$ & $\begin{array}{l}\mathbf{1}^{\circ} \text { Semestre } \\
\text { Análise de Social Media } \\
\text { Curadoria da Informação: Aquisição e } \\
\text { Organização } \\
\text { Fundamentos da Ciência da Informação } \\
\text { Gestão dos Sistemas de Informação } \\
\text { Informação e Sociedade } \\
\text { Marketing e Comunicação da Informação } \\
2^{\circ} \text { Semestre } \\
\text { Curadoria da Informação: Preservação e } \\
\text { Recuperação da Informação } \\
\text { Gestão e Comportamento Organizacional } \\
\text { Opção } 1 \\
\text { Opção } 2 \\
3^{\circ} \text { Semestre } \\
\text { Seminário de Investigação e Métodos } \\
\text { em Ciências da Informação e Gestão da } \\
\text { Informação } \\
4^{\circ} \text { Semestre } \\
\text { Dissertação em Gestão e Curadoria da } \\
\text { Informação } \\
\text { Estágio com Relatório em Gestão e Curadoria } \\
\text { da Informação } \\
\text { Trabalho de Projeto em Gestão e Curadoria } \\
\text { da Informação }\end{array}$ \\
\hline $\begin{array}{l}\text { Faculdade } \\
\text { de Letras da } \\
\text { Universidade } \\
\text { de Coimbra }\end{array}$ & $\begin{array}{l}\text { Mestrado em } \\
\text { Ciência da } \\
\text { Informação }\end{array}$ & $\begin{array}{l}\mathbf{1}^{\circ} \text { Ano / } \mathbf{1}^{\circ} \text { Semestre } \\
\text { Gestão da informação nas Organizações } \\
\text { (obrigatória) } \\
\text { Teorias e Métodos em Ciência da Informação } \\
\text { (obrigatória) } \\
\text { Opção } 1 \\
\mathbf{1}^{\circ} \text { Ano / } \mathbf{2}^{\circ} \text { Semestre } \\
\text { Organização da Informação e do } \\
\text { Conhecimento Digital (obrigatória) } \\
\text { Seminários em Ciência da Informação } \\
\text { (obrigatória) } \\
\text { Opção } 2 \\
\mathbf{2}^{\circ} \text { Ano } \\
\text { Seminário de Orientação(obrigatória) } \\
\text { Elaboração da Dissertação de Mestrado } \\
\text { (opcional) } \\
\text { Elaboração de Trabalho de Projeto (opcional) }\end{array}$ \\
\hline
\end{tabular}

28 Para a realização da componente não letiva conducente ao grau de mestre, o estudante deve optar por uma destas modalidades. 


\begin{tabular}{|c|c|c|}
\hline $\begin{array}{l}\text { Faculdade } \\
\text { de Letras da } \\
\text { Universidade de } \\
\text { Lisboa }\end{array}$ & $\begin{array}{l}\text { Mestrado em } \\
\text { Ciências da } \\
\text { Documentação e } \\
\text { Informação }^{29}\end{array}$ & $\begin{array}{l}\mathbf{1}^{\circ} \text { Ano / } \mathbf{1}^{\circ} \text { Semestre } \\
\text { Teoria e Metodologia das Ciências da } \\
\text { Documentação e Informação (obrigatória) } \\
\text { Organização da informação I (obrigatória) } \\
\text { Pesquisa e utilização de recursos de } \\
\text { informação (obrigatória) } \\
\text { Tecnologias da Informação (obrigatória) } \\
\text { Opção } 1 \\
1^{\circ} \text { Ano / 2o Semestre } \\
\text { Direito da Informação (obrigatória) } \\
\text { Gestão de sistemas de informação } \\
\text { (obrigatória) } \\
\text { Organização da informação II (obrigatória) } \\
\text { Repositórios digitais (obrigatória) } \\
\text { Opção } 2 \\
2^{\circ} \text { Ano } \\
\text { Preservação e segurança da informação - } \\
\text { semestral (obrigatória) } \\
\text { Opção } 3 \text { - semestral } \\
\text { Seminário de Investigação - semestral (em } \\
\text { alternativa com estágio) } \\
\text { Dissertação Final/Trabalho de projeto - } \\
\text { Anual (obrigatória) } \\
\text { Estágio - semestral } \\
\text { Relatório de Estágio - Anual }\end{array}$ \\
\hline $\begin{array}{l}\text { Faculdade } \\
\text { de Letras da } \\
\text { Universidade do } \\
\text { Porto }\end{array}$ & & $\begin{array}{l}\mathbf{1}^{\circ} \text { Ano / } \mathbf{1}^{\circ} \text { Semestre } \\
\text { Representação do Conhecimento } \\
\text { Sociedade da Informação } \\
\text { Gestão do Conhecimento e Colaboração } \\
\text { Opção - grupo } 1 \\
\mathbf{1}^{\circ} \text { Ano / } \mathbf{2}^{\circ} \text { Semestre } \\
\text { Arquivos e bibliotecas digitais } \\
\text { Direito da Informação } \\
\text { Análise de conteúdo e indexação } \\
\text { Consultoria em Gestão da Informação } \\
\text { Opção - grupo } 2 \\
2^{\circ} \text { Ano } \\
\text { Dissertação / Projeto - Anual } \\
\text { Metodologia de investigação } \\
\text { Opção - Grupo } 3\end{array}$ \\
\hline
\end{tabular}

Fonte: Websites das Universidades

Elaboração própria

29 O grau de mestre em Ciências da Documentação e Informação é conferido aos que tiverem obtido 120 créditos, através da aprovação no curso de mestrado em Ciências da Documentação e Informação e da aprovação na defesa de um trabalho final - dissertação de natureza científica ou um trabalho de projeto, originais e especialmente realizados para este fim, ou um estágio de natureza profissional e aprovação do seu relatório final. 
Tabela 5 - Oferta atual de formação em Ciência da Informação em Portugal - doutoramentos

\begin{tabular}{|c|c|c|}
\hline $\begin{array}{l}\text { Faculdade } \\
\text { de Letras da } \\
\text { Universidade } \\
\text { de Coimbra }\end{array}$ & $\begin{array}{l}\text { Doutoramento } \\
\text { em Ciência da } \\
\text { Informação }\end{array}$ & $\begin{array}{l}\mathbf{1}^{\circ} \text { Ano } / \mathbf{1}^{\circ} \text { Semestre } \\
\text { Humanidades Digitais (obrigatória) } \\
\text { Organização e Gestão do Conhecimento } \\
\text { (obrigatória) } \\
\mathbf{1}^{\mathbf{o}} \text { Ano } / \mathbf{2}^{\circ} \text { Semestre } \\
\text { Serviços e Sistemas de Informação (obrigatória) } \\
\text { Comunicação em Ciência (opcional) } \\
\text { Seminários interdisciplinares (opcional) } \\
\mathbf{2}^{\circ} \text { Ano/1 } \\
\text { Projeto de Tese (obrigatória) } \\
\text { Tese Plurianual (obrigatória) }\end{array}$ \\
\hline $\begin{array}{l}\text { Faculdade } \\
\text { de Letras da } \\
\text { Universidade } \\
\text { do Porto (em } \\
\text { parceria com a } \\
\text { Universidade } \\
\text { de Aveiro) }\end{array}$ & $\begin{array}{l}\text { Doutoramento } \\
\text { em Informação } \\
\text { e Comunicação } \\
\text { em Plataformas } \\
\text { Digitais }\end{array}$ & $\begin{array}{l}\mathbf{1}^{\circ} \text { Ano / } \mathbf{1}^{\circ} \text { Semestre } \\
\text { Novos Paradigmas de Informação e Comunicação } \\
\text { em Plataformas Digitais(obrigatória) } \\
\text { Culturas de Convergência nos Media(obrigatória) } \\
\text { Opção } 1 \\
\text { Opção } 2 \\
\mathbf{1}^{\circ} \text { Ano / 20 Semestre } \\
\text { Preparação do Projeto de Tese(obrigatória) } \\
\text { Seminário de Investigação I(obrigatória) } \\
\text { Métodos e Técnicas de Investigação(obrigatória) } \\
\mathbf{2}^{\circ} \text { Ano } \\
\text { Tese } \\
\text { Seminário de Investigação II (obrigatória) } \\
\mathbf{3}^{\circ} \text { Ano } \\
\text { Tese } \\
\text { Seminário de Investigação II (obrigatória) }\end{array}$ \\
\hline
\end{tabular}

Fonte: Websites das Universidades

Elaboração própria 
Tabela 6: Programas de Pós-Graduação em Ciência da Informação no Brasil

\begin{tabular}{|c|c|c|c|}
\hline & $\begin{array}{l}\text { Instituição de Ensino } \\
\text { (programas em atividade e áreas de concentração) }\end{array}$ & $\begin{array}{l}\text { Cursos e } \\
\text { data de } \\
\text { início }\end{array}$ & Nota \\
\hline 1 & $\begin{array}{l}\text { Fundação Casa de Rui Barbosa - FCRB } \\
\text { Unidade da Federação: Rio de Janeiro } \\
\text { Programa: Memória e Acervos } \\
\text { Área de Concentração: Acervos Públicos e Privados: } \\
\text { Gerenciamento, Preservação, Acesso e Usos } \\
\text { Linhas de Pesquisa: 1) Patrimônio documental: } \\
\text { representação, gerenciamento e preservação de espaços e } \\
\text { memória; 2) Práticas críticas em acervos: difusão, acesso, uso } \\
\text { e apropriação do patrimônio documental material e imaterial }\end{array}$ & MP (2016) & 3 \\
\hline 2 & $\begin{array}{l}\text { Fundação Universidade Federal de Sergipe - FUFSE } \\
\text { Unidade da Federação: Sergipe } \\
\text { Programa: Ciência da Informação } \\
\text { Área de Concentração: Gestão da Informação e do } \\
\text { Conhecimento e Sociedade } \\
\text { Linhas de Pesquisa: 1) Informação, Sociedade e Cultura; 2) } \\
\text { Produção, Organização e Comunicação da Informação }\end{array}$ & MP (2017) & 3 \\
\hline 3 & $\begin{array}{l}\text { Universidade de Brasília - UnB } \\
\text { Unidade da Federação: Distrito Federal } \\
\text { Programa: Ciência da Informação } \\
\text { Área de Concentração: Gestão da Informação } \\
\text { Linhas de Pesquisa: 1) Organização da Informação; 2) } \\
\text { Comunicação e Mediação do Conhecimento }\end{array}$ & $\begin{array}{l}\text { MA } \\
(1978) \\
\text { DO } \\
(1992)\end{array}$ & $\begin{array}{l}5 \\
5\end{array}$ \\
\hline 4 & $\begin{array}{l}\text { Universidade de São Paulo - USP } \\
\text { Unidade da Federação: São Paulo } \\
\text { Programa: Ciência da Informação } \\
\text { Área de Concentração: Cultura e Informação } \\
\text { Linhas de Pesquisa: 1) Apropriação Social da Informação; 2) } \\
\text { Gestão de Dispositivos de Informação; 3) Organização da } \\
\text { Informação e do Conhecimento } \\
\text { Programa: Gestão da Informação } \\
\text { Área de Concentração: Organização, Mediação e Circulação } \\
\text { da Informação } \\
\text { Linhas de Pesquisa: 1) Mediação Cultural; 2) Gestão de } \\
\text { Unidades de Informação; 3) Organização do Conhecimento }\end{array}$ & $\begin{array}{l}\text { MA } \\
(2006) \\
\text { DO } \\
(2006)\end{array}$ & $\begin{array}{l}4 \\
4\end{array}$ \\
\hline 5 & $\begin{array}{l}\text { Universidade do Estado de Santa Catarina - UDESC } \\
\text { Unidade da Federação: Santa Catarina } \\
\text { Programa: Gestão da Informação } \\
\text { Área de Concentração: Gestão da Informação } \\
\text { Linhas de Pesquisa: 1) Gestão de Unidades de Informação; 2) } \\
\text { Informação, Memória e Sociedade }\end{array}$ & MP (2013) & 3 \\
\hline
\end{tabular}




\begin{tabular}{|c|c|c|c|}
\hline 6 & $\begin{array}{l}\text { Universidade Estadual de Londrina - UEL } \\
\text { Unidade da Federação: Paraná } \\
\text { Programa: Ciência da Informação } \\
\text { Área de Concentração: Organização, Acesso e Apropriação da } \\
\text { Informação e do Conhecimento } \\
\text { Linhas de Pesquisa: 1) Organização e Representação da } \\
\text { Informação e do Conhecimento; 2) Compartilhamento da } \\
\text { Informação e do Conhecimento }\end{array}$ & $\begin{array}{l}\text { MA } \\
\text { (2012) }\end{array}$ & 4 \\
\hline 7 & $\begin{array}{l}\text { Universidade Estadual Paulista Júlio de Mesquita Filho - } \\
\text { UNESP } \\
\text { Unidade da Federação: São Paulo } \\
\text { Programa: Ciência da Informação } \\
\text { Área de Concentração: Informação, Tecnologia e } \\
\text { Conhecimento } \\
\text { Linhas de Pesquisa: 1) Informação e Tecnologia; 2) Produção } \\
\text { e Organização da Informação; 3) Gestão, Mediação e Uso da } \\
\text { Informação }\end{array}$ & $\begin{array}{l}\text { MA } \\
(1998) \\
\text { DO } \\
(2005)\end{array}$ & $\begin{array}{l}6 \\
6\end{array}$ \\
\hline 8 & $\begin{array}{l}\text { Universidade Federal da Bahia - UFBA } \\
\text { Unidade da Federação: Bahia } \\
\text { Programa: Ciência da Informação } \\
\text { Área de Concentração: Informação e Conhecimento na } \\
\text { Sociedade Contemporânea } \\
\text { Linhas de Pesquisa: 1) Políticas e Tecnologias da Informação; } \\
\text { 2) Produção, Circulação e Mediação da Informação }\end{array}$ & $\begin{array}{l}\text { MA } \\
(2000) \\
\text { DO } \\
(2011)\end{array}$ & $\begin{array}{l}4 \\
4\end{array}$ \\
\hline 9 & $\begin{array}{l}\text { Universidade Federal da Paraíba - UFPB } \\
\text { Unidade da Federação: Paraíba } \\
\text { Programa: Ciência da Informação } \\
\text { Área de Concentração: Informação, Conhecimento e } \\
\text { Sociedade } \\
\text { Linhas de Pesquisa: 1) Informação, Memória e Sociedade; 2) } \\
\text { Organização, Acesso e Uso da Informação; 3) Ética, Gestão e } \\
\text { Políticas de Informação }\end{array}$ & $\begin{array}{l}\text { MA } \\
(2004) \\
\text { DO } \\
(2012)\end{array}$ & $\begin{array}{l}4 \\
4\end{array}$ \\
\hline 10 & $\begin{array}{l}\text { Universidade Federal de Alagoas - UFAL } \\
\text { Unidade da Federação: Alagoas } \\
\text { Programa: Ciência da Informação } \\
\text { Área de Concentração: Informação, Tecnologia e Informação } \\
\text { Linhas de Pesquisa: 1) Produção, Mediação e Gestão da } \\
\text { Informação; 2) Informação, Comunicação e Processos } \\
\text { Tecnológicos }\end{array}$ & $\begin{array}{l}\text { MA } \\
(2019)\end{array}$ & A \\
\hline
\end{tabular}




\begin{tabular}{|c|c|c|c|}
\hline 11 & $\begin{array}{l}\text { Universidade Federal de Minas Gerais - UFMG } \\
\text { Unidade da Federação: Minas Gerais } \\
\text { Programa: Ciências da Informação } \\
\text { Área de Concentração: 1) Informação, Mediações e Cultura: } \\
\text { 2) Produção, Organização e Utilização da Informação; 3) } \\
\text { Produção, Organização e Utilização da Informação } \\
\text { Linhas de Pesquisa: 1) Memória social, patrimônio e } \\
\text { produção do conhecimento; 2) Políticas públicas e } \\
\text { organização da informação; 3) Usuários, gestão do } \\
\text { conhecimento e práticas informacionais. } \\
\text { Programa: Gestão e Organização do Conhecimento } \\
\text { Área de Concentração: 1) Ciência da Informação; 2) } \\
\text { Representação do Conhecimento }\end{array}$ & $\begin{array}{l}\text { MA } \\
(2016) \\
\text { DO } \\
(2016)\end{array}$ & $\begin{array}{l}5 \\
5\end{array}$ \\
\hline 12 & $\begin{array}{l}\text { Universidade Federal de Pernambuco - UFPE } \\
\text { Unidade da Federação: Pernambuco } \\
\text { Programa: Ciência da Informação } \\
\text { Área de Concentração: Informação, Memória Tecnologia } \\
\text { Linhas de Pesquisa: 1) Arquitetura \& Organização do } \\
\text { Conhecimento; 2) Gestão \& Tecnologia da Informação e } \\
\text { Comunicação }\end{array}$ & $\begin{array}{l}\text { MA } \\
(2009)\end{array}$ & 4 \\
\hline 13 & $\begin{array}{l}\text { Universidade Federal de Santa Catarina - UFSC } \\
\text { Unidade da Federação: Santa Catarina } \\
\text { Programa: Ciência da Informação } \\
\text { Área de Concentração: Gestão da Informação } \\
\text { Linhas de Pesquisa: 1) Organização, Representação e } \\
\text { Mediação da Informação e do Conhecimento; 2) Informação, } \\
\text { Gestão e Tecnologia }\end{array}$ & $\begin{array}{l}\text { MA } \\
(2000) \\
\text { DO } \\
(2013)\end{array}$ & \\
\hline 14 & $\begin{array}{l}\text { Universidade Federal de São Carlos - UFSCAR } \\
\text { Unidade da Federação: São Paulo } \\
\text { Programa: Ciência da Informação } \\
\text { Área de Concentração: Conhecimento, Tecnologia e Inovação } \\
\text { Linhas de Pesquisa: 1) Conhecimento e Informação para } \\
\text { Inovação; 2) Tecnologia, Informação e Representação }\end{array}$ & $\begin{array}{l}\text { MA } \\
(2016)\end{array}$ & 3 \\
\hline 15 & $\begin{array}{l}\text { Universidade Federal do Cariri - UFCA } \\
\text { Unidade da Federação: Ceará } \\
\text { Programa: Biblioteconomia } \\
\text { Área de Concentração: Biblioteconomia na Sociedade } \\
\text { Contemporânea } \\
\text { Linhas de Pesquisa: 1) Informação, Cultura e Memória; 2) } \\
\text { Produção, Comunicação e Uso da Informação }\end{array}$ & MP (2016) & 3 \\
\hline 16 & $\begin{array}{l}\text { Universidade Federal do Ceará - UFC } \\
\text { Unidade da Federação: Ceará } \\
\text { Programa: Ciência da Informação } \\
\text { Área de Concentração: Representação e Mediação da } \\
\text { Informação e do Conhecimento } \\
\text { Linhas de Pesquisa: 1) Representação da Informação e } \\
\text { do Conhecimento e Tecnologia; 2) Mediação e Gestão da } \\
\text { Informação e do Conhecimento }\end{array}$ & $\begin{array}{l}\text { MA } \\
(2016)\end{array}$ & 3 \\
\hline
\end{tabular}




\begin{tabular}{|c|c|c|c|}
\hline 17 & $\begin{array}{l}\text { Universidade Federal do Espírito Santo } \\
\text { Unidade da Federação: Espírito Santo } \\
\text { Programa: Ciência da Informação } \\
\text { Área de Concentração: Informação, Sociedade e Cultura } \\
\text { Linhas de Pesquisa: 1) Cultura, Mediação e Uso da } \\
\text { Informação; 2) Memória, Representação e Informação }\end{array}$ & $\begin{array}{l}\text { MA } \\
(2019)\end{array}$ & A \\
\hline 18 & $\begin{array}{l}\text { Universidade Federal do Estado do Rio de Janeiro - } \\
\text { UNIRIO } \\
\text { Unidade da Federação: Rio de Janeiro } \\
\text { Programa: Biblioteconomia } \\
\text { Área de Concentração: Biblioteconomia e Sociedade } \\
\text { Linhas de Pesquisa: 1) Biblioteconomia, Cultura e Sociedade; } \\
\text { 2) Organização e Representação do Conhecimento. } \\
\text { Programa: Gestão de Documentos e Arquivos } \\
\text { Área de Concentração: Gestão de Arquivos na Arquivologia } \\
\text { Contemporânea } \\
\text { Linhas de Pesquisa: 1) Arquivo, Arquivologia e Sociedade; 2) } \\
\text { Gestão da Informação Arquivística }\end{array}$ & MP (2012) & 3 \\
\hline 19 & $\begin{array}{l}\text { Universidade Federal do Pará - UFPA } \\
\text { Unidade da Federação: Pará } \\
\text { Programa: Ciência da Informação } \\
\text { Área de Concentração: Gestão da Informação e Organização } \\
\text { do Conhecimento } \\
\text { Linhas de Pesquisa: 1) Mediação e Uso da Informação; 2) } \\
\text { Organização da Informação }\end{array}$ & MP (2017) & 3 \\
\hline 20 & $\begin{array}{l}\text { Universidade Federal do Rio de Janeiro - UFRJ } \\
\text { Unidade da Federação: Rio de Janeiro } \\
\text { Programa: Ciência da Informação } \\
\text { Área de Concentração: Informação e Mediações Sociais e } \\
\text { Tecnológicas para o Conhecimento } \\
\text { Linhas de Pesquisa: 1) Comunicação, Organização e Gestão } \\
\text { da Informação e do Conhecimento; 2) Configurações } \\
\text { socioculturais, políticas e econômicas da informação }\end{array}$ & $\begin{array}{l}\text { MA } \\
(2009) \\
\text { DO } \\
(2009)\end{array}$ & \\
\hline 21 & $\begin{array}{l}\text { Universidade Federal do Rio Grande do Norte - UFRN } \\
\text { Unidade da Federação: Rio Grande do Norte } \\
\text { Programa: Ciência da Informação } \\
\text { Área de Concentração: Informação e Conhecimento na } \\
\text { Sociedade Contemporânea } \\
\text { Linha de Pesquisa: Gestão da Informação e do Conhecimento }\end{array}$ & MP (2015) & 3 \\
\hline 22 & $\begin{array}{l}\text { Universidade Federal do Rio Grande do Sul - UFRGS } \\
\text { Unidade da Federação: Rio Grande do Sul } \\
\text { Programa: Ciência da Informação } \\
\text { Área de Concentração: Informação, Ciência e Sociedade } \\
\text { Linhas de Pesquisa: XXX }\end{array}$ & $\begin{array}{l}\text { MA } \\
(2019)\end{array}$ & A \\
\hline
\end{tabular}




\begin{tabular}{|c|c|c|}
\hline 23 & $\begin{array}{l}\text { Universidade Federal Fluminense - UFF } \\
\text { Unidade da Federação: Rio de Janeiro } \\
\text { Programa: Ciência da Informação } \\
\text { Área de Concentração: Dimensões Contemporâneas da } \\
\text { Informação e do Conhecimento } \\
\text { Linhas de Pesquisa: 1) Informação, Cultura e Sociedade; 2) } \\
\text { Fluxos e Mediação Sócio-Técnicas da Informação }\end{array}$ & $\begin{array}{l}\text { MA } \\
(2009) \\
\text { DO } \\
(2014)\end{array}$ \\
\hline 24 & $\begin{array}{l}\text { Universidade FUMEC - FUMEC } \\
\text { Unidade da Federação: Minas Gerais } \\
\text { Programa: Sistemas de Informação e Gestão do } \\
\text { Conhecimento } \\
\text { Área de Concentração: Gestão de Sistemas de Informação e } \\
\text { de Conhecimento } \\
\text { Linhas de Pesquisa: 1) Gestão da Informação e do } \\
\text { Conhecimento; 2) Tecnologias e Sistemas de Informação }\end{array}$ & $\begin{array}{l}\text { MA } \\
(2011) \\
\text { DO } \\
(2015)\end{array}$ \\
\hline
\end{tabular}

MA: Mestrado Acadêmico

MP: Mestrado Profissional

DO: Doutorado

Fonte: <https://sucupira.capes.gov.br/sucupira/public/consultas/coleta/programa/ quantitativos/quantitativoles.jsf?areaAvaliacao $=31 \&$ areaConhecimento $=60700009 \mathrm{>}$ Data de acesso: 05/07/2019.

Tabela 7: Avaliação Qualis-Periódicos

\begin{tabular}{|l|l|}
\hline Conceito & Critérios \\
\hline A1 & $\begin{array}{l}\text { Periódicos de referência internacional indexados nas bases Web of } \\
\text { Science e/ou Journal Citation Ranking - JCR. }\end{array}$ \\
\hline A2 & $\begin{array}{l}\text { Periódicos de referência internacional indexados nas bases Scopus } \\
\text { e/ou Scielo, além de artigos publicados por doutores de diferentes } \\
\text { instituições com publicação de 50\% por volume de autores ou co-autores } \\
\text { filiados a instituições estrangeiras. }\end{array}$ \\
\hline B1 & $\begin{array}{l}\text { Periódicos de referência nacional indexados em pelo menos uma das } \\
\text { bases: LATINDEX (Sistema Regional de Información em Línea para } \\
\text { Revistas Científicas de América Latina, el Caribe, España e Portugal); } \\
\text { REDALYC (Red de Revistas Científicas de América Latina, el Caribe, } \\
\text { España y Portugal); DOAJ (Directory of Open Access Journals - } \\
\text { periódicos eletrônicos); CLACSO (Consejo Latinoamericano de Ciências } \\
\text { Sociales); CLASE (Citas Latinoamericanas em Ciencias Sociales y } \\
\text { Humanidades), além de artigos publicados por doutores de diferentes } \\
\text { instituições com publicação expressiva por volume de autores ou co- } \\
\text { autores filiados a instituições estrangeiras. }\end{array}$ \\
\hline B2 & $\begin{array}{l}\text { Periódicos de referência nacional indexado pela DOAJ (Directory of } \\
\text { Open Access Journals) considerando também periódico que contenha } \\
\text { artigos cujos autores doutores sejam vinculados a pelo menos 3 (três) } \\
\text { instituições diferentes daquela que edita o periódico, por volume, além } \\
\text { de manter periodicidade e acessibilidade. }\end{array}$ \\
\hline
\end{tabular}




\begin{tabular}{|l|l|}
\hline B3 & $\begin{array}{l}\text { Periódicos que contenha artigos cujos autores doutores sejam vinculados } \\
\text { a pelo menos três instituições diferentes daquela que edita o periódico, } \\
\text { por volume, além de manter periodicidade e acessibilidade. }\end{array}$ \\
\hline B4 & $\begin{array}{l}\text { Periódicos que contenha publicação de artigos com um número mínimo } \\
\text { de autores doutores pertencente a diferentes instituições daquela que } \\
\text { edita o periódico. }\end{array}$ \\
\hline B5 & $\begin{array}{l}\text { Periódicos que atendam aos critérios mínimos exigidos para ser } \\
\text { classificado como periódico científico, mas não são relevantes para a } \\
\text { area, assim como periódicos que atendam aos critérios mínimos, mas } \\
\text { não atendem às exigências adicionais descritas nos estratos anteriores. }\end{array}$ \\
\hline C & Periódicos considerados não científicos e inacessíveis para avaliação. \\
\hline
\end{tabular}

Fonte: Carvalho, J. (2007) - http://biblioo.info/saiba-o-que-e-qualis-capes/

Tabela 8: Periódicos em Ciência da Informação no Brasil

\begin{tabular}{|c|c|c|c|c|c|}
\hline & Periódico & Instituição & Periodicidade & $\begin{array}{l}\text { Ano da } \\
\text { última } \\
\text { edição }\end{array}$ & Qualis \\
\hline 01 & $\begin{array}{l}\text { Acervo: Revista do } \\
\text { Arquivo Nacional }\end{array}$ & $\begin{array}{l}\text { Arquivo } \\
\text { Nacional }\end{array}$ & Semestral & 2017 & B2 \\
\hline 02 & Ágora & UFSC & Semestral & 2017 & B1 \\
\hline 03 & Archeion Online & UFPB & Semestral & 2017 & $\mathrm{C}$ \\
\hline 04 & Arquivística.net & Particular & Semestral & 2008 & - \\
\hline 05 & $\begin{array}{l}\text { Arquivo \& } \\
\text { Admnistração }\end{array}$ & $\mathrm{AAB}$ & Semestral & 2014 & - \\
\hline 06 & $\begin{array}{l}\text { AtoZ: Novas práticas } \\
\text { em Informação e } \\
\text { Conhecimento }\end{array}$ & UFPR & Semestral & 2017 & B2 \\
\hline 07 & Biblionline & UFPB & Semestral & 2017 & B5 \\
\hline 08 & $\begin{array}{l}\text { Biblioteca escolar } \\
\text { em revista }\end{array}$ & USP & Semestral & 2017 & B3 \\
\hline 09 & $\begin{array}{l}\text { Bibliotecas } \\
\text { universitárias: } \\
\text { pesquisas, } \\
\text { experiências e } \\
\text { perspectivas }\end{array}$ & UFMG & Semestral & 2016 & $\mathrm{C}$ \\
\hline 10 & $\begin{array}{l}\text { BIBLOSs: Revista do } \\
\text { Instituto de Ciências } \\
\text { Humanas e da } \\
\text { Informação }\end{array}$ & FURG & Semestral & 2017 & B3 \\
\hline 11 & $\begin{array}{l}\text { Brazilian journal of } \\
\text { information Science }\end{array}$ & UNESP & Semestral & 2017 & B1 \\
\hline 12 & $\begin{array}{l}\text { Cadernos de } \\
\text { Biblioteconomia }\end{array}$ & $\begin{array}{l}\text { Não } \\
\text { identificado }\end{array}$ & Anual & 1989 & - \\
\hline
\end{tabular}




\begin{tabular}{|c|c|c|c|c|c|}
\hline 13 & $\begin{array}{l}\text { Cadernos de } \\
\text { informação jurídica }\end{array}$ & Particular & Semestral & 2017 & B5 \\
\hline 14 & $\begin{array}{l}\text { Ciência da } \\
\text { Informação }\end{array}$ & IBICT & Quadrimestral & 2017 & B1 \\
\hline 15 & $\begin{array}{l}\text { Ciência da } \\
\text { Informação em } \\
\text { revista }\end{array}$ & UFAL & Semestral & 2017 & B5 \\
\hline 16 & $\begin{array}{l}\text { Comunicação \& } \\
\text { informação }\end{array}$ & UFG & Quadrimestral & 2017 & B2 \\
\hline 17 & CRB-6 Informa & $\begin{array}{l}\mathrm{CRB}-6^{\mathrm{a}} \\
\text { região }\end{array}$ & Semestral & 2016 & B5 \\
\hline 18 & CRB-8 Digital & $\mathrm{CRB} / \mathrm{SP}$ & Semestral & $\begin{array}{l}\text { Não } \\
\text { identificado }\end{array}$ & B5 \\
\hline 19 & Datagramazero & Particular & Bimestral & 2015 & B3 \\
\hline 20 & $\begin{array}{l}\text { Educação temática } \\
\text { digital }\end{array}$ & UNICAMP & Quadrimestral & 2017 & B2 \\
\hline 21 & Em questão & UFRGS & Semestral & 2017 & A2 \\
\hline 22 & $\begin{array}{l}\text { Encontros Bibli: } \\
\text { Revista eletrônica } \\
\text { de Biblioteconomia } \\
\text { e Ciência da } \\
\text { Informação }\end{array}$ & UFSC & Semestral & 2017 & A2 \\
\hline 23 & $\begin{array}{l}\text { Estudos avançados } \\
\text { em Biblioteconomia } \\
\text { e Ciência da } \\
\text { Informação }\end{array}$ & $\mathrm{ABDF}$ & Anual & 1986 & - \\
\hline 24 & Folha de rosto & UFCA & Semestral & 2017 & B5 \\
\hline 25 & $\begin{array}{l}\text { InCID: Revista } \\
\text { de Ciência da } \\
\text { Informação e } \\
\text { Documentação }\end{array}$ & USP & Semestral & 2017 & B1 \\
\hline 26 & Inclusão social & IBICT & Semestral & 2017 & B4 \\
\hline 27 & Infociência & $\begin{array}{l}\text { Não } \\
\text { identificado }\end{array}$ & Anual & 2004 & - \\
\hline 28 & $\begin{array}{l}\text { Informação } \\
\text { arquivística }\end{array}$ & AAERJ & Semestral & 2016 & B5 \\
\hline 29 & $\begin{array}{l}\text { Informação \& } \\
\text { informação }\end{array}$ & UEL & Quadrimestral & 2017 & A2 \\
\hline 30 & $\begin{array}{l}\text { Informação \& } \\
\text { sociedade: estudos }\end{array}$ & UFPB & Quadrimestral & 2017 & A1 \\
\hline 31 & $\begin{array}{l}\text { Informação \& } \\
\text { tecnologia }\end{array}$ & UFPB & Semestral & 2015 & B5 \\
\hline 32 & $\begin{array}{l}\text { Informação em } \\
\text { pauta }\end{array}$ & UFC & Semestral & 2016 & B5 \\
\hline
\end{tabular}




\begin{tabular}{|c|c|c|c|c|c|}
\hline 33 & $\begin{array}{l}\text { Informação@ } \\
\text { profissões }\end{array}$ & UEL & Semestral & 2017 & B5 \\
\hline 34 & $\begin{array}{l}\text { Informare: Cadernos } \\
\text { do Programa de } \\
\text { Pós-graduaçãao } \\
\text { em Ciência da } \\
\text { Informação }\end{array}$ & UFRJ/IBICT & Semestral & 2000 & - \\
\hline 35 & Intexto & UFRGS & Quadrimestral & 2017 & B1 \\
\hline 36 & $\begin{array}{l}\text { IRIS: Revista } \\
\text { de informação, } \\
\text { memória e } \\
\text { tecnologia }\end{array}$ & UFPE & Anual & 2013 & B3 \\
\hline 37 & Liinc em revista & IBICT & Semestral & 2017 & B1 \\
\hline 38 & $\begin{array}{l}\text { Logeion: Filosofia da } \\
\text { informação }\end{array}$ & IBICT & Semestral & 2017 & B5 \\
\hline 39 & $\begin{array}{l}\text { Múltiplos olhares } \\
\text { em Ciência da } \\
\text { Informação }\end{array}$ & UFMG & Semestral & 2017 & B5 \\
\hline 40 & $\begin{array}{l}\text { Perspectivas } \\
\text { em Ciência da } \\
\text { Informação }\end{array}$ & UFMG & Trimestral & 2017 & A1 \\
\hline 41 & $\begin{array}{l}\text { Perspectivas } \\
\text { em gestão \& } \\
\text { conhecimento }\end{array}$ & UFPB & Quadrimestral & 2017 & B1 \\
\hline 42 & $\begin{array}{l}\text { Pesquisa brasileira } \\
\text { em Ciência da } \\
\text { Informação e } \\
\text { Biblioteconomia }\end{array}$ & UFPB & Semestral & 2017 & B1 \\
\hline 43 & Ponto de acesso & UFBA & Quadrimestral & 2017 & B1 \\
\hline 44 & $\begin{array}{l}\text { RACIn - Revista } \\
\text { analisando } \\
\text { em Ciência da } \\
\text { Informação }\end{array}$ & UEPB & Semestral & 2017 & B5 \\
\hline 45 & $\begin{array}{l}\text { RECIIS - Revista } \\
\text { eletrônica de } \\
\text { comunicação, } \\
\text { informação \& } \\
\text { inovação em saúde }\end{array}$ & FIOCRUZ & Trimestral & 2017 & B1 \\
\hline 46 & $\begin{array}{l}\text { RECINE: Revista } \\
\text { do Festival } \\
\text { Internacional de } \\
\text { Cinema de Arquivo }\end{array}$ & $\begin{array}{l}\text { Arquivo } \\
\text { Nacional }\end{array}$ & Anual & 2014 & $\mathrm{C}$ \\
\hline 47 & $\begin{array}{l}\text { Revista ACB: } \\
\text { Biblioteconomia em } \\
\text { Santa Catarina }\end{array}$ & ACB & Quadrimestral & 2017 & B2 \\
\hline
\end{tabular}




\begin{tabular}{|c|c|c|c|c|c|}
\hline 48 & $\begin{array}{l}\text { Revista brasileira de } \\
\text { Biblioteconomia e } \\
\text { Documentação }\end{array}$ & FEBAB & Semestral & 2017 & B1 \\
\hline 49 & $\begin{array}{l}\text { Revista brasileira de } \\
\text { educação em Ciência } \\
\text { da Informação - } \\
\text { REBECIN }\end{array}$ & ABECIN & Semestral & 2017 & B5 \\
\hline 50 & $\begin{array}{l}\text { Revista } \\
\text { conhecimento em } \\
\text { ação }\end{array}$ & UFRJ & Semestral & 2017 & B5 \\
\hline 51 & $\begin{array}{l}\text { Revista da Escola de } \\
\text { Biblioteconomia da } \\
\text { UFMG }\end{array}$ & UFMG & Semestral & 1995 & - \\
\hline 52 & $\begin{array}{l}\text { Revista de } \\
\text { Biblioteconomia e } \\
\text { Documentação }\end{array}$ & UFRGS & Anual & 2000 & - \\
\hline 53 & $\begin{array}{l}\text { Revista de } \\
\text { Biblioteconomia de } \\
\text { Brasília }\end{array}$ & UNB & Semestral & 2011 & - \\
\hline 54 & $\begin{array}{l}\text { Revista do Arquivo } \\
\text { Geral da Cidade do } \\
\text { Rio de Janeiro }\end{array}$ & AGCRJ & Semestral & 2017 & $\mathrm{~B} 2$ \\
\hline 55 & $\begin{array}{l}\text { Revista do Arquivo } \\
\text { Público Mineiro }\end{array}$ & APM & Semestral & 2015 & $\mathrm{C}$ \\
\hline 56 & $\begin{array}{l}\text { Revista digital de } \\
\text { Biblioteconomia } \\
\text { e Ciência da } \\
\text { Informação }\end{array}$ & UNICAMP & Quadrimestral & 2017 & B1 \\
\hline 57 & $\begin{array}{l}\text { Revista do } \\
\text { Departamento de } \\
\text { Biblioteconomia e } \\
\text { História }\end{array}$ & FURG & Semestral & 1983 & - \\
\hline 58 & $\begin{array}{l}\text { Revista eletrônica } \\
\text { informação \& } \\
\text { cognição }\end{array}$ & UNESP & Semestral & 1997 & - \\
\hline 59 & $\begin{array}{l}\text { Revista ibero- } \\
\text { americana de } \\
\text { Ciência da } \\
\text { Informação }\end{array}$ & UNB & Semestral & 2016 & B1 \\
\hline 60 & $\begin{array}{l}\text { Revista informação } \\
\text { na sociedade } \\
\text { contemporânea }\end{array}$ & UFRN & Semestral & 2017 & - \\
\hline 61 & $\begin{array}{l}\text { Revista } \\
\text { latinoamericana de } \\
\text { documentación }\end{array}$ & Particular & Semestral & 1983 & - \\
\hline
\end{tabular}




\begin{tabular}{|l|l|l|l|l|l|}
\hline 62 & $\begin{array}{l}\text { Revista online da } \\
\text { Biblioteca Professor } \\
\text { Joel Martins }\end{array}$ & UNICAMP & Quadrimestral & 2001 & - \\
\hline 63 & $\begin{array}{l}\text { Revista P2P \& } \\
\text { inovação }\end{array}$ & IBICT & Semestral & 2017 & C \\
\hline 64 & $\begin{array}{l}\text { Tendências da } \\
\text { pesquisa brasileira } \\
\text { em Ciência da } \\
\text { Informação }\end{array}$ & ANCIB & Semestral & 2017 & B1 \\
\hline 65 & Transinformação & $\begin{array}{l}\text { PUC } \\
\text {-Campinas }\end{array}$ & Quadrimestral & 2017 & A1 \\
\hline
\end{tabular}

Fonte: Tabela de elaboração própria

Tabela 9 - Edições do Encontro Nacional de

Pesquisa em Ciência da Informação

\begin{tabular}{|l|l|l|l|l|}
\hline Edição & Ano & Local & Cidade & Tema \\
\hline 1 & 1994 & UFMG & $\begin{array}{l}\text { Belo Horizonte } \\
\text { (MG) }\end{array}$ & Sem tema central \\
\hline 2 & 1995 & Não identificado & Valinhos (SP) & Sem tema central \\
\hline 3 & 1997 & Não identificado & $\begin{array}{l}\text { Rio de Janeiro } \\
\text { (RJ) }\end{array}$ & Sem tema central \\
\hline 4 & 2000 & UnB & Brasília (DF) & $\begin{array}{l}\text { "Conhecimento } \\
\text { para o século XXI: a } \\
\text { pesquisa na construção } \\
\text { da Sociedade da } \\
\text { Informação" }\end{array}$ \\
\hline 5 & 2003 & Não identificado & $\begin{array}{l}\text { Belo Horizonte } \\
\text { (MG) }\end{array}$ & \begin{tabular}{l} 
Não identificado \\
\hline 6
\end{tabular} \\
\hline 2005 & Não identificado & Florianópolis (SC) & $\begin{array}{l}\text { "A política científica } \\
\text { e os desafios da } \\
\text { Sociedade da } \\
\text { Informação" }\end{array}$ \\
\hline 7 & 2006 & Não identificado & Marília (SP) & $\begin{array}{l}\text { "A dimensão } \\
\text { espistemológica da } \\
\text { Ciência da Informação e } \\
\text { suas interfaces técnicas, } \\
\text { políticas e institucionais } \\
\text { nos processos de } \\
\text { produção, acesso } \\
\text { e disseminação da } \\
\text { informação" }\end{array}$ \\
\hline
\end{tabular}




\begin{tabular}{|c|c|c|c|c|}
\hline 8 & 2007 & UFBA & Salvador (BA) & $\begin{array}{l}\text { "Promovendo a inserção } \\
\text { internacional da } \\
\text { pesquisa brasileira em } \\
\text { Ciência da Informação" }\end{array}$ \\
\hline 9 & 2008 & SENAC & São Paulo (SP) & $\begin{array}{l}\text { "Diversidade cultural e } \\
\text { políticas de informação" }\end{array}$ \\
\hline 10 & 2009 & UFPB & João Pessoa (PB) & $\begin{array}{l}\text { "A responsabilidade } \\
\text { social da Ciência da } \\
\text { Informação" }\end{array}$ \\
\hline 11 & 2010 & UFRJ/IBCT & $\begin{array}{l}\text { Rio de Janeiro } \\
\text { (RJ) }\end{array}$ & $\begin{array}{l}\text { "Inovação e inclusão } \\
\text { social: questões } \\
\text { contemporâneas da } \\
\text { informação" }\end{array}$ \\
\hline 12 & 2011 & UnB & Brasília (DF) & $\begin{array}{l}\text { "Políticas de informação } \\
\text { para a sociedade" }\end{array}$ \\
\hline 13 & 2012 & Fiocruz & $\begin{array}{l}\text { Rio de Janeiro } \\
\text { (RJ) }\end{array}$ & $\begin{array}{l}\text { "A sociedade em rede } \\
\text { para a inovação e } \\
\text { o desenvolvimento } \\
\text { humano" }\end{array}$ \\
\hline 14 & 2013 & UFSC & Florianópolis (SC) & $\begin{array}{l}\text { "Informação e } \\
\text { interação: ampliando } \\
\text { perspectivas para } \\
\text { o desenvolvimento } \\
\text { humano" }\end{array}$ \\
\hline 15 & 2014 & UFMG & $\begin{array}{l}\text { Belo Horizonte } \\
\text { (MG) }\end{array}$ & $\begin{array}{l}\text { "Além das 'nuvens': } \\
\text { expandindo as } \\
\text { fronteiras da Ciência da } \\
\text { Informação" }\end{array}$ \\
\hline 16 & 2015 & UFPB & João Pessoa (PB) & $\begin{array}{l}\text { "Informação, memória } \\
\text { e patrimônio: do } \\
\text { documento às redes" }\end{array}$ \\
\hline 17 & 2016 & UFBA & Salvador (BA) & $\begin{array}{l}\text { "Descobrimentos da } \\
\text { Ciência da Informação: } \\
\text { desafios da Multi, Inter } \\
\text { e Transdisciplinaridade } \\
\text { (MIT)" }\end{array}$ \\
\hline 18 & 2017 & UNESP & Marília (SP) & $\begin{array}{l}\text { "Informação, sociedade, } \\
\text { complexidade" }\end{array}$ \\
\hline 19 & 2018 & UEL & Londrina (PR) & $\begin{array}{l}\text { "Sujeito informacional } \\
\text { e as perspectivas } \\
\text { atuais na Ciência da } \\
\text { Informação" }\end{array}$ \\
\hline
\end{tabular}

Fonte: <https://www.ancib.org.br/enancib> 


\section{Siglas}

AAB - Associação dos Arquivistas Brasileiros

AAERJ - Associação dos Arquivistas do Estado do Rio de Janeiro

ABECIN - Associação Brasileira de Educação em Ciência da Informação

ABDF - Associação dos Bibliotecários do Distrito Federal

ACB - Associação Catarinense de Bibliotecários

AGCRJ - Arquivo Geral da Cidade do Rio de Janeiro

AN - Arquivo Nacional

ANCIB - Associação Nacional de Pesquisa e Pós-Graduação em Ciência da Informação

APBAD - Associação Portuguesa de Bibliotecários, Arquivistas e Documentalistas

APM - Arquivo Público Mineiro

CRB - Conselho Regional de Biblioteconomia

CRB/SP - Conselho Regional de Biblioteconomia do Estado de São Paulo

FEBAB - Federação Brasileira de Associações de Bibliotecários

FIOCRUZ - Fundação Oswaldo Cruz

IBICT - Instituto Brasileiro de Informação em Ciência e Tecnologia

FURG - Universidade Federal do Rio Grande

PUC - Pontifícia Universidade Católica

UEL - Universidade Estadual de Londrina

UEPB - Univeridade Estadual da Paraíba

UEPB - Universidade Estadual da Paraíba

UFAL - Universidade Federal de Alagoas

UFAM - Universidade Federal do Amazonas

UFBA - Universidade Federal da Bahia

UFC - Universidade Federal do Ceará

UFCA - Universidade Federal do Cariri

UFES - Universidade Federal do Espírito Santo

UFG - Universidade Federal de Goiás

UFMG - Universidade Federal de Minas Gerais

UFPA - Universidade Federal do Pará

UFPB - Universidade Federal da Paraíba

UFPE - Universidade Federal de Pernambuco

UFPR - Universidade Federal do Paraná

UFRGS - Universidade Federal do Rio Grande do Sul

UFRJ - Universidade Federal do Rio de Janeiro 
UFRN - Universidade Federal do Rio Grande do Norte

UFSC - Universidade Federal de Santa Catarina

UFSM - Universidade Federal de Santa Maria

UNB - Universidade de Brasília

UNESP - Universidade Estadual Paulista

UNICAMP - Universidade Estadual de Campinas

UP - Universidade do Porto

USP - Universidade de São Paulo 


\title{
OS ARQUivos E A ARQUIVOLOGIA NOS PROGRAMAS DE PÓS-GRADUAÇÃO EM CIÊNCIA DA INFORMAÇÃo BRASILEIROS: VÍNCULOS INSTITUCIONAIS E POSSI- BILIDADES DE DIÁLOGOS EPISTEMOLÓGICOS
}

\author{
ARCHIVESAND ARCHIVAL SCIENCE IN BRAZILIAN
} INFORMATION SCIENCE GRADUATE PROGRAMS : INSTITUTIONAL LINKS AND EPISTEMOLOGICAL DIALOGUE POSSIBILITIES

\section{Angelica Alves da Cunha Marques \\ Universidade de Brasília \\ angelicacunha@unb.br}

ORCID: https://orcid.org/0000-0003-4642-5912

RESUMO - Este capítulo propõe reflexões sobre as relações entre a Arquivologia e a Ciência da Informação a partir dos seus vínculos institucionais e das possibilidades de diálogos epistemológicos entre as duas disciplinas. Apresenta resultados de uma pesquisa acerca da trajetória de formação e configuração da Arquivologia como disciplina no Brasil, da sua classificação no âmbito das áreas do conhecimento, dos seus vínculos institucionais, da formação e titulação dos docentes dos cursos. Mais especificamente, analisa 5.148 referências bibliográficas arquivísticas contidas em 125 pesquisas sobre arquivos e Arquivologia, produzidas nos programas de pós-graduação em Ciência da Informação brasileiros, entre 1972 e 2012. A metodologia consiste em uma pesquisa documental 
e bibliográfica, complementada com técnicas bibliométricas. Os referenciais teóricos contemplam conceitos de autores da Filosofia e da Sociologia da Ciência. Os resultados quantitativos remetem à referência de obras produzidas predominantemente na década de 1990 , por autores brasileiros, em português, sobre a organização de arquivos, os fundamentos e a terminologia da Arquivologia. Os resultados qualitativos indicam a qualidade da produção científica brasileira, o acesso a obras em português e preocupações com os arquivos contemporâneos. Reiteram as especificidades da Arquivologia em relação à Ciência da Informação, sem comprometer a identidade de cada disciplina e as suas relações, que são explicitamente institucionais e potencialmente epistemológicas. PALAVRAS-CHAVE - Arquivologia; Ciência da Informação; Epistemologia arquivística; Produção científica em arquivos e Arquivologia.

ABSTRACT - This chapter proposes reflections on relations between Archival Science and Information Science based on institutional links and the epistemological dialogue possibilities between them. It presents results from a research about the path of formation and configuration of Archival Science as a discipline in Brazil, its classification in the scope of knowledge areas, its institutional links, and the formation and title of faculty of the courses. More specifically, it analyzes 5,148 Archival Science bibliographic references in 125 pieces of research on archives and Archival Science, produced in Brazilian Information Science Graduate programs between 1972 and 2012. The methodology consists of a documental and bibliographic research, complemented with bibliometric techniques. The theoretical references contemplate concepts by authors of Philosophy and Sociology of Science. The quantitative results point to referencing works producted predominantly in the 1990s, by Brazilian authors, in 
Portuguese, on the organization of archives, and the fundamentals and terminology of Archival Science. The qualitative results indicate the quality of Brazilian scientific production, access to works in Portuguese, and concerns on contemporary archives. They reiterate specificities of Archival Science in relation to Information Science, without compromising the identity of each discipline and their relations, which are explicitly institutional and potentially epistemological.

KEYWORDS - Archival Science; Information Science; Archival Science epistemology; Scientific production in archives and Archival Science.

\section{Considerações iniciais}

Há dezoito anos nos dedicamos ao estudo histórico-epistemológico da Arquivologia a fim de compreendermos a formação e a configuração dessa disciplina e do arquivista nos contextos internacionais e, mais particularmente, no brasileiro (Cunha, 2003; Marques, 2007 e 2011).

Ao investigarmos a trajetória dos arquivos e da Arquivologia, observamos que aqueles, como objeto de estudo dessa disciplina, são tão antigos quanto o homem. A Arquivologia, por sua vez, começa a ser delineada como disciplina científica no século XVI (Fonseca, 2005), quando dos seus primeiros manuais, na tentativa de formalizar os conhecimentos práticos para garantir a sua transmissão e difusão em maior escala, ainda que vários autores da área concebam o Manual dos Arquivistas Holandeses, de 1898, o marco primeiro da sua cientificidade - a exemplo de Cook, (1997), Duchein (1992) e Silva et al (1999).

Já a Ciência da Informação é identificada como tal em meados do século XX e, como uma metaciência, é dedicada ao estudo da informação, sem a especificidade arquivística, que é o arquivo ou o documento de arquivo (Schmidt, 2015) ou, ainda, a informação orgânica registrada 
(Rousseau e Couture, 1998), conforme os diferentes posicionamentos dos estudiosos da Arquivologia. Assim, uma das definições mais (re) conhecidas de "Ciência da Informação" é a de Borko (1968):

É a disciplina que investiga as propriedades e o comportamento da informação, as forças que governam seu fluxo, e os meios de processá-la para otimizar sua acessibilidade e uso. A CI está ligada ao corpo de conhecimentos relativos à origem, coleta, organização, estocagem, recuperação, interpretação, transmissão, transformação e uso de informação. (Borko, 1968, tradução nossa).

Diante da precedência histórica e das especificidades epistemológicas da Arquivologia em relação à Ciência da Informação, tomamos como pressuposto que as duas disciplinas não podem ser confundidas. Contudo, no cenário internacional, as concepções sobre as suas relações são diversas, mesmo na perspectiva político institucional.

Na França, por exemplo, a relação direta da Ciência da Informação se dá explicitamente com a Informática, no âmbito do Institut des sciences de l'information et de leurs interactions (INS2I) e, da Arquivologia, implicitamente, com a História, no Institut des sciences bumaines et sociales (INSHS) (Centre national de la recherche scientifique, 2018).

No Brasil, as relações entre a Ciência da Informação e a Arquivologia são classificadas pelo Conselho Nacional de Desenvolvimento Científico e Tecnológico (1984), em sua Tabela de Áreas do Conhecimento (TAC), que tem a Arquivologia como uma subárea da Ciência da Informação.

No âmbito teórico-epistemológico, a diversidade de concepções acerca dessas relações entre as duas disciplinas é ainda maior, variando entre autores que têm a Arquivologia como uma parte da Ciência da Informação (Gagnon-Arguin, 1992; Silva et al.,1999; Pinheiro, 1999; Mariz, 2004) e aqueles que reconhecem a sua autonomia ou, pelo menos, as suas singularidades (Jardim e Fonseca, 
1995; Silva, 1996; Fonseca, 2005; Marques, 2007; 2011), somente para citar alguns autores das duas áreas.

Considerando os dissensos sobre as relações entre a Arquivologia e a Ciência da Informação, uma questão perpassa insistente e perenemente o nosso projeto de pesquisa: a aproximação da Arquivologia com a Ciência da Informação, no Brasil, é de cunho teórico-epistemológico ou um expediente meramente político-institucional?

A partir dessa questão (mas sem a pretensão de respondê-la), propomos, neste capítulo, reflexões sobre as relações entre a Arquivologia e a Ciência da Informação. Nesse sentido, apresentamos os resultados da nossa pesquisa acerca da trajetória de formação e configuração da Arquivologia como disciplina no Brasil, sua classificação no âmbito das áreas do conhecimento, seus vínculos institucionais, a formação e titulação dos docentes dos cursos e, especialmente, a sua produção científica nos programas de pós-graduação em Ciência da Informação.

Para tanto, realizamos uma extensa pesquisa documental e bibliográfica e, para o mapeamento da referida produção científica, uma pesquisa bibliométrica, analisada com base nos nossos referenciais teóricos. Os procedimentos metodológicos consistiram: a) consulta ao banco de teses da Coordenação de Aperfeiçoamento de Pessoal de Nível Superior (CAPES), em 2016, utilizando como filtros temáticos "arquivos", "Arquivologia" e "arquivística”, conforme proposto por Fonseca (2004); b) análise das teses, dissertações e Trabalhos de Conclusão de Curso (TCCs) levantados, com a identificação daqueles arquivísticos, não arquivísticos e afins; c) mapeamento de todas as referências bibliográficas arquivísticas das pesquisas identificadas como arquivísticas na fase anterior, produzidas entre 1972 e 2012; d) análise dessas referências para identificar os períodos, os autores, os títulos e os idiomas de publicação, considerando aquelas que agruparam pelo menos um por cento do total de ocorrências. 


\section{Revisitando os referenciais teóricos}

O primeiro autor a ser revisitado é Michel Foucault (2005; 2008), que, em uma abordagem histórico-filosófica, tece suas reflexões acerca da constituição e circulação do discurso na correlação entre saber e poder. Sua abordagem comporta duas dimensões metodológicas complementares, das quais gostaríamos de destacar a primeira: 1) a arqueologia dos saberes, a qual delineia a forma das problematizações por meio da investigação do surgimento e da transformação dos saberes, explicitando o nível do discurso; e 2) a genealogia, voltada para as práticas que perpassam as relações de poder, isto é, o caráter estratégico dos discursos.

Assim, este autor nos é muito caro, ao apresentar o "campo dos acontecimentos discursivos", a partir do qual podemos compreender a formação, sistematização e circulação das tendências históricas do pensamento arquivístico internacional como discursos (acontecimentos regulares e em série, decorrentes e propiciadores de condições de possibilidades) e suas marcas na trajetória da Arquivologia no Brasil.

A arqueologia do saber nos remete a outro autor cujas reflexões também são muito relevantes para a compreensão do nosso objeto de pesquisa. Bourdieu (1983; 2001) conjuga a formação histórica (habitus) com a formação do espaço conquistado pelas disciplinas (campo científico), regulado pelos movimentos do capital científico. Desse autor, gostaríamos de realçar os dois primeiros conceitos.

O babitus articula o passado e o futuro ao contemplar reprodução de estruturas objetivas e objetivos de um projeto: como "transcendental histórico", funciona como estrutura estruturada e produzida por toda uma série de aprendizagens comuns ou individuais (Bourdieu, 2001). Assim, dinamicamente, o habitus, funciona como elemento de coesão do grupo, alinhavando e alinhando os 
avanços e os recuos teóricos das disciplinas ao longo do tempo, na constituição do campo científico.

O campo científico, por sua vez, é perpassado por uma lógica interna de funcionamento, na qual se "produz e supõe uma forma específica de interesse", que diz respeito às práticas orientadas para a aquisição de autoridade científica (prestígio, reconhecimento, celebridade, etc). Dessa maneira, Bourdieu o concebe como um "espaço objetivo de um jogo onde compromissos científicos estão engajados" (Bourdieu, 1983, p. 123-124). Para o autor, o que está em jogo é o "poder de impor uma definição de ciência": a delimitação do campo dos problemas, dos métodos e das teorias científicas.

Existe assim, a cada momento, uma hierarquia social dos campos científicos - as disciplinas - que orienta fortemente as práticas e, particularmente, as "escolhas" de "vocação". No interior de cada um deles há uma hierarquia social dos objetos e dos métodos de tratamento. (Bourdieu, 1983, p. 128).

Desse modo, ele afirma que o campo científico retoma, simultaneamente, a unidade existente na ciência e as diversas posições que as diferentes disciplinas ocupam no espaço, isto é, sua hierarquização. O que acontece no campo depende dessas posições e este pode ser descrito como um conjunto de campos locais (disciplinas), que têm interesses e princípios mínimos em comum.

Para Bourdieu, "Cada disciplina (como campo) é definida por um nomos [lógica] particular de visão e de divisão, um princípio de construção da realidade objetiva irredutível àquele de outra disciplina” (Bourdieu, 2001, p. 103, tradução nossa). A disciplina é, assim, um campo relativamente estável e delimitado.

E é nesse sentido que compreendemos a Arquivologia como uma disciplina científica singular, diferente da Ciência da Informação e ambas compartilhando espaços no "campo da informação": 
[...] entendido como o campo científico e profissional que abriga disciplinas que têm por objeto a gênese, organização, comunicação e disponibilização da informação. Desse modo, defendemos que nesse campo estão entrecruzadas as trajetórias da Arquivologia, Biblioteconomia, Museologia, Documentação e, mais recentemente, da CI, como (sub/inter)campos simultaneamente parceiros, cooperativos, conflitantes, relativamente comuns e singulares (Marques, 2011, p. 76).

\section{Os arquivos e a Arquivologia no Brasil}

A Arquivologia no Brasil é gestada, como no contexto internacional, a partir de demandas práticas voltadas para a organização de documentos produzidos e acumulados, majoritariamente, pelo Estado. O Arquivo Nacional do Brasil foi criado em 1838, como “Arquivo Público do Império" e, já nos seus relatórios e regulamentos do século XIX, apresenta informações acerca da necessidade de formação do pessoal de arquivo e de criação de cursos que propiciassem essa formação.

Mesmo com várias iniciativas da instituição para a criação de cursos com este objetivo, nenhuma delas se concretiza até o final dos anos 1950 (Marques, 2007). Em 1959, Henri Boullier de Branche, arquivista francês, vem ao Brasil para ministrar alguns cursos e colaborar na organização de documentos custodiados pelo Arquivo Nacional. Ao final da sua estadia, ele apresenta um relatório técnico, no qual destaca diversas fragilidades dos arquivos brasileiros, dentre elas, a de formação profissional. Segundo esse arquivista, essa fragilidade seria contornada com a oferta de cursos regulares para a formação de arquivistas (Boullier de Branche, 1975) ${ }^{1}$. Logo em seguida, é criado o Curso Permanente de Arquivos (CPA) pelo Arquivo Nacional, que funciona nessa instituição de 1960 a 1977, formando especialistas e

\footnotetext{
1 A primeira edição desse relatório é de 1960.
} 
capacitando pessoal para o trabalho nos arquivos. Esse é, portanto, o primeiro curso regular para a formação de arquivistas no Brasil.

A Arquivologia no Brasil, concebida nos anos 1960 a partir do CPA, dá grandes passos no cenário brasileiro na década seguinte: em 1970, é publicado o Mensário do Arquivo Nacional (MAN), uma espécie de correio de notícias arquivísticas internacionais e nacionais; em 1971, é criada a Associação dos Arquivistas Brasileiros $(\mathrm{AAB})^{2}$, que realiza o I Congresso Brasileiro de Arquivologia (CBA), quando é recomendada a definição de um currículo mínimo para os cursos de Arquivologia, que têm a sua criação em nível superior aprovada, no mesmo ano, pelo Conselho Federal de Educação (CFE); em 1974, é fixado o currículo mínimo e a duração para os cursos de Arquivologia em nível superior, pelo CFE; em 1976, é aprovado o quadro de professores do CPA e dos cursos avulsos do Arquivo Nacional; e, em 1977, o CPA é transferido para a Federação das Escolas Federais Isoladas do Estado do Rio de Janeiro (FEFIERJ), atual Universidade Federal do Estado do Rio de Janeiro (UNIRIO), com a denominação de "Curso de Arquivologia", inaugurando a conquista de espaços universitários para os outros quinze cursos que a partir daí seriam criados em várias universidades brasileiras, conforme quadro 1 .

Quadro 1: Cursos de graduação em Arquivologia no Brasil (1960-2015)

\begin{tabular}{|l|l|l|l|}
\hline UNIVERSIDADE & $\begin{array}{l}\text { ANO DE } \\
\text { CRIAÇÃo }\end{array}$ & DEPARTAMENTO & FACULDADE/INSTITUTO/CENTRO \\
\hline UNIRIO & 1960 & Arquivologia & $\begin{array}{l}\text { Centro de Ciências Humanas e } \\
\text { Sociais }\end{array}$ \\
\hline UFSM & 1976 & Documentação & $\begin{array}{l}\text { Centro de Ciências Sociais e } \\
\text { Humanas }\end{array}$ \\
\hline
\end{tabular}

2 A AAB funcionou por 44 anos, até a sua extinção em 2015. 


\begin{tabular}{|c|c|c|c|}
\hline UFF & 1978 & $*$ & $\begin{array}{l}\text { Instituto de Arte e Comunicação } \\
\text { Social }\end{array}$ \\
\hline UnB & 1990 & $*$ & $\begin{array}{l}\text { Faculdade de Ciência da } \\
\text { Informação }\end{array}$ \\
\hline UEL & 1997 & $\begin{array}{l}\text { Ciência da } \\
\text { Informação }\end{array}$ & $\begin{array}{l}\text { Centro de Educação, } \\
\text { Comunicação e Artes e Centro } \\
\text { de Ciências } \\
\text { Humanas }\end{array}$ \\
\hline UFBA & 1997 & $*$ & $\begin{array}{l}\text { Instituto de Ciência da } \\
\text { Informação }\end{array}$ \\
\hline UFRGS & 1999 & $\begin{array}{l}\text { Ciências da } \\
\text { Informaçã̃o }\end{array}$ & $\begin{array}{l}\text { Faculdade de Biblioteconomia } \\
\text { e Comunicação }\end{array}$ \\
\hline UFES & 1999 & Arquivologia & $\begin{array}{l}\text { Centro de Ciências Jurídicas } \\
\text { e Econômicas }\end{array}$ \\
\hline UNESP/Marília & 2002 & $\begin{array}{l}\text { Ciência da } \\
\text { Informação }\end{array}$ & Faculdade de Filosofia e Ciências \\
\hline UEPB & 2006 & $*$ & $\begin{array}{l}\text { Centro de Ciências Biológicas } \\
\text { e Sociais e Aplicadas }\end{array}$ \\
\hline UFPB & 2007 & $\begin{array}{l}\text { Ciência da } \\
\text { Informaçãoo }\end{array}$ & $\begin{array}{l}\text { Centro de Ciências Sociais } \\
\text { Aplicadas }\end{array}$ \\
\hline FURG & 2008 & $*$ & $\begin{array}{l}\text { Instituto de Ciências Humanas } \\
\text { e da Informação }\end{array}$ \\
\hline UFMG & 2008 & $*$ & Escola de Ciência da Informação \\
\hline UFAM & 2008 & Biblioteconomia & $\begin{array}{l}\text { Instituto de Ciências Humanas } \\
\text { e Letras }\end{array}$ \\
\hline UFSC & 2009 & $\begin{array}{l}\text { Ciência da } \\
\text { Informação }\end{array}$ & Centro de Ciências da Educação \\
\hline UFPA & 2011 & Biblioteconomia & $\begin{array}{l}\text { Instituto de Ciências Sociais } \\
\text { Aplicadas }\end{array}$ \\
\hline
\end{tabular}

Fonte: elaboração própria.

* Cursos que não estão vinculados a departamentos, conforme nossa consulta aos seus sítios eletrônicos.

Podemos observar que oito dos dezesseis cursos de graduação em Arquivologia estão vinculados administrativamente a um departamento, faculdade ou instituto de Ciência da Informação. Também é na Ciência da Informação que grande parte dos docentes desses cursos se titulou como mestres e doutores (Marques, 2007; Oliveira, 2014). 
Essa vinculação da Arquivologia à Ciência da Informação é feita semelhantemente pelo $\mathrm{CNPq}$, em sua TAC, conforme mencionamos. A versão em vigor do documento enuncia o objetivo prático dessa classificação, conforme seu texto introdutório: "A Classificação das Áreas do Conhecimento tem finalidade eminentemente prática, objetivando proporcionar aos órgãos que atuam em ciência e tecnologia uma maneira ágil e funcional de agregar suas informações" (Conselho Nacional de Desenvolvimento Científico e Tecnológico, 1984). Na grande área "Ciências Sociais Aplicadas", a Ciência da Informação (no singular) é apresentada como uma área, subdividida em três subáreas: 1) Teoria da Informação (com as especialidades Teoria Geral da Informação; Processos da Comunicação; e Representação da Informação); 2) Biblioteconomia (com as especialidades Teoria da Classificação; Métodos Quantitativos, Bibliometria; Técnicas de Recuperação da Informação; e Processos de Disseminação da Informação); e 3) Arquivologia (com a especialidade Organização de Arquivos). A Arquivologia é, então, contemplada como subárea da área Ciência da Informação, ainda que posteriormente já tenha sido sugerida a sua autonomia em relação a esta disciplina, em uma nova proposta de TAC, em 2005, que não foi aprovada e, consequentemente, não se concretizou (Marques, 2016).

Contudo, essas relações institucionais e institucionalizadas entre as duas disciplinas (nos vínculos acadêmico-institucionais dos cursos e na classificação do CNPq) além da titulação dos docentes dos cursos em mestrados e doutorados de Ciência da Informação, não nos parecem aspectos suficientes - histórica e epistemologicamente - para considerar a Arquivologia como uma parte da Ciência da Informação, desconsiderando a sua trajetória e a sua identidade. Assim, julgamos pertinente iniciar um estudo epistemológico, começando pela análise das obras referenciadas na produção científica sobre arquivos e Arquivologia nos programas de pós-graduação stricto sensu brasileiros. 
A produção científica sobre arquivos e Arquivologia na Ciência da Informação

Ao longo da nossa pesquisa, realizamos vários levantamentos sobre a produção científica arquivística e as suas referências bibliográficas, também arquivísticas (Marques, 2011; Marques e Marques, 2014; Donato, 2017; Moreira, 2017; Marques, 2017). No mapeamento mais atual, identificamos 470 teses, dissertações e TCCs com esses temas, produzidas em diversos programas de pós-graduação stricto sensu brasileiros, entre 1972 e 2016, predominantemente naqueles de Ciência da Informação, que abrigam 45\% dessa produção (Marques, 2017).

Gráfico 1: Programas de pós-graduação stricto sensu brasileiros onde foram produzidas teses, dissertações e TCCs sobre arquivos e Arquivologia (1972-2016)

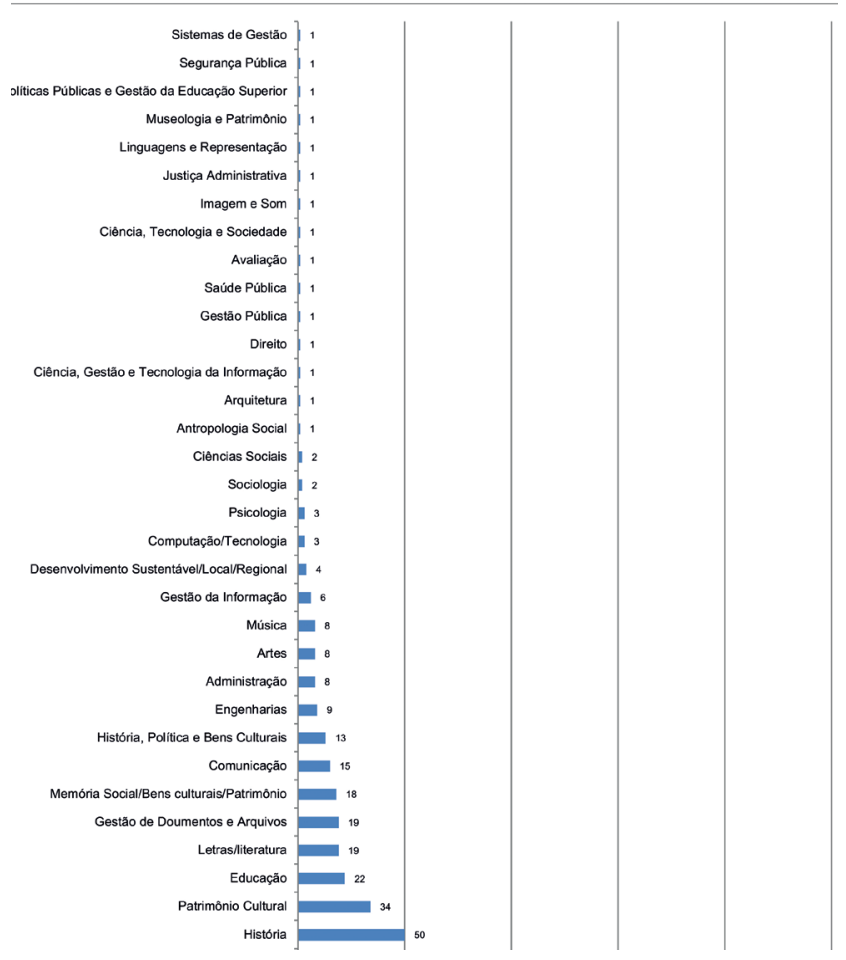

Fonte: Marques (2017, p. 86). 
Tendo em vista o estudo das teses, das dissertações e dos TCCs sobre arquivos e Arquivologia produzidos nos diversos programas de pós-graduação stricto sensu brasileiros, verticalizamos a nossa análise, ao buscar identificar as suas referências bibliográficas. Até o momento, o fizemos das pesquisas produzidas entre 1972 e 2012, o que contempla 253 (53\%) pesquisas do nosso universo. Dessas 253 teses, dissertações e TCCs, 125 foram defendidos em programas de pós-graduação em Ciência da Informação, ou seja, quase $50 \%$.

Nas 253 pesquisas, identificamos 22.924 referências bibliográficas (arquivísticas, não arquivísticas e afins). ${ }^{3}$ Desse total, 8.963 referências eram arquivísticas (39,09\%). Considerando somente as referências bibliográficas das teses, dissertações e TCCs sobre arquivos e Arquivologia produzidos nos programas de pós-graduação em Ciência da Informação, chegamos a 5.148 referências arquivísticas $(57 \%$ do total de referências bibliográficas identificadas como arquivísticas). Doravante, apresentaremos os resultados parciais da análise dessas 5.148 referências quanto aos anos de sua publicação, à sua autoria, aos seus títulos e aos seus idiomas.

As 5.148 referências bibliográficas arquivísticas das pesquisas sobre arquivos e Arquivologia dizem respeito a obras publicadas predominantemente nas décadas de 1990 e de 2000, com $37,33 \%$ e $35,65 \%$ do total, respectivamente, conforme ilustrado no gráfico 2 .

3 Consideramos "referências bibliográficas arquivísticas" aquelas que explicitamente contemplavam os arquivos e a Arquivologia; "referências bibliográficas não arquivísticas", aquelas que diziam respeito a outros assuntos alheios aos arquivos e à Arquivologia, inclusive aquelas que se dedicavam à Ciência da Informação; e "referências bibliográficas afins", aquelas que não eram de interesse exclusivo da Arquivologia, mas também lhe interessavam, como referências sobre conservação e preservação de documentos, gestão da informação etc. 
Gráfico 2: Períodos de publicação das referências bibliográficas arquivísticas das pesquisas sobre arquivos e Arquivologia (1972-2012)

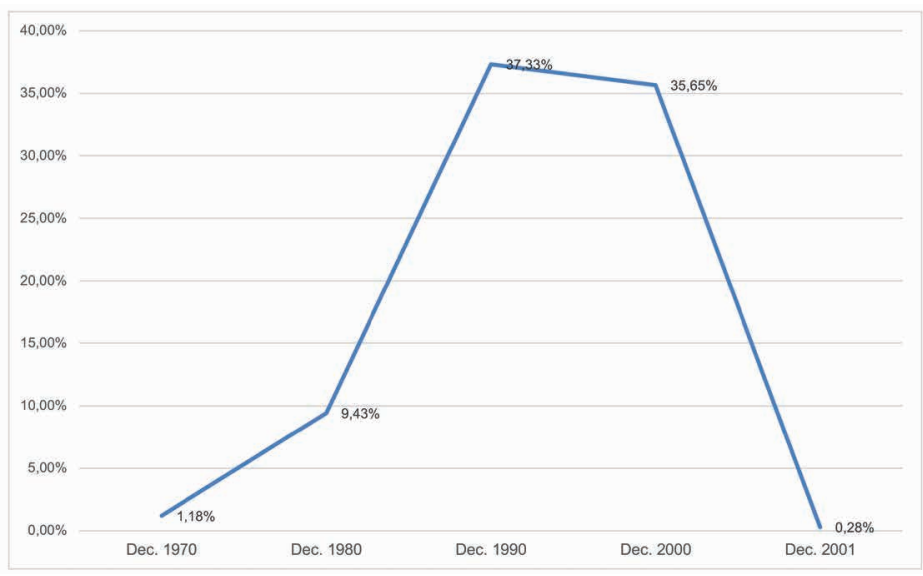

Fonte: elaboração própria.

Esses resultados nos remetem a obras recentes que agregam, à teoria arquivística tradicional, desafios relacionados às tecnologias, aos suportes e aos formatos dos documentos contemporâneos. No caso brasileiro, é interessante lembrar que, no início da década de 1990, a Lei 8.159 de 08 de janeiro de 1991, conhecida como "Lei de Arquivos", é promulgada, reconhecendo o dever do Estado quanto à gestão e preservação dos documentos públicos e o direito de acesso a esses documentos pelo cidadão. Desse modo, essa lei demanda o trabalho especializado do arquivista, bem como a expansão dos cursos de formação desse profissional, além de estudos que culminam em avanços para a teoria e as práticas arquivísticas (Brasil, 1991).

Identificamos 1.392 autores nas referências bibliográficas arquivísticas das pesquisas sobre arquivos e Arquivologia produzidas nos Programas de pós-graduação em Ciência da Informação, dentre os quais se destacaram brasileiros $(20,01 \%)$, canadenses $(7,55 \%)$, norte-americanos (1,99\%), portugueses $(1,52 \%)$, espanhóis $(1,45 \%)$ e franceses $(1,37 \%)$. 
Dos autores brasileiros, observamos que professores/pesquisadores de cursos de Arquivologia (de graduação e de especialização) são os mais referenciados; dos canadenses, pesquisadores de Arquivologia também se destacam; dos portugueses, professores de cursos de Ciência da Informação; e dos norte-americanos e franceses, arquivistas. Temos quatro autorias institucionais em destaque: três brasileiras e uma internacional, conforme gráfico 3 .

Gráfico 3: Autores das referências bibliográficas arquivísticas das pesquisas sobre arquivos e Arquivologia (1972-2012)

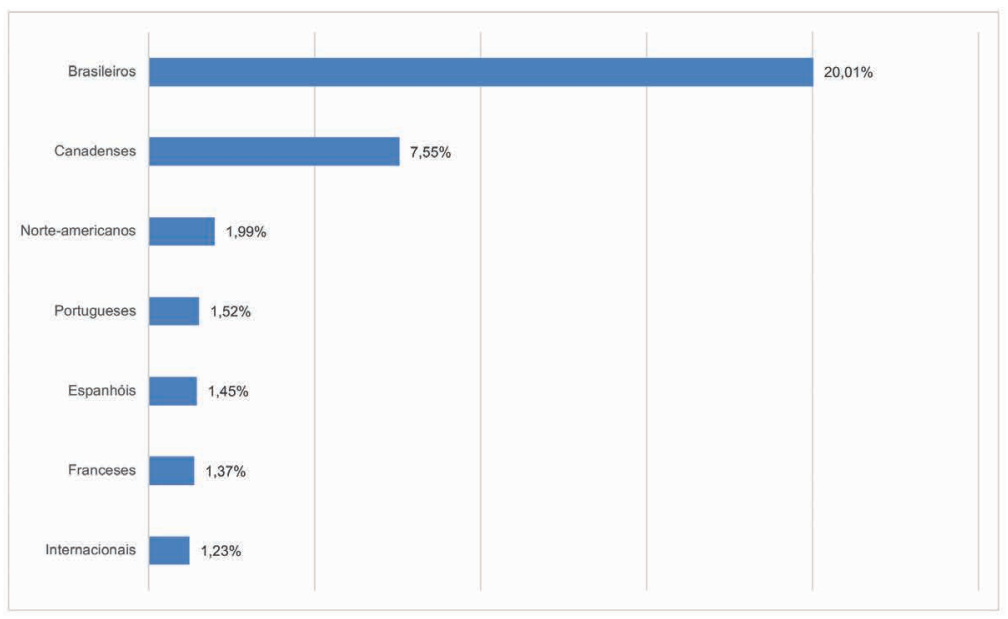

Fonte: elaboração própria.

A predominância de autores brasileiros sinaliza a produção de obras de boa qualidade teórica no Brasil, sintonizadas aos principais avanços do pensamento arquivístico internacional, conforme já havíamos constatado nas análises anteriores (Marques e Rodrigues, 2009; Marques, 2011; Marques e Marques, 2014).

A grande ocorrência de autores canadenses nos remete à relevância e à repercussão teórica da Arquivística Integrada no Brasil, proposta por esses autores, além das suas preocupações com a preservação dos documentos nos suportes contemporâneos. Desse modo, os pesquisado- 
res brasileiros parecem acompanhar, mesmo que um pouco atrasados, a evolução das tendências históricas internacionais. Observamos, ao longo do tempo, a corrente arquivística europeia (marcada pelo historicismo) compartilhar reflexões com a corrente norte-americana (mais próxima da gestão da informação) e, mais recentemente, essas duas correntes compartilharem suas preocupações com parte do pensamento arquivístico canadense, não distinguindo as vertentes administrativas e históricas dos arquivos. A proposta canadense parece, portanto, abrigar algumas das reflexões teóricas atuais da Arquivologia brasileira e que não são apenas administrativas ou históricas, mas integradas, preocupando-se com todo o ciclo documental, da produção à organização e ao acesso aos documentos de arquivo e às suas informações.

A pouca ocorrência de autores australianos no nosso mapeamento nos indica o acompanhamento tardio do pensamento arquivístico internacional pelos pesquisadores brasileiros ${ }^{4}$. Nos últimos anos, a Austrália tem avançado e contribuído para o desenvolvimento da teoria arquivística, sobretudo em relação aos desafios decorrentes da descontextualização da informação trazida pelos registros eletrônicos. Assim, a baixa frequência desses autores no universo pesquisado pode sinalizar algumas lacunas teóricas na Arquivologia brasileira.

Dos títulos, verificamos que cinco se destacam com mais de um por cento de ocorrências: dois de obras brasileiras; um de obra norte-americana, traduzida para o português (do Brasil); um de obra canadense, traduzida para o português (de Portugal); e um de obra portuguesa, conforme gráfico 4 .

4 Embora alguns estudiosos no Brasil já trabalhem com questões aprofundadas pelos australianos, como é o caso de Rondinelli (2004), que desenvolveu uma dissertação sobre o Gerenciamento Arquivístico de Documentos Eletrônicos, título do seu livro e o CONARQ tenha se apoiado numa norma australiana para apresentar o seu Modelo de Requisitos para Sistemas Informatizados de Gestão Arquivística de Documentos (Conselho Nacional de Arquivos, 2018). Informações disponíveis em: <http://www. arquivonacional.gov.br/br/publicacoes/publica\%C3\%A7\%C3\%B5es-t\%C3\%A9cnicas/e-arq-brasil-detail. html>. Acesso em 19 jul. 2018. Recentemente, uma dissertação produzida no Programa de Pós-graduação em Ciência da Informação da UnB se dedicou ao estudo do modelo australiano records continuum para a compreensão das limitações do ciclo vital dos documentos (Costa Filho, 2016). 
Gráfico 4: Títulos das referências bibliográficas arquivísticas das pesquisas sobre arquivos e Arquivologia (1972-2012)

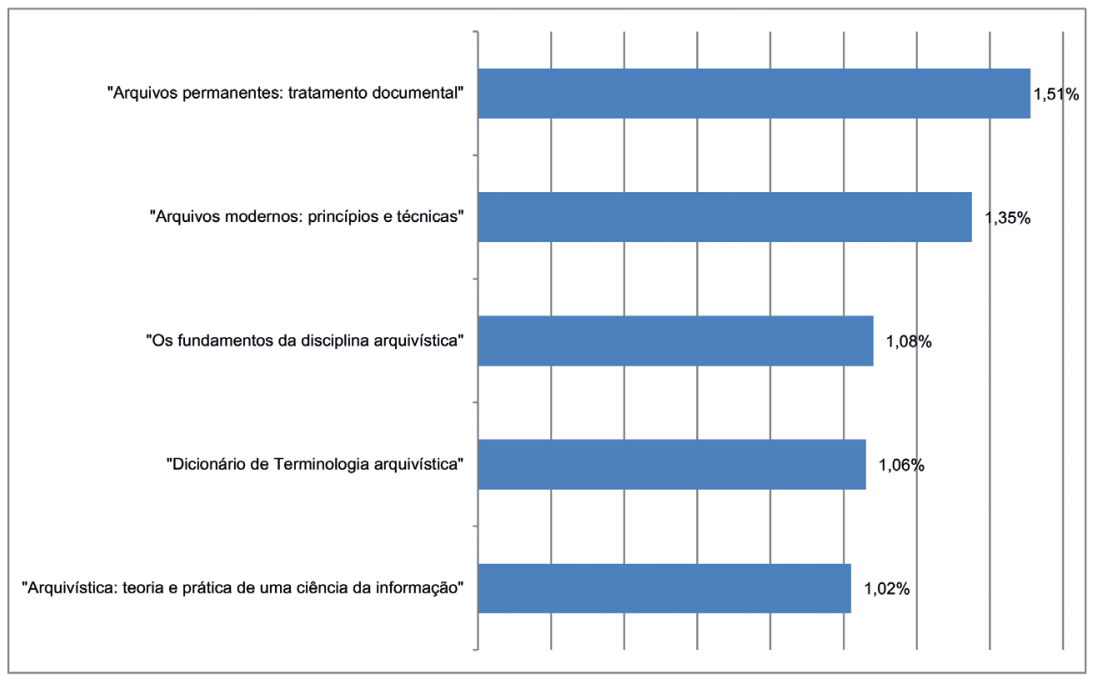

Fonte: elaboração própria.

"Arquivos permanentes: tratamento documental", de autoria de Heló́sa Liberalli Belloto (que apareceu como a segunda autora mais referenciada), foi a obra mais referenciada (1,51\%). Publicada em 1991, até o momento o livro teve quatro edições (1991; 2004; 2005; 2006), cujos temas centrais relacionam-se à identificação de fundos, à sistemática de arranjo, à ordenação interna dos fundos, bem como à sua dispersão e reintegração, à descrição de documentos, à difusão em arquivos e aos arquivos privados (Bellotto, 2004).

"Arquivos modernos: princípios e técnicas" (Modern archives: principles and techniques), de Theodore Roosevelt Schelenberg (que aparece na sexta posição no ranking dos autores), foi a segunda obra mais referenciada (1,35\%). Publicada em 1956, na Inglaterra, a obra tem a sua segunda edição no país de seu autor, Estados Unidos, em 1957. Traduções são feitas para o espanhol (1958 e 1987) e português do Brasil (1974), com reimpressão em 1975. Nela, Schellenberg sistematiza a teoria da arquivística americana, concentrando-se nos 
problemas referentes aos documentos modernos, inclusive na sua gestão. Distingue documentos administrativos e documentos de arquivo; valor primário e valor secundário; valor histórico e valor informativo. Preocupa-se com a conservação do máximo de informação, preservando o mínimo de documentos (Schellenberg, 1974).

"Os fundamentos da disciplina arquivística" (Les fondements de la discipline archivistique), escrita pelos canadenses Jean-Yves Rousseau e Carol Couture, que aparecem no nono e quinto lugares, respectivamente, dentre os autores mais referenciados, foi a terceira obra em destaque (1,08\%). Publicada em 1994, tem a sua tradução para o português de Portugal em 1998. Ao retomar estudos anteriores dos autores, considera a Arquivologia como uma disciplina integrada, na qual o arquivo é entendido globalmente, contemplando os princípios arquivísticos, o ciclo de vida dos documentos de arquivo, as três idades dos documentos e as intervenções do arquivista (denominadas de "funções arquivísticas") (Rousseau e Couture, 1998).

O "Dicionário de Terminologia Arquivística", coordenado por Ana Maria de Almeida Camargo e Heloísa Liberalli Belloto (autoras que se destacam em décimo e em segundo lugar, respectivamente) e editado pela Associação dos Arquivistas Brasileiros, Núcleo Regional São Paulo, foi a quarta obra em destaque (1,06\%). Publicado em 1996, o dicionário contempla 640 verbetes relacionados à teoria arquivística (princípios e funções); metodologia e tratamento documental; documento e análise documental; acesso, utilização e difusão; preservação (acondicionamento, armazenamento, conservação e restauração); reprografia; e informática (Camargo e Bellotto, 1996).

"Arquivística: teoria e prática de uma Ciência da Informação" foi a quinta obra mais referenciada pelos autores das pesquisas sobre arquivos e Arquivologia produzidas nos Programas de pós-graduação em Ciência da Informação (1,02\%). Escrita por Armando Malheiro da Silva (12 $2^{a}$ posição no ranking dos autores), Fernanda Ribeiro, 
(19 ${ }^{\mathrm{a}}$ posição) Júlio Ramos ( $822^{\mathrm{a}}$ posição) e Manuel Luís Real ${ }^{5}$, a obra foi publicada em 1999, em português de Portugal. Como o próprio título indica, o livro contempla a Arquivologia no âmbito da Ciência da Informação e tem um capítulo dedicado à epistemologia arquivística (Silva et al, 1999).

O destaque para obras em português também se reflete no idioma predominante de todas as referências: mais de 66\% das referências bibliográficas arquivísticas analisadas estavam em português $(66,21 \%)$, seguidas daquelas em inglês (16,09\%), em espanhol (10,84\%) e em francês $(5,94 \%)$, como pode ser observado no gráfico 5 .

Gráfico 5: Idiomas das referências bibliográficas arquivísticas das pesquisas sobre arquivos e Arquivologia (1972-2012)

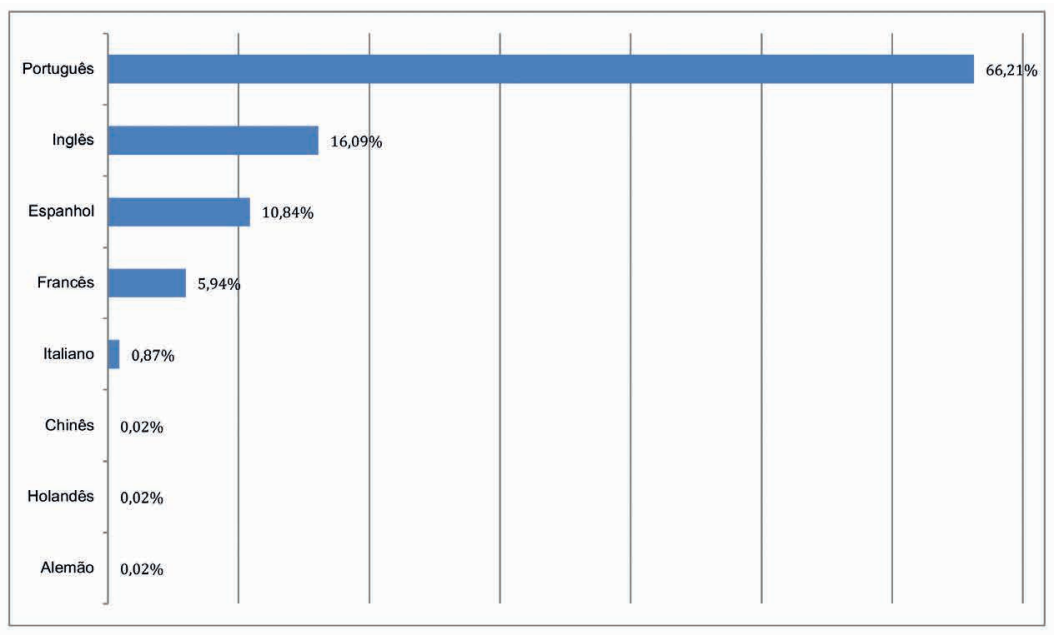

Fonte: elaboração própria.

Em outras etapas da pesquisa chegamos ao mesmo resultado quanto ao idioma predominante nas referências bibliográficas arquivísticas e esboçamos algumas conclusões: a predominância de

5 Este autor não aparece no ranking dos autores, provavelmente por ser o quarto autor da obra. Segundo a Associação Brasileira de Normas Técnicas (ABNT), NBR 6023 de 2002, quando a obra tiver mais de três autores, somente o primeiro deve ser indicado, seguido da expressão et al (Associação Brasileira de Normas Técnicas, 2002). 
autores brasileiros parece conjugar o reconhecimento da relevância das suas obras para a Arquivologia brasileira e a comodidade da leitura em português, considerando que nem todos os pesquisadores têm acesso a outros idiomas. Assim, temos obras de reconhecida qualidade e aprofundamento teórico e com autores atuantes na configuração científica da disciplina. A circulação dessas obras em programas de pós-graduação corrobora a sua relevância para a pesquisa, imprescindível para os avanços da área (Marques, 2011).

Essa predominância nos remete a uma produção científica sobre os arquivos e a Arquivologia diversa, mas ainda concentrada em poucos autores (Marques, 2009; 2011).

Sobre as traduções de obras estrangeiras para o português, embora quantitativamente pequeno $(2,43 \%$ das obras com mais de um por cento de ocorrências), o percentual de traduções aparece como um indicador qualitativamente considerável em relação à relevância das obras estrangeiros na formação da Arquivologia no País, mediante a permeabilidade dos discursos dos seus autores (Marques, 2011).

No quadro 2 , apresentamos os principais resultados do nosso levantamento das referências bibliográficas arquivísticas das teses, dissertações e TCCs produzidos nos Programas de pós-graduação stricto sensu em Ciência da Informação brasileiros, entre 1972 e 2012.

Quadro 2: Indicadores predominantes nas referências bibliográficas arquivísticas das pesquisas sobre arquivos e Arquivologia dos Programas de pós-graduação em Ciência da Informação (1972-2012)*

\begin{tabular}{|l|l|l|l|}
\hline $\begin{array}{l}\text { Períodos de } \\
\text { publicação }\end{array}$ & Autores & Títulos & Idiomas \\
\hline $\begin{array}{l}\text { Déc. } 1990 \\
(37,33 \%)\end{array}$ & $\begin{array}{l}\text { Brasileiros } \\
(20,01 \%)\end{array}$ & $\begin{array}{l}\text { "Arquivos permanentes: tratamento } \\
\text { documental" (1,51\%) }\end{array}$ & $\begin{array}{l}\text { Português } \\
(66,21 \%)\end{array}$ \\
\hline $\begin{array}{l}\text { Déc. } 2000 \\
(35,65 \%)\end{array}$ & $\begin{array}{l}\text { Canadenses } \\
(7,55 \%)\end{array}$ & $\begin{array}{l}\text { "Arquivos modernos: princípios e } \\
\text { técnicas" (1,35\%) }\end{array}$ & $\begin{array}{l}\text { Inglês } \\
(16,09 \%)\end{array}$ \\
\hline
\end{tabular}




\begin{tabular}{|l|l|l|l|}
\hline & $\begin{array}{l}\text { Norte- } \\
\text { americanos } \\
(1,99 \%)\end{array}$ & $\begin{array}{l}\text { "Os fundamentos da disciplina } \\
\text { arquivística" (1,08\%) }\end{array}$ & $\begin{array}{l}\text { Espanhol } \\
(10,84 \%)\end{array}$ \\
\hline & $\begin{array}{l}\text { Portugueses } \\
(1,52 \%)\end{array}$ & $\begin{array}{l}\text { "Dicionário de Terminologia } \\
\text { Arquivística" (1,06\%) }\end{array}$ & $\begin{array}{l}\text { Francês } \\
(5,94 \%)\end{array}$ \\
\hline & $\begin{array}{l}\text { Espanhóis } \\
(1,45 \%)\end{array}$ & $\begin{array}{l}\text { "Arquivística: teoria e prática de uma } \\
\text { Ciência da Informação" (1,02\%) }\end{array}$ & \\
\hline $\begin{array}{l}\text { Franceses } \\
(1,37 \%)\end{array}$ & & \\
\hline
\end{tabular}

Fonte: elaboração própria.

* Consideramos os anos, os autores, as obras e os idiomas que apresentaram pelo menos $1 \%$ de ocorrências.

\section{Considerações finais}

Sabemos que o mapeamento e a análise das referências bibliográficas arquivísticas das pesquisas sobre arquivos e Arquivologia dos Programas de pós-graduação em Ciência da Informação não são suficientes para responder à questão que apresentamos no início deste capítulo. Todavia, este estudo pode ser o início do mapeamento de obras que possam trazer indícios das possíveis relações epistemológicas entre a Arquivologia e a Ciência da Informação.

Até o momento, temos evidentes vínculos institucionais e institucionalizados entre as duas disciplinas, nas universidades e nas agências brasileiras de fomento à pesquisa. Temos, também, pistas das relações epistemológicas entre elas, uma vez que a Ciência da Informação dedica-se ao estudo da informação de forma ampla e, a Arquivologia, ao estudo do documento de arquivo, de forma mais específica. Nessas perspectivas, evidentemente as duas disciplinas se encontram, dialogam, disputam espaços e recursos e constroem alianças nos processos de gênese, organização, comunicação e disponibilização da informação, no âmbito do que denominamos "campo da informação". Contudo, esses (des)encontros, diálogos, 
disputas e alianças não podem sobrepor as duas disciplinas, tampouco submeter a identidade da Arquivologia à Ciência da Informação, ignorando os seus percursos históricos distintos.

Afinal, o que a grande ocorrência de obras especificamente arquivísticas, produzidas a partir dos anos 1990, por brasileiros e em português, em pesquisas sobre arquivos e Arquivologia, produzidas em Programas de pós-graduação em Ciência da Informação pode nos indicar?

Se a Arquivologia não tivesse as suas peculiaridades científicas, certamente não haveria tantas referências a obras sobre os seus fundamentos, a sua terminologia e a organização de arquivos, seu objeto de estudo. Das cinco obras mais citadas, somente uma situa a Arquivologia como uma parte da Ciência da Informação (Silva et al, 1999). Os autores mais referenciados são pesquisadores e professores de Arquivologia ou arquivistas, o que reitera as especificidades práticas dos arquivos e teóricas da disciplina.

$\mathrm{E}$ o fato de esses autores serem majoritariamente brasileiros nos remete a uma situação intrigante: enquanto os cursos de Arquivologia são predominantemente oferecidos na graduação (temos 16 cursos de graduação e somente um mestrado profissional em Gestão de Documentos e Arquivos, na UNIRIO), os cursos de Ciência da Informação são ofertados em uma situação inversa, majoritariamente na pós-graduação (34 cursos - 11 doutorados, 15 mestrados e oito mestrados profissionalizantes - e somente dois cursos de graduação) (Coordenação de Aperfeiçoamento de Pessoal de Nível Superior, 2018; Ministério da Educação e Cultura, 2018). Ainda que a Arquivologia anteceda historicamente a Ciência da Informação e já tenha objeto, princípios e métodos explicitados na sua literatura - diferentemente da Ciência da Informação, que não tem, nas suas obras, menção dos seus princípios (Kuroki, 2016) -, parece que, para as instituições brasileiras, a Ciência da Informação possui mais estatuto científico do que a Arquivologia, que estaria mais próxima de um conjunto de técnicas do que de uma disciplina científica. 
Embora esta situação nos chame a atenção, não é nosso objetivo questionar o estatuto científico da Ciência da Informação, que certamente tem os seus méritos, a sua história e as suas peculiaridades teórico-epistemológicas. O nosso objetivo é apresentar mais elementos que propiciem reflexões em torno das singularidades científicas da Arquivologia, no sentido de identificá-la no campo da informação sem sobrepô-la ou submetê-la a nenhuma outra disciplina, reconhecendo os seus habitus e o seu espaço nesse campo, a partir de referências a obras propriamente arquivísticas, voltadas para as práticas nos arquivos, os fundamentos e a terminologia de uma disciplina única.

Ressaltemos, assim, que reconhecemos e vislumbramos interlocuções entre a Arquivologia e a Ciência da Informação que não comprometam a identidade de cada uma. Afinal, como bem lembram Couture, Ducharme e Rousseau (1988, p. 58), "Autonomia não significa isolamento".

Entendemos, assim, que no Brasil há uma produção científica sobre arquivos e Arquivologia consolidada, fortemente comunicada a partir de referências a autores e a obras nacionais citados em teses, dissertações e TCCs com temáticas arquivísticas.

Paralelamente, a validação do pensamento arquivístico pela circulação internacional de obras, inclusive por meio de traduções, reforça a consolidação científica da disciplina no País, remetendo-nos às reflexões de Bourdieu (2001) acerca das estratégias de consagração do campo científico. Os critérios de legitimidade são inerentes ao próprio campo: eles representam os interesses dos agentes em luta. E nesse sentido, a autoridade científica funciona como "uma espécie particular de capital que pode ser acumulado, transmitido e até mesmo, em certas condições, reconvertido em outras espécies" (Bourdieu, 1983, p. 130). Essa acumulação de capital decorre dos movimentos do campo científico em torno da sua estrutura, das suas regras, das estratégias dos agentes e dos habitus que os agregam. E é assim que a ordem científica se estabelece: a partir do funcionamento do campo, ou seja, "da estrutura da distribuição 
do capital específico de reconhecimento científico entre os participantes na luta" (Bourdieu, 1983, p. 136).

Um número significativo de pesquisas sobre arquivos e Arquivologia (253), referenciando obras arquivísticas de pesquisadores, professores e arquivistas, parece representar não somente a acumulação de capital científico, como a estruturação e o funcionamento de um campo específico: a Arquivologia como disciplina científica, com história, fundamentos teóricos e epistemológicos, mas ainda carente de reconhecimento de espaços institucionais que lhe dêem voz no Brasil.

\section{Referências Bibliográficas}

Associação Brasileira de Normas Técnicas. (2002). NBR 6023: informação e documentação - referências - elaboração. Rio de Janeiro.

Bellotto, H. L. (2004). Arquivos permanentes: tratamento documental (2 ed.). Rio de Janeiro: FGV.

Borko, H. (1968). Information Science: what is it? American Documentation, 19 (1), p.3-5.

Boullier de Branche, H. (1975). Relatório sobre o Arquivo Nacional do Brasil (2 ed.). Rio de Janeiro: Ministério da Justiça; Arquivo Nacional.

Bourdieu, P. (1983). O campo científico. In R. Ortiz. Pierre Bourdieu: sociologia (122-155). São Paulo: Ática.

Bourdieu, P. (2001). Science de la science et réflexivité: Cours du Collège de France 2000-2001. Paris: Raisons d'agir.

Brasil. (1991). Lei $n^{\circ} 8.159$, de 8 de janeiro de 1991. Dispõe sobre a política nacional de arquivos públicos e privados e dá outras providências. Recuperado de http:// www.planalto.gov.br/ccivil_03/leis/L8159.htm

Camargo, A. M. de A. \& Bellotto, H. L. (1996). Dicionário de Terminologia Arquivística. São Paulo: Associação dos Arquivistas Brasileiros - Núcleo Regional de São Paulo: Secretaria de Estado da Cultura.

Centre national de la recherche scientifique. (2018). Présentation. Recuperado de http://www.cnrs.fr/fr/organisme/presentation.htm

Conselho Nacional de Arquivos, 2018. e-Arq Brasil. Recuperado de: http://www. arquivonacional.gov.br/br/

Conselho Nacional de Pesquisa e Desenvolvimento Científico e Tecnológico. (1984). Áreas do Conbecimento: Classificação, Brasília, DF: CNPq. 
Costa Filho, C. (2016). Possíveis limitações do ciclo vital dos documentos ante o Póscustodialismo: o modelo australiano records continuum como instrumento de elucidação. Brasília: Universidade de Brasília.

Cook, T. (1997). What is past is prologue: a History of Archival ideas since 1898, and the future paradigm shift. Archivaria, 43, 17-63.

Coordenação de Aperfeiçoamento de Pessoal de Nível Superior. (2018). Cursos recomendados e reconhecidos. Recuperado de: https://sucupira.capes.gov.br/ sucupira/public/consultas/coleta/programa/quantitativos/quantitativoles. jsf?areaAvaliacao $=31 \&$ areaConhecimento $=60700009$

Couture, C.; Ducharme, D; Rousseau, J.-Y. (1988). L'Archivistique a-t-elle trouvé son identité? Argus, 17, (2), 51-60.

Cunha, A. A. da; Rodrigues, G. M. (2003). A pesquisa em Arquivística no Brasil: um estudo da produção científica nos programas de pós-graduação e de iniciação científica e do papel das agências financiadoras (9 ed.). In Congresso de Iniciação Científica da UnB. Brasília: UnB.

Donato, J. A. (2017). Mapeamento de referências bibliográficas arquivísticas em dissertações e teses com temáticas na área (2012) (23 ed). In Congresso de Iniciação Científica da UnB. Brasília: UnB.

Duchein, M. (1992). The history of European Archives and the development of the Archival Profession in Europe. American Archivist, 55 (1), 14-25.

Fonseca, M. O. (2005). Arquivologia e ciência da informação. Rio de Janeiro, RJ: FGV.

Foucault, M. A arqueologia do saber (7 ed.). (2005). Rio de Janeiro: Forense Universitária.

Foucault, M. (2008). A ordem do discurso: aula inaugural no Collège de France, pronunciada em 2 de dezembro de 1970 (16 ed.). São Paulo: Loyola.

Gagnon-Arguin, L. (1992). L'Archivistique: son histoire, ses acteurs depuis 1960. Québec: Presses Universitaires du Québec.

Jardim, J. M. \& Fonseca, M. O. (1995). As relações entre a Arquivística e a Ciência da Informação. INFORMARE, 1 (1), 41-50.

Kuroki, Í. F. M. (2016). Demarcações conceituais dos princípios científicos da Arquivologia e da Ciência da Informação: contribuições para a configuração científica das disciplinas no Campo da Informação. Brasília: Universidade de Brasília.

Mariz, A. C. A. (2004). Relações interdisciplinares entre a Arquivística e a Ciência da Informação. Cenário Arquivístico, 3 (1), 29-36.

Marques, A. A. da C. (2007). Os Espaços e os Diálogos da Formação e Configuração da Arquivística como Disciplina no Brasil. Brasília: Universidade de Brasília.

Marques, A. A. da C. (2011). Interlocuções entre a Arquivologia nacional e a internacional no delineamento da disciplina no Brasil. Brasília: Universidade de Brasília.

Marques, A. A. da C. (2016). Arquivologia e Ciência da Informação: de mãos dadas? Informação \& Sociedade (UFPB. Online), 26, 169-184.

Marques, A. A. da C. (2017). A investigação científica em Arquivologia e a sua busca de identidade. Pesquisa Brasileira em Ciência da Informação e Biblioteconomia, 12, 77-89.

Marques, A. A. da C. \& Rodrigues, Georgete Medleg. (2009). A Arquivística nos Encontros Nacionais de Pesquisa em Ciência da Informação (ENANCIB's): análise 
preliminar da influência do pensamento arquivístico internacional. In $E N A N C I B$ (10 ed.) João Pessoa: UFPB.

Marques, A. A. da C. \& Marques, M. S. (2014). A produção científica arquivística na Ciência da Informação: estudo das suas referências. In Encontro Nacional de Pesquisa em Ciência da Informação ( $15^{\mathrm{a}}$ ed.). Belo Horizonte: UFMG.

Ministério da Educação e Cultura. (2018). Instituições de Educação Superior e Cursos Cadastrados. Recuperado de http://emec.mec.gov.br/

Moreira, V. L. S. (2017). Mapeamento de referências bibliográficas arquivísticas em dissertações e teses com temáticas na área (2009-2010). In Congresso de Iniciação Científica da UnB (23 ed.). Brasília: UnB.

Oliveira, F. H. de. (2014). A formação em Arquivologia nas universidades brasileiras: objetivos comuns e realidades particulares. Brasília: Universidade de Brasília.

Pinheiro, L. V. R. (1999). Campo interdisciplinar da Ciência da Informação: fronteiras remotas e recentes. In L. V. R. Pinheiro (org.). Ciência da Informação, Ciências Sociais e Interdisciplinaridade (155-182). Brasília/Rio de Janeiro: IBICT/DDI/DEP.

Rondinelli, R. C. (2004). Gerenciamento arquivístico de documentos eletrônicos: uma abordagem teórica da diplomática arquivística contemporânea (2 ed.). Rio de Janeiro: FGV.

Rousseau, J.-Y. \& Couture, C. (1998). Os fundamentos da disciplina arquivística. Lisboa: Publicações Dom Quixote.

Schellenberg, T. R. (1974). Documentos públicos e privados: arranjo e descrição. Rio de Janeiro: Fundação Getúlio Vargas.

Schmidt, C. M. dos S. (2015). A construção do objeto científico na trajetória bistóricoepistemológica da Arquivologia. São Paulo: ARQ-SP.

Silva, A. M. da. et al. (1999). Arquivística: teoria e prática de uma Ciência da Informação. Porto: Afrontamento.

Silva, J. G. e. (1996). Socialização da informação arquivística: a viabilidade do enfoque participativo na transferência da informação. Rio de Janeiro: Universidade Federal do Rio de Janeiro. 


\title{
LA B I B L I OTECA UNIVERSITARIA ¿AL SERVICIO DE LA INVESTIGACIÓN?
}

\author{
THE UNIVERS ITY LIBRARY \\ AT THE SERVICE OF RESEARCH? \\ A B IBLIOTECA UNIVERSITÁRIA \\ AO SERVIÇO DA INVESTIGAÇÃO?
}

Llarina González-Solar

Universidad da Coruña. Grupo de Investigación

Historia, Arqueología, Documentación y Cultura

General Secretariat of the Council of the European Union. Library

llarina.gonzalez@udc.es

ORCID: https://orcid.org/0000-0003-4443-4102

Viviana Fernández Marcial

Universidad da Coruña. Facultad de Humanidades y Documentación

viviana.fernandez@udc.es ORCID: https://orcid.org/0000-0002-9277-266X

RESUMEN - El trabajo aborda el papel que las bibliotecas académicas están asumiendo en un nuevo entorno en el que el prestigio de las universidades se relaciona directamente con los resultados de investigación obtenidos por sus académicos. Para ello se contextualiza esta situación desde la revisión de las condiciones que llevan a la investigación a constituirse como un elemento clave, con especial referencia a los rankings de universidades. Se revisa 
la noción de servicios a la investigación, concretando el papel de la biblioteca al asumir este rol activo a través de un posible catálogo de servicios bibliotecarios, y se examina el nivel de aceptación de los mismos por parte de los usuarios investigadores en base a las relaciones y percepciones de estos. Finalmente, se reflexiona sobre las implicaciones de todo ello para conocer en qué medida se está avanzando en esta dirección.

PALABRAS CLAVE - Biblioteca universitaria; Servicios de apoyo a la investigación; Rankings universitarios; Colaboración bibliotecario-investigador.

ABSTRACT - The work addresses the role that academic libraries are assuming in a new environment, in which universities prestige is directly related to their academic's research results. To this end, the situation is contextualized, examining what conditions are leading the research becoming a key element, with special reference to university rankings. The notion of research services is reviewed, specifying the role of the library in assuming an active contribution through a possible catalogue of library services, and their level of acceptance from researchers is examined on the basis of their relationships and perceptions. Finally, we reflect on their implications with a view to ascertaining to what extent is being made in this direction.

Keywords - Academic libraries; Research support services; Universities rankings; Librarian-researcher collaboration.

\section{Introducción}

La biblioteca universitaria es definida por la American Library Association (ALA, 1989) como "una combinación orgánica de personas, colecciones y edificios cuyo propósito es ayudar a sus usuarios 
en el proceso de transformar la información en conocimiento", "la biblioteca (o sistema de éstas) es establecida, mantenida y administrada por una universidad para cubrir las necesidades de información de sus estudiantes y apoyar sus programas educativos, de investigación y demás servicios" (ALA, 2013, p. 263).

Bajo este enfoque, la biblioteca universitaria ha tenido históricamente una doble finalidad que incluye tanto el apoyo a la docencia como el apoyo a la investigación. Estas definiciones reflejan con claridad que la función última de la biblioteca universitaria es atender a las necesidades de la universidad, aunque lo cierto es que durante muchos años, décadas, el apoyo a la investigación ha quedado relegado a un segundo plano, mientras que la orientación a dar soporte a la actividad docente ha sido la clave de su gestión.

Desde hace algunos años el soporte a la investigación ha ido adquiriendo una nueva relevancia en la actividad de las bibliotecas universitarias. Muestra de ello es el interés evidenciado por las sucesivas ediciones del Top Trends in Academic Libraries publicado por la Association of College \& Research Libraries (ACRL). Así, por ejemplo, la edición de 2014 incorporaba como parte de las principales tendencias actividades específicas vinculadas con la investigación, tales como open access, gestión de datos y altmetrias (ACRL Research Planning and Review Committee, 2014).

Este renovado interés por los servicios de apoyo a la investigación es sustentado también por MacKenzie (2014, p.165) para quien "encontrar maneras de proporcionar apoyo a los investigadores es una creciente preocupación en las bibliotecas universitarias" y forma parte del objetivo amplio de las bibliotecas académicas por apoyar la investigación (Mitchell, 2013).

En estas condiciones, el servicio a los investigadores puede ser considerado como una de las principales tendencias actuales en las bibliotecas académicas (Anglada, 2012) hasta el punto de que "caminamos hacia la biblioteca que busca embeberse en el propio 
proceso de investigación" (Plaza-Navas, Ponsati Obiols, Bernal y Baquero Arribas, 2012, p. 3).

Aun cuando las bibliotecas universitarias han ido asumiendo este renovado papel, el debate se centra en valorar las posibilidades reales y el nivel de aceptación por parte de los usuarios investigadores y de la comunidad científica. La literatura recoge un conjunto de propuestas $\mathrm{y}$ actividades que deben ser asumidas, pero cabe preguntarse si en realidad esto es así. ¿Están las bibliotecas universitarias asumiendo y (aún más) están preparadas para asumir un rol activo en el apoyo a la actividad investigadora de las universidades? De ser así ¿hasta qué punto o en qué medida se está avanzando en esta dirección? Estas cuestiones serán abordadas en el presente trabajo.

\section{La investigación - factor competitivo de las universidades}

El concepto de universidad europea nacido en el siglo XI, modelo que en esencia perduró hasta finales del pasado siglo XX, está hoy en quiebra. Los efectos de una economía global han transformado las universidades, acercándose en su noción a criterios mercantilistas y economicistas más que a los propios de entidades donde se estimula y transmite ciencia, saber, cultura y valores cívicos. La universidad de hoy y la del futuro va a estar condicionada por los imperativos de eficiencia económica, donde los términos competitividad y rentabilidad se abren paso.

¿Cuáles son los elementos detonantes de esta situación? Sería posible establecer tres fundamentales. Por una parte, el modelo de educación basado en la financiación casi exclusiva del estado y/o de entes públicos se ha fracturado durante la crisis económica, algo que se aplica fundamentalmente para el caso de las universidades europeas. La pérdida de su fuente de financiación tradicional se traduce en la búsqueda de nuevos mecanismos que la sustituyan. 
El aumento de ingresos por vía de la actividad docente no consigue ser suficiente y se requiere, de cara a los posibles patrocinadores o mecenas, de datos objetivos, mensurables y contrastables que acrediten rentabilidad de lo invertido.

En segundo lugar, se observa la paulatina disolución del tradicional monopolio geográfico de estudiantes e incluso de la noción de mercado nacional, existentes previamente. En un contexto globalizado, el mercado se define a través de nuevas fronteras que trascienden el ámbito geográfico natural; esto implica plantear una nueva noción del espacio de actuación de las universidades que, ahora, compiten entre sí por un mercado ya deslocalizado, un mercado que debe ser atraído con recursos, medios y un posicionamiento que permita una ventaja competitiva frente al resto. Siendo como es una tendencia mundial, esto plantea ventajas para las universidades, en cuanto a la difusión del conocimiento, pero también implica amenazas, como la creciente preeminencia del idioma y la ciencia en inglés o una mayor competencia por la captación de talentos y fuentes de financiación (García Vegas, 2012).

Esta situación se complementa con un tercer elemento que, como no puede ser de otro modo, se articula en torno a la omnipresencia de las tecnologías de la información en el proceso de enseñanzaaprendizaje, aspecto que sirve de base a la globalización planteada en punto anterior. De este modo, con modelos de educación online y contenidos fluidos (como en el caso de los cursos en línea masivos y abiertos - MOOC), emerge un nuevo escenario de "competencia interuniversitaria global, no sólo a nivel institucional, sino también en sus elementos singulares, como en el de los contenidos formativos" (Rué, 2014, p. 10). Actualmente, en el entorno europeo sigue existiendo una cierta homogeneidad en el valor de los títulos expedidos por distintas universidades, pese a lo cual es previsible que, paulatinamente, comience a aparecer cierta competencia en esta función certificadora. De esta forma, junto con la mayor cir- 
culación internacional de titulados, un título de una universidad de renombre constituirá "un aval al portador" que garantizará un mejor acceso al empleo (Rué, 2014, p. 10). La valoración de este prestigio previsiblemente recaerá en sistemas accesibles como los rankings y se apoyará en los modelos de conducta de una sociedad acostumbrada al efecto marca.

En estos tres elementos hay un denominador común, la investigación que se convierte en fuente de ingresos y en elemento de poderoso atractivo para inversores y también para potenciales estudiantes. Por ello conviene precisar cuál es la función de la universidad en la sociedad actual. Es posible afirmar que la misión de la universidad contemporánea, pese a las peculiaridades del medio sociocultural, tiene como rasgos primordiales "la investigación científica, la transmisión crítica de la ciencia y la formación cultural y humana a nivel superior" (Medina Rubio, 2005, p. 19) todos los cuales conviven en una "una tensión creativa" (Etzkowitz, Webster, Gebhardt y Terra, 2000, p. 326). Así se observa en la definición de su papel planteada en el preámbulo de la Carta Magna de las Universidades:

" $1^{\circ}$ que el porvenir de la humanidad, en este fin de milenio, depende en gran medida del desarrollo cultural, científico y técnico que se forja en los centros de cultura, conocimiento e investigación en que se han transformado las auténticas Universidades; $2^{\circ}$ que la tarea de difusión de los conocimientos que la Universidad debe asumir hacia las nuevas generaciones implica, hoy en día, que se dirija también al conjunto de la sociedad; cuyo porvenir cultural, social y económico requiere, especialmente, un considerable esfuerzo de formación permanente;

$3^{\circ}$ que la Universidad debe asegurar a las generaciones futuras una educación y una formación que les permitan contribuir al respeto de los grandes equilibrios del entorno natural y de la vida" (European University Association, 1988). 
La perspectiva económica afecta a estos tres elementos que constituyen el "triángulo del conocimiento" (Figura 1), dentro de las nociones derivadas de la Estrategia de Lisboa. En concreto, se evidencia de forma clara en la función investigadora, en la cual adopta dos vertientes. Por una parte la universidad tiene un papel primordial en el triángulo del conocimiento (León Serrano, 2011) al ser generadora de un conocimiento, cuya transmisión al tejido productivo y social conlleva mejoras económicas. Por otra, se plantea la posibilidad de que las universidades sean financiadas en orden a sus resultados, típicamente a sus resultados en investigación.

Figura 1: Triángulo del conocimiento

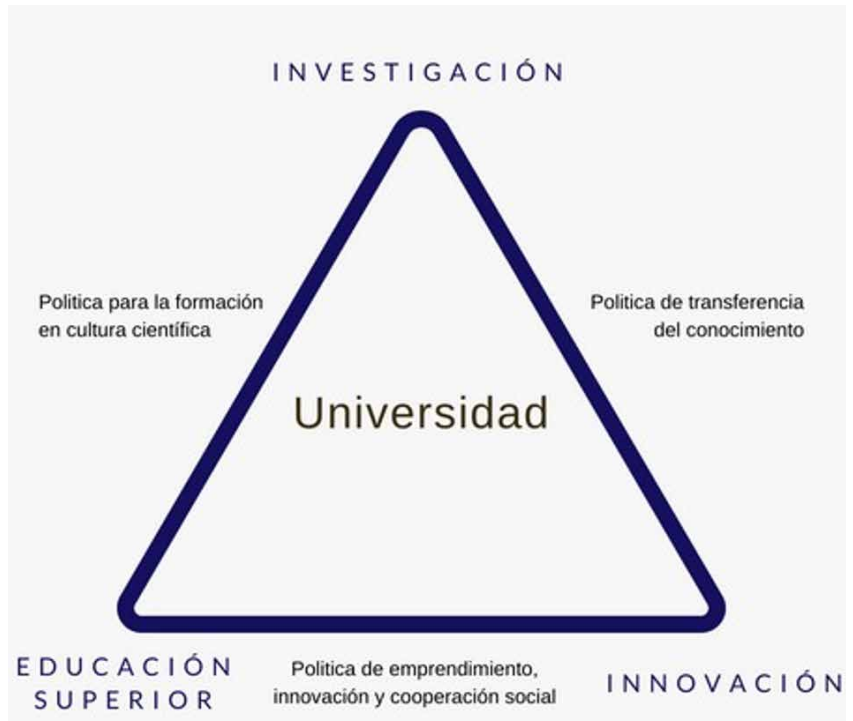

Fuente: elaboración propia.

Ambas vertientes tienen repercusión en algunos de los documentos fundamentales de la Unión Europea. Respecto de la primera, se afirma que "la investigación y el desarrollo y el sector universitario constituyen la base de la competitividad en la Unión Europea” 
(Comisión Europea, 2006) o que el "desarrollo científico y tecnológico es el motor del crecimiento económico y social” (Comisión Europea, 2000). Igualmente se aborda la segunda vertiente, aunque de un modo más pragmático al incidir en que:

"Las universidades deben beneficiarse de subvenciones que se basen más en sus actuaciones que en su reputación, centrando la financiación más en sus resultados que en sus aportaciones, y adaptándola a los perfiles institucionales de las universidades. Las universidades que se dedican a la investigación no deberían ser evaluadas y financiadas sobre la misma base que las otras universidades, que conceden menos peso a la investigación, pero que poseen más estudiantes procedentes de medios desfavorecidos o que actúan como motores de la economía local. Cada país debe encontrar el equilibrio adecuado entre la financiación básica, la derivada de procedimientos de licitación y la ligada a los resultados (basada en un aseguramiento de la calidad) en la enseñanza superior y la investigación universitaria" (Comisión Europea, 2006).

Todo ello tiene consecuencias en la gobernanza de las universidades, cuestión ya de interés en la Declaración de Lisboa de 2010 en donde se afirma:

"Las universidades (...) trabajarán para consolidar sus planes estratégicos de investigación con el objeto de introducir estrategias de gestión apropiadas. Estas estrategias se destinarán a reforzar la investigación y a crear vías para aprovechar al máximo las oportunidades de financiación ofrecidas por organismos nacionales y europeos (elementos principales de financiación externa de la investigación universitaria). Aunque el talento individual sigue siendo un elemento clave en el desarrollo de una investigación básica de calidad, la formación de masa crítica y la optimización de la 
creación y utilización de infraestructuras seguirán siendo factores cruciales para una investigación de calidad. Los costes de la actividad investigadora, en constante aumento, harán más apremiante la necesidad de centrarse en áreas prioritarias de investigación”.

\subsection{La evaluación de la investigación y el ranking de universidades}

Tanto la financiación pública de la mayor parte de las universidades como su autonomía son los motivos fundamentales de la actual obligación de rendición de cuentas a la sociedad que las financia y ampara; a través de la transparencia se busca crear un clima de confianza con su entorno, a fin de fortalecer dichas fuentes de financiación (Irure, 2006). Pero también, como se ha indicado anteriormente, los nuevos modelos de financiación procedente del sector empresarial imponen un modelo de gestión basado en resultados y evidencias.

La multidimensionalidad de la universidad en lo relativo a sus funciones y, por lo tanto, a sus metas y objetivos, genera un entorno complejo para llevar a cabo esta medición. La diversidad y complejidad de sistema y de las políticas científicas han propiciado el desarrollo de múltiples y variados modelos de evaluación (Barberá, 2006) abarcando distintos puntos de vista (económico, funcional, de gestión, estratégico). Estos modelos han sido desarrollados desde diversas instancias como son las propias universidades, organismos independientes o los gobiernos.

Esta evaluación es uno de los pilares de la mejora de la calidad universitaria pese a enfrentarse a diversas críticas como la utilización generalizada del Factor de impacto ${ }^{1}$ y otros indicado-

1 El factor de impacto es el indicador de impacto más extendido, pese a ello ha sido criticado por evaluar fundamentalmente el aspecto formal o continente de la revista, más que el contenido, o por utilizarse para su cálculo bases de datos con determinados sesgos lingüísticos o temáticos. En este sentido es fundamental la lectura de la San Francisco Declaration on Research Assessment (DORA) del año 2013, suscrita 
res bibliométricos como criterio principal de evaluación. Estos indicadores, referidos tanto a la actividad como al impacto, proporcionan información sobre el proceso investigador (volumen, evolución, visibilidad y estructura) de forma objetiva y verificable permitiendo el análisis de un gran volumen de datos (Lascurain, 2006). Estas ventajas han llevado, como indica el Manifiesto de Leiden (Hicks et al., 2015), a una excesiva dependencia de las métricas cualitativas basadas en la citación y no en características cualitativas, distorsionando el panorama académico al convertir el sistema de medición en un fin en sí mismo.

Como modelo alternativo se han propuesto las alimetrías (altmetrics), utilizando los recursos de la Web 2.0 (Priem y Hemminger, 2010), y de los indicadores de uso (usage bibliometrics), basados en nivel de utilización y descarga de los materiales científicos (Kurtz y Bollen, 2010), para el análisis de la actividad académica. La función de estos nuevos indicadores no parece, hoy por hoy, orientarse a la sustitución de los tradicionales indicadores bibliométricos, pero sí a complementarlos al medir facetas diversas que la citación no puede representar, como el impacto social de la ciencia y el impacto inmediato de las publicaciones (Torres, Cabezas y Jiménez, 2013). Siendo su utilización un factor de gran interés para una mejor evaluación del rendimiento científico, supone un importante aumento en la complejidad de los procesos de evaluación al multiplicarse las fuentes y los propios indicadores.

Además, una parte sustancial de estos esfuerzos para medir la calidad de las universidades, en realidad se centran en la valoración de los profesores-investigadores en momentos como el acceso, la promoción, la adquisición de complementos retributivos

originalmente por 82 grandes asociaciones, instituciones y empresas, y el Manifiesto de Leiden (Hicks, Wouters, Waltman, Rijcke, y Rafols, 2015). 
o la financiación de proyectos de investigación. Para los investigadores esto implica una sobrecarga de trabajo, la dispersión de esfuerzos en actividades de carácter administrativo y la ingeniería curricular; para las instituciones de financiación conlleva dificultades en el control del retorno de la inversión (como recoge la Declaración de Lisboa, 2000).

Junto a estos esfuerzos de carácter institucional, en los últimos años han crecido en importancia y en número los rankings de universidades. Los rankings son listas de carácter clasificatorio que ordenan las instituciones de educación superior en función de sus resultados, definidos por indicadores y representando diversas facetas de calidad. Estas listas han evolucionado en modelos más complejos que permiten la clasificación por diversos de estos indicadores, por territorios y áreas temáticas, para favorecer la comparación entre universidades.

Los rankings son considerados útiles herramientas para el benchmarking entre universidades (Hazelkorn, Loukkola, Zhang, 2014; Romero y Pastor, 2012) y aportan beneficios al sistema, en cuanto que "responden a demanda de los consumidores de una información fácilmente interpretable sobre el estado de las instituciones de educación superior; estimulan la competencia entre ellas; proporcionan algunos argumentos para la asignación de fondos; y ayudan distinguir entre tipos diferentes de instituciones y diferentes programas y disciplinas. Además, cuando son correctamente entendidos e interpretados, contribuyen a la definición de la 'calidad' en las instituciones de educación superior de un país particular, complementando el trabajo riguroso conducido en el contexto de la evaluación de calidad y de la revisión llevada a cabo por agencias públicas e independientes de acreditación" (International Ranking Expert Group, 2006).

Pese a esta utilidad han sufrido fuertes críticas referidas a que transmiten una realidad sesgada, ya que la mayoría de 
estos indicadores están relacionados con la investigación y el prestigio (ANECA, 2007); a cuestiones metodológicas, de selección, recogida y tratamiento de los datos, entre otras, así como la inconsistencia metodológica que suelen presentar (Romero y Pastor, 2012); a la parcialidad que causa la recopilación de datos de producción en un grupo reducido de bases de datos (Pérez Esparrells y Gómez Sancho, 2011); la incapacidad para recoger un número relevante de instituciones de países no centrales o no anglosajones; el no relativizar los datos adecuadamente según el tamaño de la universidad (Sanz-Casado, García-Zorita, SerranoLópez, Efraín-García y de Filippo, 2013); y al hecho de que se estén utilizando como elementos de referencia para la toma de decisiones (ANECA, 2013, p. 105).

La utilización de rankings se enfrenta a un problema metodológico de base y es la dificultad de definir la noción de "calidad" y "excelencia" en un entorno complejo y heterogéneo como es la universidad. Sin ánimo de exhaustividad se presentan a continuación y de forma esquemática los aspectos evaluados por algunos de los principales rankings:

Tabla 1: Criterios de evaluación utilizados por los distintos rankings y su peso relativo.

\begin{tabular}{|l|l|l|l|}
\hline \multirow{2}{*}{ Ranking } & Criterio & Indicadores & Peso \\
\hline \multirow{3}{*}{ ARWU } & $\begin{array}{l}\text { Calidad de la } \\
\text { Docencia }\end{array}$ & $\begin{array}{l}\text { Antiguos alumnos de una institución con } \\
\text { premios Nobel y medallas Fields }\end{array}$ & $10 \%$ \\
\cline { 2 - 4 } & $\begin{array}{l}\text { Calidad del } \\
\text { Profesorado }\end{array}$ & $\begin{array}{l}\text { Profesores de una institución que han } \\
\text { obtenido premios Nobel y medallas Fields } \\
\text { Investigadores con alto índice de citación en } \\
\text { diversas materias }\end{array}$ & $40 \%$ \\
\cline { 2 - 5 } & $\begin{array}{l}\text { Producción } \\
\text { Investigadora }\end{array}$ & $\begin{array}{l}\text { Artículos publicados en Nature y Science } \\
\text { Artículos indexados en Science Citation Index - } \\
\text { Expanded y Social Science Citation Index }\end{array}$ & $40 \%$ \\
\cline { 2 - 5 } & $\begin{array}{l}\text { Rendimiento } \\
\text { per Cápita }\end{array}$ & $\begin{array}{l}\text { Rendimiento académico per cápita de una } \\
\text { institución }\end{array}$ & $10 \%$ \\
\hline
\end{tabular}




\begin{tabular}{|c|c|c|c|}
\hline \multirow{5}{*}{ THE } & Enseñanza & $\begin{array}{l}\text { Encuesta de reputación } \\
\text { Ratio personal-estudiantes } \\
\text { Ratio de doctorados y licenciados } \\
\text { Ratio de doctorados y personal académico } \\
\text { Ingresos institucionales }\end{array}$ & $30 \%$ \\
\hline & Investigación & $\begin{array}{l}\text { Encuesta de reputación } \\
\text { Ingresos por investigación } \\
\text { Productividad de la investigación }\end{array}$ & $30 \%$ \\
\hline & Citas & & $30 \%$ \\
\hline & $\begin{array}{l}\text { Panorama } \\
\text { internacional }\end{array}$ & $\begin{array}{l}\text { Ratio de estudiantes internacionales y } \\
\text { nacionales } \\
\text { Ratio de personal internacional y nacional } \\
\text { Colaboración internacional }\end{array}$ & $7,5 \%$ \\
\hline & $\begin{array}{l}\text { Ingresos de la } \\
\text { industria }\end{array}$ & & $2,5 \%$ \\
\hline \multirow{5}{*}{ QS } & $\begin{array}{l}\text { Academic } \\
\text { Reputation }\end{array}$ & & $40 \%$ \\
\hline & $\begin{array}{l}\text { Employer } \\
\text { Reputation }\end{array}$ & & $10 \%$ \\
\hline & $\begin{array}{l}\text { Faculty/Student } \\
\text { Ratio }\end{array}$ & & $20 \%$ \\
\hline & $\begin{array}{l}\text { Citations per } \\
\text { faculty }\end{array}$ & & $20 \%$ \\
\hline & $\begin{array}{l}\text { International } \\
\text { Faculty Ratio } \\
\text { \& International } \\
\text { Student Ratio }\end{array}$ & & $10 \%$ \\
\hline \multirow[t]{3}{*}{ SIR } & Investigación & $\begin{array}{l}\text { Excelencia con liderazgo } \\
\text { Impacto normalizado } \\
\text { Resultados } \\
\text { Bolsa de talento científico } \\
\text { Liderazgo científico } \\
\text { Colaboración internacional } \\
\text { Publicaciones de alta calidad } \\
\text { Excelencia }\end{array}$ & $50 \%$ \\
\hline & Innovación & $\begin{array}{l}\text { Conocimiento innovador } \\
\text { Impacto tecnológico } \\
\text { Patentes }\end{array}$ & $30 \%$ \\
\hline & Societario & $\begin{array}{l}\text { Backnets } \\
\text { Tamaño web }\end{array}$ & $20 \%$ \\
\hline NTU & $\begin{array}{l}\text { Productividad } \\
\text { de la } \\
\text { investigación }\end{array}$ & $\begin{array}{l}\text { Número de artículos en los últimos } 11 \text { años } \\
\text { Número de artículos en el año en curso }\end{array}$ & $25 \%$ \\
\hline
\end{tabular}




\begin{tabular}{|l|l|l|l|}
\hline & $\begin{array}{l}\text { Impacto de la } \\
\text { investigación }\end{array}$ & $\begin{array}{l}\text { Número de citaciones en los últimos 11 años } \\
\text { Número de citaciones en los últimos 2 años } \\
\text { Número medio de citaciones en los últimos 11 } \\
\text { años }\end{array}$ & $35 \%$ \\
\cline { 2 - 4 } & $\begin{array}{l}\text { Índice h de excelencia en investigación de los } \\
\text { últimos 2 años } \\
\text { Número de documentos muy citados } \\
\text { Número de artículos en el año en curso en } \\
\text { revistas de alto impacto }\end{array}$ & $40 \%$ \\
\hline
\end{tabular}

Fuente: Elaboración propia a partir de (ARWU, 2015; NTU, 2017; QS, 2018; SIR, 2018; THE, 2018).

En estos rankings se aprecia el peso de la investigación. Por ejemplo, en el ARWU se observa que, junto a los criterios de "producción investigadora", aparecen otros bajo la denominación de "calidad docente" referidos en realidad a premios cuya concesión se depende completamente de los resultados de investigación y el número de citas recibido. Igualmente, los criterios de investigación más los de citaciones suponen el $60 \%$ del resultado que una universidad obtiene en el ranking THE; la innovación y la investigación son el $80 \%$ en el caso del Scimago y el valor con más peso de QS se refiere a la reputación, altamente influenciada por la investigación. En el caso del NTU, el total de indicadores se orienta a la investigación.

Como contraposición han aparecido diversos proyectos con el afán explícito de recoger la multidimensionalidad de las funciones de la universidad, entre ellos U-Multirank y Qrossroads. Sin embargo, su impacto es más limitado y son menos conocidos.

Esta orientación a la investigación tiene un reflejo directo en la toma de decisiones en las universidades, los gobiernos y las agencias de financiación. El informe Rankings in institutional strategies and processes: impact or illusion muestra que hasta un $87 \%$ de las instituciones monitorean su presencia en rankings, generalmente a alto nivel (trasladándose al rector en un $54 \%$ de los casos y a un órgano colectivo de máximo nivel en un 31\%) y sus resultados pueden condicionar la toma de decisiones de carácter estratégico, 
organizativo, de gestión o académico (un 39\% ya lo hace y un 32\% se lo plantea) (Hazelkorn, et al., 2014). Por otra parte, los rankings se han ido convirtiendo paulatinamente en elementos de referencia para la toma de decisiones por parte los responsables del gobierno y agencias de financiación (ANECA, 2013) como demuestra que organismos e instituciones financiadores de becas de movilidad internacional y muchos países están limitando estas becas, que conceden a sus estudiantes más brillantes, a universidades bien posicionadas en los rankings internacionales (Sanz-Casado, 2015).

En este contexto resulta indiscutible que la investigación debe ser considerada como un factor crítico, que no solo afecta al adecuado desarrollo de otras funciones de la universidad, como son la docencia y la transferencia de conocimiento, sino que es fundamental para la propia viabilidad de la institución, en cuanto que se encuentra en un entorno cada día más competitivo. El acercamiento a modelos de financiación provenientes del mundo anglosajón y, concretamente, estadounidense puede definir la necesidad de una auténtica reorganización de las estructuras de la universidad, en una orientación más adecuada a los objetivos propuestos en sus planes estratégicos.

\section{Servicios de apoyo a la investigación: definición y alcance}

Este papel central de la universidad en el desarrollo científico se ha traducido en un conjunto de servicios de apoyo a la investigación, que pueden ser definidos como todos aquellos servicios que tienen como propósito dar soporte a uno o varios de los distintos ámbitos relacionados con el proceso de creación de conocimiento. Estos servicios, en respuesta a las exigencias de las numerosas facetas de la investigación, adquieren un perfil cada vez más diverso en lo que atañe a su diseño, proceso, financiación y divulgación. Así, por ejemplo, 
en el contexto del sistema universitario español se ha desarrollado una amplia gama de servicios que permite su categorización en los siguientes bloques (Fernández Marcial y González-Solar, 2017):

- Servicios de carácter instrumental: infraestructuras científico-técnicas que agrupan los equipamientos de la universidad, dando un servicio centralizado o por áreas a los distintos grupos de investigación; incluyendo, por ejemplo, laboratorios de diverso tipo.

- Servicios de gestión de la investigación: aquellos de carácter más claramente administrativo, abarcando funciones como la gestión de personal, asuntos económicos o gestión de proyectos.

- Oficinas de transferencia de resultados de la investigación: orientadas a canalizar las relaciones universidad-empresa, especialmente en términos de transferencia de resultados investigación; abarcando la identificación de demandas, el asesoramiento a los investigadores en aspectos como redacción y elaboración de contratos, comercialización de resultados, tramitación de patentes o creación de empresas.

- Servicios relacionados con la internacionalización de la investigación: centrados en dar soporte en el complejo proceso de tramitación de convocatorias de proyectos internacionales (por ejemplo, dentro del proyecto Horizonte 2020 de la Unión Europea). Incorporan aspectos como la difusión de noticias, formación, asesoramiento, preparación de propuestas o actuar como enlace con los organismos y comisiones adjudicadoras.

- Otros servicios: cada universidad desarrolla servicios, creados o no ad hoc para dar soporte a la investigación a través de una gran variedad de estructuras, incluyendo: servicios de publicaciones, unidades de cultura y divulgación científica, comités de ética, servicios de experimentación animal, de traducción, de organización de eventos, etc. Dentro de estos se encuentran la biblioteca universitaria y otros servicios de información. 
Esta clasificación apunta a que la biblioteca universitaria es uno de los servicios de apoyo a la investigación en las universidades.

Resultan pertinentes diversas reflexiones, en primer lugar la calidad de la biblioteca debe medirse en base a la satisfacción de las necesidades de sus usuarios, pero debe ser evaluada en el contexto de una institución y demostrar hasta qué punto contribuye al cumplimiento de la misión de esta (Pritchard, 1996). Pese a la naturaleza multifacética de esta misión, se constata que la investigación es tomada como elemento fundamental en la medida de la calidad y el prestigio a través de rankings y, por lo tanto, esta debe ser un área clave para que la biblioteca genere valor (González-Solar, 2016). Como cuestiona Parker (2012, p. 1): "si la reputación de las universidades es juzgada casi exclusivamente por su actividad investigadora ¿qué pueden hacer las bibliotecas para dar soporte a sus universidades y cómo están abordando estos nuevos requerimientos?".

La biblioteca universitaria tiene, y debe tener, una orientación múltiple hacia las distintas facetas de la misión de la universidad, incluyendo, pero no limitándose, a la investigación y focalizando su acción a través de servicios específicos. Así, se deben entender los servicios bibliotecarios de apoyo a la investigación como "todas aquellas actividades que se realizan en el seno de bibliotecas académicas con el fin último de dar soporte a las actividades de investigación y producción científica en la mejora de sus resultados y de su impacto" (González-Solar, 2016, p. 61). Múltiples autores han llamado a demostrar el valor de la biblioteca universitaria a través del apoyo a la investigación (Bourg, Coleman y Erway, 2009; Corrall, Kennan y Afzal, 2013; MacColl, 2010; Webb, Gannon-Leary y Bent 2007). Igualmente se puede observar en documentos institucionales, como la actual estrategia de Research Libraries UK (RULK) que esta orientada a "dar forma al futuro de nuestras bibliotecas asegurando que ofrecen el máximo valor a la comunidad investigadora, tanto en el Reino Unido como en el ámbito internacional" (RULK, 2014, p. 3). 
El nuevo escenario conlleva la necesidad de profundos cambios si las bibliotecas universitarias quieren seguir ocupando un papel central en los procesos de creación de nuevo conocimiento; tal y como propone el manifiesto Support for the Research Process (Bourg et al., 2009) según el cual las bibliotecas deberían:

1. Comprometerse al estudio continuo de los patrones de trabajo y las necesidades de los investigadores; con especial atención en las diferencias entre disciplinas y entre generaciones en la adopción de nuevas formas de investigación y publicación.

2. Diseñar nuevos servicios flexibles centrados en las partes del proceso de investigación que causan a los investigadores más frustración y dificultad.

3. Integrar en los flujos de trabajo de los investigadores el contenido, los servicios y el personal de la biblioteca; la integración con otros servicios responde a las necesidades del investigador.

4. Asumir el papel de expertos buscadores de información (expert information navigators) y redefinir el servicio de referencia como una consulta de investigación y no como la búsqueda de datos.

5. Reevaluar las descripciones de puestos de trabajo garantizando que la formación y la contratación se realizan acorde a las necesidades de habilidades, educación y experiencia propias del apoyo a la investigación.

6. Reconocer que el descubrimiento de la información se producirá fuera de la biblioteca pero que es la biblioteca la encargada de hacerlo posible dándole metadatos y organización para darle visibilidad.

7. Abrazar las oportunidades para enfocarse a los servicios y recursos centrales y únicos; buscar colaboraciones para ofrecer ágilmente otros servicios y recursos comunes.

8. Buscar la manera de demostrar a los administradores de la universidad, acreditadores y los auditores, el valor de los servicios bibliotecarios y recursos a los académicos; mientras se prestan servicios que pueden parecer invisibles a los investigadores. 
9. Involucrar a los investigadores en la identificación de conjuntos de datos de investigación primaria que deben ser conservados y accesibles a largo plazo.

10. Ofrecer plataformas alternativas de publicación y difusión, integrados con los repositorios adecuados y servicios de preservación.

Estas diez propuestas reflejan, por una parte, una visión integral de la actividad investigadora como un todo que debe ser objetivo de apoyo y, por otra, una visión integradora de las capacidades de la biblioteca, que es capaz de ir más allá de sus funciones tradicionales y acercarse a otras que pueden ser novedosas o, simplemente, estar relacionadas con áreas de actuación típicas de otras unidades (como puede ser la publicación). Esta idea conecta directamente con la filosofía que subyace en la noción de CRAI, que "debería ofrecer nuevos productos, prestaciones y servicios adaptados a las necesidades y expectativas de los investigadores" (Pinto Molina, Sales Salvador y Martínez Osorio, 2008, p. 138).

Por otra parte, se observan dos rasgos de gran importancia, la necesidad de conocer y comprender al usuario, y la capacidad de actuar sobre sus demandas incluso antes de que estas sean generadas. Ambos aspectos están profundamente conectados como bien apuntan Gover y Hale (1988), quienes afirman que el bibliotecario debe comprender los patrones de conducta de los investigadores para poder ofrecer un servicio proactivo a estos. De este modo, "el papel del bibliotecario en el proceso de investigación es anticiparse a los patrones de los investigadores", a lo que añaden una perspectiva muy actual de lo que significa este papel al incidir en que, en paralelo a los colegios invisibles, el bibliotecario debe ser considerado una fuente fiable de información y formar parte del colegio "visible" del investigador, esto es, "la persona que el investigador conoce y respeta como una fuente de información" (Grover y Hale, 1988, p. 12). 
Todo ello implica la aparición de servicios que completen el esquema tradicional de servicios pasivos (como la adquisición de documentos y su puesta a disposición) y servicios reactivos (como la reserva de un libro o la realización de una bibliografía). Entre los servicios de tipo proactivo se incluyen actividades como: la búsqueda de recursos de interés y adecuados a las necesidades de sus usuarios; proporcionar herramientas para que los usuarios hagan el mejor uso posible de esos recursos (por ejemplo con material autoformativo o con buenas descripciones de los recursos que permitan valorar rápidamente su utilidad para cada caso); ofrecer sesiones personalizadas de formación en software y fuentes de información electrónica; y servicios para investigadores asistentes o en formación, como pueden ser la capacitación en recursos concretos (Lewis, 2002).

Es importante incidir en esta idea de la complementariedad así, la proactividad debe ser una actitud constante de la biblioteca, paralela y no contradictoria con la reactividad, que no se ciña al modo en que se llevan a cabo los servicios sino que incorpore nuevas perspectivas a través, por ejemplo, de la difusión de las actividades de la biblioteca, la elaboración de contenidos y el afianzamiento de la reputación de la universidad, todo ello con el objetivo de potenciar el propio valor de la biblioteca (Housewright, Schonfeld y Wulfson, 2013).

Proactivos o reactivos, existe cierta dificultad en categorizar los servicios de soporte a la investigación debido a que rara vez se concentran bajo una denominación que los describa como tales (Camón, 2012). Tradicionalmente las bibliotecas académicas han ofrecido estos servicios sin que hayan sido concebidos como tal, pudiendo destacar los servicios de referencia o de préstamo interbibliotecario, cuyo origen no se vincula necesariamente a los procesos de generación de nuevo conocimiento. No obstante, estos servicios, que pueden aparecer en otros tipos de bibliotecas, adquieren en las bibliotecas universitarias un mayor valor, especialmente durante los procesos 
de investigación realizados por los docentes, los estudiantes y otros miembros de la comunidad universitaria.

A fin de avanzar en la conceptualización de los servicios de apoyo a la investigación en las bibliotecas académicas, es preciso determinar las categorías o bloques en los que estos se desarrollan. En la literatura científica se verifica que no existe una sistematización de la oferta de servicios. Identificar un único modelo de catálogo de servicios de soporte a la investigación es complejo por la dispersión de la información y por la diversidad de prestaciones. Partiendo del análisis de sitios webs (Fernández Marcial, Costa y González-Solar, 2016) y de los trabajos de diversos autores que describen o citan distintos servicios (Keller, 2015, Fister 2015b; Anglada 2012; González-Fernández-Villavicencio 2015b; Cox y Pinfield 2014; ACRL Research Planning and Review Committee, 2015; Brewerton 2011; Camón 2012; Pinto Molina et al., 2008; Research Information Network, 2010; Tovar Sanz, 2015) es posible identificar los siguientes:

- Servicios orientados a apoyar el proceso de creación y construcción del conocimiento: incluye aquel conjunto de servicios centrados en apoyar el proceso de creación y construcción del conocimiento. En este concepto se encuadran tanto la renovación del servicio de referencia, que adopta una perspectiva más amplia sobre la información y un modelo más flexible, como la gestión de los datos de investigación, que incluye un complejo conjunto de procesos que abarcan el ciclo completo de vida de los datos.

- Servicios de apoyo a gestión de la identidad: a modo de consultoría en las actuaciones de los investigadores para el establecimiento de su identidad digital y fortalecimiento de su reputación a través de su presencia en redes y sistemas especializados. Por su especial significación, destaca el 
papel de la biblioteca frente a los sistemas de información científica (CRIS) utilizados para el control y la preservación de los resultados de investigación.

- Servicios de apoyo a la publicación y la evaluación: que comprenden tanto el refuerzo en la toma de decisiones de los investigadores en cuanto a la publicación de los resultados de investigación en unas condiciones óptimas de visibilidad e impacto, incluyendo las cuestiones relacionadas con el acceso abierto; como su evaluación, incidiendo tanto en lo referido a la mejora en la obtención de indicios de calidad, como en el papel de los bibliotecarios como expertos en bibliometría y cienciometría.

\subsection{Servicios orientados a apoyar el proceso de creación y construcción del conocimiento}

\subsubsection{Servicios de referencia}

Los servicios de referencia son un claro ejemplo de servicios proactivos. Esto se hace patente en el cambio de denominación de Servicios de Referencia (Reference Services) a, más habitualmente, Servicios de Información (Information Services) (Corrall et al., 2013). Este cambio no es un simple cuestión semántica, subyace una visibilización de algo más profundo, una nueva actitud frente a las necesidades cambiantes de los usuarios; la biblioteca avanza desde su papel de "intermediaria entre lo publicado y lo que necesitaba la comunidad universitaria" a ser "intérprete del anárquico mundo de información electrónica" (Moscoso, 2003, p. 9).

La búsqueda de información se ha simplificado gracias a las facilidades que ofrece la red y al desarrollo de interfaces amigables e intuitivas; pese a ello, el usuario, hoy día, se enfrenta a un caos informativo que es incapaz de interpretar en la mayor parte 
de las ocasiones. El aumento de la complejidad en las fuentes y en los formatos, así como el exceso de información en internet y la necesidad de un buen filtrado son las causas de un cierto "renacimiento" de este servicio, en el que se requiere que los bibliotecarios se adapten cada día más a las novedades tecnológicas y a preguntas más complejas por parte de sus usuarios (Meyer, Forbes, y Bowers, 2010).

A pesar de lo antes expuesto, parece que las consultas de referencia están decreciendo (Sharman, 2014) por lo que plantean nuevas propuestas. Las dos tendencias principales observadas en la bibliografía son, por una parte, la referencia multimodal que utiliza varios canales, y los servicios personalizados y deslocalizados. Sharman (2014, p. 188) propone "liberar los bibliotecarios para que, de forma proactiva, abandonen la comodidad de la biblioteca y del mostrador de referencia y vayan al encuentro de sus usuarios ofreciendo una ayuda personalizada" planteando un modelo de la referencia en movilidad (roving librarian) en una clara intencionalidad hacia el acercamiento a los usuarios. En la misma línea está el roaming reference service de McCabe y MacDonald (2011, p. 2) descrito como "servicios prestados de una manera no tradicional: itinerantes, de puesto avanzado, fuera de las instalaciones y en los puntos en que son necesarios. En esencia, es todo aquello que ocurre fuera de los confines del mostrador de referencia".

Un servicio como este precisa de una fuerte planificación (ya que se presta fuera o dentro de la biblioteca, en puntos indicados y con horarios concretos) y personal altamente cualificado. Se ha detectado que una mayor complejidad en las consultas puede crear alianzas más estrechas entre los bibliotecarios y los investigadores (Alexander et al., 2011). En este nuevo panorama surgen tres perfiles bibliotecarios de interés, el subject librarian, el liaison librarian y el embedded librarian.

El subject librarian o bibliotecario temático es aquel que posee "conocimientos especiales en, y la responsabilidad sobre, un tema 
o temas en particular" (Feather y Sturges, 2003, p. 624) Aunque habitualmente aparece bajo el nombre subject librarian también se conoce como bibliographer y research librarian. Su característica principal es, por lo tanto, el conocimiento específico en determinadas áreas temáticas, lo que conlleva múltiples funciones. Estas pueden diferir dependiendo de la institución, pero siempre bajo la idea de es un especialista en las principales fuentes de información de un tema y que su labor no se limita al apoyo a los investigadores aunque, en el reparto tradicional de roles de la biblioteca universitaria, sería la persona más adecuada.

Este modelo, conocido desde los años 50, ha evolucionado por múltiples vías, siendo una de ellas el bibliotecario integrado en la investigación (research group librarian o embedded librarian). Los pilares fundamentales de este perfil son la deslocalización, la colaboración y la profesionalización de los bibliotecarios en ayuda de los procesos de creación de nuevo conocimiento. Dewey (2004, p. 6) los describe como "una integración más completa de un grupo en el otro en la medida en que, al buscar la integración está experimentando y observando, tanto como le es posible, la vida cotidiana del grupo primario".

Igualmente, el bibliotecario de enlace o liaison librarian constituye una evolución, una variación, en el peso relativo de funciones y competencias basada en el rol del bibliotecario temático; se ha pasado de poner el énfasis en el conocimiento y la experiencia en los recursos de un dominio particular, a dar prioridad a las relaciones con los usuarios y a la promoción del trabajo en las bibliotecas entre los usuarios potenciales (Cooke et al., 2011). Su labor de enlace se entiende como "una actividad formal y estructurada en la cual el personal bibliotecario sistemáticamente contacta con el personal docente e investigador, para estudiar estrategias de soporte directo a sus necesidades como docentes y a las de sus estudiantes. Esta actividad formal se distingue de 
los contactos ocasionales que son habituales entre bibliotecarios y PDI" (Rodwell y Fairbairn, 2008, p. 117, citando a Miller, 1977).

\subsubsection{Servicios de gestión de datos de investigación}

El concepto de e-ciencia ha impactado en los últimos años en el entorno de las bibliotecas académicas, muchas veces amalgamado con el de ciencia abierta. La e-ciencia ha sido definida por como "una ciencia de uso intensivo de datos y relativamente nueva que, por lo general, se lleva a cabo a través de capacidades de computación en grid para generar y analizar conjuntos de datos extremadamente grandes" (Diekema, Wesolek y Walters, 2014, p. 323). Se observan como rasgos característicos el gran volumen de datos manejado y de investigadores, junto con un modelo de organización del trabajo colaborativo y distribuido.

Los datos son parte de la propia comunicación científica, que no se limita a la publicación de textos. Los bibliotecarios deben contribuir en su gestión para hacerlos más accesibles. Los datos se pueden clasificar en múltiples tipologias que pueden sistematizarse, en función de su obtención o de la metodología aplicada, como datos observacionales, experimentales computacionales y de simulación (Melero y Hernández-San-Miguel, 2014).

Los datos de investigación son, además de un valioso método de verificación de la ciencia, un potente recurso que puede aprovecharse de múltiples formas evitando el coste de producirlos de nuevo. Para que esto sea posible los datos deben estar disponibles y adoptar formas que favorezcan su reutilización, por este motivo junto a las numerosas pautas y regulaciones ${ }^{2}$ se ha normalizado

2 Sin ánimo de exhaustividad se pueden citar, por ejemplo: Alliance of German Science Organisations, 2010; Comisión Europea, 2016a; OECD, 2007, Research Councils UK, 2011, 2015; Research Information Network, 2008 
la exigencia de planes de gestión de datos como requisito previo a la financiación (con el ejemplo claro del programa piloto integrado en Horizonte 2020).

Las universidades, en cuanto que grandes proveedores de datos de investigación, comienzan a diseñar servicios concretos de soporte o research data services (RDS), convirtiéndose la gestión de datos en una prioridad estratégica para ellas (Cox y Pinfield, 2014). Numerosos autores se muestran partidarios de que la biblioteca se ocupe de una buena parte de estas tareas (Antell, Foote, Turner y Shults, 2014; Corrall et al., 2013; Cox y Pinfield, 2014; Diekema et al., 2014). De hecho, ya desde 2012 en los informes de ACRL se señalaba como una tendencia la curación de datos de investigación (ACRL Research Planning and Review Committee, 2012; 2014; 2018). El reciente informe Environmental Scan (ACRL Research Planning and Review Committee, 2017, p. 21) indica que "las bibliotecas deben hacer que los datos sean abiertos, localizables y usables".

A partir de lo antes expuesto surge una interrogante ¿qué papel puede ejercer la biblioteca en los procesos de gestión de datos? Se perfila como respuesta la necesidad de un planteamiento integral en el que la biblioteca va mucho más allá de las funciones de archivo y asume diversas finciones del ciclo de vida de los datos (Figura 2). Así se posicionan por ejemplo el LERU Research Data Working Group (2013) o LIBER E-Science working group (2012).

No obstante, hasta el momento no todas estas tareas estan recibido la misma atención. Hasta el momento las bibliotecas se han centrado en el análisis y tratamiento de los datos volcados en repositorios; mientras que otras se centran en la presentatión de microdatos en formatos múltiples, la catalogación y la preservación o la colaboración con investigadores en la creación, limpieza y publicación de datos en repositorios, se encuentran menos avanzadas (Martínez-Uribe y Fernández, 2015). 
Figura 2: Las bibliotecas en el ciclo de vida de los datos.

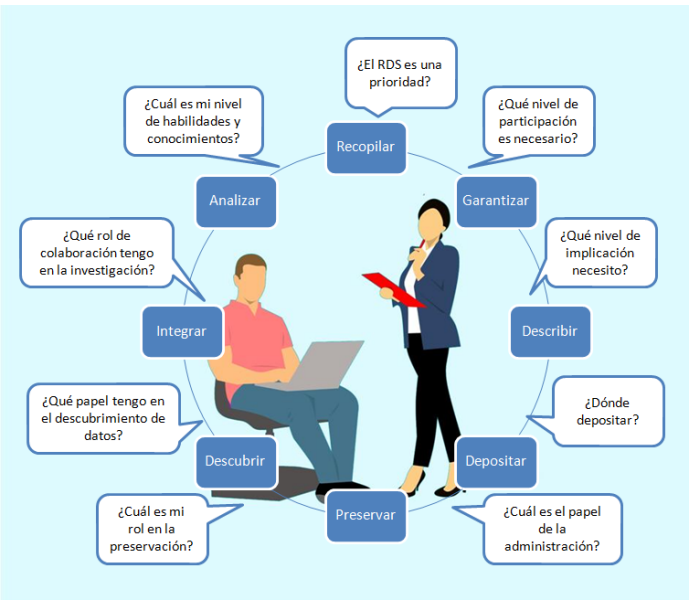

Fuente: Adaptado de Tenopir, C., Birch, B., y Allard, S. (2012, p. 12).

En general se constata que esta función no está plenamente asumida por las bibliotecas a causa de múltiples motivos como: la falta de claridad en los papeles que deben ejercer cada uno de los implicados, incluyendo a investigadores y bibliotecarios (Corrall et al., 2013); las agencias de financiación (Antell et al., 2014); las dificultades técnicas consustanciales a este tipo de servicios de gran complejidad (Mitchell, 2013); o la necesidad de que la biblioteca demuestre, a la universidad y a cada investigador, que tiene la capacidad de ofrecer las soluciones adecuadas en gestión de datos. Para afrontar este último aspecto clave, Gabridge (2009) recomienda un modelo en dos frentes: por una parte, la creación de sistemas de colaboración y aprovechamiento de sinergias entre la biblioteca y otros servicios universitarios; y por otra, el desarrollo de servicios de datos cré́bles y valorados, combinando los esfuerzos de los distintos perfiles bibliotecarios.

En este contexto altamente especializado aparece la figura del bibliotecario de datos (data librarían o databrarian), como un 
perfil idóneo para asumir estas nuevas funciones (ACRL Research Planning and Review Committee, 2014; Antell et al., 2014; Cox y Pinfield, 2014; Martínez-Uribe y Fernández, 2015). Martínez-Uribe y Fernández (2015) describen entre sus cometidos el velar por la calidad de los datos desde el momento de su creación mediante la formación de los investigadores y la promoción de métodos adecuados para su reutilización futura; desarrollar infraestructuras que permitan almacenar, descubrir, compartir y publicar datos, incluyendo los repositorios; participar y apoyar en la elaboración de políticas institucionales sobre gestión de datos; y guiar y liderar la creación y gestión de datos y la preparación y mantenimiento de los planes de gestión.

\subsection{Servicios de apoyo a gestión de la identidad}

\subsubsection{Servicio de apoyo a la gestión de la identidad y reputación digital}

La globalización de la ciencia hace cada vez más difícil llevar a cabo la identificación unívoca e inequívoca de los investigadores en base a su nombre. En el entorno digital esta complejidad aumenta y, sin embargo, definir identidad científica pasa por el concepto de identidad digital, entendida como "el esfuerzo consciente que realiza el investigador por ser identificado y reconocido en un contexto digital, distinguiéndose del conjunto de investigadores a través de la normalización, mediando el uso de identificadores, y la disponibilidad de resultados de investigación en redes y plataformas de diversa naturaleza" (Fernández-Marcial y González-Solar, 2015, p. 657).

Los sistemas relacionados con la identidad digital actúan en dos ejes, la desambiguación y la visibilidad de los resultados de investigación. La desambiguación se desarrolla en dos vertientes, la primera es la diferenciación de los autores con nombres simila- 
res y la identificación de un nombre independientemente de cómo este haya sido formateado. La segunda, especialmente importante en tiempos de la e-ciencia, pasa por la asignación de roles claros a cada uno de los participantes en la investigación, más allá de lo que permiten las normas que asocian la posición de las firmas en la publicación con el nivel de participación en la misma.

Los sistemas relacionados con la identidad digital han sido clasificados de múltiples formas. El OCLC Research Registering Researchers in Authority Files Task Group (2014) propone una de las más completas incluyendo diez categorías, entre las que se destacan: plataformas de autoridades (authority hubs) como ResearcherID o VIAF; plataformas de identificadores (ID bubs) como ORCID o ISNI; sistemas de gestión de referencias (reference management systems) como Mendeley; plataformas de investigación y colaboración (research and collaboration hubs) como nanoHUB; sistemas de perfiles de investigadores (researcher profile systems) como Google Scholar, LinkedIn o ResearchGate; sistemas de identificación temáticos (subject author ID systems) como AuthorClaim; y repositorios temáticos (subject repositories) como arXiv o E-Lis.

En los últimos años se han presentado diversos estudios analizando la presencia de investigadores en estos sistemas, elemento de gran importancia para el trabajo bibliotecario. Se objetiviza un desequilibrio en la representación de las distintas disciplinas en cada sistema, con una mayor presencia de investigadores de las áreas de Ciencias Sociales y Humanidades en Academia.edu, de Ciencias Naturales y Ciencias de la Salud en ResearchGate y de Informática en Google Scholar Citations (Nández y Borrego, 2013; Jordan, 2014; Thelwall y Kousha, 2014, 2017; Ortega y Aguillo, 2012; FernándezMarcial y González-Solar, 2015; Ortega, 2015).

En este nuevo contexto, la noción de reputación científica entendida como "el prestigio de un investigador obtenido gracias a la calidad e impacto de sus resultados de investigación" (Fernández 
Marcial y González-Solar, 2015, p. 657) se vincula directamente con la noción de identidad digital. Así, es posible hablar de reputación digital, online o e-reputación y de reputación offline. Se observa, de hecho, que puntualmente existe confusión entre ambos términos (como se evidencia en Nicholas et al., 2015). Es preciso matizar que, pese a estar estrechamente relacionados, la identidad digital se configura como un camino para obtener el reconocimiento y, por tanto, no son ideas asimilables.

La reputación científica se puede desarrollar por dos vías, la de los investigadores y la institucional. La evaluación de la reputación de las instituciones está, hoy día, ligada sustancialmente a los resultados en los rankings. En la composición de sus indicadores se ha observado que esta reputación institucional depende directamente de la de sus investigadores e incluso se podría hablar de que es una sumatoria de la reputación de estos. En ambos casos es un aspecto crítico de desarrollo (MacColl, 2010) pero, dada esta relación, es posible afirmar que actuando sobre la reputación de los investigadores se está trabajando sobre la reputación de sus instituciones.

Las posibilidades de actuación de la biblioteca son amplias incluyendo la posición de facilitadora, puede informar a los usuarios de la disponibilidad de estos medios y facilitar su acceso; de formadora mediante la realización de talleres y cursos o elaborando material autoformativo (alfabetización científica); de asesoramiento personalizado; o actuando a través de los departamentos a modo de bibliotecarios integrados. Otra de las líneas de trabajo será la integración de estos sistemas externos, con los propios de la biblioteca; por ejemplo, con la identificación de los autores en el repositorio institucional y en el catálogo a través de ORCID (González-Solar, 2016).

Se perfila la asunción de un papel activo, pero con ciertos límites y basado en la responsabilidad compartida. Así, "la biblioteca, en su papel mediador, puede desencadenar los procesos de identidad y 
reputación digital que deben ser continuados por el investigador. En otras palabras, la biblioteca puede crear un perfil en ResearchGate pero no suplantar la intervención del investigador en los foros, en el intercambio de información y tampoco tiene capacidad para actualizar la información de toda una comunidad" (Fernández-Marcial y González-Solar, 2015, p. 663).

\subsubsection{Servicio a la gestión de currículos}

Desde el punto de vista de las universidades, la información sobre la actividad investigadora cuenta con numerosas facetas incluyendo gestión del personal y de la financiación, pero también la conservación de la producción científica institucional o el control de los resultados. Los nuevos sistemas de información científica (Current Research Information Systems -CRIS-; Research Information Management -RIM- o Research Information Systems -RIS-) aportan una visión integradora de estas facetas de forma que son capaces de "gestionar toda la información relevante de la investigación, comenzando por las posibilidades de financiación, pasando por la etapa de desarrollo y la presentación de propuestas, continuando con las propuestas que logran éxito y se convierten en proyectos activos que deben gestionarse hasta su finalización - una etapa en que se generan resultados, muchos de los cuales son o publicaciones o algún otro producto de la actividad de investigación terminada" (Joint, 2008, p. 571).

Entre los beneficios de los CRIS destacan su interoperabilidad, basada en el uso de Common European Research Information Format (CERIF); sus utilidades a nivel bibliométrico, al permitir reutilizar los datos en convocatorias; incluir resultados de difícil control como libros; y facilitar la elaboración de memorias científicas (Torres-Salinas y Cabezas-Clavijo, 2011). Además, permiten evaluar las oportunidades de financiación; evitar la duplicidad 
de las actividades de investigación; analizar las tendencias; enlazar con el texto completo; identificar nuevos mercados para los productos de la investigación; facilitan la realización del CV del investigador y generan productos como los informes de gestión y los informes a los financiadores (Grupo de Repositorios de REBIUN, 2013).

Los principales problemas que plantean tienen que ver con la consistencia de los datos introducidos por los investigadores o de forma automatizada. El papel de garantes de la validez de los datos bibliográficos integrados en los CRIS está empezando a ser asumido por los propios bibliotecarios (Torres-Salinas y CabezasClavijo, 2011). La biblioteca puede, además, favorecer las sinergias con sus repositorios. Estos tipos de interconexión se observan en el sistema nacional holandés NARCIS (National Academic Research and Collaborations Information System) o el noruego CRIStin o en sistemas mantenidos por universidades concretas como la University of St Andrews que conecta el CRIS Pure con su repositorio Research@StAndrews.

\subsection{Servicios de apoyo a la publicación y la evaluación}

\subsubsection{Servicio de apoyo a la publicación científica, acceso abierto y aumento de la visibilidad}

Las bibliotecas académicas están profundamente implicadas en los procesos de comunicación científica, como muestra la encuesta de Radom, Feltner-Reichert y Stringer-Stanback (2012) según la cual un $93 \%$ de bibliotecas prestan algún servicio en áreas relacionadas con la comunicación y la edición. Coexisten modelos de carácter centralizado, como la Harvard Library's Office of Scholarly Communication o la Office of Scholarly Publishing, Licensing, and Copyright (OSPLC) de las MIT Libraries; junto con otros distribuidos 
como en las Purdue Libraries u Oxford Libraries (Marcum, Schonfeld y Thomas, 2015).

Las bibliotecas universitarias tienen un amplio conocimiento sobre el acceso abierto, sobre las licencias y derechos de autor, experiencia en bibliometría y en la aplicación de indicadores de calidad para la evaluación de la investigación, así como acceso a un amplio conjunto de recursos y herramientas (Zhao, 2014) a la vez que existe un vasto corpus que permite conocer los hábitos de los investigadores y su relación con los servicios bibliotecarios (Hansson y Johannesson, 2013). Todo ello posiciona ventajosamente a la biblioteca académica que puede definir su lugar al respecto.

Puede ser un agente activo en el área de las publicaciones con el alojamiento de revistas y actas de congresos, en el soporte a las publicaciones de alumnos, en alianza (e incluso fusión) con las editoriales universitarias, apoyando la publicación en revistas de acceso abierto o, incluso, fundando nuevas editoriales académicas (Fister, 2015a). El ACRL Research Planning and Review Committee (2013) indica al respecto que "las bibliotecas académicas deben experimentar con nuevos modelos de publicación, para la creación de contenido y de recursos, modelos que promueven el proceso de comunicación científica" y "la administración de la biblioteca debe explorar las oportunidades para desarrollar y difundir la producción académica digital, incluyendo, pero no limitado a, las asociaciones con sus editoriales" (p. 8-9).

La biblioteca puede trabajar en estrategias de mejora de la visibilidad de los resultados científicos. Estas están claramente establecidas para algunas disciplinas, pero en otras como las Humanidades y Ciencias Sociales son casi desconocidas (Alonso Arévalo, 2014). Los buenos resultados de la aplicación de las tradicionales técnicas de Search Engine Optimization (SEO) han conducido al desarrollo de Academic Search Engine Optimization (ASEO), entendida como "la creación, publicación y modificación de la literatura académica 
de una manera que hace que sea más fácil para los motores de búsqueda académicos, tanto su rastreo como su indexación" (Beel, Gipp y Wilde, 2010, p. 177).

El movimiento a favor del acceso abierto (open access, OA) es una de las tendencias más influyentes en la edición científica de los últimos años. Los bibliotecarios se encuentran en una posición única al poder actuar como mediadores entre los investigadores y los editores (ACRL Research Planning and Review Committee, 2013) pudiendo ejercer múltiples papeles entre los que destacan: albergar y gestionar en repositorios institucionales los documentos científicos, difundir y educar en cuestiones relacionadas con el acceso abierto, ayudar en la financiación del proceso de publicación en revistas de OA y dar soporte al establecimiento de revistas académicas propias (campus-based) en acceso abierto (Dawson, 2014).

Uno de los primeros cometidos que tiene la biblioteca en este tema es propiciar la difusión sobre los aspectos esenciales del OA, tanto a un nivel conceptual como práctico. A este fin se han creado programas formales de comunicación académica (scholarly communication), que pueden ser asumidos por las ya citadas oficinas de comunicación académica o mediante puestos de trabajo específicos en las bibliotecas (Lapinski, Osterbur, Parker y McCray, 2012, p. 22). Dentro de esta faceta destaca la necesidad de informar sobre el impacto del OA en la citación, cuidadosamente y sin caer en triunfalismos. Los estudios realizados parecen mostrar una ventaja de citación en los documentos en acceso abierto que tiende a ser menor en disciplinas con mayor tasa de OA; como indica AlonsoArévalo (2014) "si el 100\% de los artículos estuvieran en abierto el OA no tendría ninguna ventaja competitiva" (p. 24).

El papel principal de las bibliotecas aparece como el de gestoras de los repositorios institucionales, como parte de la llamada ruta verde, que ha recibido el impulso de agencias y programas de financiación, junto con mandatos institucionales concretos para 
algunas universidades. Destaca entre todos ellos el Piloto de Acceso Abierto del Séptimo Programa Marco I+D, sustituido en 2013 por el programa Horizonte 2020, para el cual "cada beneficiario debe garantizar el libre acceso a todas las publicaciones científicas revisadas por pares en relación con sus resultados" (Comisión Europea, 2016, p. 4). De esta forma, para todas las publicaciones deben garantizarse dos aspectos: el depósito en repositorios, hayan sido o no publicadas en revistas de acceso abierto, y la accesibilidad en el acceso y el uso.

Son varios los motivos por los que los investigadores son reticentes al autoarchivo de sus publicaciones, destacando la carga de trabajo añadido que supone y las dificultades que encuentran (y que se materializan en metadatos de baja calidad) (Lapinski et al., 2014), así como, una cierta tendencia a archivar solo aquello que se considera de mayor calidad (Melero, 2008). Se plantea como solución el archivo delegado, realizado normalmente desde las bibliotecas, sin intervención directa del investigador en el proceso de envío. Pese a ciertas dudas sobre si es o no tarea de la biblioteca, todo parece apuntar a que es una oportunidad para afianzar la posición de la biblioteca en la universidad y para "llenar los repositorios de contenido" (Corrall et al., 2013, p. 639-640), con una menor inversión de tiempo por parte del investigador y una mayor calidad y porcentaje de cumplimiento (Anglada, 2012). La convivencia entre el autoarchivo y el archivo delegado, denominado archivo mixto, parece la solución óptima.

En lo relativo a la ruta dorada, el papel central se asigna a los autores como clientes de las editoriales, desplazando a las bibliotecas en su papel intermediario. No obstante, se observan áreas de intervención como la de formación ante la falta de conocimientos sobre estas revistas (ACRL Research Planning and Review Committee, 2013), la información sobre revistas y editoriales predadoras o la intervención sobre los gastos de publicación (article processing 
charge -APC-), cuestión esta última que deberá ser cuidadosamente abordada en los próximos años ante el inminente cambio en la gestión de los costes por adquisiciones.

\subsubsection{Servicio de bibliometría y cienciometría}

El análisis bibliométrico, la búsqueda de indicadores de calidad y el asesoramiento en ellos son una de las principales tendencias de actuación en bibliotecas académicas como consecuencia de los modelos actuales de evaluación de la investigación. Es de interés destacar la propuesta de Aguillo (2016) de un modelo en el que los bibliotecarios actúen como mediadores imparciales de la evaluación, concretando los currículos enviados por los investigadores en datos bibliométricos directamente evaluables por las agencias y sus expertos.

La asunción de tareas relacionadas con la bibliometría en las bibliotecas puede observarse desde los años 70 del siglo pasado (Corrall et al., 2013). Con ello se verifica la experiencia de los profesionales de la información y su conocimiento sobre los indicadores y las fuentes que los proveen; pueden ayudar satisfactoriamente a los investigadores a demostrar su contribución a la ciencia y superar los procesos de evaluación (Kear y Colbert-Lewis, 2011; Key Perspectives, 2009). Se evidencia igualmente que esta capacidad es percibida muy positivamente por los investigadores que consideran fundamental el apoyo de la biblioteca durante los procesos de acreditación, sexenios, solicitud de proyectos, etc. (Iribarren-Maestro, Grandal, Alecha, Nieva y San-Julián, 2015).

La encuesta realizada por Corrall et al. (2013) sobre los servicios bibliométricos ofrecidos por bibliotecas académicas de cuatro países anglosajones indica que la mayoría de ellas ofrece algún tipo de servicio bibliométrico, siendo los más frecuentes el de formación y el de elaboración de informes y cálculo del impacto 
de la investigación. Sin embargo, a través de los distintos informes y estudios de caso, abundantes en la literatura, se observa un panorama heterogéneo. Por ejemplo, las bibliotecas australianas están profundamente integradas en estos procesos, los bibliotecarios tienen de sí mismos una imagen de expertos y asesores en bibliometría, todos los esfuerzos de la biblioteca se agrupan bajo el epígrafe Research Impact, y existe un enfoque holístico (Keller, 2015). En cambio, la participación de las bibliotecas inglesas es mucho menor y más tardía, pese a tener una buena infraestructura para dar apoyo (Key Perspectives, 2009).

Los retos y limitaciones de estos servicios son múltiples, incluyendo la falta de confianza personal de los bibliotecarios para cuya emponderación es necesario reforzar la enseñanza de la bibliometría en los estudios sobre Ciencias de la Información (Corral et al., 2013). Aparecen dificultades asociadas a la emergencia de las altmétricas, que las bibliotecas académicas han comenzado a abordar (ACRL Research Planning and Review Committee, 2014) a través de múltiples funciones como: colaborar en su desarrollo; mostrar a los administradores universitarios su valor para la evaluación de sus investigadores (especialmente en disciplinas difícilmente evaluables con herramientas tradicionales); atemperar las expectativas de estos administradores sobre ellas evidenciando sus límites y usos adecuados; promover que los editores suministren indicadores altmétricos individuales para los autores; y seguir siendo proveedores y consultores para los investigadores (Roemer y Borchardt, 2013).

\section{3 ¿Están los usuarios y los bibliotecarios preparados para este nuevo rol de apoyo a la investigación?}

Las bibliotecas académicas se enfrentan a múltiples dificultades cuando comienzan a asumir nuevos roles que no son los que 
los usuarios y los administradores les otorgan como propios. En concreto, al arrogarse un papel más activo y nuevas competencias relacionadas con el apoyo a la investigación confrontan fundamentalmente dos riesgos: que aquellos a los que están dirigiendo sus esfuerzos no reconozcan la necesidad de estos servicios y que se considere a los bibliotecarios como los agentes adecuados (ACRL, 2007).

La investigación es una de las misiones más importantes de la universidad junto con la docencia y, en los últimos años, el cambio de paradigma en la evaluación universitaria ha propiciado que sea considerada como el elemento crítico para la construcción de la reputación institucional a través, principalmente, de los rankings. Ante ello la pregunta clave es ¿qué puede hacer la biblioteca para colaborar en el cumplimiento de esta misión? y, secundariamente, ¿cómo se podría medir esta contribución?" (Pinto Molina et al., 2008). Fister (2015a) recuerda que los bibliotecarios siempre han apoyado en la creación de nuevo conocimiento a través de actividades como la búsqueda de información, desarrollo de colecciones y elementos de gestión de la información. La aparición de los documentos electrónicos, entre otras razones, ha causado que los usuarios muchas veces observen estas tareas como de apoyo a la docencia y el aprendizaje (Corrall et al., 2013).

Ahora bien, el punto de debate se centra en la aceptación por parte de los investigadores, gestores y hasta de los propios bibliotecarios de estas nuevas funciones, que suponen un papel más activo y una verdadera imbricación en las diferentes etapas el proceso de comunicación científica. La base de este cambio estará en la cultura de los sistemas de educación superior y de la investigación de cada país o región, del modelo de biblioteca, del tamaño de la universidad, de la flexibilidad de sus estructuras, o los modos de financiación y rendición de cuentas. Keller (2015) apunta diferencias entre las bibliotecas europeas y las australianas, 
las cuales "se ven a sí mismas como socias genuinas en la investigación" (Keller, 2015, p. 75). Como consecuencia de esta mayor implicación se autodefinen como aliadas poderosas, con interés por contribuir a la investigación excelente, algo que la autora no percibe en el entorno de las bibliotecas europeas continentales.

Varias encuestas recientes han confirmado que los profesionales de las bibliotecas observan el soporte a la investigación como una de las funciones de importancia en sus bibliotecas (Brewerton, 2012; Schonfeld y Long, 2014; Wolff y Schonfeld, 2017). Los receptores de este servicio lo visualizan también de manera muy positiva como muestra la encuesta Bridging the Librarian-Faculty Gap in the Academic Library (2015) según la cual un $84 \%$ de los docentes considera el apoyo a la investigación un servicio esencial de la biblioteca, a la vez que la biblioteca en sí misma es un elemento clave en la investigación para casi un 90\% de docentes. Variando los porcentajes, este tipo de afirmaciones son consistentes con los datos obtenidos por otras encuestas como las del modelo Ithaka o los obtenidos en Gran Bretaña por el Research Support Libraries Group (2002).

Quizá el intento más sistemático por analizar estas percepciones y su evolución en el tiempo es el que realiza la consultoría Ithaka con encuestas periódicas en países anglosajones. Este modelo facilita la comparación entre territorios y años. Así, Borrego (2014), al adaptar el modelo a Cataluña evidencia patrones compartidos $y$, concretamente, que los investigadores perciben que la función principal de las bibliotecas es pagar por los recursos de información (Figura 3). Este consenso es un indicio de que la percepción del valor de la biblioteca se basa en una estructura tradicional del trabajo bibliotecario, centrado en el desarrollo de las colecciones y con una menor relevancia de los servicios. Este perfil de la biblioteca como suministradora de recursos de elevado coste, puede ser uno de los motivos por el que otras encuestas muestran que, para 
los investigadores, la financiación de la biblioteca debería ser una cuestión prioritaria (Brown y Swan, 2007).

Figura 3: Importancia de las funciones de la BU para los investigadores

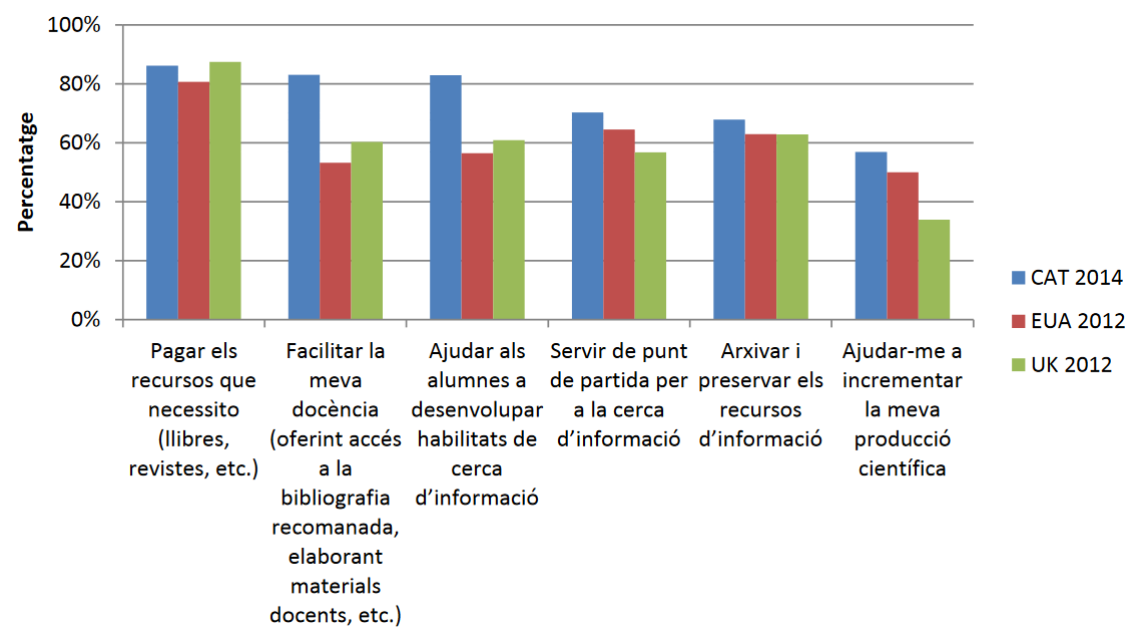

Fuente: adaptado de Borrego (2014, p. 34)

Por lo tanto, la biblioteca tiene, para los investigadores, una posición central en sus procesos de descubrimiento y creación del conocimiento. No obstante, se ha evidenciado también que la comodidad y la rapidez son elementos esenciales para ellos y que tienden a desarrollar una cultura de trabajo fundamentalmente autosuficiente. En este sentido, perciben la biblioteca como "difícil de utilizar" o como "último recurso" frente a los buscadores (Google) o a los colegas, que ofrecen un mayor grado de "conveniencia" (ACRL Research Planning and Review Committee, 2012). Sin embargo, valoran positivamente la existencia de servicios de apoyo a la investigación, especialmente si estos son puntos de consulta que están ahí cuando los necesitan y no interfieren en el desarrollo de sus actividades, ni con el trabajo creativo del proceso de investigación (Research Information Network, 2010). Servicios just in time o de 
bibliotecarios embebidos podrían ser la solución a este escenario (ACRL Research Planning and Review Committee, 2012).

Desde el punto de vista de los investigadores es, por lo tanto, fundamental la comodidad a la hora de llevar a cabo sus actividades y en las situaciones diarias de búsqueda de información. Pinto Molina, Fernández-Marcial y Gómez-Camarero (2010), en un estudio realizado entre 2003 y 2006 sobre profesores e investigadores del área de Ciencias y Tecnología de siete universidades españolas, revelan patrones de interés en su relación con la biblioteca:

- Respecto a las principales tendencias, el estudio evidencia cierta reticencia a que los bibliotecarios adopten una posición más activa como mediadores de la información mientras que los valoriza en servicios más tradicionales. Esto implica una concepción tradicionalista de la biblioteca y reservas a la hora de otorgarles (o delegar en ellos) ciertas funciones.

- Se detecta una posible confusión respecto a los conocimientos y funciones de los bibliotecarios, ya que las respuestas recogen, por una parte, la necesidad de formación en sistemas de recuperación de la información y, por otra, la preferencia de los docentes por el uso autónomo de las mismas.

- Aunque el estudio evita preguntar directamente sobre ello, las respuestas de los usuarios dejan entrever una serie de tareas en las que el nuevo perfil bibliotecario podría participar: guía sobre recursos especializados, ayuda en la elaboración de recursos electrónicos para la enseñanza y la investigación, estudio periódico de las necesidades de información de los profesores, información sobre proyectos y difusión selectiva de la información.

En 2007, ante la previsión de los cambios generados por la expansión de la e-ciencia y el acceso abierto, la encuesta 
del Research Information Network (RIN) preguntaba a los investigadores en qué papeles, de 13 propuestos, veían a los bibliotecarios tras un periodo de cinco años (Brown y Swan, 2007). Pese a algunas diferencias entre disciplinas, se observa cierta homogeneidad en las respuestas que apuntan a un rol principal como custodias de la información (un 75\%), en una concepción tradicional de las funciones bibliotecarias. No obstante, la segunda función con mayor acuerdo es la de gestores de repositorios, seguida de la de administrador que trabaja con presupuestos y provee servicios de información. No hay consenso sobre el papel como expertos temáticos y, especialmente, los investigadores de Ciencias Físicas y de la Vida muestran mayor reticencia. Otras funciones con un número relevante de respuestas son las de alfabetizador informacional, gestor de datasets y experto en nuevas tecnologías. La posición de los bibliotecarios sobre esta misma cuestión es sensiblemente distinta, ya que se ven fundamentalmente como alfabetizadores informacionales, también conceden gran importancia a las funciones de custodios de información y expertos temáticos y, sin embargo, relegan las de administrador de repositorios al quinto lugar. Esta percepción diversa parece tener que ver con la complejidad de las relaciones entre ambos colectivos.

Como se ha indicado anteriormente son los elementos culturales los que sirven de sustrato a este nuevo rol de las bibliotecas en el apoyo a la investigación. Siendo su base la relación entre bibliotecarios y docentes. La descripción y análisis de las relaciones entre bibliotecarios y profesores han estado presentes en la literatura al menos desde los años 80 (Kotter, 1999); destacando las aportaciones de los bibliotecarios (Christiansen, Stombler y Thaxton, 2004; Phelps y Campbell, 2012). La razón es que son fundamentales para garantizar la continuidad de las bibliotecas universitarias; como afirma Kotter (1999, p. 301) "las buenas 
relaciones entre bibliotecarios y profesores son una necesidad, no un lujo. La clave del éxito es la cooperación, no el conflicto".

Una buena relación entre investigadores/docentes y bibliotecarios es, por lo tanto, de importancia estratégica para la biblioteca (Anthony, 2010; Frank, Raschke, Wood y Yang, 2001) desde el punto de vista de que estos pueden tener influencia, junto con los administradores de la universidad, en la obtención de una adecuada financiación y recursos para la biblioteca. De hecho, la revisión de la literatura lleva a colegir que, una mejora en las relaciones bibliotecarios-profesores, basadas en el compañerismo y en un cierto consenso sobre los objetivos de la institución, se traduciría en un mayor apoyo para que la biblioteca se enfrente a sus nuevos desafíos de modo creativo. Esta mejora podría materializarse en un mayor aprovechamiento de los recursos de la biblioteca por los profesores y, este a su vez, en el soporte administrativo a la biblioteca; una mayor implicación del profesorado en actividades como la gestión de la colección o la formación de usuarios; y la posibilidad para los bibliotecarios de participar en las actividades investigadoras del profesorado ofreciendo un servicio proactivo (Kotter, 1999). Por todo ello es crucial demostrar el valor de la biblioteca a estos grupos a fin de que la biblioteca pueda posicionarse dentro de la estructura de la universidad.

La cuestión que se plantea es ¿cómo mejorar estas relaciones para maximizar su potencial? Donham y Green (2004) estudian la colaboración de ambos colectivos proponiendo la idea de bibliotecario como consultor en la que la cooperación "tiene varias características importantes: objetivos mutuos, el respeto mutuo, la planificación anticipada, y contribuciones sustantivas por ambas partes para el diseño de los objetivos y actividades instruccionales para luego llevarlos a cabo" (p. 314). Varios autores manifiestan dudas sobre el modelo de cooperación en cuanto que puede ocultar situaciones se subordinación (Meulemans y Carr, 2013) que 
Frank et al. (2001) intentan evitar, con su modelo de consultant, afirmando:

\begin{abstract}
"cuando los bibliotecarios enfocan su trabajo con los académicos como una asociación existen importantes implicaciones. En lugar de una atmósfera de 'cooperación', donde una de las partes tiene sus propios objetivos y ambos cooperan con el fin de lograr estos objetivos, se plantea una atmósfera de 'colaboración'. Cada persona trae sus propios objetivos de la asociación, pero juntos definen los objetivos comunes y trabajan para alcanzar dichos objetivos compartidos" (p. 92).
\end{abstract}

La gran dificultad estriba en conocer y analizar las relaciones entre ambos colectivos como paso inicial para su mejora y aprovechamiento. En la abundante literatura no existe consenso sobre la naturaleza real de estas relaciones que, en realidad, han sido descritas de la forma más variopinta, yendo desde la descripción como "enemigos" que hace Logsdon (1970 en su artículo The librarian and the scholar: eternal enemies), hasta la situación armónica y de buena fe que presenta Scherer (1970).

Especialmente interesante es el análisis de Christiansen et al. (2004) quienes describen una desconexión asimétrica entre bibliotecarios y profesores, que están distanciados pese a ser mutuamente dependientes y necesarios para el éxito de la universidad. Los autores se sorprenden de este limitado contacto considerando el potencial para la interacción, colaboración e intereses compartidos, además del impacto que tiene el trabajo de los unos en el de los otros. Esta idea de desconexión está también presente en la encuesta Bridging the Librarian-Faculty Gap in the Academic Library (2015) en la que se demuestran prioridades muy dispares, siendo, por ejemplo, el apoyo a la investigación un servicio considerado fundamental por los docentes y secundario para los bibliotecarios. 
La explicación a esta desconexión es de diversa naturaleza. En la bibliografía aparecen múltiples posibles causas como:

- que la biblioteca se ha estado orientando hacia sí misma (looking inward) y no hacia sus usuarios Donham y Green (2004);

- la frecuente imagen estereotipada de los bibliotecarios (Church, 2003);

- muchos de los cambios que han sufrido las bibliotecas universitarias en los últimos años han tenido como target a los estudiantes y han afectado indirectamente al profesorado, quienes pueden haberlo percibido erróneamente (Anthony, 2010);

- las diferencias de estatus (Church, 2003);

- puntos de vista diferentes sobre cuál debe ser el papel de cada grupo en cuanto a la gestión de la propia biblioteca (Biggs, 1981);

- el modo de trabajo autónomo característico de los investigadores (Hardesty, 1995);

- que los docentes no visualicen a los bibliotecarios como un apoyo a la hora de resolver problemas y que incluso puedan llegar a avergonzarse de hacerlo (Kotter, 1999).

Conviene analizar el impacto de las cuestiones de status puesto que afectan presupuestariamente a la biblioteca (Anthony, 2010). Los académicos perciben una diferencia de estatus entre los directores de biblioteca y los bibliotecarios debido a que en el siglo XIX y principios del XX los directores de biblioteca provenían del profesorado (Biggs, 1981).

Las distintas subculturas organizacionales de bibliotecarios y profesorado (incluyendo cuestiones sobre el modo de organización de la institución, como la participación en comités, la localización física 
de los campus, etc. que no están necesariamente relacionadas con el status social) tienen influencia en esta desconexión (Christiansen et al., 2004). Blackburn (1968, citado por Church, 2003) refiere las diferencias demográficas de género (entre bibliotecarios, mayoritariamente mujeres, e investigadores, mayoritariamente hombres) como parte del problema junto con patrones de comportamiento específicos de los bibliotecarios a diferencia de los investigadores.

Otros obstáculos, quizá más fácilmente superables a través de planteamientos flexibles de servicio, como los bibliotecarios integrados o los servicios de referencia en movilidad, son las barreras físicas o la falta de espacios compartidos entre ambos colectivos, algo que se ha agudizado con la llegada de los recursos electrónicos (Anthony, 2010).

El nivel de relación es uno de los factores de mayor interés ya que es controlable y puede gestionarse hacia la mejora. En general, la sucesión de interacciones entre ambos colectivos conlleva una mejora en la percepción del valor de la biblioteca (Church, 2003; Ducas y Michaud-Oystryk, 2003) y es fundamental cuidar estas relaciones desde el principio, puesto que:

\begin{abstract}
"la colaboración entre el bibliotecario y el nuevo docente tiene su propia dinámica particular, ya que las primeras impresiones pueden dar lugar a percepciones y patrones de interacción a largo plazo. Por otra parte, los nuevos profesores tienen diferentes expectativas y la experiencia que sus colegas mayores, y esto repercute en su acercamiento a la investigación y la enseñanza y, en consecuencia, sobre su relación con la biblioteca” (Horava, 2005, p. 482).
\end{abstract}

A pesar de que los tensiones y problemas que pueden existir entre ambos colectivos son de difícil solución e incluso estructurales, por lo que no podrán ser eliminadas por completo (Kotter, 1999), se han planteado diversas estrategias para su mejora. Amante y Extremeño 
(2012) indican que los bibliotecarios "deben desarrollar un papel más dinámico y activo en la misión educativa de las universidades, con un liderazgo más agresivo y conocer mejor las cuestiones relativas a la educación, para poder estar tan comprometidos con ella como con la biblioteconomía" (p. 301).

El análisis de la literatura recoge múltiples posibles estrategias para llevarlo a cabo. Algunas tienen una aplicación más sencilla en bibliotecas de tradición anglosajona que en las de la Europa continental ${ }^{3}$, entre las restantes cabe destacar:

- La mejora de los servicios o la creación de otros nuevos mejor adaptados a las necesidades de los usuarios. Específicamente los orientados a ofrecer servicios de alto valor añadido y personalizados (Amante y Extremeño, 2012; Ducas y MichaudOystryk, 2003; Frank et al., 2001; Kotter, 1999).

- Una mayor implicación de los docentes en actividades de la biblioteca, como la gestión de la colección, y una mayor participación de los bibliotecarios en actividades de docencia, como el diseño instruccional o la formación de usuarios estudiantes. La colaboración aumenta la visibilidad de las capacidades de cada colectivo (Anthony. 2010; Kotter, 1999).

- La promoción y valorización de los servicios de la biblioteca entre los docentes e investigadores (building advocacy) a través de medios que abarquen tanto los más tradicionales como la creación de programas de bibliotecarios de enlace (Anthony. 2010; Kotter, 1999).

- Potenciación del compañerismo (collegiality) que se construye rompiendo las brechas sociales y organizacionales entre ambos grupos y creando relaciones personales (Anthony, 2010).

3 Por ejemplo las actividades honoring de faculty, consistentes en ofrecer honores, recepciones y distinguir a los profesores que se hayan destacado (Kotter, 1999). 
- El refuerzo del intercambio y el diálogo entre ambos colectivos reforzando además los canales de comunicación y garantizando que cualquier recurso o servicio provisto por la biblioteca sea reconocido como tal a través de técnicas de branding (Brown y Swan, 2007).

\section{Conclusiones}

La investigación es un factor clave para el crecimiento y desarrollo de las universidades. Este hecho no es novedoso, pero sí lo es un interés renovado en la misma. La universidad, como institución, asiste a un nuevo modelo de gestión el cual, a su vez, modifica la visión y valor de la investigación, que conecta de forma directa con el crecimiento y el prestigio de la universidad. La biblioteca universitaria, siempre entendida como un servicio base en el funcionamiento de la institución, de igual forma se hace eco de esta nueva visión hacia la investigación. La evidencia de la implicación de la biblioteca está en la creación de un conjunto de servicios de apoyo a la investigación. Pero esta nueva realidad va más allá.

El bibliotecario se aproxima al proceso de investigación y su trabajo no se limita a ser reactivo. Así, el catálogo de prestaciones ha avanzado, no solo en la variedad de la oferta, sino además en el aumento del grado de implicación, pues la intervención de los bibliotecarios, que es ahora más intensa y cercana al proceso de investigación. En términos generales, el avance se experimenta, no solo en la oferta de servicios con carácter unidireccional, de la biblioteca al investigador, que siempre ha existido, sino en que una verdadera contribución de la biblioteca pasa por articular servicios sustentados sobre la base de verdaderas y auténticas relaciones de colaboración. 
$Y$ he aquí donde es preciso establecer un nuevo modelo de trabajo con otros principios de funcionamiento. El bibliotecario se erige como un nuevo elemento en el proceso de investigación, parte del colegio invisible del investigador y persona de confianza para llevar a cabo tareas de perfil altamente técnico y cualificado. Para que esto sea posible no basta con proponer nuevos servicios, es necesario que docentes e investigadores sean receptivos y que asuman este rol, reconociendo con ello la capacidad y competencias de los bibliotecarios.

Se han propuesto diversos perfiles de bibliotecarios que buscan reforzar esta imagen y su posicionamiento ante problemas concretos. Son modelos que no pueden llevarse a cabo en todas las bibliotecas académicas, pero guían el proceso de adquisición de competencias y la planificación de determinadas especializaciones buscando, como siempre, la posibilidad de ofrecer un mejor servicio.

En todo caso la cuestión central es que la biblioteca y sus bibliotecarios, a través de esta panoplia de servicios y perfiles, debe potenciar los resultados de la universidad allí donde es más necesario y, en este momento concreto, la función investigadora de la universidad es el elemento crítico sobre el que se hace imprescindible para la biblioteca actuar de formas novedosas.

Se ha abordado aquí un catálogo amplio y flexible de posibles servicios especialmente adecuados al apoyo a la investigación, muchos de ellos ya se están implementado de distintas maneras y a distintos niveles en muchas bibliotecas. Paulatinamente también se han ido configurando como un conjunto de servicios con un objetivo común como es el ofrecer soporte a la investigación. A la vez se está trabajando en fortalecer las relaciones entre académicos y bibliotecarios, mostrando mejor sus habilidades, conocimientos y el potencial que tiene la colaboración. Las bibliotecas académicas avanzan en la vía de reforzar su posición como servicios a la investigación sin perder su lugar clave en la docencia. 


\section{Referencias Bibliográficas}

ACRL (2007). Changing Roles of Academic and Research Libraries. Recuperado de: http://www.ala.org/acrl/issues/value/changingroles

ACRL Research Planning and Review Committee (2012). 2012 Top ten trends in academic libraries: a review of the trends and issues affecting academic libraries in higher education. College \& Research Libraries News, 76(6), 311-320. doi: $10.5860 /$ crln. 73.6 .8773

ACRL Research Planning and Review Committee (2013). Environmental Scan 2013. Recuperado de http://www.ala.org/acrl/issues/whitepapers

ACRL Research Planning and Review Committee (2014). Top trends in academic libraries: A review of the trends and issues affecting academic libraries in higher education. College \& Research Libraries News, 75(6), 294-302. doi: 10.5860/ crln.75.6.9137

ACRL Research Planning and Review Committee (2015). Environmental Scan 2015. Recuperado de http://www.ala.org/acrl/issues/whitepapers

ACRL Research Planning and Review Committee (2017). Environmental Scan 2017. Recuperado de http://www.ala.org/acrl/issues/whitepapers

ACRL Research Planning and Review Committee (2018). Top trends in academic libraries: a review of the trends and issues affecting academic libraries in higher education. College \& Research Libraries News, 79(6), 294-302. doi: 10.5860/ crln.79.6.286

Aguillo, I. F. (2016). Informetría para bibliotecarios: descripción de su papel clave en los procesos de evaluación. El Profesional de la Información, 25(1), 5-10. doi:10.3145/epi.2016.ene.01

ALA (1989) Standards for University Libraries: Evaluation of Performance

ALA (2013). Glossary of Library and Information Science ( $4^{\circ}$ ed.). Chicago: American Library Association.

Alonso-Arévalo, J. (2014, marzo). Alfabetización en comunicación científica: acreditación, OA, redes sociales, altmetrics, bibliotecarios incrustados y gestión de la identidad digital. En: Alfabetización informacional: reflexiones y experiencias. Encuentro Nacional de Bibliotecas universitarias. Recuperado de http://hdl. handle.net/10760/22838

Amante, M. J. y Extremeño, A. I. (2012). Bibliotecarios universitarios-profesores ¿caminos convergentes? Revista Española de Documentación Científica, 35(2), 298-324. doi:10.3989/redc.2012.2.849

ANECA (2007). Informe sobre el estado de la evaluación de la calidad en las universidades españolas. Recuperado de http://www.aneca.es/Documentos-ypublicaciones/Informes-sobre-calidad-universitaria

ANECA (2013). Informe sobre el estado de la evaluación de la calidad en las universidades españolas. Recuperado de http://www.aneca.es/Documentos-ypublicaciones/Informes-sobre-calidad-universitaria

Anglada, L. (2012). Bibliotecas universitarias: cabalgando la tecnología, siguiendo al usuario. El Profesional de la información, 21(6), 553-556. doi:10.3145/epi.2012.nov.01 
Antell, K., Foote, J. B., Turner, J., y Shults, B. (2014). Dealing with data: Science librarians' participation in data management at Association of Research Libraries institutions. College \& Research Libraries, 75(4), 557-574. doi: 10.5860/crl.75.4.557

Anthony, K. (2010). Reconnecting the disconnects: library outreach to faculty as addressed in the literature. College \& Undergraduate Libraries, 17(1), 79-92. doi:10.1080/10691310903584817

ARWU (2015). The Academic Ranking of World Universities: metodologia. Recuperado de http://www.shanghairanking.com/es/ARWU-Methodology-2015.html

Barberá, S. (2006). Las consecuencias de la evaluación para el PDI: la visión institucional. En: VI foro ANECA: consecuencias de las políticas de evaluación de la docencia y la investigación del PDI (p. 7-8). Madrid: ANECA.

Beel, J., Gipp, B., y Wilde, E. (2010). Academic Search Engine Optimization (ASEO). Journal of Scholarly Publishing, 41(2), 176-190. doi:10.3138/jsp.41.2.176

Biggs, M. (1981). Sources of tension and conflict between librarians and faculty. The Journal of Higher Education, 52(2), 182-201. doi:10.2307/1981090

Borrego, Á. (2014). Comportament informatiu del professorat de les universitats catalanes: Estudi realitzada per encàrrec del Consorci de Serveis Universitaris de Catalunya (CSUC). Recuperado de http://hdl.handle.net/2072/242106

Bourg, C., Coleman, R., y Erway, R. (2009). Support for the research process: An academic library manifesto. Recuperado de http://www.oclc.org/content/dam/ research/publications/library/2009/2009-07.pdf

Brewerton, A. (2011). ' $\ldots$ and any other duties deemed necessary:' An analysis of subject librarian job descriptions. SCONUL Focus, 51, 60-67. Recuperado de http:// www.sconul.ac.uk/page/focus-51

Brewerton, A. (2012). Re-Skilling for Research: Investigating the Needs of Researchers and How Library Staff Can Best Support Them. New Review of Academic Librarianship, 18(1), 96-110. doi:10.1080/13614533.2012.665718

Bridging the Librarian-Faculty Gap in the Academic Library Survey (2015). Recuperado de http://lj.libraryjournal.com/downloads/2015-bridging-the-librarian-facultygap-in-the-academic-library

Brown, S., y Swan, A. (2007). Researchers' use of academic libraries and their services. Recuperado de http://www.rin.ac.uk/system/files/attachments/Researcherslibraries-services-report.pdf

Camón, E. (2012). La funció de suport a la recerca de les biblioteques universitàries españoles. Tesis doctoral, Universitat de Barcelona. Recuperado de http://hdl. handle.net/10803/94138

Christiansen, L., Stombler, M., y Thaxton, L. (2004). A report on librarian-faculty relations from a sociological perspective. The Journal of Academic Librarianship, 30(2), 116-121. doi:10.1016/j.acalib.2004.01.003

Church, G. M. (2003). In the eye of the beholder: How librarians have been viewed over time. En W. A Kaspar y C. R. Benefiel, (Eds.), The image and role of the librarian (p. 5-24). Binghamton: Haworth Information Press. doi:10.1300/ J120v37n78_02

Comisión Europea (2000). Hacia un espacio europeo de investigación. Recuperado de http://eur-lex.europa.eu/legal-content/ES/TXT/?uri=celex:52000DC0006 
Comisión Europea (2006). Cumplir la agenda de modernización para las universidades: educación, investigación e innovación. Recuperado de http://eur-lex.europa.eu/ legal-content/ES/TXT/?uri=URISERV:c11089

Comisión Europea (2016b). Guidelines on Open Access to Scientific Publications and Research Data in Horizon 2020. Recuperado de http://ec.europa.eu/research/ participants/data/ref/h2020/grants_manual/hi/oa_pilot/h2020-hi-oa-pilot-guide_en.pdf

Cooke, L., Norris, M., Busby, N., Page, T., Franklin, G., Gadd, E., y Young, H. (2011). Evaluating the impact of academic liaison librarians on their user community: a review and case study. New review of academic librarianship, 17(1), 5-30. doi:10.1080/13614533.2011.539096

Corrall, S., Kennan, M. A., y Afzal, W. (2013). Bibliometrics and research data management services: emerging trends in library support for research. Library trends, 61(3), 636-674. doi: 10.1353/lib.2013.0005

Cox, A. M., y Pinfield, S. (2014). Research data management and libraries: Current activities and future priorities. Journal of Librarianship and Information Science, 46(4), 299-316. doi:10.1177/0961000613492542

Dawson, D. (2014). The scholarly communications needs of faculty: An evidencebased foundation for the development of library services. Evidence Based Library and Information Practice, 9(4), 4. doi: 10.18438/b8r88c

Declaración de Lisboa (2010). Recuperado de http://www.eua.be/activities-services/ publications/eua-policy-positions.aspx

Dewey, B. I. (2004). The embedded librarian. Resource Sharing \& Information Networks, 17(1-2), 5-17. doi:10.1300/j121v17n01_02

Diekema, A. R., Wesolek, A., y Walters, C. D. (2014). The NSF/NIH effect: surveying the effect of data management requirements on faculty, sponsored programs, and institutional repositories. The Journal of Academic Librarianship, 40(3-4), 322-331. doi:10.1016/j.acalib.2014.04.010

Donham, J., y Green, C. W. (2004). Perspectives on... develop a culture of collaboration: librarian as consultant. The Journal of Academic Librarianship, 30(4), 314-321. doi:10.1016/j.acalib.2004.04.005

Ducas, A. M., y Michaud-Oystryk, N. (2003). Toward a New Enterprise: Capitalizing on the Faculty-Librarian Partnership. College \& Research Libraries, 64(1), 55-74. doi:10.5860/crl.64.1.55

Etzkowitz, H., Webster, A., Gebhardt, C., \& Terra, B. R. C. (2000). The future of the university and the university of the future: evolution of ivory tower to entrepreneurial paradigm. Research Policy, 29(2), 313-330. doi: 10.1016/s0048-7333(99)00069-4

European University Association (1988) Magna Charta Universitatum. Recuperado de http://www.magna-charta.org

Feather, J., y Sturges, P. (Eds.). (2003). International encyclopedia of information and library science ( $2^{\mathrm{a}}$ ed.) Londres: Routledge.

Fernández-Marcial, V.; Costa, L.M. y González-Solar, L. (2015). Top Universities, Top Libraries: do research services in academic libraries contribute to university output?. En: Library Leadership in a Sea of Change, 37th Annual IATUL http:// docs.lib.purdue.edu/iatul/2016/spaces/2 
Fernández Marcial, V., y González-Solar, L. (2015). Promoción de la investigación e identidad digital: el caso de la Universidade da Coruña. El Profesional de la Información, 24(5), 656-664. doi:10.3145/epi.2015.sep.14

Fernández Marcial, V., y González-Solar, L. (2017). Servicios a la investigación en la biblioteca universitaria: gestión de la identidad digital. En: Comunicação $e$ Transformações Sociais, IX Congreso da SOPCOM (Vol. 1, p. 10-23). Associação Portuguesa de Ciências da Comunicação. http://hdl.handle.net/2183/19355

Fister, B. (2015a). Librarians Supporting the Creation of New Knowledge. En N. Allen (Ed.), New roles for the road abead: essays commissioned for the ACRL's 75th anniversary (p. 100-102). Recuperado de http://www.ala.org/acrl/issues/ whitepapers

Fister, B. (2015b). Valuing Libraries. En N. Allen (Ed.), New roles for the road abead: essays commissioned for the ACRL's 75th anniversary (p. 69-71). Recuperado de la página web de la American Libraries Association: http://www.ala.org/acrl/ issues/whitepapers

Frank, D. G., Raschke, G. K., Wood, J., y Yang, J. Z. (2001). Information consulting: The key to success in academic libraries. The Journal of Academic Librarianship, 27(2), 90-96. doi:10.1016/S0099-1333(00)00180-4

García Vegas, R. (2012). Tendencias globales y escenarios de la educación universitaria en el siglo XXI. En M. Arenilla Sáez (Ed.), La reforma de la universidad española: Un análisis desde su gobernanza (p. 30-65). A Coruña: Netbiblo.

González-Fernández-Villavicencio, N. (2015). Qué entendemos por usuario como centro del servicio. Estrategia y táctica en marketing. El Profesional de la Información, 24(1), 05-13. doi:10.3145/epi.2015.ene.01

González-Solar, L (2016). La biblioteca universitaria orientada a la investigación: propuesta de un modelo de servicio centrado en el usuario desde la perspectiva del marketing. Tesis doctoral, Universidade da Coruña. Recuperado de http:// hdl.handle.net/2183/17112

Grover, R., y Hale, M. L. (1988). The Role of the Librarian in Faculty Research. College E Research Libraries, 49(1), 9-15. doi:10.5860/crl_49_01_9

Grupo de Repositorios de REBIUN (2013). Sistemas CRIS y repositorios institucionales en las universidades españolas. Recuperado de http://www.rebiun.org/sites/ default/files/2017-11/CRISyRepositorios2013.pdf

Hansson, J., y Johannesson, K. (2013). Librarians' views of academic library support for scholarly publishing: An every-day perspective. The journal of academic librarianship, 39(3), 232-240. doi: 10.1016/j.acalib.2013.02.002

Hardesty, L. (1995). Faculty culture and bibliographic instruction: an exploratory analysis. Library Trends, 44(2), 339-368.

Hazelkorn, E., Loukkola, T., y Zhang, T. (2014). Rankings in institutional strategies and processes: impact or illusion. Recuperado de: http://www.eua.be/risp

Hicks, D., Wouters, P., Waltman, L., de Rijcke, S., y Rafols, I. (2015). Bibliometrics: The Leiden Manifesto for Research Metrics. Nature, 520, 429-431. doi:10.1038/520429a

Horava, T. (2005). A new approach to faculty-librarian collaboration: a "new professors' fund" for collection development. The Journal of Academic Librarianship, 31(5), 482-485. doi:10.1016/j.acalib.2005.06.003 
Housewright, R., Schonfeld, R., C, y Wulfson, K. (2013b). Ithaka S $+R$ US faculty Survey 2012. Recuperado de http://sr.ithaka.org/?p=22502

International Ranking Expert Group (2006). Berlin principles on ranking of higher education institutions. Recuperado de http://ireg-observatory.org/en/index.php/ berlin-principles

Iribarren-Maestro, I., Grandal, T., Alecha, M., Nieva, A., y San-Julián, T. (2015). Apoyando la investigación: nuevos roles en el servicio de bibliotecas de la Universidad de Navarra. El Profesional de la Información, 24(2), 131-137. doi:10.3145/epi.2015.mar.06

Irurre, J. (2006). La rendición de cuentas de las universidades. En: Gobernanza y rendición de cuentas: las universidades ante la sociedad del conocimiento. Foro ANECA $7^{\circ}$, Madrid: ANECA.

Joint, N. (2008). Current research information systems, open access repositories and libraries. Library Review, 57(8), 570-575. doi:10.1108/00242530810899559

Jordan, K. (2014). Academicss Awareness, Perceptions and Uses of Social Networking Sites: Analysis of a Social Networking Sites Survey Dataset. SSRN Electronic Journal. doi:10.2139/ssrn.2507318

Kear, R., y Colbert-Lewis, D. (2011). Citation searching and bibliometric measures Resources for ranking and tracking. College E Research Libraries News, 72(8), 470-474. doi:10.5860/crln.72.8.8620

Keller, A. (2015). Research support in Australian university libraries: an outsider view. Australian Academic \& Research Libraries, 46 (2), 73-85. doi:10.1080/000 48623.2015.1009528

Key Perspectives (2009). Recuperado de http://library.oclc.org/cdm/ref/collection/ p267701coll27/id/372

Kotter, W. R. (1999). Bridging the great divide: Improving relations between librarians and classroom faculty. The Journal of Academic Librarianship, 25(4), 294-303. doi:10.1016/s0099-1333(99)80030-5

Kurtz, M. J., y Bollen, J. (2010). Usage bibliometrics. Annual Review of Information Science and Technology, 44(1), 1-64. doi: 10.1002/aris.2010.1440440108

Lapinski, P. S., Osterbur, D., Parker, J., y McCray, A. T. (2012). Supporting Public Access to Research Results. College \& Research Libraries, 75(1), 20-33. doi:10.5860/crl12-382

Lascurain, M. L. (2006) La evaluación de la actividad científica mediante indicadores bibliométricos. Boletín Bibliotecas, 24, 1-12.

León Serrano, G. (2011). Nuevos enfoques para la gestión estratégica de I+D e innovación en las universidades. Revista de Educación, 355, 83-108. Recuperado de http://www.revistaeducacion.educacion.es/re355.htm

LERU Research Data Working Group (2013). LERU roadmap for research data. Recuperado de https://www.leru.org/publications/leru-roadmap-for-research-data

Lewis, S. H. (2002). Three-Tiered Approach to Faculty Services Librarianship in the Law School Environment, A. Law Library Journal, 94, 89-100.

LIBER E-Science working group (2012). Ten recommendations for libraries to get started with research data management. Recuperado de: https://libereurope.eu/ wp-content/uploads/The\%20research\%20data\%20group\%202012\%20v7\%20final.pdf 
Logsdon, R. H. (1970). The Librarian and the Scholar: Eternal Enemies. Library Journal, 95(16), 2871-74.

MacColl, J. (2010). Library Roles in University Research Assessment. LIBER Quarterly, 20(2), 152-168. doi:10.18352/lq.7984

MacKenzie, E. (2014). Academic Libraries and Outreach to the Sciences: Taking a Closer Look at Research Groups. Science \& Technology Libraries, 33(2), 165-175. doi:10.1080/0194262x.2014.914011

Marcum, D., Schonfeld, R. C., y Thomas, S. (2015). Office of Scholarly Communication: scope, organizational placement, and planning in ten research libraries. Recuperado de http://sr.ithaka.org?p=275206

Martínez-Uribe, L., y Fernández, P. (2015). Servicios de datos: función estratégica de las bibliotecas del siglo XXI. El Profesional de la Información, 24(2), 193-199. doi:10.3145/epi.2015.mar.13

McCabe, K. M., y MacDonald, J. R. (2011). Roaming reference: Reinvigorating reference through point of need service. Partnership: The Canadian Journal of Library and Information Practice and Research, 6(2). doi: 10.21083/partnership.v6i2.1496

Medina Rubio, R. (2005). Misiones y funciones de la universidad en el Espacio Europeo de Educación Superior. Revista Española de Pedagogía, 63(230), 17-42.

Melero, R. (2008). El paisaje de los repositorios institucionales open access en España. BiD: Textos Universitaris de Biblioteconomia i Documentació, 20 (junio). Recuperado de http://bid.ub.edu/20meler4.htm

Melero, R., y Hernández-San-Miguel, J. (2014). Acceso abierto a los datos de investigación, una vía hacia la colaboración científica. Revista Española de Documentación Científica, 37(4), e066. doi:10.3989/redc.2014.4.1154

Merino Moreno, C., Verde Cordero, A. y Villar Mártil, L. (2008). La Función de transferencia tecnológica en las OTRIs. Revista Madrid, 47 Recuperado de: https:// dialnet.unirioja.es/servlet/articulo? codigo $=2877777$

Meulemans, Y. N., y Carr, A. (2013). Not at your service: building genuine faculty $\bigotimes$ librarian partnerships. Reference Services Review, 41(1), 80-90. doi:10.1108/00907321311300893

Meyer, E., Forbes, C., y Bowers, J. (2010). The Research Center: creating an environment for interactive research consultations. Reference Services Review, 38(1), 57-70. doi:10.1108/00907321011020725

Mitchell, E. T. (2013). Research Support: The New Mission for Libraries. Journal of Web Librarianship, 7(1), 109-113. doi:10.1080/19322909.2013.757930

Moscoso, P. (2003, mayo). La nueva misión de las bibliotecas universitarias ante el espacio europeo de enseñanza superior. En: Los centros para recursos del aprendizaje y la investigación: nuevos espacios arquitectónicos para el apoyo a la innovación docente, I Jornadas CRAI. Recuperado de http://hdl.handle.net/10017/809

Nández, G., y Borrego, Á. (2013). Use of social networks for academic purposes: a case study. The Electronic Library, 31(6), 781-791. doi: 10.1108/el-03-2012-0031

Nicholas, D., Herman, E., Jamali, H. R., Bravo, B. R., Boukacem-Zeghmouri, C., Dobrowolski, T., y Pouchot, S. (2015). New ways of building, showcasing, and measuring scholarly reputation. Learned Publishing, 28(3), 169-183. doi: $10.1087 / 20150303$ 
NTU (2017). Performance Ranking of Scientific Papers for World Universities 2017: Methodology. Recuperado de http://nturanking.lis.ntu.edu.tw/BackgroundMethodology/ Methodology-enus.aspx

OCLC Research Registering Researchers in Authority Files Task Group (2014). Registering researchers in authority files. Recuperado de https://www.oclc.org/ research/themes/research-collections/registering-researchers.html

Ortega, J. L. (2015). Disciplinary differences in the use of academic social networking sites. Online Information Review, 39(4), 520-536. doi:10.1108/oir-03-2015-0093

Ortega, J. L., y Aguillo, I. F. (2012). Science is all in the eye of the beholder: Keyword maps in Google scholar citations. Journal of the American Society for Information Science and Technology, 63(12), 2370-2377. doi:10.1002/asi.22761

Parker, R. (2012, febrero). What the library did next: strengthening our visibility in research support. En eM-powering eFutures. VALA conference. Recuperado de http://www.vala.org.au/direct-download/vala2012-proceedings

Pérez Esparrells, M. C. y Gómez Sancho, J. M. (2011, febrero). Los rankings internacionales de las instituciones de educación superior y las clasificaciones universitarias en España: visión panorámica y prospectiva de futuro. En Economía pública: Reflexiones para después de la crisis. XVIII Encuentro de economía pública. Recuperado de https://dialnet.unirioja.es/servlet/ articulo?codigo $=3630642$

Phelps, S. F., y Campbell, N. (2012). Commitment and trust in librarian-faculty relationships: a systematic review of the literature. Journal of Academic Librarianship, 38(1), 13-19. doi:10.1016/j.acalib.2011.11.003

Pinto Molina, M., Fernández-Marcial, V., y Gómez-Camarero, C. (2010). The impact of information behavior in academic library service quality: a case study of the Science and Technology Area in Spain. The Journal of Academic Librarianship, 36(1), 70-78. doi:10.1016/j.acalib.2009.11.008

Pinto Molina, M., Sales Salvador, D. y Martínez Osorio, P. (2008). Biblioteca universitaria, CRAI y alfabetización informacional. Gijón: Trea.

Plaza-Navas, M. À., Ponsati Obiols, A., Bernal, I., y Baquero Arribas, M. (2012). La biblioteca de recerca i la seva aportació al desenvolupament de l'activitat I+D+i. Item: Revista de Biblioteconomia i Documentació, 56, 13-32. Recuperado de http://www.cobdc.org/publica/item/item56.html

Priem, J., y Hemminger, B. (2010). Scientometrics 2.0: New metrics of scholarly impact on the social Web. First Monday, 15(7). doi: 10.5210/fm.v15i7.2874

Pritchard, S. M. (1996). Determining quality in academic libraries. Library Trends, 44(3), 572-595. Recuperado de http://hdl.handle.net/2142/8041

QS (2018). QS World University Rankings methodology. Recuperado de: https:// www.topuniversities.com/qs-world-university-rankings/methodology

Radom, R., Feltner-Reichert, M., y Stringer-Stanback, K. (2012). Organization of scholarly communication services: SPEC Kit, 332. Recuperado de http://publications.arl.org/ Organization-of-Scholarly-Communication-Services-SPEC-Kit-332

Research Information Network (2008). Stewardship of digital research data: $a$ framework of principles and guidelines. Recuperado de http://www.rin.ac.uk/ system/files/attachments/Stewardship-data-guidelines.pdf 
Research Information Network (2010). Research support services in UK universities. Recuperado de https://www.soas.ac.uk/careers/earlycareerresearchers/file69090.pdf

Research Support Libraries Group (2002). Final report. New Review of Academic Librarianship, 8(1), 3-86. doi:10.1080/13614530209516827

Rodwell, J., y Fairbairn, L. (2008). Dangerous liaisons? Defining the faculty liaison librarian service model, its effectiveness and sustainability. Library Management, 29(1/2), 116-124. doi:10.1108/01435120810844694

Roemer, R. C., y Borchardt, R. (2013). Institutional altmetrics and academic libraries. Information Standards Quarterly, 25(2), 14-19. doi: 10.3789/isqv25no2.2013.03

Romero, J., y Pastor, J. M. (2012). Las universidades españolas bajo la influencia de los rankings. Regional and Sectoral Economics Studies, 12(3), 105-126. Recuperado de http://www.usc.es/economet/eers.htm

Rué, J. (2014). La universidad española, sus desafíos y su capacidad de agencia. Educar, 50, 9-31. Recuperado de http://www.redalyc.org/articulo.oa?id=342132562002

RULK (2014). Powering scholarship: RULK strategy 2014-17. Recuperado de http://www. rluk.ac.uk/wp-content/uploads/2014/02/RLUK-Strategy-2014-online-updated.pdf

San Francisco Declaration on Research Assessment: Putting science into the assessment of research (2012). Recuperado de http://www.ascb.org/dora

Sanz-Casado, E. (Coord.) (2015). Guía de buenas prácticas para la participación de las universidades españolas en los rankings internacionales. Recuperado de: http:// www.uib.cat/digitalAssets/317/317232_guia_bones_practiques_ranquings_2015.pdf

Sanz-Casado, E., García-Zorita, C., Serrano-López, A. E., Efraín-García, P., y De Filippo, D. (2013). Rankings nacionales elaborados a partir de múltiples indicadores frente a los de índices sintéticos. Revista Española de Documentación Científica, 36(3), e012. doi:10.3989/redc.2013.3.1.023

Scherer, H. (1970). The faculty and the librarian. Library College Journal, 3(4), 37-43.

Schonfeld, R. C., y Long, M. P. (2014). Ithaka S $+R$ US Library Survey 2013. Recuperado de http://sr.ithaka.org? $\mathrm{p}=22787$

Sharman, A. (2014). Roving librarian: the suitability of tablets in providing personalized help outside of the traditional library. New Review of Academic Librarianship, 20(2), 185-203. doi:10.1080/13614533.2014.914959

SIR (2018). Scimago Institutions Rankings methodology. Recuperado de http://www. scimagoir.com/methodology.php

THE (2018). Times Higher Education World University Rankings 2018 methodology. Recuperado de https://www.timeshighereducation.com/world-university-rankings/ methodology-world-university-rankings-2018

Thelwall, M., y Kousha, K. (2016). ResearchGate articles: Age, discipline, audience size, and impact. Journal of the Association for Information Science and Technology, 68(2), 468-479. doi:10.1002/asi.23675

Torres-Salinas, D., Cabezas-Clavijo, Á., y Jiménez-Contreras, E. (2013). Altmetrics: New indicators for scientific communication in Web 2.0. Comunicar, 21(41), 53-60. doi: 10.3916/C41-2013-05

Torres-Salinas, D., y Cabezas-Clavijo, Á. (2011). Herramientas para la evaluación de la ciencia en universidades y centros I+ D: descripción y usos. Anuario ThinkEPI, 6, 142-146. Recuperado de http://hdl.handle.net/10760/16923 
Tovar Sanz, M. R. (2015). El apoyo a la investigación en las bibliotecas universitarias españolas. Documentación de las Ciencias de la Información, 38, 311-326. doi: 10.5209/rev_dcin.2015.v38.50822

Webb, J., Gannon-Leary, P., y Bent, M. (2007). Providing effective library services for research. London, Facet.

Wolff, C., \& Schonfeld, R. (2017). Ithaka S+R US Library Survey 2016. doi:10.18665/ sr.303066

Zhao, L. (2014). Riding the wave of Open Access: Providing library research support for scholarly publishing literacy. Australian Academic \& Research Libraries, 45(1), 3-18. doi:10.1080/00048623.2014.882873 


\title{
A CIÊNCIA DA INFORMAÇÃO E O MERCADO DE TRABALHO NA ERA DIGITAL: DESAFIOS NA FOR- MAÇÃO DO PROFISSIONAL DA INFORMAÇÃO
}

\author{
INFORMATION SCIENCE AND THE JOB MARKET IN \\ THE DIGITAL AGE: CHALLENGES IN THE ACADEMIC \\ TRAINING OF THE INFORMATION PROFESSIONAL
}

Francisco Carlos Paletta

Universidade de São Paulo, Brasil

fcpaletta@usp.br ORCID: https://orcid.org/0000-0002-4112-5198

José Antonio Moreiro-Gonzalez Universidade Carlos III de Madrid, Espanha

jamore@bibuc3.es ORCID: https://orcid.org/0000-0002-8827-158X

Waldomiro de Castro Santos Vergueiro, Universidade de São Paulo, Brasil wdcsverg@usp.br ORCID http://orcid.org/0000-0002

RESUMO - Reflete-se sobre as características do momento atual e os desafios que este representa para a Ciência da Informação no que diz respeito aos impactos da tecnologia e à formação profissional, discutindo-se também as competências e habilidades do profissional da informação na gestão do conhecimento. Enfatizam-se os valores que devem permear a atuação profissional na era digital, dando-se 
ênfase especial a questões de criatividade e ética. Finaliza-se apresentando uma reflexão sobre aspectos da formação profissional em ambiente digital, refletindo-se sobre as competências informacionais e digitais, bem como sobre a necessidade das organizações de ensino se aparelharem para as mudanças, aperfeiçoando seus processos de formação pela incorporação das demandas e expectativas tanto das organizações como do mercado de trabalho.

PALAVRAS-CHAVE - Ciência da Informação; Era Digital; Profissional da Informação; Mercado de Trabalho; Ética da Informação.

ABSTRACT - Looks upon the characteristics of the present time and the challenges it represents to Information Science in what regards to the impacts of the technology and to professional education, also discussing the information professional's competences and abilities on knowledge organization. The values that should permeate the professional performance in the digital era are emphasized, with special attention to issues related to creativity and ethics. It finishes with a consideration about aspects of the professional education in the informational environment, taking in account the informational and digital competences, as well as the need of the education organizations to prepare themselves to properly answer to those changes, improving their processes of education by the incorporation of the demands and expectations both from the organizations as the work market.

KEYWORDS - Information Science; Digital Era; Information professional; Work market; Information Ethics.

\section{Introdução}

Vive-se um momento em que as organizações alteram suas hierarquias e burocracias com o objetivo de criar oportunidades para o 
pensamento criativo, além de considerarem a inovação e o uso das tecnologias da informação e comunicação como fator fundamental na busca por vantagem competitiva na era digital. Nesse ambiente, torna-se imperativa a reflexão sobre as contribuições da Ciência da Informação para com o perfil e formação do profissional da informação, de forma a possibilitar que estes profissionais possam não apenas se preparar para as exigências que essa era lhes coloca como, também, oferecer à sociedade o tipo de contribuição que ela deseja.

O desafio da Ciência da Informação está em identificar sua responsabilidade e os compromissos que precisam ser estabelecidos com foco na produção de conhecimentos e formação do profissional frente à transformação digital e às demandas do mercado de trabalho global. Sem dúvida, a era digital impõe uma nova agenda de discussão para a Ciência da Informação que permita entender o papel das novas tecnologias da informação e comunicação, da organização e análise de quantidades cada vez maiores de dados Big Data, da inovação, da inteligência artificial, da ciência de dados, da curadoria digital, das humanidades digitais.

Assim, compete à Ciência da Informação entender os desafios impostos pela transformação digital, já às portas da terceira década do século XXI, em que o profissional da informação está exposto e submetido à pressão por resultados em um mercado de trabalho global e competitivo. Ao mesmo tempo, precisa estimular o profissional ao entendimento de que o uso das tecnologias digitais implica em mudar as perspectivas de atuação no campo da organização da informação e do conhecimento e ver as coisas sob um novo ângulo.

Além disso, é preciso levar o profissional da informação a refletir sobre os limites da ética no processo criativo e na busca pelo desempenho e sucesso profissional. A linha que separa a criatividade e os limites éticos é muito tênue e a busca por resultados a qualquer preço pode ser um fator decisivo para romper este limite. Somente a ética e a moral podem estabelecer parâmetros de controle onde 
resultados a qualquer preço, sem respeito aos valores éticos, é caminho sem volta ao fracasso pessoal e organizacional.

\section{Competindo em um Cenário Global na Era Digital}

A era digital desafia a Ciência da Informação a contribuir na formação de profissionais com capacidade de aprender a construir e administrar organizações criativas e inovadoras. Os profissionais da informação terão que interagir em ambientes multi-inter-transdisciplinar e a lidar com grupos humanos capazes de prover inovação, de transformar suas ideias em tecnologia, produtos e processos, capazes e desejosos de aceitar o novo sem romper com as barreiras da ética nos limites da criatividade e da competitividade global.

Em um período de intensas mudanças e de crescente competição entre as organizações, é preciso descobrir novos caminhos, fomentar a criatividade e desenvolver talentos. Contribuir para a formação e capacitação profissional no momento em que a inteligência artificial, a análise do fenômeno Big Data, o uso das tecnologias da informação e comunicação, a inovação, a organização da informação e do conhecimento são considerados formas de assegurar a competitividade cada vez mais globalizada é, sem dúvida alguma, prioridade primeira para a Ciência da Informação.

As instituições da área de informação não estão alheias a essas tendências. Muito pelo contrário, como defende Brendan Ryan ao refletir sobre as bibliotecas acadêmicas e o impacto da era digital sobre elas.

É claro que a era digital traz às bibliotecas acadêmicas várias contingências a apoiar. A variedade de habilidades necessária para dar suporte a uma série de formatos, aparelhos, questões de direito, e outras considerações está além do campo até mesmo das instituições mais bem financiadas e equipadas em termos de pessoal. O rápido desenvolvimento das tecnologias na era digital 
traz às bibliotecas muitos problemas potenciais em conjunção com soluções (2013, p. xii-xiii, tradução nossa). ${ }^{1}$

Preocupação semelhante já havia aparecido em 1997, em pesquisa sobre bibliotecas públicas financiada pela Benton Foundation, dos Estados Unidos, quando, após a realização de seis grupos de foco com usuários entre 19 e 65 anos, uma das principais constatações foi a de que o público dessas bibliotecas vê que o papel do bibliotecário como navegador da informação deve ser reforçado na era digital (BENTON FOUNDATION, 1998, p. 83-84).

Nesse sentido, um dos aspectos mais importantes a considerar nesse novo momento é a criatividade. Do latim creatio (criação), trata-se da capacidade de pensar produtivamente à revelia das regras, bem como de criar coisas novas, combinando de maneira inusitada o saber já disponível.

A criatividade é o recurso mais fecundo com que o homem, desde sempre, procura derrotar os seus inimigos atávicos: a fome, o cansaço, a ignorância, o medo, a feiura, a solidão, a dor e a morte. Em cada esquina do planeta, em cada fase da sua evolução, a criatividade humana consegue atribuir uma forma ao caos, um significado às coisas (De Masi, 2003).

Cada vez mais é possível acreditar, como afirma o físico David Bohm em texto originalmente escrito em 1968, que "a longo prazo, nenhum problema, por mais sutil, profundo ou abrangente que seja, poderá ser resolvido, em qualquer campo, se não por pessoas que sejam capazes de responder de uma forma original e criativa à natureza sempre mutável e evolutiva do fato geral com que es-

1 It is clear that the digital age presents academic libraries with a number of contingencies to support. The range of skills necessary to support the array of digital formats, devices, rights issues, and other considerations is outside the realm of even the most highly budgeted and staffed institutions. The rapid development of technologies in the digital age presents libraries with many potential problems in conjunction with solutions. 
tão confrontando" (1995, p. 15, tradução nossa) ${ }^{2}$. Ou seja, pode-se afirmar que, no futuro, a criatividade - em todas as áreas - será o ingrediente-chave para o êxito em todas as atividades, em qualquer tipo de organização pública ou privada. Assim, quando a tecnologia passar a ser um produto comum e habitual e todas as organizações alcançarem o mesmo nível de competência digital - digital literacy, só a criatividade poderá fazer a diferença.

Neste cenário altamente competitivo, o crescimento pessoal e profissional passou a ser imperativo. A dimensão pessoal da criatividade considera aspectos como filosofia, temperamento, atitudes, hábitos e valores, assim como o conhecimento e as habilidades; vários estudos, inclusive, demonstraram que uma pessoa criativa em geral apresenta as seguintes características:

· Articulação (fluência verbal)

- Pensamento metafórico

- Tomada de decisão flexível

- Habilidade para visualizar problemas internamente

- Independência

- Tolerância à ambiguidade

- Disposição para sobrepujar obstáculos e perseverança

- Disposição para assumir riscos

- Coragem de suas próprias convicções

- Alta energia

- Independência de julgamento

2 In the long run no really subtle, deep, and far-reaching problems can be solved in any field whatsoever, except by people who are able to respond in an original and creative way to the ever changing and developing nature of the overall fact by which they are confronted. 
- Autonomia

- Autoconfiança, firmeza, e crença na sua própria criatividade

- Habilidade para resolver e acomodar seus próprios aspectos conflitivos interiores. (Sawyer, 2006, p. 47, tradução nossa). ${ }^{3}$

Desta forma, para obter sucesso em sua carreira, o profissional precisa investir com afinco no resgate da sua capacidade criativa e inovadora, valorizando o livre fluxo de informação, compartilhando o conhecimento e desenvolvendo novas habilidades que the permitam lidar com os desafios próprios desse novo contexto. A criatividade não é um dom dos deuses e apesar de restar muito a ser desvelado sobre o pensamento criativo, a ciência já traz boas notícias: a criatividade pode, sim, ser estimulada e treinada. Leva tempo, demanda paciência. Mas com um pouco de flexibilidade intelectual e cérebro alimentado de conhecimento, todos podemos exercitar o espírito criativo (Aristóteles; Crisp, 2014).

Essa aptidão certamente foi um dos motores do homem ao longo de sua história. Aristóteles, depois de afirmar que todos temos, por natureza, o desejo de conhecer, diz no primeiro livro da Metafísica que, para escapar da ignorância, os primeiros filósofos entregaram-se à filosofia, buscando a ciência para compreender. "Aperceber-se de uma dificuldade e espantar-se é reconhecer sua própria ignorância": a construção do saber passa exatamente pelo enfrentamento e pela tentativa de superação de aporias. Ainda que seja para sempre voltar a encontrá-las (Aristóteles; Crisp, 2014).

3 articulacy (verbal fluency); metaphorical thinking; flexible decision making; the ability to internally visualize problems; independence; tolerance of ambiguity; willingness to surmount obstacles and persevere; willingness to take risks; the courage of one's convictions; high energy; independence of judgment; autonomy; self-confidence, assertiveness, and belief in oneself as being "creative"; ability to resolve and accommodate apparently opposite or conflicting traits within oneself 
Já desde década de 1970 o sociólogo e futurólogo Alvin Toffler (1971, 1989, 1991), assim como outros antes dele, alertava sobre a crescente importância do conhecimento no desenvolvimento da sociedade, destacando o papel das idéias na criação de progresso para a humanidade. Segundo Ferrari (2005), hoje medimos e definimos a inteligência de modo diferente daquele de décadas atrás, incorporando a esse conceito áreas que já não têm muito a ver com os domínios cognitivos tradicionais do pensamento, da resolução de problemas e do saber. Outros tipos de inteligência - como a emocional e a social - são considerados, e a habilidade de perceber emoções, necessidades e motivações em si mesmo e nos outros é também qualificada como inteligência.

A gestão da informação e do conhecimento vem ao encontro das ponderações desses dois autores, podendo ser vista como uma coleção de processos que governa a criação, disseminação e utilização do conhecimento para atingir plenamente os objetivos da organização. O conhecimento é a chave para a competitividade na era digital e as organizações necessitam de uma abordagem operacional com foco no conhecimento coletivo, que representa um diferencial competitivo no mercado global (Choo, 1998; Davenport \& Prusak, 1999).

De acordo com o Manual de Oslo, gestão do conhecimento envolve aquisição, utilização e compartilhamento. Trata-se de administrar interações e fluxos de conhecimento, incluindo métodos e procedimentos de busca de conhecimento externo, buscando o estabelecimento de relacionamentos mais estreitos com empresas, consumidores ou instituições de pesquisa (OECD, 2005).

Para o Manual, as práticas de gestão do conhecimento voltadas para a melhoria do fluxo interno e do uso da informação incluem:

- Bases de dados sobre as "melhores práticas";

- Educação regular ou programas de capacitação; 
- Grupos de trabalho formais e informais para promover a comunicação entre os colaboradores e sua interação;

- Atividades de integração entre setores de diferentes áreas.

As decisões sobre como usar e trocar conhecimentos existentes por novos são fundamentais para a operação das organizações e a produção de inovações. No caso desta última, destaca-se que ela não pode ser representada por uma sequência linear de eventos a partir apenas de um único fator, mas ocorre de forma interativa, envolvendo múltiplas relações e aspectos. Assim, os sistemas adequados à gestão do conhecimento podem melhorar a competitividade e a capacidade inovadora (OECD, 2008).

Nesse contexto, a Tecnologia da Informação tem um papel fundamental e estratégico: ajudar o desenvolvimento coletivo e do aprendizado contínuo, tornando mais fácil para os profissionais da informação compartilharem problemas, expectativas, idéias e soluções.

\section{Ciência da Informação, Criatividade e Ética na Era Digital}

O desenvolvimento da Ciência e Tecnologia - para o que a criatividade e a inovação têm de estar necessariamente presentes -, é apoiado por três premissas fundamentais: a primeira delas se deve à existência do cérebro humano e ao incentivo a sua potencialidade; a segunda pode ser localizada na mobilização das pessoas e instituições em torno de objetivos, de bandeiras, de metas geradoras de algum benefício estratégico ou social; a terceira refere-se ao esforço para canalizar recursos adequados para a área científica e tecnológica. (Matos, 2005).

A era digital tem modificado o comportamento humano. Uma das principais e mais evidentes realidades da Internet é o individualismo extremo; esse fator, muitas vezes associado à falta de ética 
pessoal, tem levado alguns profissionais a defender seus interesses particulares acima dos interesses das empresas em que trabalham, colocando-as em risco. Nesse sentido, os aspectos éticos da profissão assumem especial relevância, na medida em que, no dizer de McNemeni, Poulter e Burton (2007, p. 8, tradução nossa) "As ramificações potenciais de um profissional desempenhar qualquer atividade sem a devida atenção a padrões éticos pode prejudicar pessoas ou grupos, e pode ter consequências legais profundas para o professional envolvido e a organização que o emprega". ${ }^{4} \mathrm{E}$ esses aspectos, ainda segundo os mesmo autores, adquirem dimensão destacada para os profissionais da informação da era digital, especialmente devido a questões de organização, armazenamento e disseminação. Esse quadro nos remete diretamente à questão da formação de recursos humanos, pois são as pessoas as bases de qualquer tentativa para iniciar o resgate da ética nas empresas e nas relações de trabalho e gestão da informação e do conhecimento.

O mundo das organizações está se tornando a cada dia mais complexo, competitivo, imprevisível, e seus problemas mais difíceis de serem solucionados. O mundo está sendo atribulado por uma multiplicidade de questões que exigem profissionais com formação técnica e visão humanista:

- A riqueza sem trabalho;

- O prazer sem consciência;

- Os negócios sem ética;

- O discurso sem prática;

- A ciência sem humanidade;

4 The potential ramifications of a professional performing any task without due care for ethical standards may be to the detriment of individual people or groups, and could have profound legal consequences for the professional concerned and the employing organization. 
- A religião sem espiritualidade e fé autêntica;

- O trabalho sem satisfação pessoal e auto-realização;

- As informações em excesso, porém desprovidas de sabedoria;

- O conhecimento sem compromisso com a verdade;

- O marketing pessoal com embalagem atraente, porém, sem conteúdo

Neste contexto, além das competências técnicas, o profissional da informação deve estar preparado para lidar com os seus limites éticos; avaliar detalhadamente os valores da organização; trabalhar sempre com base em fatos; avaliar os riscos de cada decisão que tomar, saber que, mesmo ao optar pela solução mais ética, poderá se envolver em situações delicadas; ser ético significa, muitas vezes, perder dinheiro, poder, status, e benefícios.

A necessidade de fazer diferente está se tornando mais importante e decisiva, à medida que as organizações descobrem que seus métodos de operação e gestão de pessoas, inclusive, correm o risco de fracassar. Com a crescente concorrência global e usuários cada vez mais exigentes, tanto as pequenas como as grandes empresas necessitam estar focadas em se reinventarem criando novas e melhores formas de produzir, administrar, atingir diferentes mercados, recrutar, desenvolver, motivar e manter os melhores talentos.

A competitividade organizacional dar-se-á no campo da mente de seus colaboradores e não no campo de seus assets físicos ou financeiros. Os setores mais promissores do desenvolvimento de uma sociedade são justamente os que impõem às organizações os desafios de aprender a pensar a longo prazo e investir na organização da informação e do conhecimento - itens estratégicos na construção de uma estratégia competitiva global. Ao fundamentar suas decisões, elas organizações legitimam seus atos de gestão e 
contribuem para sua permanência ao longo do tempo. Elas exigem, hoje, a aplicação dos mais elevados valores éticos à conduta de seus dirigentes e colaboradores. As atitudes devem ser rápidas e certeiras, mas sempre seguindo estratégias globais; estas, sim, capazes de diferenciação e garantia de resultados consistentes no que diz respeito à sobrevivência. As empresas hoje buscam profissionais com um perfil diferenciado. A era da informação é implacável: joga para escanteio quem não têm competências e habilidades adequadas e coloca no ápice aqueles mais bem preparados.

Os sistemas formais da organização correspondem aos métodos, às políticas e aos procedimentos que claramente identificam qual o negócio, quando, como, onde e por que ele se realiza. Quando eles contêm um direcionamento ético claro, os profissionais têm uma compreensão correta das expectativas e exigências. Quando, por outro lado, não são claros ou quando a mensagem ética varia entre os diversos sistemas, os indivíduos buscam outro ponto de referência para uma orientação definitiva, uma dimensão tipicamente de liderança.

Toda ciência é uma atividade social determinada por condições históricas e socioeconômicas. Desta forma, a sociedade da informação necessita de uma ciência que estude as propriedades da informação e os processos de sua construção, comunicação e uso. Hoje, o objeto da Ciência da Informação não é mais o mesmo da Biblioteconomia e de suas veneráveis disciplinas coirmãs. Não é mais a biblioteca e o livro, o centro de documentação e o documento, o museu e o objeto, mas é a informação que apresenta foco (Le Coadic, 1996).

\section{Ciência da Informação e Formação Profissional}

$\mathrm{Na}$ área da gestão da informação, a rápida obsolescência do conhecimento associa-se à necessidade de um profissional com 
visão holística; habilidades gerenciais, metodológicas, culturais e sistêmicas devem ocupar posição central nos programas de formação. A competitividade global impõe um novo perfil, que tem como desafio equilibrar as habilidades de uma sólida formação acadêmica, visão técnica aplicada, com a capacidade de gestão dos processos produtivos com foco na competitividade e atuação global dos profissionais e das organizações.

O desenvolvimento da tecnologia seguiu o curso do processo de industrialização. Inicialmente, a competência exigida era eminentemente técnica. Em um segundo momento, à medida que a indústria se diversificava e sofisticava, passou a ser requerida a qualificação científica. Já na terceira etapa, adicionam-se a necessidade das competências gerenciais. A direção seguida no processo foi a da especialização crescente. Avançou-se, então, para um quarto estágio, a que se chegou optando pela direção inversa - indo-se da especialização para a formação holística, como uma exigência da mobilidade e relacionada à flexibilidade mental e, portanto, à inovação. A relação entre conhecimento holístico, mercados globalizados, economia do conhecimento e desenvolvimento sustentável é intrínseca. Por consequência, ainda que bibliotecas de todos os tipos continuem a existir e exigir profissionais para funcionar, o trabalho da informação em geral pode ser desvinculado de tais instituições e ao fazê-lo pode ser melhor entendido como apoiando uma maior variedade de atividades humanas. Uma abstração da base de conhecimento para incluir um visão mais larga e holística do trabalho de informação em todos os tipos de lugares e sob todos os tipos de condições iria preparar melhor os PI (profissionais da informação) para o mundo complexo no qual vivemos. (Mybourg, 2005, p. 203, tradução nossa). ${ }^{5}$

5 While libraries of all types will undoubtedly continue to exist and require professionals to staff them, information work in general can be uncoupled from such 
Para um profissional da informação, ter formação holística significa agregar às competências técnicas básicas novas conhecimentos e habilidades. Ele deverá conviver em comunidades e culturas diversificadas, que interagem e resolvem questões e problemas do cotidiano a partir de um olhar peculiar e característico. Ao mesmo tempo, deverá ter capacidade de comunicação e saber trabalhar em equipes multidisciplinares. Ter consciência das implicações sociais, ecológicas e éticas envolvidas na gestão, acesso e uso da informação. Falar mais de um idioma e estar disposto a trabalhar em qualquer parte do mundo também são características demandadas pelo mercado de trabalho que coloca a competitividade e produtividade no centro da sua estratégia.

Nesse sentido, a inteligência é um imperativo devido a fatores como capacidade de competir globalmente, dominar os recursos tecnológicos apresentados pela era digital, organizar e gerenciar a informação e o conhecimento. Sua presença visa estabelecer vantagem competitiva organizacional, lidar com a diversidade e a multidisciplinaridade operacional da sociedade em rede, estabelecer os limites éticos na busca de resultados e sustentabilidade do negócio, compreender e praticar a responsabilidade socio-ambiental.

Uma compilação de estudos realizada pelo Observatório do Mercado de Trabalho do Profissional da Informação Documentação (OMTID, 2018) demonstra o tipo de competências e habilidades requeridas hoje de um profissional da informação:

institutions and in so doing may be better understood as supporting a wider range of human activities. An abstraction of the knowledge base to include a wider and holistic view of information work in all sorts of places and under all sorts of conditions would better prepare IPs for the complex world in which we live. 
Quadro 1 - Competências e Habilidades do Profissional da Informação

Aplicação dos conhecimentos de gestão, organização, acesso e uso da informação

Atuação em equipes multidisciplinares

Identificação, formulação e solução de problemas de gestão do conhecimento

Senso de responsabilidade ética e profissional

Reconhecimento da necessidade de treinamento continuado

Utilização de técnicas e ferramentas modernas das boas práticas de organização, acesso, uso e gestão da informação

Projeto de sistemas, componentes e processos para atender a necessidades específicas dos usuários

Responsabilidade socioambiental

Compreensão do impacto das soluções de TICs em um contexto global e social

Fonte: Autores

A formação de tais habilidades exige que as disciplinas técnicas previstas nas diretrizes curriculares sejam complementadas com conteúdo interdisciplinar, e que a teoria esteja acoplada à solução de problemas. Nesse caso, a cooperação entre a universidade e as organizações é fundamental. A compreensão do contexto em que se desenvolvem as atividades de Ciência da Informação nos diversos países ajuda a quebrar as barreiras culturais. A educação continuada ou a aprendizagem ao longo da vida é exigência de um ambiente complexo e em transformação acelerada, uma vez que "em um mercado de trabalho em rápido desenvolvimento, aqueles com habilidades atualizadas se aproveitam das oportunidades de trabalho mais atrativas"; (Brine, 2005, p. 78, tradução nossa). ${ }^{6}$

Assim, cabe às universidades, por meio de seus cursos na área, estar atentas às mudanças do mercado de trabalho, identificando

6 In a fast paced employment market, those with proven, up to-date skills are able to take advantage of the most attractive job opportunities. 
as demandas que as organizações públicas e do setor produtivo colocam para os profissionais da informação. Para isso, necessitam organizar um esquema permanente de prospecção das necessidades da sociedade, tanto pela realização de pesquisas com egressos como pelo contato, tanto direto como indireto, com os fornecedores de emprego, visando entender suas necessidades e incorporá-las à formação profissional. Nem sempre isso acontece, pois sabe-se que o ritmo de adaptação da Academia às mudanças sociais carece de velocidade para permitir que os profissionais que se colocam no mercado respondam de forma efetiva a essas demandas. Nesse sentido, uma iniciativa efetiva visando dirimir essa limitação foi a pesquisa desenvolvida por José Antonio Moreiro González e Waldomiro Vergueiro (2012), que, a partir de 200 vagas de emprego anunciadas por meio da internet, identificaram competências e atitudes exigidas pelo mercado de trabalho brasileiro, constatando uma concentração de solicitações relacionadas às tecnologias da informação, apontando para a necessidade, cada vez maior, das Universidade, entre outras coisas, capacitarem os futuros profissionais para "disseminar informação por meio da Internet e de organizar informações em bases de dados”, habilidade que exige também "dominar as técnicas multimídia, saber navegar pelas redes de comunicação e conhecer em profundidade as normas, formatos e métodos normalizados de descrição, apresentação e transmissão" (Moreiro González \& Vergueiro, 2012, p. 206-207). Concluem, assim, os autores, que:

(...) os anúncios supõem que os candidatos possuem uma série de qualidades técnicas adquiridas entre as competências básicas que outorgam os cursos universitários, mas além disso lhes pedem, em geral, um alto manuseio da tecnologia e a adaptação a sua evolução, bem como conhecimento da informática e seu software mais habitual, experiência em ambientes tecnológicos concretos, 
um nível cultural próprio de quem passou pela universidade e, em exigência crescente, um bom domínio de idiomas (Moreiro González \& Vergueiro, 2012, p. 211).

Conseguirão os cursos da área dar conta de tantas exigências? Essa é uma questão cada vez mais premente, pois um dos principais desafios da educação na área da Ciência da Informação é o desenvolvimento de currículos que proporcionem uma formação alinhada com os desafios do mercado global, sem deixar de se preocupar com a formação cultural e humanística, fundamental na gestão da informação e produção de conhecimento. Fator relevante nesse processo de formação de profissionais que atuam na área da organização da informação é a estruturação de instituições de ensino que contemplem um corpo docente que reúna não apenas mestres e doutores reconhecidos na área, mas, também, profissionais que ocupem posições ativas e estratégicas no mercado de trabalho, o que permite enriquecer o ambiente acadêmico com novas visões e tendências. O modelo de ensino na era digital deve fazer uso de modernos recursos computacionais que permitam a reprodução de ambiente de pesquisa, desenvolvimento e produção, levando aluno e professor a vivenciar a realidade competitiva em que as organizações estão inseridas.

Para os desafios da competitividade internacional, impõe-se o valor estratégico da ciência e do conhecimento. Dentre as questões macro conjunturais apresentadas para a Ciência da Informação, uma que interessa sobremaneira trata da modernização e internacionalização do nosso modelo acadêmico. Não basta mais garantir a boa formação aos estudantes, é preciso desenvolver as novas habilidades exigidas pelos mais diversos campos de trabalho global (como, por exemplo, aquelas apontadas no Quadro 1).

No contexto da Ciência da Informação, Biblioteconomia, Arquivologia, Museologia e áreas afins, é possível identificar forte 
demanda por profissionais com competências e habilidades multidisciplinares, sem fronteiras geopolíticas, com diversidade cultural, com expressiva dependência por inovação e uso das tecnologias. Assim, torna-se fundamental estudar e compreender o projeto político pedagógico praticado pelas universidades nesta área do conhecimento, sua necessidade de atualização, com foco no perfil do egresso, que esteja preparado para atuar nos setores estratégicos e indutores de desenvolvimento sustentável da sociedade moderna: produtivo, educação e pesquisa.

Nesse panorama de mudanças cada vez mais dinâmicas, o conhecimento torna-se obsoleto rapidamente. Assim, é preciso pensar em uma qualificação holística, valorizando habilidades de gestão, comunicação, liderança, metodológicas, culturais, multidisciplinares e sistêmicas - todas destacadas na economia do conhecimento.

Para bem pensar hoje o ofício da educação, é preciso compreender e valorizar a complexidade do mercado de trabalho global. Além de uma competência técnica específica, no caso da Ciência da Informação absolutamente indispensável, a maioria das novas ou renovadas profissões exigirá a prática de inúmeras capacidades culturais. Educar o profissional da informação para o século XXI é equilibrar o binômio especialista, em sua dimensão técnica versus generalista, ou seja, de caráter multidisciplinar. Nessa linha de pensamento, é importante ter em conta que a iniciativa pessoal adquire especial relevância, na medida em que, como bem lembra o filósofo polonês Zigmunt Bauman (2007, p. 10, grifo no original),

A virtude que se proclama servir melhor aos interesses do indivíduo não é a conformidade às regras (as quais, em todo caso, são poucas e contraditórias), mas a flexibilidade: a prontidão em mudar repentinamente de táticas e de estilo, abandonar compromissos e lealdades sem arrependimento - e buscar oportunidades mais de acordo com sua disponibilidade atual do que com as próprias preferências. 


\section{Conclusão}

Num mundo sem barreiras à produção do conhecimento, mobilidade e capacidade de cooperação em rede passaram a ser conceitos-chave para todos os profissionais que atuam com a gestão da informação e para as organizações que competem em um mercado de trabalho cada vez mais globalizado.

Mobilidade deve ser entendida não apenas no seu aspecto físico - até porque, num mundo integrado pela tecnologia da informação e da comunicação, ela está se tornando cada vez mais virtual, principalmente no sentido de flexibilidade, de adaptabilidade, e de interatividade. Ela é o conjunto de atributos que permite ao profissional, aproveitar novas oportunidades em um cenário global, exigindo competências que vão além da formação acadêmica tradicional e da garantia oferecida por padrões internacionais de certificação e validação dos diplomas de nível superior. Esta é uma tendência irreversível que decorre de novas formas de organização da produção, de que são exemplos o outsourcing, ou terceirização dentro das fronteiras nacionais, o offshoring, ou terceirização internacional, e a formação de cadeias de suprimento, de informações e de conhecimento. Assim, pode-se dizer que a mobilidade impõe-se pela necessidade de garantir a competitividade dos blocos econômicos regionais, bem como o desenvolvimento local, em resposta aos esforços da competitividade global. Para alcançá-la, o profissional da informação necessita aliar o conhecimento técnico e científico tradicional elementos básicos da Ciência da Informação - a habilidades de gestão que o qualificam a assumir responsabilidades no novo ambiente organizacional.

A criatividade vem se apresentando cada vez mais como uma característica imprescindível para equipes e indivíduos nos atuais ambientes de trabalho das empresas. O desafio da 
sociedade moderna está em poder identificar a linha tênue onde a criatividade rompe a barreira da ética e ali impor os limites corporativos. Colocar a criatividade a serviço do ser humano é um desafio do mundo moderno; saber caminhar na fina linha que separa o comportamento e atitude ética é uma decisão solitária de cada um.

As mudanças ocasionadas pela tecnologia, relacionadas à geração, disseminação, acesso e uso da informação, demandam novas habilidades e competências. É neste ponto que surge um usuário da informação com solicitações relacionadas aos recursos computacionais e com capacidade para produzir conhecimentos.

A Web 3.0 ou Web Semântica é uma das grandes propostas para o futuro da Internet, pois será ela que definitivamente organizará todas as informações que estejam na Internet. Permitirá que os aplicativos baseados na Web sejam OpenSource e viabilizará uma grande interatividade em diversas áreas da Web. Com o fenômeno do Big Data, a Web 3.0 terá como objetivo organizar as informações para que os usuários tenham mais facilidade no acesso e uso. A busca Semântica, como são chamados os buscadores da Web 3.0, organizam informações por assuntos determinados, algo bem mais complexo do que é usado atualmente pelo mundo inteiro.

Evidencia-se, desta forma, a influência que a tecnologia da informação pode e deve exercer na gestão e organização do conhecimento, permitindo a universalização do acesso à informação. Neste sentido, cabe à Ciência da Informação, em sintonia perfeita e em cooperação tecnológica com o setor produtivo e de serviços, contribuir para a formação adequada dos recursos humanos, oferecendo não só a formação técnica, mas também humanística, de modo que os novos profissionais da Ciência da Informação se tornem vetores de produção de riqueza, distribuição de renda, e desenvolvimento econômico sustentável. 


\section{Referências Bibliográficas}

ARISTOTELES; CRISP, P. (2014). Nicomachean ethics. Cambridge: Cambridge University Press.

BAUMAN, Z. (2007). Tempos líquidos. Rio de Janeiro: Zahar.

BENTON FOUNDATION (1998). The future's in the balance: a toolkit for libraries and communities in the digital age. Washington, D.C.: Benton Foundation.

BOHN, D. (1968). On creativity. London and New York: Routledge.

BRINE, A. (2005). Continuing professional development: a guide for information professionals. Oxford: Chandos Publ.

CHOO, C. W. (1998). The knowing organization: how organizations use information to construct meaning, create knowledge, and make decisions. New York and Oxford: Oxford University Press.

DAVENPORT, T.; PRUSAK, L. (1999). Conbecimento empresarial. Rio de Janeiro: Editora Campus; São Paulo: Publifolha.

DE MASI, D. (2003). Criatividade e grupos criativos. Rio de Janeiro: Sextante.

FERRARI, A C. O. (2004). Desejo de conhecer. Viver mentęcérebro, São Paulo, 13(142), 3.

LE COADIC, Y-F. (1996). A ciência da informação. Brasília, DF: Briquet de lemos Livros.

McNEMENI, D.; POULTER, A.; BURTON, P. (2007). A handbook of ethical practice: a practical guide to dealing with ethical issues in information and library work. Oxford: Chandos Publ.

MATOS, J. R. (2005). Gestão da tecnologia e inovação. São Paulo: Editora Saraiva.

MOREIRO-GONZÁlEZ, J. A.; VERGUEIRO, W. (2012). Por um novo profissional para o setor de informação-documentação: competências e atitudes exigidas pelo mercado de trabalho brasileiro. In: ALMEIDA, Francisco Alberto Severo de; SILVA, Armando Malheiros da; FRANCO, Mário José Batista; FREITAS, Carla Conti de. (org.). Educação, gestão da informação e sustentabilidade. Porto: Universidade do Porto. p. 199-212.

MYBOURG, S. (2005). The new information professional: how to thrive in the Information Age doing what you love. Oxford: Chandos Publ.

OECD (2005). Oslo Manual: guidelines for collecting and interpreting innovation data. 3rd Ed. Paris: OECD Publishing. Acedido a 29 de abril de 2019, em: https://www.oecdilibrary.org/docserver/9789264013100-en.pdf?expires $=1531707363 \&$ id=id\&accname $=\mathrm{g}$ uest\&checksum=FD6EB01F8094083569A60A8D2100C55B.

OECD (2008). Manual de Frascati 2002: proposta de práticas exemplares para inquéritos sobre investigação e desenvolvimento experimental, F-Iniciativas, Barcelona. Acedido a 29 de abril de 2019, em: https://www.oecd-ilibrary.org/science-and-technology/ manual-de-frascati-2002_9789264065611-pt.

OMTID (2018). Observatório do Mercado de Trabalbo em Informação e Documentação. Acedido a 29 de abril de 2019, em: dgp.cnpq.br/dgp/espelhogrupo/1137720761096165

RYAN, B. (2013) Optimizing academic library services in the digital milieu: digital devices and their emerging trends. Oxford: Chandos Publishing.

SAWYER, R. K. (2006). Explaining creativity: the science of human innovation. Oxford University Press. 
TOFFLER, A. (1971). Future shock. New York: Random House.

TOFFLER, A. (1971). Powershift: knowledge, wealth and violence at the edge of the $21^{\text {st }}$. century. New York: Bantam Books.

TOFFLER, A. (1989). The third wave. New York: Bantam Books. 


\title{
A INFORMAÇÃo COMO BASE PROPOSITIVA, DE DESENVOLVIMENTO E DE MANUTENÇÃO DE MODE- LOS DE NEGÓCIOS: RELACIONANDO INFORMAÇÃO E INOVAÇÃO EM CONTEXTOS COMPETITIVOS
}

\author{
INFORMATION ASA PROPOSITIONAL BASIS
} FOR THE DEVELOPMENT AND MAINTENANCE OF BUSINESS MODELS: RELATING INFORMATION AND INNOVATION IN COMPETITIVE CONTEXTS

George Leal Jamil Informações em Rede Consultoria e Treinamento Ltda., Brasil

RESUMO - O tema "modelos de negócios" vem sendo explorado imensamente na imprensa de negócios, demandando agilidade da Academia em responder aos diversos questionamentos teóricos, de fundamento, para ter consistente evolução. Neste capítulo, aborda-se a perspectiva da contribuição indispensável da Ciência da Informação, notadamente da Gestão da Informação e do Conhecimento para maior compreensão destes modelos, de suas implicações, da formulação de decisões organizacionais e da aplicação de tecnologia da informação, todos temas que têm sobremaneira a ganhar com a visão multidisciplinar trazida pela Ciência da Informação. Como tendência, é frente de ampla e forte pesquisa nos próximos anos, dado o dinamismo do relaciona- 
mento estratégico dos modelos de negócios e das tecnologias emergentes com a gestão da informação.

PALAVRAS-CHAVE - Ciência da Informação; Modelos de negócios; Inovação; Gestão da Informação; Tecnologias da Informação.

ABSTRACT - Business models is nowadays one of the most cited and provocative themes of Management, being expressively cited by business areas, demanding fast responses by Academic institutions to produce answers to several theoretical issues, fundamentals, allowing a robust evolution. This chapter approaches the undeniable and indispensable contribution from Information Science, remarkably Information and Knowledge Management to improve these modelling techniques comprehension, along with their implications, decision-making and information technology application, some of numberless topics which can receive contributions from the multidisciplinary view of Information Science. As a trend, business models are a wide and strong research front in the forthcoming years, as the dynamics of its strategic relationship and emerging technologies with information management.

KEYWORDS - Information Science; Business models; Innovation; Information management; Information Technologies.

\section{Introdução}

A modelagem de negócios é, na atualidade, uma das forças competitivas de mercado, compreendendo-se mesmo como a base das inovações organizacionais, conforme enunciado por Schumpeter (1942), Utterback (1971; 1996). A compreensão do que representa, efetivamente, um modelo de negócios (BM), torna-se oportuna e necessária para empreendedores e agentes econômicos variados, incluindo seus parceiros 
de cadeias produtivas, gestores públicos, principalmente nos temas relativos à legislação e regulação, agentes de comunicação, e clientes em potencial. Um BM é, geralmente, percebido como a descrição de como as partes de uma organização podem ser inter-relacionadas, visando à oferta de valor a clientes selecionados (Casedesus-Massanel e Ricart, 2010; Amit e Zott, 2010).

$O$ interesse deste trabalho é de situar a informação nesta proposta de construir, capturar e ofertar valor, relacionar-se com a estratégia empresarial e, finalmente, permitir a manutenção, evolução e desenvolvimento de modelos de negócios. Dada a relevância do tema no contexto empreendedor atual, acredita-se que tal resultado poderá trazer a devida relevância à informação e sua gestão associada neste moderno cenário competitivo baseado em inovação.

A conexão teórico-prática da gestão da informação em modelagem de negócios pode ser entendida, de forma breve, em três fases maiores: (1) A sua proposição, onde as definições conexas à estratégia são relacionadas ao modelo, que instruirá a operação final dos empreendimentos; (2) O desenho efetivo do modelo, relacionando-o aos fatos posteriores, de gestão tática e operacionalização de ações e (3) A implementação do referido modelo, bem como sua manutenção, quando será verificado, através de mapeamentos e monitoramento efetivo de indicadores e seus processos de interpretação, se as previsões e delimitações da modelagem de negócios produziram algo de maneira efetiva, entregando os resultados previstos e permitindo sua gestão (Newt, 2015). É, numa visão ainda superficial, um contexto oportuno para apreciar a gestão da informação, como um agente ainda não completamente relevado, uma visão adicional de processo que trará inegável ganho de nitidez analítica.

No contexto da aplicação dos BMs, portanto, encontram-se várias instâncias onde informações e sua gestão apresentam perspectiva essencial, não recebendo, neste momento, visão mais aprofundada da literatura e das análises práticas. Embora vários destes modelos de 
negócios sejam estritamente baseados em soluções informacionais, como as modernas propostas para a adoção de recursos como big data, analíticos e computação colaborativa, os focos de avaliação residem sobre fatos e processos de ordem tecnológica e resultados financeiros e/ou operacionais, traduzindo-se em um quadro incompleto de apreciação (Wirtz e Daiser, 2017; Bashir e Verma, 2017). Esta lacuna, em termos de análise resulta em perdas de direcionamento, capacidade de desenvolvimento e efetiva identificação das oportunidades, implicando em adicional vulnerabilidade executiva ou perda de sustentação estratégica para os modelos construídos (Verhoeven e Johson, 2017). Em outras palavras, a percepção do fator informacional nestes modelos resulta em maior compreensão de sua funcionalidade, aproveitamento e perspectivas de desempenho, permitindo, entre outras implicações, a melhor relação de produtos e serviços a serem ofertados em oportunidades estratégicas a clientes com perfil de melhor segmentação, repercutindo em situações de potencial ampliação de oferta de valor (Davenport e Prusak, 1998; Phillips, 1999; Takeuchi, Nonaka, 2008; Outvorst, de Vries e de Wall, 2016).

O objetivo deste capítulo é de manter o diálogo Gestão - Ciência da Informação, usando os modelos de negócios como direcionamento de foco. Desta forma, construindo conceituação reflexiva sobre elementos componentes das decisões atinentes a esta modelagem, busca-se, maior compreensão das propostas destes modelos, amparados pelo que provê a postura pós-custodial da Ciência da Informação.

Tal objetivo é buscado através da seguinte sequência: primeiramente, o tema de modelagem de negócios é contextualizado, diante das expressivas demandas atuais nos campos científico e de competição mercadológica. Adiante, na mesma seção, o estudo conceitual contempla potencial relacionamento entre gestão da informação e a proposta e implementação de BMs a ser desenvolvido no decorrer do texto. $\mathrm{Na}$ seção seguinte, tipos praticados de modelos são examinados, do ponto 
de vista conceitual e prático, com base nos fundamentos da Ciência da Informação (CI). Em sequência, uma seção aborda algumas das oportunidades em áreas e temas tradicionais da Ciência da Informação para o estudo dos modelos de negócios, pelo exercício prático, observando como estes dois temas podem se correlacionar nos modernos cenários de implementação, muitos deles com grande relevância na geração e uso de informações para sua implementação. Finalmente, emitem-se reflexões para estudos posteriores, com o atributo de convocar o leitor ao contexto interdisciplinar da CI, no que este estudo pretende se situar como uma provocação inicial, de acompanhar e evoluir boas perspectivas para a modelagem dos empreendimentos, desde que contemplados pela ótica da Ciência da Informação.

Finalizando esta apresentação, afirma-se a crença na oportunidade em perceber e aprimorar temas de várias áreas do conhecimento, com destaque para a gestão organizacional, através do tema de modelos de negócios, com as análises contributivas da CI, onde vários dos aspectos das soluções tornam-se mais nítidos e de melhor aproveitamento, como se aguarda na prática da interdisciplinaridade.

\section{Modelos de negócios e a perspectiva da Ciência da Informação}

Defende-se que há oportunidade no estudo da proposição, construção e vida útil dos modelos de negócios ao analisar o papel da informação como elemento componente essencial de suas definições conceituais e práticas. Este relevante aspecto é base do presente estudo, em que se pretende, fundamentalmente, explorar a mudança de paradigma da Ciência da Informação, ao aderir ao contexto do paradigma pós-custodial. Esta forma de estudo do campo científico prioriza a avaliação dos fatos, processos e métodos ligados ao contexto prático da informação nos atuais cenários organizacionais, contribuindo para a observação, do ponto de vista da CI, para a atual dinâmica dos BMs, bases para inovação organizacional. 
Assim sendo, desenvolve-se, de imediato, uma abordagem do atual conceito de modelos de negócios, avaliando como a informação - e os fatos concernentes à sua gestão - desempenham papel efetivo no que é esta modelagem no atual ambiente competitivo. Dentro da proposta do estudo, explora-se, desde o momento da conceituação, como a informação representa de construto elementar e de oportunidade para os modelos.

A definição de modelos de negócios foi objeto de discussão em meio científico por vários anos, alcançando-se relativa estabilidade recentemente. Pratica-se, neste estudo, o que é coletado e definido por Casadesus-Masanell e Ricart $(2007,2010)$ que modelos de negócios são "a lógica da empresa e a forma como ela opera e cria valor para os stakeholders". Importante notar que, na fonte de 2010, enuncia-se, de forma que alinha a este estudo, que a informação é um dos principais conteúdos de entrega, como integrante da oferta de valor. Os exemplos práticos destes relacionamentos serão apresentados na seção devida, a seguir.

Para estabelecer a conexão ensejada, é importante avaliar de Jamil, Jamil e Santos (2018) como dados, informação e conhecimento, geridos pelos modernos sistemas de informação, que têm por base o uso de recursos tecnológicos de big data e analíticos, são aplicáveis, no contexto dos sistemas de informação, em gestão estratégica organizacional. Este é o primeiro nível de relacionamento que se busca neste trabalho, de definir caminhos onde a informação permite o planejamento e gestão estratégicos organizacionais, portanto, definindo-se como compreender a oportunidade da Ciência da Informação e, efetivamente, contribuir com a Estratégia empresarial. Tal fato corrobora intuições de Magretta (2002), Porter (2008) e Mintzberg, Ahlstrand e Lampel (2010), quando enunciavam, ainda em momento de impacto das primeiras levas de tecnologia da informação disseminada, a função dos sistemas informacionais, providos com base de tecnologia, para formulação, desenho, proposta, execução e monitoramento estratégicos. 
O outro relacionamento de objetivo inicial nesta seção é o que contempla o relacionamento conceitual e prático desta modelagem com a estratégia empresarial. Novamente recorre-se à CasadesusMasanell e Ricart (2010), quando estes determinam que a estratégia supera os modelos de negócios ao ser esta a fonte da definição de qual modelo a ser praticado para atuação competitiva, ofertando e transacionando valor aos clientes finais. Mesmo na literatura de gestão estratégica, em fontes que podem ser consideradas de fundamento para os atuais cenários competitivos, como Penrose (1959), Barney (1991) e Drucker (1993), verificam-se citações em apoio a esta argumentação referente ao efetivo uso de modelos de negócios e estratégia. Desta forma, toma-se por base que a modelagem de negócios surge como uma alternativa relevante ao estrategista, que pode propor tais macrodefinições organizacionais como base essencial de sua formulação estratégica. Oportunamente, lembra-se, de Porter (2008), entre outras várias fontes, que a estratégia organizacional orienta o posicionamento de futuro desta no seu ambiente de atuação.

É, portanto, plausível enunciar o relacionamento da formulação de BMs e informação pelo caminho da estratégia empresarial. Como a estratégia define modelos de negócios e há, inequivocamente, oportunidades para que os vários recursos informacionais contribuam de maneira efetiva, com destaque aos sistemas de informação, para todo o processo de gestão estratégica organizacional, tem-se uma perspectiva sólida de relacionamento entre a gestão da informação e a modelagem de negócios.

Há, entretanto, possibilidade de explorar além este relacionamento de grande potencial ao verificar-se que, principalmente no que tange aos novos modelos de negócios, há contribuição da gestão da informação para que este elemento ativo - a informação - se torne não só insumo, mas produto, isoladamente como único elemento a ser provido ou como importante componente do valor agregado que é negociado com os clientes finais (Mahrt e Scharkow, 2013; 
Mullins, 2014; Massa e Tucci, 2014). Aqui, verifica-se, como afirmado em Jamil e Carvalho (2018), como os modernos recursos tecnológicos que envolvem o ambiente de soluções ofertadas por várias corporações, como os sistemas de big data, analíticos, computação em nuvem e mobilidade, são orientados para prover informação ou serviços baseados em informação aos seus clientes finais. Acham-se, nestes exemplos, sistemas de informação de saúde, em geral, os ligados ao transporte urbano e movimentação de cargas (logística e cadeias de suprimentos) e de ambiente para prestação de serviços financeiros, entre muitos outros.

Tal alinhamento foi alvo de estudo de Osterwalder, Pigneur e Tucci (2005), que é citado com expressão nas pesquisas de modelagem de negócios, onde os autores, todos com envolvimentos significativos no ambiente empresarial, contribuem com o resultado em que enunciam como acervos de informação e conhecimento direcionados ao provimento aos clientes finais com elevado potencial de agregação de valor, tornam-se fator estratégico preponderante nas modelagens de negócios.

O potente relacionamento da gestão da informação e dos modelos de negócios, enunciado com base na estratégia empresarial é, portanto, validado ao leitor como base deste texto, servindo, neste ponto, de apoio contextual para a seguinte avaliação com maior detalhamento das informações no âmbito dos modelos de negócios.

\section{Análise informacional de propostas de modelos de negócios}

O contexto da proposição de modelos de negócios é, nos dias atuais, desafiador, crítico e competitivo. Organizações de todo o tipo e tamanho buscam avaliar suas modelagens no sentido de se manterem em condições de atender a seus clientes e de se manterem em posições de vantagem nos processos de negociação envolvidos (Khanaga, Volberda e Oshi, 2014; Kavadias, Ladas e 
Loch, 2016). Como uma publicação de base para tal motivação, a proposta dos negócios em "Oceanos Azuis" (Kim e Mauborgne, 2015) inseriu definitivamente o contexto da inovação em posicionamento de valor como tema essencial de vida competitiva das empresas como organizações típicas. Neste livro, por vezes disseminado de maneira um tanto açodada, o que leva a imprecisões, os autores relacionaram a inovação via nova proposta de BMs (Schumpeter, 1942; OECD, 2005) com a gestão estratégica, perfazendo conexão inicial que nos interessa para a presente abordagem, pois, diante do afirmado na seção anterior, principia também o cenário para discutir as contribuições da Ciência da Informação nas modelagens de negócios que seriam praticadas para a definição de postura em mercados gerados, inovadores, onde o valor ofertado, praticado e conhecido pelos clientes é também inovador, característica dos "oceanos azuis".

Nesta seção, alguns dos modelos praticados com maior frequência em ambientes de mercado serão avaliados sob a ótica informacional adicionando, desta forma, percepção aprofundada às suas perspectivas competitivas, como uma contribuição destacada da Ciência da Informação.

Numa primeira análise, têm-se os chamados modelos de recursos compartilhados, de onde originam-se as definições de marketplace, nos quais provedores de serviços são registrados em plataforma de acesso identificado pelos usuários, que, através de seleções feitas com auxílio de mecanismos destas plataformas, requisitam, pagam e avaliam os serviços prestados (Mullins, 2014; Jamil, Lema e Peñalver, 2018). De maneira genérica, são referidos como modelos de "Uberização", em assinalamento trivial à empresa de compartilhamento de transportes norte-americana Uber, um dos empreendimentos de maior visibilidade no uso desta modelagem.

Consideram-se, tais modelos, como totalmente baseados em gestão da informação, evidenciando-se tal fato nos seguintes aspectos de sua operacionalização: 
- São orientados à coleta de dados e informações de usuários e de provedores (motoristas e demais prestadores de serviços das várias ofertas no tipo de plataforma). Com estas, de maneira adaptativa, são processadas avaliações dos clientes, que originam indicações aos clientes, promovendo a oferta.

- Integram várias outras ferramentas que atuam com dados dinâmicos, como plataformas de monitoramento de tráfego (como exemplo, a solução "Waze" da empresa Google, entre várias outras), serviços de GPS, tabelas de preços e cotações (nos casos de serviços liberais e sindicalizados), ofertando ao cliente uma versão integrada de todas estas informações.

- Podem ser adequadas a ambientes de integração com analíticos e formação de acervos de big data (McAfee e Brynjolfsson, 2012) para oferta a outras plataformas, em negociação de acervos e conteúdos informacionais, bastante adequada ao contexto de produtos e serviços a base de informação, bem como para a oferta de novos produtos e serviços diferenciados em planos estratégicos potenciais.

Torna-se importante relevar o aspecto destacado destes ambientes, que originam, na atualidade, várias propostas não apenas de oferta a clientes finais (consumidores individuais), mas também entre empresas em modalidade de inter-relacionamento, com o conhecido "business to business" (ou, em sigla amplamente adotada, B2B), forma de extrema importância no atual relacionamento empresarial de cadeias produtivas.

Para alguns autores, este modelo é, basicamente, uma estrutura baseada em sistema de informação, em seu mais amplo conceito - conjunto de componentes orientados a possibilitar a gestão da informação - dotado de interfaces que possibilita seu acesso em equipamentos diversificados. O sucesso do modelo torna-se passível de maior interpretação quando observado pela análise provida pela Ciência da Informação. 
Outro modelo de negócios é o que implementa uma versão da demanda por repetição, estudada em serviços de logística (Bowersox et al., 2013), porém com formas variadas ao implementar, que os tornam mais atrativos, como o de prover o cliente com sistemas baseados em "assinaturas". Nesta conhecida modalidade, o cliente contrata uma entrega de produtos periodicamente (por exemplo, todo mês), recebendo uma "cesta" ou conjunto de produtos elencados pelo provedor, através de sorteio parcial ou total (Sako, 2012; Mullins, 2014).

Há inúmeras aplicações dos fundamentos da gestão de informação no lançamento e na manutenção destes serviços, sendo este último aspecto motivo de riscos, falhas e até mesmo fracassos destas iniciativas. É usual a constatação de mercado que serviços como estes têm grande popularidade no início, em mercados como os de alimentos (vinhos, alimentos "saudáveis", gastronomia sofisticada, entre outros), produtos de linhas esportiva (vestuário, acessórios), ligados ao ambiente "geek / nerd" (jogos computadorizados, recursos de informática, etc.), perdendo a atratividade progressivamente e / ou enfrentando problemas na reposição de estoques, variedade de entregas e gestão financeira.

A aplicação da gestão da informação nas análises de mediação, recuperação de analíticos para a definição de perfis e antecipação de reações de clientes, desenvolvimento de mercados e gestão de relacionamento de clientes são pontos que podem ser implementados com relativa facilidade em termos do direcionamento de implementação tecnológica, caso a GI seja usada como base. As teorias de marketing, gestão de custos, estoques e finanças, já premiam esta associação com a gestão da informação por décadas, tornando o conhecimento disponível para as alternativas estratégicas, no exato alinhamento discutido em seção anterior, entre estratégia, modelo de negócios e tática, visando a operação com influência e colaboração da GI.

Uma outra modalidade de grande difusão como modelo de negócios de base tecnológica é a que implementa o SaaS, do inglês Software 
as a Service, software como um serviço (Sako, 2012; Mullins, 2014; Jamil, Lema e Peñalver, 2018). São soluções densamente providas de recursos informacionais, evoluções dos modelos predecessores de clientes e provedores, advindos de concepções da tecnologia da informação (Jamil, 2014). Nesta modalidade, o usuário final (cliente ou consumidor) tipicamente utiliza um programa receptor e de interface em um equipamento móvel, acessando bases de dados e recursos mais sofisticados e demandantes de infraestrutura, residentes em um sistema servidor, via acesso por redes como a Internet.

De uso amplamente disseminado, esta é a base de soluções como a provedora de vídeos em modalidade "streaming" (de continuidade) Netflix (também de áudio, como o Spotify), a servidora de pagamentos Paypal e serviços de compartilhamento de informações para a gestão, como o sistema Sales Force. Esta modalidade pode ser considerada genuinamente uma forma de processo baseada em dados e informações. Enquadra-se, de maneira ampla, também numa concepção de sistema de informação equipado com interfaces, cabendo aqui todo imenso potencial de contribuição da CI no desenho de sistemas de recuperação, acesso, interfaces de aptidão e adestramento do usuário, seleção dinâmica de carteira ou cardápio de ofertas (um dos maiores atrativos destes modelos), entre outras situações.

Uma característica que chama especialmente a atenção nos serviços de continuidade, como típicas soluções de modelagem de negócios de base para SaaS, é a geração de aprendizado, provida pelas inovadoras concepções de big data, uso instantâneo, mobilidade e analíticos, em associação. Na prática, tais aplicações, que têm por fonte a base conceitual e prática da gestão da informação, permitem ao provedor, através da coleta, processamento e análise de interações com os usuários, vários níveis de aprendizado - como exemplos: formas de interação, garantindo que o cliente não se afaste prematuramente de uma oferta; avaliar seleções combinadas, em conjunto (como ofertar um episódio de série adicional ao cliente, por este se enquadrar 
potencialmente em perfil que se agradará desta nova oferta, avaliando suas preferencias anteriores), composição de "playlists" ou sequências prévias de escolha e, finalmente, predição de comportamentos, numa busca que é ensejada sempre pelas teorias de marketing, ao buscar a predição de anseios do consumidor.

Importante ressaltar que, com a modernização e agilidade dos recursos tecnológicos, o campo teórico é requisitado para enunciar fundamentações práticas com agressiva intensidade. Num exemplo objetivo, o cliente pode receber sugestões online para sua próxima aquisição em virtude de suas últimas reações, havendo perspectiva que o próprio provedor o reclassifique em outro perfil de consumo caso se torne menos ou mais ativo, com uma nova segmentação de perfil mercadológico, motivando tratamento diferenciado. Este é o ambiente usual de competitivos serviços de comércio eletrônico, como exemplo os da loja Amazon e de sites de comercialização como o Mercado Livre, em que o cliente é "reconhecido" e tem tratamento ajustado com dinâmica invejável, levando à gestão de relacionamento flexível, rápida e gerenciável. Adicionalmente, o serviço integrado de provimento de informações possibilita que serviços integrados como e-mail, mensagens em redes sociais (providos na base de acesso do cliente por instalação de arquivos de configuração usualmente denominados "cookies", entre outros) e demais formas de acesso, torne a interação com os potenciais e reais clientes mais efetiva. Esta modalidade tem possibilitado mesmo a integração de equipamentos de acesso, como relógios de pulso, óculos e outros aparatos, introduzindo nova versão da chamada "servitização", modalidade que busca adicionar valor agregado a produtos pela oferta complementar de serviços associados - por exemplo, no uso de óculos com implementação tecnológica que permita ao cliente assistir vídeos selecionados por um provedor de continuidade.

Os modelos baseados em gestão de escassez (Sako, 2012; Mullins, 2014) são considerados especialização da gestão de cadeias de su- 
primentos e logística, no seu acoplamento aos sistemas de produção. Destinam-se, fundamentalmente, a provocar o consumo de artigos em ciclos de demanda, ajustando rigorosamente a oferta, em sentido inverso: o potencial consumidor é provocado ao consumo ao ser informado que o ciclo de oferta se acha em prazo ou situação final. O provedor, portanto, oferta os artigos em caráter limitado e informa ao consumidor desta restrição, pressionando as negociações. Efetivamente dependente de situações mercadológicas, como as encontradas nas redes de "fast-fashion", de maneira emblemática, estes modelos de negócios também são praticados em outras cadeias produtivas, como a automotiva e a de alimentos. As empresas com "bandeiras fortes" - marca, oferta, concentração de mercado e condições de negociação em vantagem - conseguem produzir tais ciclos e gerenciar sua proposição aos clientes, reduzindo seu poder de barganha na negociação, numa inequívoca evocação do relacionamento entre estratégia, modelos de negócios e dinâmicas propiciadas pelos princípios da gestão da informação.

A GI é processo crítico para o que este modelo seja aplicável, uma vez que o pleno ajuste dos sistemas de suprimento, comercialização e produção é essencial para que os limites de oferta sejam vantajosos ao empreendedor. Além disso, o cliente é envolvido de maneira indispensável em rede de comunicações, uma vez que sua motivação em transacionar com o provedor da oferta é essencial para o sucesso do modelo. Mensagens, anúncios e evidências, propiciados por elementos tão cotidianos como as "janelas em pop-up" na navegação internet, mensagens SMS, uso de comunicação de mensagens instantâneas (como o tipo apresentado pelo sistema "Whatsapp", de propriedade da empresa Facebook), entre outros, definem a base de tais processos. Estes, por sua vez, são contextos informacionais em que a seleção correta de perfis através da análise de dados massificados, a adequação da oferta, definições de parâmetros quantitativos como prazos, preços e condições de 
negociação são fatores primordiais para que tal modelo possa ser considerado como bem-sucedido.

Outra proposta de modelagem, que pode ser considerada como adaptação de algumas das anteriores, é a de plataformas. Como discutido por Gautatis (2017), trata-se de conceito amplo, ainda disperso, dado que é justamente descrito como uma oferta conjunta de serviços por parte de um sistema baseado na Internet, que pode prover interconexão a outras plataformas, redes e corporações. Com uma conceituação tão vasta, as plataformas podem ser configuradas para entrega de um conjunto de serviços a clientes de uma corporação, unindo, por exemplo, provimento de áreas em disco para colaboração, e-mail, identificação digital, sede de serviços web particulares, monitoramento de analíticos, comunicação e gerenciamento de contatos, entre vários outros. Como exemplo, podem ser inscritos neste tipo os recursos disponíveis nos contextos de empresas como Google, Facebook, Amazon, entre outras, usualmente caracterizadas como a "nova onda" de competidores digitais oriundos do setor de tecnologia da informação.

Vale notar, entretanto, ampliando o uso do mesmo conceito, que as bases de operação de instalações industriais modernizadas, como as intituladas "Indústria 4.0" (Jamil, Lema e Peñalver, 2018), podem apresentar importante configuração e conexão de plataformas, uma vez que nestes inovadores ambientes, os serviços ligados ao planejamento, monitoramento e execução de operações - perfazendo uma base de gestão otimizada de produção industrial - envolvendo sistemas automáticos, robôs e programas orientados a otimização de linhas produtivas, podem favorecer a conexão de cadeias produtivas. Assim sendo, empresas possuem suas plataformas, que podem ser ligadas a outras plataformas. São bases informacionais multisserviços que se conectam a outras, ampliando o potencial de gestão e produtividade.

Tais arranjos, buscando observar pelo lado da gestão da informação, têm a oferecer justamente a GI como potencial benefício 
de suas integrações. Numa forma de simples de avaliar, um usuário de uma base Google ou Facebook, por exemplo, pode ter vários de seus requisitos, desejos (como intenções de aquisição de bens e serviços), identificação, preferências, formas de comunicação e outras ações, monitoradas e registradas pelas plataformas. Neste ambiente, os usuários são provedores, construtores, desenvolvedores e clientes de contextos informacionais, numa dinâmica que acaba por realizar o que era antecipado por autores como Silva (2009), quando abordou a existência, demanda e evolução dos níveis mediadores, a partir do campo da Ciência da Informação. Ali, o autor antevia sinais de tensão na mudança de paradigma analítico da CI ao pós-custodial, permitindo que fossem verificadas perspectivas como esta, de integração de plataformas informacionais, em oferta que direciona a teoria à prática.

Esta é uma seção impraticável de ser concluída. Descreveram-se os modelos marketplace, por demanda (assinatura), SaaS, escassez e plataforma, que, por si apenas, já ensejam adaptações e dinâmicas diversas. Uma só interface bem adaptada a um dispositivo ou serviço web, amparada por uma grande empresa transnacional, de setores variados como entretenimento, turismo ou comércio, poderá traduzir-se em uma oferta combinada, que redesenhe os conceitos apresentados. Portanto, a tênue base conceitual apresentada tende a se esgotar em breve, pela substituição estratégica que busca gerar novas oportunidades de mercado.

Portanto, há ainda a possibilidade, deixada na abordagem das "plataformas" de integração entre modelos entre as bases conceituais. Se há integração e as ofertas ampliadas, o que se tem ao final? É a mesma plataforma? Algo ampliado, que foi modificado? É um tanto difícil de ter-se uma conceituação restrita, objetiva, ao menos neste momento. Tal desafio advém de aspectos organizacionais internos, como sua estratégia formulada (que se apoia, por sua vez, também em contextos externos) e de mudanças externas, como a modificação 
de sistemas de acesso e conexão. Portanto, um ambiente provocativo, instável e de grande competitividade ao redor de tecnologias, culturas, formas de uso e serviços emergentes que se alinha ao espírito chamativo do capítulo, de provocar o leitor à evolução dos estudos.

Procurou-se ilustrar ainda algumas oportunidades de aplicação de estudos e contribuições pela Ciência da Informação nestas formulações de modelos de negócios, com o intuito de prover também sua apreciação para outros que possam ser propostos e desenhados a partir do cenário atual. O campo de oportunidades para a CI é ilimitado, trazendo adicional pressão para que esta análise não seja de conclusão possível, apenas de apresentação inicial, adequada ao que se propôs no início deste capítulo, situando-se como estudo exploratório que busca provocar o leitor na contínua observação destes desenvolvimentos.

A próxima seção compõe algumas oportunidades para a Ciência da Informação, avançando neste cenário crítico e de difícil delimitação.

\section{Perspectivas para a Ciência da Informação em análises de modelos de negócios}

A Ciência da Informação possibilita ao estrategista várias alternativas para aprofundamento da compreensão das complexas decisões envolvidas na formulação estratégica de um modelo de negócios, bem como nas análises de quando este é efetivamente posicionado no mercado. Nesta seção, de maneira abrangente, com o intuito de motivar o aprofundamento do debate, alguns temas do campo científico serão avaliados para aplicar-se no estudo dos BMs.

Inicia-se esta avaliação pelos chamados estudos centrados no usuário. O percurso histórico da CI contempla, inicialmente, os estudos de base quantitativa, ainda úteis para a aplicação em gerir os modernos modelos de negócios que buscam avaliar o montante de dados e informações coletadas, armazenadas, distribuídas e 
efetivamente recebidas. De maneira simples, como adequado aos paradigmas anteriores da Ciência da Informação, favorecem ao dimensionamento de recursos de infraestrutura computacional, auxiliam na delimitação de volumes de comunicação e interações entre parceiros e o usuário final e na aferição de relacionamentos finais de cadeias produtivas, entre outros. Apresentam limitações nas projeções e na qualificação destes contatos, principalmente quando se deseja analisar a efetividade dos sistemas e dos recursos aplicados para comunicar (Rabello, 2013; Carvalho, 2018). Como exemplo, no modelo de negócios de gestão por escassez poderiam contribuir para diferir o motivo de aceite ou recusa, por um potencial cliente, do contato realizado, possibilitando o ajuste nas interações futuras, aprimorando a prática do modelo em si.

Adicionando-se o escopo de estudos qualitativos de comportamento do usuário da informação, ao aplicar metodologias participativas, de grupos de controle e foco, entre várias outras, é possível responder ao "porquê" destes resultados, efetivamente encontrando as razões de sua ocorrência. Neste sentido, correlacionando ao simples exemplo acima apresentado, poder-se-ia compreender, com maior detalhe, o que levou o usuário a retornar ou evadir-se da negociação com o empreendimento, racionalizando-se causas ao efeito, possibilitando o desejado ajuste do ambiente.

Outra área a ser significativamente beneficiada com a aplicação do campo da Ciência da Informação é a de projeto de interfaces. Fator crítico no aceite e na satisfação do usuário de sistemas informacionais - via aparelhos de mobilidade, interativos, via web, via aplicativos em equipamentos descentralizados e dispositivos especiais, como relógios, pulseiras, etc. - o projeto de interfaces há muito deslocou-se dos imediatos aspectos tecnológicos, envolvendo princípios de jogos digitais, mapeamento, comunicação via avatares (personificação de seres humanos semelhante às dos desenhos animados), entre outros recursos. 
As questões típicas de usabilidade, rapidez e efetividade no acesso às informações, desenvolvimento de relacionamento com os acervos de informações, usos de símbolos e recursos de comunicação em substituição aos textos e aplicação de multimídia são temas versados em Ciência da Informação, em que estudos do campo científico podem trazer benefícios às modelagens de negócios que se apoiam em interações deste tipo (Costa e Ramalho, 2010). Num exemplo livre, pode-se avaliar como um sistema SaaS, de oferta de vídeos em sistema de continuidade, pode ofertar, em navegação imediata, títulos que complementam, satisfazem e provocam o usuário, ajustando-se dinamicamente a interface aos potenciais desejos deste, ampliando a noção de agregação de valor. Tais princípios subsidiam o uso das bases Youtube e Netflix, entre várias outras atualmente, com grande aceite por clientes potenciais e frequentes, tornando-se verdadeiros indexadores ativos para o uso das bases de vídeos.

As perspectivas de gestão da informação e do conhecimento (GIC), em processos associados, também podem determinar possibilidades de difusão dos modelos de negócios como instrumentos estratégicos (Jamil, 2014; Jamil, Lema e Peñalver, 2018). Ao buscar a construção de acervos de maior qualificação e poder intrínseco, como pode se definir o conhecimento, a prática destes modelos de negócios adiciona, em perspectivas aos estrategistas organizacionais, o poderio de fatos potencialmente geradores de vantagens competitivas (Barney, 1991; Porter, 2008), como a redefinição de processos integrados, antecipação nas sintonias entre demanda e produção, redefinição em períodos breves de novos perfis de usuário com associação da atratividade de cada segmento, enfim, campos importantes de coordenação de disciplinas e unidades táticas e operacionais, adequando-se ao perfil estratégico enunciado como fundamento deste estudo.

A GIC tem suas concepções, conforme apresentada e conceituada nas fontes acima, com base na disponibilidade de recursos de tecnologia da informação, uso destes em processos determinados 
de coleta, armazenamento, preparo, compartilhamento e monitoração do uso e, finalmente, na avaliação contínua das condições do ambiente onde os acervos são efetivamente aplicados (Silva, 2002; Jamil, 2014). As modernas concepções do processo de GIC enquadram, potencialmente, os sistemas de analíticos como geradores de percepções adicionais à coleta e preparo de informações, produzindo curvas de tendências, gerando recomendações de ações e, atualmente, iniciando a implementação através de recursos de interação automáticos (como os chamados "chatbots", automações de conversa homem - máquina). É campo vasto que já seguia entre controvérsias e grande produção pelos estudos da Ciência da Informação e que, agora, necessita de abordagens adicionais, dado que a CI já desenvolveu, através da aplicação de vários métodos de pesquisa, bases e análises conceituais passíveis de compreensão por parte dos proponentes de modelos de negócios. É interessante afirmar que, para muitos autores, o próprio conhecimento tornou-se fator estratégico, tanto na sua retenção, por si só, como pelos processos de GIC, relacionando-se também à formulação de vantagem competitiva.

Dentre várias definições e exercícios conceituais, definem-se os sistemas de informação (SIs), em consolidação de Turban, Rainer Jr. e Potter (2007), O’Brien e Marakas (2008) e Stair e Reynolds (2009), como um conjunto integrado de metodologias de processos, dispositivos, programas e pessoas que objetiva tratar a informação em ambientes organizacionais, com amplitude de funções e relevância de entregas. As evidências práticas dos SIs são várias, compondo desde análises mais críticas de sistemas transacionais simples, como os de apoio à burocracia empresarial essencial (folhas de pagamento, registros contábeis e processamento de pedidos de clientes) até os mais complexos, destinados, por exemplo, a prover informações em tempo real sobre eventos climáticos, saúde, evolução de ambientes de negociação financeira, entre outros. 
A abordagem da Ciência da Informação para os SIs é vasta e repleta de análises e repercussões teóricas e práticas, ao observar dois campos conceituais tão fortes: os sistemas (como integração ativa de partes, componentes com finalidade específica) e a informação, propriamente dita. Ressalte-se, como contribuição extremamente significativa da CI, a concepção de totalidade dos sistemas de informação ao propor estudos como:

- O estudo de cada elemento componente, porquanto integrante de um conjunto completo, na configuração organizacional desejada para um sistema de informações;

- A abordagem da integração dos elementos, nos conjuntos de interações entre estes.

- A associação entre os próprios sistemas de informações, possibilitando a integração entre organizações, tipicamente empresas, propondo definições que se enquadram em alternativas estratégicas de ponta.

Desta forma, é importante a possibilidade da contribuição da CI para estes novos contextos nos quais sistemas de informação passam a se constituir em base e, eventualmente, até mesmo no todo dos modelos de negócios, como discutido em partes anteriores deste texto, quando alguns dos modelos típicos, como SaaS e plataformas, foram assemelhados a concepções de sistemas de informação. A análise pela Ciência da Informação, em temas como os que aqui são mencionados em caráter de motivação inicial para os estudos, traz contribuições inegáveis para o melhor aproveitamento dos sistemas de informação, ampliando aquilo que campos, como a Administração e Ciência da Computação, realizam. Dado que é contexto integrado, algumas das possibilidades em perceber os SIs via apreciação informacional seriam: 
- As interações com usuários intermediários (de cadeias produtivas) e finais (consumidores) com os grandes contextos dos sistemas de informação, analisando carências, formas de acesso, avaliações dinâmicas de retornos, aprimoramento de uso, necessidades de treinamento, etc.

- A avaliação qualitativa da composição dos acervos - aqui destacando-se a atual imaturidade de recursos como os big data e analíticos, em seus primeiros momentos de uso e já demonstrando resultados estratégicos - permitindo aos projetistas e, finalmente, para os estrategistas, o aprimoramento e várias otimizações de desenho e uso dos sistemas de informação (reiterando-se que alguns são, de maneira completa, os modelos de negócios em si).

- Maior esclarecimento nos potenciais de conexão entre os componentes - por exemplo, ao permitir melhor percepção dos papeis dos usuários da informação diante das ofertas, tecnologias de recuperação, armazenamento e acesso, entre outras. Este fato enriquece o projeto dos SIs.

- Adicionando aos contextos estratégicos de uso dos sistemas de informação, associando suas produções e usos aos processos críticos de tomadas de decisão neste nível - riscos, mitigação, impactos, implementação de soluções, etc.

Outro aspecto em constante modificação e aprimoramento são os estudos de recuperação de informação, considerados uma das características contribuições da CI. Antes somente apoiados em bases quantitativas, permitindo análises sintonizadas com os estudos da Engenharia e Computação, onde os objetivos eram de dimensionamento de capacidades de transmissão e alocação de dados, o ganho em análise qualitativa e de satisfação dos usuários ampliou sobremaneira a percepção de como estes processos de recuperação podem ser decisivos (Marques et al., 2008; Rodrigues e Crippa, 2009; Monteiro et al., 2017). 
Por último, a argumentação incessante a um fato inegável: a interdisciplinaridade praticada nos estudos da Ciência da Informação. Como temas orgânicos, integrados e de evolução imprevisível, os modelos de negócios não podem ser estudados de forma unilateral, com abordagens restritas. Os enunciados das avaliações quantitativas, comentados no decorrer deste estudo, de elevada contribuição para várias funções são, atualmente, considerados limitados, cabendo provocações para estudos qualitativos complementares, demonstrando a necessidade de ampliação das visões científicas em modelagem de negócios para que sejam efetivas.

Neste tocante, a CI apresenta-se como campo ainda pouco explorado, de grande potencial contributivo, onde o presente texto tem, como objetivo, ser mera motivação inicial, instigando ao leitor o decurso dos estudos ligados aos temas já abordados - como sistemas, recuperação, uso e papeis dos usuários da informação, entre outros. Acredita-se, com evidências do desenvolvimento histórico da evolução da CI, como na mudança fundamental de paradigma ocorrida, que esta possa ainda apresentar inéditos campos de análise que trarão benefícios à modelagem de negócios.

\section{Conclusões}

O presente capítulo teve por objetivo motivar a análise de como a informação é tema e conceito integrante das proposições dos modernos modelos de negócios, apresentando o campo da Ciência da Informação como candidato efetivo a compor o acervo científico para a adoção destas soluções. A CI, conforme discutido no texto, já é de extrema aplicabilidade, para teóricos e praticantes, ao permitir a visualização das soluções integradas, dos modelos já em prática e é contribuição evidente para a manutenção e desenvolvimento destas proposições. 
No decorrer deste estudo, a conceituação do alinhamento estratégico para a modelagem de negócios, sua associação aos aspectos e processos ligados à informação, a análise de várias propostas de modelos de negócios em uso no mercado atualmente - com o amparo de base conceitual - adicionando-se as visões da CI para cada caso e sugestões para a aplicação do que já desempenha a CI, formaram a sequência de abordagem.

Acredita-se que a Ciência da Informação pode se apoiar na atual difusão dos modelos de negócios, inclusive no paradoxo de sua adoção intempestiva e descontrolada para prover aos empreendedores e consultores, o amparo analítico que levará à maior substância e chances de sucesso na agregação de valor desejada em todas as situações. O papel da informação como elemento integrador, difusor, intermediador e de gestão em evolução constante, representa inegável fator estratégico para organizações em suas modelagens estratégicas de negócios.

Recomenda-se ao leitor, finalmente, o prosseguimento dos estudos nas direções propiciadas pela Ciência da Informação, como os citados no final do desenvolvimento textual, com discussão ainda em início, de grande oportunidade de pesquisa e implementação e, inegavelmente, carência pela comunidade empreendedora.

\section{Referências Bibliográficas}

Barney, J. (1991). Firms Resources and Sustained Competitive Advantage. Journal of Management, 17(1), 99-120.

Bashir, M. \& Verma, R. (2017). Why business model innovation is the new competitive advantage. IUP Journal of Business Strategy, XIV (1), 8-17.

Bowersox, D.; Cooper, B. M.; Bowersox, J. e Closs, D. (2013). Gestão Logística e da cadeia de suprimentos. São Paulo: Mc Graw Hill.

Carvalho, J. (2018). Estudo de usuários de informação. Acedido em agosto de 2018 em http://biblioo.info/estudos-de-usuarios-da-informacao/.

Casadesus-Masanell, R. \& Ricart, J. E. (2007). Competing Through Business Models. IESE Business School Working Paper No. 713. Acedido em maio de $2018 \mathrm{em}$ https://ssrn.com/abstract=1115201 or http://dx.doi.org/10.2139/ssrn.1115201. 
Casadesus-Masanell, R. \& Ricart, J. E. (2010). From strategy to business models and to tactics. Long range planning, 43 (2-3), April-June 195-215, https://doi. org/10.1016/j.lrp.2010.01.004.

Costa, L. F. \& Ramalho, F. A. (2010). A usabilidade nos estudos de uso da informação: Em cena usuários e sistemas interativos de informação. Perspectivas em Ciência da Informação, 15 (1), 92-117, janeiro - abril.

Davenport, T. \& Prusak, L. (1998). Conhecimento empresarial. São Paulo: Editora Campus.

Drucker P. F. (1993). Post-Capitalist society. New York: HarperCollins.

Gatautis, R. (2017). The rise of platforms: business models innovation perspectives. Inzinerine Ekonomika-Engineering Economics, 28(5), 585-591, http://dx.doi. org/10.5755/j01.ee.28.5.19579.

Goldsby, T. J. \& Zinn, W. (2016). Technology Innovation and New Business Models: Can Logistics and Supply Chain Research Accelerate the Evolution? Journal of Business Logistics, 37(2), 80-81.

Jamil, G. L. (2014). Why quality? Why value? Is it information related to these aspects? In Jamil, G. L.; Silva, A. M. e Ribeiro, F. Rethinking the conceptual base for new practical applications in information quality and value. 1-18. Hershey, United States: IGI Global.

Jamil, G. L.; Jamil, C. C. \& Santos, L. H. R. (2018). Market intelligence as an information system element: delivering knowledge for decisions in a continuous process. In Jamil, G. L. Handbook on research of expanding business opportunities with information systems and analytics. 1-14. Hershey, United States: IGI Global.

Jamil, G. L. \& Carvalho, L. F. M. (2018). Improving Project management decisions with big data analytics. In Jamil, G. L. In Handbook on research of expanding business opportunities with information systems and analytics. 1 - 16. Hershey, United States: IGI Global.

Jamil, G. L.; Peñalver, A. B. \& Lema, D. G. P. (2018). Reflecting on industrial business models: a history of tradition, challenges and potential innovations. In Alcaraz, J. L. G., Cadavid, L. R., González-Ramírez, R. G., Jamil, G. L., Chong Chong, M. G. Best Practices in Manufacturing processes: experiences from Latin America. Suíça: Springer Nature.

Kavadias, S.; Ladas, K; \& Loch, C. (2016). The transformational business model. Harvard Business Review, Acedido em maio de 2018 em https://hbr.org/2016/10/ the-transformative-business-model.

Khanaga, S.; Volberda, H. \& Oshi, I. (2014). Business model renewal and ambidexterity: structural alteration and strategy formation process during transition to a Cloud business model. $R$ \& D Management. 44(3), 322-340.

Kim, W. C. \& Mauborgne, R. (2015). Blue Ocean Strategy: Expanded Edition. Harvard Business Review Press, Cambridge, USA.

Mahrt, M. \& Scharkow, M. (2013). The value of big data in Digital Media research. Journal of Broadcasting E Electronic Media 57(1), 2013, 20-33 DOI: 10.1080/08838151.2012.761700.

Malmström, M. \& Johansson J. (2017). Practicing business model management in new ventures. Journal of Business Models, 5 (1). 1-13.

Marques, A. A. C.; Carvalhêdo, S. P.; Costa, M. G.; Oliveira, F. H. \& Silva, P. A. (2008). Recuperação da informação: o foco comum entre a Ciência da Informação e a Arquivística. Anais do IX Enancib, mídia digital, São Paulo, 2008. 
Massa, L \& Tucci, C. L. (2014). Business model innovation. In Dogdson, M.; Gann, D. \& Nelson P. (editors) The Oxford Handbook of innovation management. Oxford University Press, Oxford, United Kingdom, p. 420-441.

McAfee, A. \& Brynjolfsson, E. (2012). Big data: the management revolution. Harvard Business Review, 90 (10), 60-68, Harvard Business Publishing, Cambridge, USA.

Mintzberg, H.; Alhstrand, B. \& Lampel, J. (2008). Strategy Safari. Pearson Education, New York, USA.

Monteiro, S. D.; Fernandes, R. P. M.; DeCarli, G. C. e Trevisan, G. L. Sistemas de recuperação da informação e o conceito de relevância nos mecanismos de busca: semântica e significação. Encontros Bibli, 22 (50), acedido em agosto de 2018 em https://periódicos.ufsc.br/index.php/eb/article/view/1518-2924.2017v22n50p161.

Mullins, J. (2014). Customer-funded business: start, finance or grow your company with customer's cash. Wiley, Hoboken, USA.

Newt, F. (2015). Business Models and Strategy. In Business models and strategic management, capítulo 5. Boston: Harvard Business Publishing, 220-230.

Nonaka, I. \& Takeuchi, H. Gestão do conhecimento. Porto Alegre: Ed. Bookman, 2008.

OECD - Organization for Economic Cooperation and Development. (2005). Oslo Manual. Acedido em https://www.oecd.org/sti/inno/2367580.pdf, em maio de 2018.

Osterwalder, A.; Pigneur, Y. \& Tucci, C. L. (2005). Clarifying business models: past, present and future of the concept. Communications of Association for Information Systems, 15(1), 1-25.

Outvorst, F. v.; de Vries, E. \& de Wall, B. M. E. (2016). Sourcing of business information management. Proceedings da European conference on management, leadership and Governance, outubro de 2016.

O’Brien, J. \& Marakas, G. (2008). Management Information Systems. Irwin: Mc Graw Hill.

Penrose E. T. (1959). The Theory of the Growth of the Firm. Wiley, New York, USA.

Phillips, J. (1999) Information management in new business models. The information management journal, Julho de 1999, 58-60.

Porter, M. (2008). On Competition. Harvard Business School Press, Cambridge, USA.

Rabello, R. (2013). Leituras sobre usuário e uso de informação em Ciência da Informação. Perspectivas em Ciência da Informação, 18 (4), 152-184, outubro - dezembro de 2013

Ries, E. (2011). The Lean Startup: How Today's Entrepreneurs Use Continuous Innovation to Create Radically Successful Businesses. Crown Business, New York, USA.

Rodrigues, B. C. e Crippa, G. (2009). A recuperação da informação e o conceito de informação: o que é relevante em mediação cultural? Perspectivas em Ciência da Informação, 16 (1), 45-64, janeiro - março de 2009.

Sako, M. (2012). Business models for strategy and innovation. Communications of ACM 55 (7), 22-24.

Schumpeter, J. A. (1942). Capitalism, Socialism and Democracy. Harper-Collins, New York, USA. 
Silva, A. M. (2009) Mediações e mediadores em Ciência da Informação. Revista Prisma.com, no. 9, 68-104.

Silva, S. L. (2002). Informação e competitividade: a contextualização da gestão do conhecimento em processos organizacionais. Revista Ciência da Informação. 31(2), 142-151, Maio - Agosto de 2002.

Stair, R. \& Reynolds, G. (2009). Principles of information systems. Course Technology.

Turban, E., Rainer Jr., R. K., Potter, R. E. (2007). Introduction to information systems. Hoboken, USA: John Wiley and Sons.

Utterback, J. M. (1971). The process of technological innovation of the firm. Academy of management journal. March 14 (1), 75-88.

Utterback, J. M. (1996). Mastering the dynamics of innovation $-2^{\text {nd }}$ Ed. Harvard Business Press Review, Cambridge, USA.

Verhoeven, B. \& Johnson, L. W. (2017), Business Model Innovation Portfolio Strategy for Growth Under Product-Market Configurations, Journal of Business Models, 5 (1), 35-50.

Wirtz, B. W. \& Daiser, P. (2017), Business Model Innovation: An Integrative Conceptual Framework, Journal of Business Models, 5 (1), 14-34.

Zott, C. \& Amit, R. (2010). Business Model Design: An Activity System Perspective. In Long Range Planning, 43, 216-226. 
(Página deixada propositadamente em branco) 
Maria Beatriz Marques - Professora Auxiliar da Faculdade de Letras da Universidade de Coimbra. Doutorada em Ciência da Informação, na especialidade de Gestão da Informação e de Serviços de Informação, pela Universidade da Coimbra. Licenciada em História e pós-graduada em Ciências Documentais, opção de Arquivo e opção de Biblioteca e Documentação, pela FLUP. É investigadora do Centro de Investigação Transdisciplinar "Cultura, Espaço e Memória» (CITCEM) da Universidade do Porto e colaboradora do Centro de Estudos de Geografia e Ordenamento do Território (CEGOT) da Universidade de Coimbra. Tem desenvolvido a sua atividade profissional e de docência na área da Ciência da Informação e tem como áreas principais de investigação a Gestão da Qualidade e o Marketing de Serviços de Informação - Satisfação dos Clientes de Serviços de Informação, o Estudo dos Sistemas e Políticas de Informação, a Epistemologia da Ciência da Informação, a Teoria e Crítica da Sociedade da Informação, o Planeamento Estratégico, a Responsabilidade Social das Organizações e a Informação e Interatividade (Comunicação Institucional/Digital).

Liliana Esteves Gomes - Professora Auxiliar Convidada da Faculdade de Letras da Universidade de Coimbra (FLUC). Doutorada em Ciência da Informação pela Universidade da Corunha. Mestre em Ciências da Documentação e Informação; licenciada em História e pós-graduada em Ciências Documentais, opção de Arquivo e opção de Biblioteca e Documentação, pela FLUC. É investigadora do Centro de Investigação Transdisciplinar "Cultura, Espaço e Memória» (CITCEM). Tem desenvolvido a sua atividade profissional e de docência na área da Ciência da Informação e tem como áreas principais de investigação a Gestão de Informação nas Organizações, a Informação e Interatividade (Comunicação Institucional/Digital), a Arquivística e a Organização e Representação da Informação. 
Série Investigação

Imprensa da Universidade de Coimbra

Coimbra University Press

2020

COIMBRA

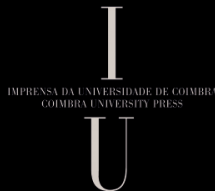

